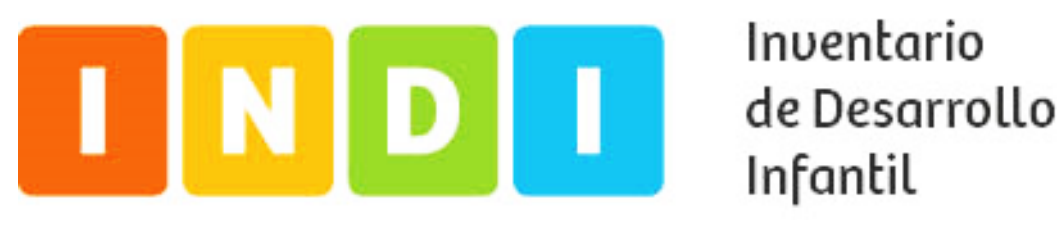

\title{
El Inventario de Desarrollo Infantil y la evaluación sistemática del desarrollo en contextos educativos.
}

\section{Teoría, creación e implementación.}

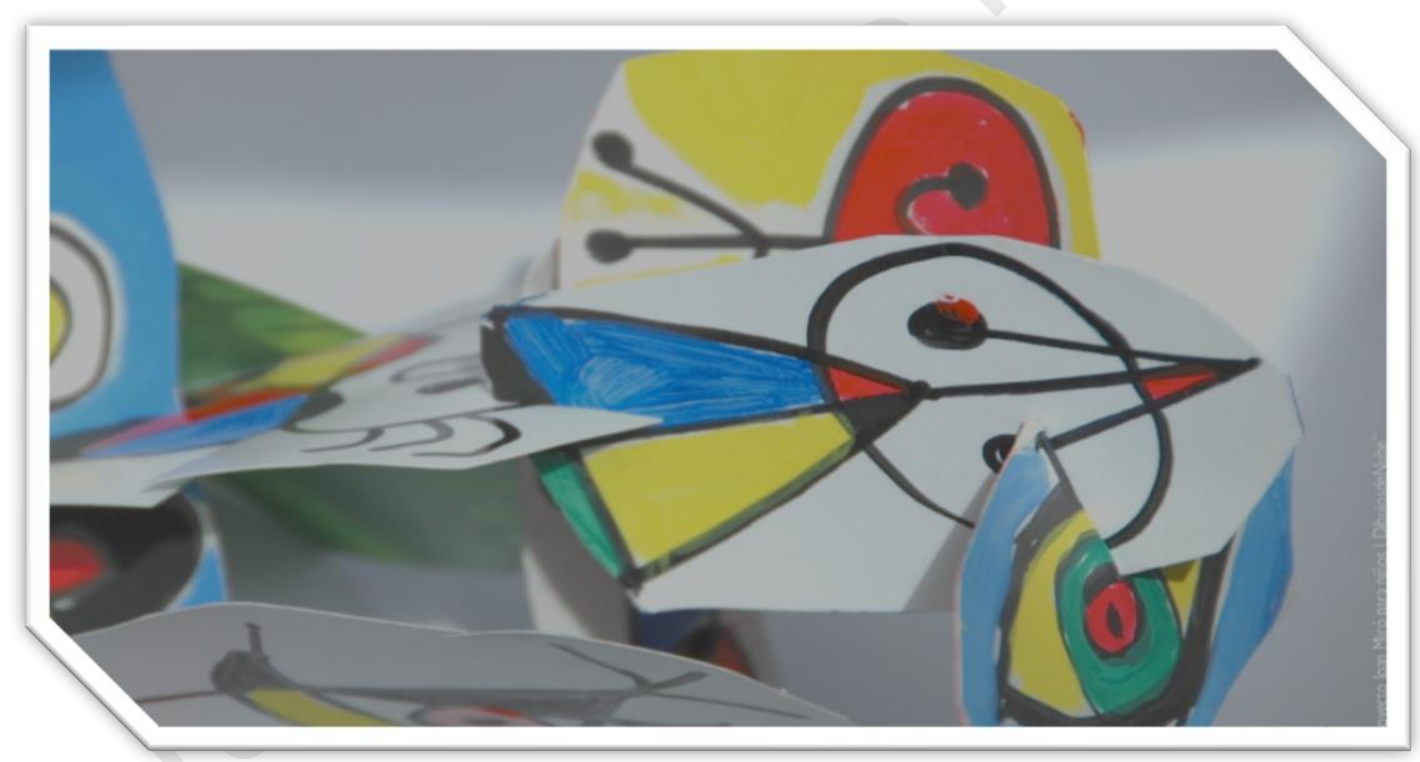

Editado por Alejandro Vásquez Echeverría 
PÁGINA INTENCIONALMENTE EN BLANCO 


\title{
El Inventario de Desarrollo Infantil y la evaluación sistemática del desarrollo en contextos educativos.
}

Teoría, creación e implementación.

\author{
Editado por: \\ Alejandro Vásquez Echeverría
}

Con contribuciones de:

Maite Liz, Clementina Tomás, Mónica Pérez, Ana Inés Mandl y Juan I. Rodríguez 
Los autores de este libro son integrantes del equipo de Desarrollo del INDI de la Facultad de Psicología, Universidad de la República, Uruguay.

La realización de este libro ha sido posible mediante la colaboración y apoyo de la Comisión Sectorial de Investigación Científica, Universidad de la República, el Consejo de Educación Inicial y Primaria, y el Consejo Directivo Central, ANEP.

(C) Universidad de la República, Uruguay.

(c) Los autores, 2020.

\section{Contacto.}

La correspondencia relativa a esta obra puede encaminarse mediante estas formas:

Web: indi.psico.edu.uy

Correo e.: indi@psico.edu.uy, avasquez@psico.edu.uy

Dirección postal:

Instituto de Fundamentos y Métodos en Psicología. Facultad de Psicología, Universidad de la República. Tristán Narvaja 1674 Montevideo, Uruguay.

Recursos de apoyo.

Materiales adicionales a este libro puede encontrarse en:

https://indi.psico.edu.uy/librovol1

Imagen de tapa.

Proyecto Joan Miró para niños / Dibujos de Nube.

ISBN: 978-9974-94-935-5

Este libro será cargado primero a repositorios académicos mediante la versión antes de imprenta (pre-print).

\section{Agradecimiento.}

Además de los coautores de esta obra, son muchísimas las personas que han colaborado durante estos años en la creación, validación e implementación del INDI, a las que estoy profundamente agradecido. Me gustaría destacar especialmente a Karen Moreira, Virginia Andrade y Alejandro Maiche por sus contribuciones decisivas al desarrollo del INDI, a las autoridades educativas por su confianza en nuestro trabajo y la Inspección Nacional de Educación Inicial (bajo diversas direcciones) por sus aportes constructivos.

A.V.E. 


\section{Tabla de Contenidos}

Introducción

Capítulo 1

Desarrollo psicológico en la primera infancia y disposición para la escolarización.

1.1. Características generales del desarrollo durante la etapa 3 a 6 .

1.2. La transición de Educación Inicial a Primaria: La Disposición para la escolarización.

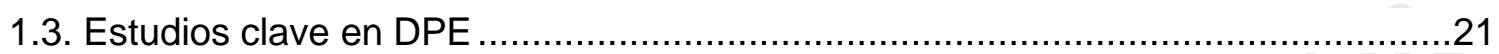

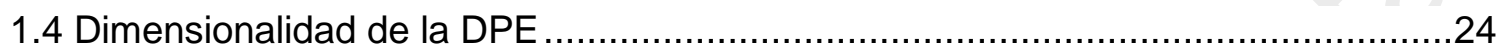

Capítulo 2

La evaluación del desarrollo en primera infancia: comprendiendo el funcionamiento de los

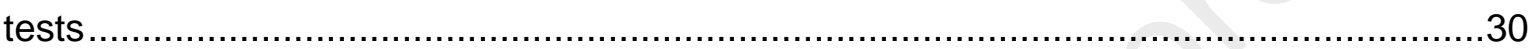

2.1. La evaluación de la DPE: ¿es un ámbito psicológico o educativo?........................31

2.2. Características de la evaluación psicológica .........................................................32

2.3. Cómo hacer interpretables los resultados de un test: referencia a la norma y

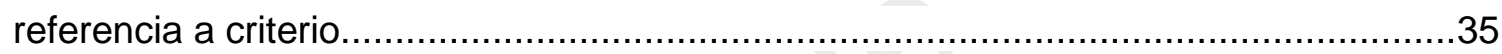

2.4. La calidad de los tests y la psicometría. Confiabilidad y validez ..........................37

2.5. Particularidades de la evaluación del desarrollo en primera infancia.....................43

2.6. Las particularidades de la evaluación de la DPE. ................................................44

Capítulo 3

La relación entre la evaluación y la intervención: el modelo de respuesta de intensidad

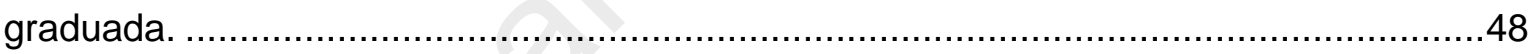

3.1. ¿Qué es el modelo de respuesta de intensidad graduada y cómo surge? .............49

3.2. ¿Cómo se lleva a la práctica un modelo RIG? ................................................51

3.3. Desafíos para la implementación de un modelo RIG ...........................................56

3.4. Algunos mitos asociados a la implementación de los modelos RIG......................57

3.5. Importancia de la atención temprana: aspectos educativos y de salud..................59

Capítulo 4

El Inventario de Desarrollo Infantil: creación, estructura y administración

4.1. Aspectos históricos del proceso de creación, validación y universalización del INDI.

4.2. Marco de referencia del INDI: estructura dimensional y componentes. .................72

4.2.1. Desarrollo cognitivo ........................................................................ 73

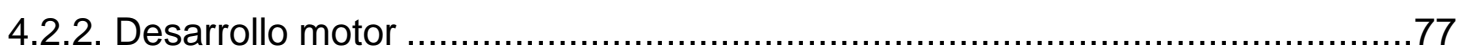

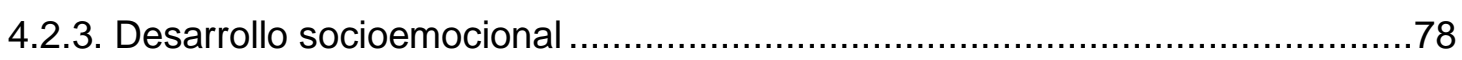

4.2.4. Disposición para el aprendizaje ........................................................ 80 
4.3. Conociendo mejor el Inventario de Desarrollo Infantil.......................................81

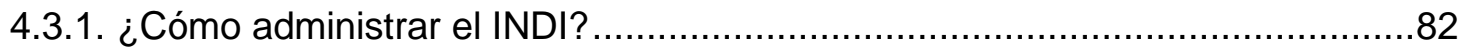

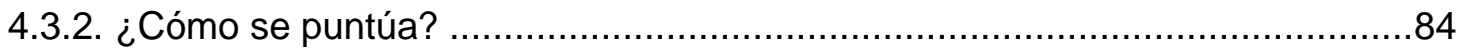

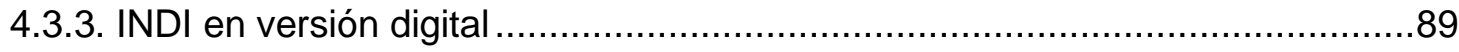

Capítulo 5

Reportes automáticos del Inventario de Desarrollo Infantil y su interpretación .90

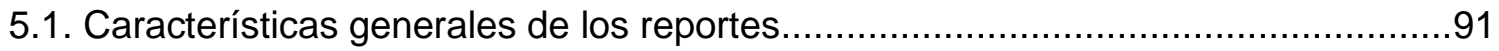

5.2. Perfiles de desarrollo en base a los resultados de la evaluación ..........................92

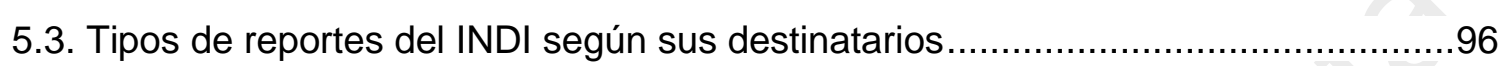

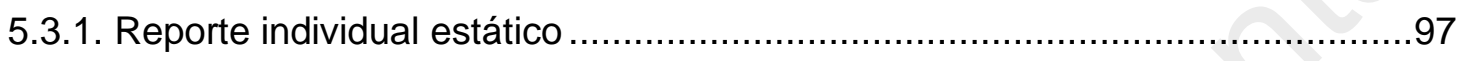

5.3.2. Reporte individual de trayectoria ......................................................... 101

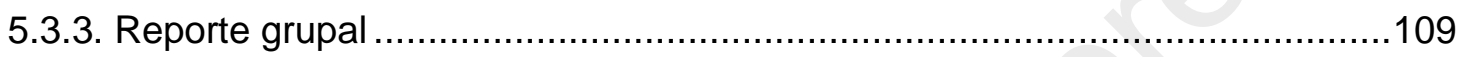

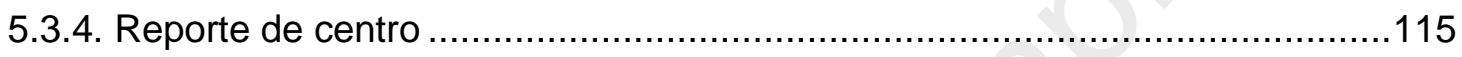

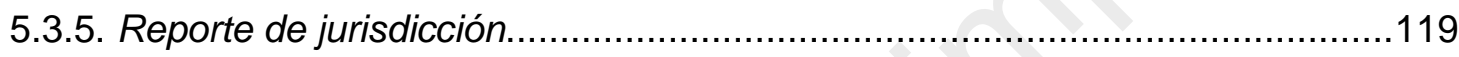

Capítulo 6

EI INDI y su relación con otros documentos uruguayos de referencia en primera infancia.

Análisis Comparativo

6.1. Contextualización del INDI en relación a otros marcos rectores del trabajo en primera infancia.

6.2. Marco Curricular para la atención y educación de niñas y niños uruguayos desde el nacimiento hasta los seis años. 126

6.3 Programa de Educación Inicial y Primaria 132

6.4. Guía Nacional para la vigilancia del Desarrollo del niño y la niña menores de 5 años del MSP

6.5. Consideraciones finales 147

Referencias Bibliográficas 151

Anexos

Anexo 1. Referencias de instrumentos utilizados y número de participantes en los estudios de validez concurrente 


\section{Introducción}

\section{Alejandro Vásquez Echeverría}

Dos hallazgos científicos, consistentes y ampliamente replicados en la literatura sobre el desarrollo, han hecho que la atención a la primera infancia y al periodo de transición entre la Educación Inicial y Primaria, sea cada vez una preocupación mayor para los profesionales vinculados al ámbito educativo, a la salud infantil y a la política pública. El primer hallazgo refiere a que los niveles de desarrollo infantil antes de los 6 años son uno de los mejores — sino el mejor - predictor de logro académico posterior. El segundo hallazgo, también ampliamente replicado, es que ciertos grupos de niños empiezan a diferenciarse desde pequeños (más claramente luego de los 2 años) en su nivel de desarrollo, según variables sociodemográficas relevantes como el nivel socioeconómico o su grupo étnico. Cuando estos dos fenómenos son vistos en su conjunto, ocurre la denominada brecha de ingreso a la escuela, definida como las diferencias notables entre ciertos grupos sociales antes de ingresar a la escuela primaria (Janus \& Duku, 2007), y que están emparentadas tanto con el bienestar del niño durante su tránsito por la primera infancia, así como con las brechas en los resultados educativos posteriores. Estos datos resultan abrumadores ya que, en las declaraciones gubernamentales de la mayoría de los países democráticos, la educación primaria y secundaria están diseñadas para igualar oportunidades, de forma que solo nos diferencien los talentos y las virtudes. Sin embargo, en algunos contextos, varios resultados sugieren que estos sistemas educativos no son capaces de reducir las brechas de logro académico (Ryan, Fauth \& Brooks-Gunn, 2006).

Paralelamente, también se ha dado un cambio de enfoque conceptual respecto a los problemas de aprendizaje y las discapacidades intelectuales leves, que se entienden cada vez más como alteraciones en los sistemas de desarrollo (Cairns \& Cairns, 2006). Si bien su identificación mayoritariamente ocurre en los primeros años de la escuela primaria, estos problemas encuentran su origen en rezagos del desarrollo durante la primera infancia, que van horadando la adquisición de nuevas competencias. Éstas dependen de la adquisición y consolidación de habilidades previas que operan como cimientos, así como de los aspectos actitudinales del niño hacia su propio proceso de aprendizaje y de interacción con pares en contextos educativos.

Es por este motivo que, a nivel mundial, muchos gobiernos han decidido implementar políticas para atender el desarrollo en primaria infancia de manera integral, a sabiendas de las consecuencias negativas en lo inmediato, en el bienestar infantil y a largo plazo, en los resultados educativos de su falta de promoción. Especialmente dentro del contexto educativo, muchas de las políticas se han enfocado en generar programas de estimulación del bienestar evolutivo que protejan el desarrollo de niños y faciliten la transición a la escuela primaria. Esto es, políticas de disposición para la escolarización (DPE).

A tal punto esto es así que la ONU incorporó a la DPE en sus objetivos de desarrollo sostenible. Dentro de la meta 4, que reza Garantizar una educación inclusiva, 
equitativa y de calidad y promover oportunidades de aprendizaje durante toda la vida, para todos, el Objetivo 4.2 está específicamente vinculado a generar condiciones de igualdad en el desarrollo y la atención temprana.

"De aquí a 2030, asegurar que todas las niñas y todos los niños tengan acceso a servicios de atención y desarrollo en la primera infancia y educación preescolar de calidad, a fin de que estén preparados para la enseñanza primaria" (Organización de Naciones Unidas, s/f)

Partiendo de una base de cobertura muy alta, en el quinquenio 2015-2020 Uruguay, a través de la Administración Nacional de Educación Pública (ANEP), ha puesto un énfasis importante en generar políticas de promoción del desarrollo en el ciclo de educación inicial (Niveles 3, 4 y 5 años). En este sentido, nuestro grupo de investigación en Evaluación del Desarrollo de la Facultad de Psicología de la Universidad de la República ha participado de este proceso mediante la creación del Inventario de Desarrollo Infantil (INDI), un instrumento de evaluación multidimensional de la disposición para la escolarización, así como colaborando en la generación de políticas para atender a la población de mayor riesgo. De hecho, hemos visto como durante este proceso de implementación del INDI la atención oportuna a la primera infancia ha cobrado mayor relevancia. El seguimiento del desarrollo mediante la evaluación sistemática es una piedra angular para el bienestar de los niños y su atención, ya que, sin él, muchas situaciones de compromiso del bienestar infantil pueden no valorarse con su debida importancia. Por esto, el lema que le dimos al INDI, Fortaleciendo el derecho a la atención oportuna.

Somos conscientes de que no es un camino fácil, pero estamos orgullosos de que Uruguay se haya encaminado en este proceso de evaluación censal que tiene elementos pioneros a nivel de implementación de política pública a nivel regional y mundial. Uno de ellos es haber logrado la evaluación censal del desarrollo durante la educación preescolar (en Uruguay denominada inicial) mediante el INDI. Es en este contexto que se desarrolla la presente obra.

Evidentemente esto no es logro exclusivo de una administración ni de un grupo de investigación. El compromiso de todos los actores, especialmente del cuerpo docente, ha sido fundamental para alcanzar este hito crucial para implementar políticas de DPE basadas en evidencia. Asimismo, esto se enmarca en un contexto histórico de la educación inicial en Uruguay, donde se fundó el primer jardín de infantes público de Latinoamérica, bajo el influjo de Enriqueta Compte y Rique. En dicho contexto, siendo Compte directora de ese jardín, inculca al personal docente de esos centros la cultura de la evaluación y su registro:

"Manifesté a mis compañeras de trabajo, que el niño debería ser atendido y estudiado individualmente, tomando nota de todas las manifestaciones que le fueran características, en el orden físico, intelectual y moral; pero en este principalmente, siempre que hubiera ocasión, porque a mi entender, los sentimientos humanos, son los que requieren más vigilante, la obra de educación." (Compte y Rique, 1926/2010, p.43). 
De hecho, en ese contexto de fines del Siglo XIX, Compte y su equipo docente implementaron las biografías escolares (Ivaldi, 2014). Estas biografías representan un antecedente lejano, pero con muchos paralelismos, de la evaluación que se realiza con el INDI en el Siglo XXI. Sin duda, han forjado una tradición propiamente uruguaya de evaluación muy arraigada en el cuerpo docente y en las políticas para la Educación Inicial. Esas biografías escolares relevaron datos de aspectos físicos de los niños, del carácter o la forma de ser, del desarrollo del trabajo en aula y de la capacidad mental o inteligencia. El trabajo de Ivaldi (2014) es revelador en cuanto a la energía e importancia puesta por Compte en el trabajo de evaluación y monitoreo de los progresos de los niños en varios aspectos de su desarrollo. Compte, muchos años después, valoró su trabajo en evaluación infantil y en la exploración de las diferencias individuales de los niños, como una innovación que anticipó a la mismísima escala de Binet, considerado el primer test en el mundo para la evaluación psicológica y del desarrollo:

"...nacieron en Montevideo las primeras Biografías que vio el mundo pedagógico, 14 ó 15 años antes de que Binet lo revolucionara con la aparición de su Escala Métrica de la inteligencia, mientras que en diversos escritos censuraba acerbamente (cruel, rigurosa 0 desapaciblemente) a los maestros porque dentro de una misma clase trataban a todos los niños de la misma manera." (Compte y Rique1945, citada por Ivaldi, 2014).

\section{Público objetivo de esta obra}

Este libro presenta las conceptualizaciones teóricas sobre disposición para la escolarización y evaluación del desarrollo que dan sustento al INDI, y sistematiza nuestra experiencia previa en la formación a docentes del país para su administración e interpretación. Pretende, por tanto, servir de material de referencia en actividades formativas, reuniendo en un único material los principales contenidos, y ofreciéndolo como punto de partida para la profundización en textos más específicos de acuerdo al perfil formativo del estudiante o lector. Por tanto, el público objetivo para el cual ha sido redactado incluye docentes en actividad, estudiantes de magisterio, especialmente aquellos en primera infancia, y estudiantes de psicología interesados en temas de psicología del desarrollo, psicología educacional y evaluación psicológica. Este libro también puede resultar de interés para un conjunto importante de estudiantes y graduados de otras profesiones vinculadas a la educación y la atención a la primera infancia: psicopedagogos, psicomotricistas, trabajadores sociales, psicólogos, entre otros profesionales que se vinculan con la evaluación y las políticas en primera infancia y que han participado en nuestros cursos o se han interesado en el INDI. Por último, este libro puede ser de interés para aquellos que necesiten conocer el marco de referencia e interpretar los resultados de que brinda el INDI, para, por ejemplo, comprender mejor cómo se implementa en contexto de aula y qué significan las puntuaciones en cada uno de sus componentes. 
En suma, esperamos que esta obra pueda servir de referencia para que los lectores profundicen en la evaluación del desarrollo y el INDI de forma autónoma y/o en el contexto de las instancias formativas de grado y posgrado.

\section{Organización de la obra}

Este libro posee seis capítulos, con dos partes claramente distinguibles. Los tres primeros configuran una primera parte de carácter esencialmente teórico, para contextualizar los principios científicos sobre los que se fundamenta la construcción del INDI. En la segunda parte, los tres últimos capítulos son de carácter más aplicado, centrados en comprender el origen del INDI, su marco de referencia, su forma de administración e interpretación y su relación con otros documentos de alta relevancia en el contexto de la Educación Inicial.

El Capítulo 1 aborda algunos aspectos centrales que hacen al desarrollo psicológico en la primera infancia para introducir al lector en el concepto de disposición para la escolarización: su definición, aspectos claves, dimensiones, y principales estudios de referencia. En el Capítulo 2 se presentan algunas ideas fundamentales en torno a la evaluación psicológica y educativa, la psicometría y los test psicológicos, así como se realizan algunas puntualizaciones sobre la evaluación en contextos de desarrollo y en DPE. En el Capítulo 3, profundizamos en un modelo conceptual que entendemos de relevancia para articular la evaluación sistemática con la intervención en contextos educativos: los modelos de respuesta de intensidad graduada.

En el Capítulo 4 se introduce el Inventario de Desarrollo Infantil (INDI), un instrumento nacional diseñado para evaluar el desarrollo y aspectos de la disposición para la escolarización en edad 3 a 6 . Allí exponemos aspectos de creación, validación e implementación a nivel de la educación pública del Consejo de Educación Inicial y Primaria (CEIP). Asimismo, presentamos su estructura multidimensional y una guía para su administración. En el Capítulo 5, ofrecemos un panorama detallado de cómo es el proceso de emisión de los reportes que se emiten automáticamente luego de finalizada la evaluación en el contexto de GURI y una guía para su interpretación. Por último, el Capítulo 6 está destinado a analizar las convergencias del INDI con algunos de los principales documentos rectores de la Educación inicial, como lo son el Marco Curricular y los programas de Nivel 3, 4 y 5 de Educación Inicial. Su convergencia no es de extrañar por varias razones, entre las que se destacan que el INDI parte de concepciones comunes del desarrollo y la educación en primera infancia con respecto a las comunidades que elaboraron estos documentos, y de los aportes que realizaron los docentes -conocedores de primera mano de los mismos-. Asimismo, desarrollamos un análisis de equivalencia de contenidos respecto a la Guía Nacional de Vigilancia del Desarrollo (segunda versión) del MSP, como instrumento de referencia de evaluación en contextos pediátricos.

En síntesis, pensamos esta obra para que sirva de introducción a los temas de DPE, evaluación del desarrollo y el INDI, con un fuerte componente de autoaprendizaje. Invitamos a los lectores que tengan intención de profundizar en estos temas a visitar el sitio web indi.psico.edu.uy donde disponemos de muchos otros recursos 
complementarios (audiovisuales, guías, otras publicaciones, etc.) generados en estos cinco años de trabajo con el INDI. 


\section{PRIMERA PARTE}

Aspectos teóricos y metodológicos en torno a la evaluación del desarrollo y la disposición para la escolarización.

Los fundamentos conceptuales del INDI. 
PÁGINA INTENCIONALMENTE EN BLANCO 


\title{
Capítulo 1.
}

\section{Desarrollo psicológico en la primera infancia y disposición para la escolarización}

\author{
Alejandro Vásquez Echeverría y Clementina Tomás
}

\section{Objetivos de aprendizaje}

Al finalizar este capítulo el lector será capaz de:

1. Caracterizar aspectos centrales del desarrollo psicológico en la primera infancia.

2. Definir disposición para la escolarización (DPE).

3. Describir los principales antecedentes de investigación en torno a la DPE.

4. Conceptualizar la DPE a partir de modelos multidimensionales.

\section{Ideas fuerza}

- Durante la primera infancia transcurren cambios sustantivos a nivel de los sustratos biológicos del desarrollo, las funciones psicológicas y sus manifestaciones comportamentales.

- La transición desde el nivel de Educación Inicial a Primaria constituye un momento de cambios significativos en la vida del niño.

- La promoción de la DPE no supone adelantar los contenidos curriculares de la educación primaria en el nivel inicial.

- La promoción de la DPE implica maximizar el potencial del niño en áreas claves del desarrollo, emparentadas con los procesos educativos.

- Históricamente las concepciones de DPE han migrado desde un estándar fijo de maduración del niño, hacia un conjunto de perfiles de desarrollo compatibles con una transición saludable al ciclo primario.

- Los modelos multidimensionales enfatizan el rol de la familia y los centros educativos como agentes de promoción de DPE. 
Como todo instrumento de evaluación, el INDI está diseñado y concebido desde ciertos modelos teóricos y resultados de investigación. En nuestro caso, el INDI se basó en dos aspectos de la literatura del desarrollo, muy emparentadas entre sí: (a) la producción que refiere a las características generales del desarrollo en la etapa de los 3 a los 6 años, internacionalmente conocida como preescolar —en Uruguay de Educación inicial- y especialmente (b) la producción que refiere a la disposición para la escolarización (del inglés school readiness, a veces traducida como preparación para la escolarización).

\subsection{Características generales del desarrollo durante la etapa 3 a 6 .}

El desarrollo humano se caracteriza por presentar cierta variabilidad. Los niños muestran diferencias en su desarrollo cognitivo, motor, socioemocional, así como en sus preferencias desde muy pequeños. Esto es esperable, pues por diferencias genéticas, de ciertas condiciones perinatales o de tránsito del embarazo, y la cantidad y calidad de las interacciones con los ambientes sociales y culturales, no todos adquirimos las mismas capacidades exactamente a las mismas edades. Por ejemplo, es posible que algunos niños den sus primeros pasos a los 10 meses, mientras otros lo hagan sobre los 14. A largo plazo, esta variabilidad en talentos, preferencias y virtudes es una fortaleza, especialmente cuando funcionan de forma complementaria en grupos o comunidades.

Para caracterizar una etapa del desarrollo, sin embargo, sí se pueden establecer calendarios madurativos, o, dicho de otra forma, edades (generalmente establecidas en meses) en las que, en términos estadísticos, la mayoría de los bebés o niños logran ciertos hitos o conductas. Además, para esta caracterización, es necesario entender los contextos de actividad que los diferentes sistemas ofrecen al niño. En el caso de la primera infancia, hay dos sistemas de suma relevancia: (a) el acceso y la calidad del cuidado sustituto y, eventualmente, de los centros educativos y (b) la calidad del ambiente familiar, como sistema más proximal de vínculo del niño.

En este contexto es que toda caracterización de una etapa concreta del desarrollo infantil debe realizarse con las salvedades necesarias. Las funciones del desarrollo no son lineales, esto es, no todo el crecimiento es sostenido, pudiendo existir periodos de desaparición o crecimiento muy rápido de una habilidad o función. Por otro lado, es muy difícil realizar una contextualización de una etapa de forma universal, i.e., para todas las regiones, tiempos históricos y culturas del mundo (ver recuadro de efecto Flynn). En tanto estos factores pueden hacer variar las expectativas de desarrollo, cualquier lineamiento que se ofrezca debe ser entendido con esto en mente. También es importante entender la continuidad natural del desarrollo, lo que significa que los cambios que se logran en una etapa están apoyados en los desarrollos de la etapa anterior. Por ello, debe recordarse que las caracterizaciones específicas por etapa representan un proceso de delimitación con fines analíticos de la heterogénea realidad del desarrollo humano. 


\section{EL EFECTO FLYNN}

El efecto Flynn refiere al incremento progresivo, documentado en varias poblaciones del mundo, del coeficiente intelectual durante el Siglo XX. Esto es, cuando los individuos de generaciones posteriores toman el mismo test, en promedio, logran puntuaciones mucho más elevadas que sus antecesores de décadas. Este fenómeno se ha intentado explicar por varias razones, entre las que se incluyen una mejor salud perinatal, mejor nutrición infantil, mejores condiciones de escolarización y mayor tasa de adulto por niño en los hogares, lo que incrementa la atención parental.

Este efecto recibe su nombre en crédito a James Flynn, un investigador neozelandés que hizo mucho por documentar y explicar las implicaciones del fenómeno.

En términos generales, el desarrollo durante la etapa 3 a 6 se ve fortalecido por un gran desarrollo cerebral, con especial crecimiento, tanto en volumen y grosor, de la corteza prefrontal. El cerebro pasa del $75 \%$ del volumen adulto mediando los dos años a casi el total (95\%) sobre los 6 años (Giedd et al., 2009). Asimismo, se pronuncia la tendencia de las redes cerebrales a funcionar de forma global, interconectando cada vez más regiones de forma progresiva (en oposición a un funcionamiento predominantemente local). Esto sienta las bases de algunas de las transformaciones en términos cognitivos y comportamentales que va a experimentar el niño.

A nivel cognitivo, se aprecia una consolidación del pensamiento simbólico que permite una complejización del pensamiento concreto. Esto se asocia a la capacidad cada vez mayor en el uso del lenguaje. Sobre esta base, el niño tendrá un uso cada vez más flexible del lenguaje que le permite desarrollar habilidades para entender y manipular unidades subléxicas (conciencia fonológica) en lo que se puede apreciar en el juego cada vez más frecuente de buscar similitudes entre las palabras. En estos años también se comienza a desarrollar y perfeccionar la numerosidad de tipo simbólico, la capacidad de conteo, la secuenciación, entre otros. Se produce un salto importante en habilidades vinculadas a la manipulación de la información, como ser la memoria de trabajo. Pero hay dos vectores del desarrollo cognitivo que ocurren en este momento de la vida, que son especialmente relevantes, por sus implicancias a nivel de los procesos educativos:

(a) la capacidad del niño de controlar y/o regular su comportamiento y sus pensamientos; que va a permitir que el niño se inserte en los procesos de aula colectivos, siga sus reglas, y además logre manejar un espacio mental interno para ligar experiencias y representaciones, habilitando otra manera de procesar la información (i.e. el procesamiento controlado o explícito).

(b) el desarrollo del self y sus procesos cognitivos de base (de auto-proyección), que facilitan entender a las demás personas como agentes intencionales, facilitando enormemente el aprendizaje (ya sea mediante formas de aprendizaje vicario o por el niño poder capturar la intención de enseñanza del par o del adulto), así como la puesta en marcha de la acción intencional propia. Esto es especialmente relevante para el aprendizaje y adquiere las formas de "me interesa saber más sobre/saber hacer esto". 
A nivel del desarrollo social y emocional se producen dos procesos paralelos: un incremento en la socialización, como hito fundamental: los pares comienzan a ser actores relevantes para el bienestar del niño. Emocionalmente, a su vez, esta demanda extra de socialización requiere aprender a canalizar los gustos, preferencias y miedos de formas cada vez más sofisticadas. Enrabado con esto, se comienzan a delinear los rasgos de la personalidad, que toman forma a partir de los elementos del temperamento infantil y las experiencias vividas hasta ese entonces. Los niños salen de este periodo, con los cinco rasgos de personalidad ya pasibles de ser identificados (Caspi \& Shiner, 2006; Shiner \& Masten, 2008).

Para finalizar, señalamos que en esta etapa se produce un refinamiento de la integración perceptivo-motora, que conduce a un mejor manejo del cuerpo en relación al entorno, así como a la progresiva capacidad para manipular herramientas, hacer deportes, entre otros procesos que implican la coordinación de la información sensorial con el movimiento adaptativo y voluntario de las partes del cuerpo.

\subsection{La transición de Educación Inicial a Primaria: La Disposición para la escolarización.}

El estudio de las transiciones durante el curso vital es un tema central en el desarrollo, ya que los cambios significativos que estas provocan en el contexto vital de las personas demandan, para su adecuada tramitación, ciertos recursos cognitivos y emocionales. A su vez, las transiciones provocan una dinámica de ganancias y pérdidas que debemos analizar en detalle para entender los efectos que pueden tener en cada individuo (Baltes, 1987). El ingreso a la escuela primaria es una de las transiciones que más atención ha reclamado en las últimas tres décadas dentro de la psicología del desarrollo, la psicología de la educación y las ciencias de la educación, entre otras disciplinas, por las consecuencias a largo plazo que tiene la forma y calidad en que se realice esta transición (Duncan et al., 2007; Morrison, Kim, Coonor \& Grammer, 2019).

La transición a la educación primaria se da en un contexto de cambios vertiginosos en las capacidades de los niños -entre los cuatro y los siete años de edad- (Sameroff \& Haith, 1996), en lo que puede llamarse el desplazamiento más significativo del desarrollo. Justo en ese momento, la mayoría de los países del mundo dan comienzo al dispositivo educación primaria. Según información del Banco Mundial (2020), el $71,4 \%$ de los países da inicio a la primaria cuando los niños tienen 6 años, $16,7 \%$ cuando tienen 7 y 11,9\% cuando tienen 5 . Si bien para la mayoría de la población infantil esta transición se realiza de forma saludable, muchos niños, familias y maestros lo viven como una discontinuidad, más allá de la asistencia previa o no a los centros de atención o educación en primera infancia. En términos concretos, esto significa que muchos maestros de primer y segundo año de primaria deben afrontar su planificación de aula sabiendo que hay niños que presentan rezagos en su desarrollo cognitivo, comportamental o socioemocional, con los que no podrán cumplir las expectativas de aprendizaje que el programa determina. Lo anterior probablemente se relaciona a la alta tasa de retención que ocurre en primer año en el sistema educativo uruguayo. Los apoyos que pueda recibir ese niño antes de ingresar a la escuela primaria y durante el 
primer año de primaria son claves para que la transición vital, a la que todos los seres humanos contemporáneos estamos expuestos, no alcance un nivel de crisis.

Algunos de los cambios más significativos entre la educación inicial y la primaria que alteran las demandas psicológicas a las que debe responder el niño para tener un ajuste adecuado al nuevo contexto social son:

(a) Cambio en las expectativas. Al inicio de una nueva etapa educativa tanto familiares como personal educativo redefinen sus expectativas respecto al comportamiento de los niños. Esto también se ve reflejado en las expectativas que tienen los maestros de inicial y los de primaria en cuanto a las competencias con las que debe llegar el niño a la educación primaria.

(b) El rol del juego se ve disminuido. El juego, que tiene una posición central en la educación inicial pasa a tener un rol menos preponderante en primaria, donde la carga horaria de actividad dirigida al aprendizaje directo o explícito es mayor.

(c) El uso de los espacios, que es más descontracturado, flexible y adaptado al juego en Inicial, mientras que, en Primaria, la actividad está fundamentalmente centrada en el uso de los espacios con una mayor orientación hacia el docente, más individualizados y con un aumento de la carga expositiva, respecto a la etapa anterior.

(d) Las formas de evaluación. En el primer año de escuela se incorpora un dispositivo que media la relación entre el niño y la maestra y entre pares: las calificaciones. El rendimiento es evaluado de forma explícita, y se otorga retroalimentación al niño y sus familias. Eventualmente, hay formas de penalización para las situaciones de rendimiento bajo, que pueden ser formales (e.g.: repetición) o informales (e.g.: valoración social de compañeros o familiares). La evaluación, si bien puede existir en la educación antes de la primaria (mediante diversos dispositivos) es de corte informal o vinculado a evaluaciones del desarrollo y, muy raramente, de estos procesos depende una decisión de retención/repetición.

Se ha propuesto el concepto disposición para la escolarización (o school readiness, en la literatura especializada en inglés, a veces también traducido como preparación para la escolarización) para explicar las diferencias en como sucede esta transición. La disposición para la escolarización (DPE) puede definirse como el conjunto de habilidades y competencias requeridas para una transición saludable hacia la escuela primaria, promoviendo una trayectoria exitosa a través de los ciclos educativos preprimarios $^{1}$ y primarios (Vásquez-Echeverría \& Moreira, 2016). Detrás de la introducción de este concepto, está la observación científica de que las diferencias en el desarrollo de ciertas competencias al finalizar la educación preescolar o al inicio de la primaria, logran predecir las trayectorias académicas de los niños durante la primaria, la secundaria e incluso la educación terciaria o universitaria. Esto es, para que el niño transite adecuadamente a la educación primaria se demandan ciertas competencias y actitudes que se desarrollan previamente, entre los 0 y los 6 años. Un desfase significativo en los niveles de desarrollo demandados por la educación primaria puede provocar que esa transición se convierta, para un conjunto de niños, en una crisis, con consecuencias psicológicas y educativas de diversa magnitud. Los mecanismos explicativos de este fenómeno pueden encontrarse en dos modelos. Primero, en el modelo de expectativa-

\footnotetext{
${ }^{1}$ La obligatoriedad de propuestas educativas que se ofrecen antes de la primaria varía entre países. En Uruguay, a 2020, es obligatoria la educación desde los cuatro años de edad
} 
valor, que postula que el valor subjetivo asignado a la educación está dado en función de las expectativas de rendir adecuadamente y en caso contrario, se produce la desmotivación y la frustración por creer que no se puede responder adecuadamente a las demandas o expectativas del ambiente educativo. Segundo, por comparación social con otros niños (sus pares), que puede provocar la reducción del autoconcepto académico y el desinvolucramiento hacia el propio proceso de aprendizaje. Estos mecanismos tienden a retroalimentarse y a asociarse progresivamente a un peor pronóstico, si no se atienden en tiempo y forma, bajo un enfoque preventivo. En vistas de la creciente importancia del análisis de las trayectorias educativas, el concepto de DPE ha mostrado una gran validez predictiva para informar sobre las situaciones que son de mayor riesgo.

Hoy en día la definición de DPE no está centrada en si los niños están listos para aprender o no, ya que, por la disposición natural del ser humano, siempre estamos listos para aprender. En cambio, el concepto hoy se centra en el ajuste entre las expectativas del sistema educativo, tanto formales (e.g.: currículo o programa para el nivel) como informales, al ingreso a primaria y lo que es el niño capaz de aprender en función de su nivel de desarrollo. La relación entre desarrollo, aprendizaje y enseñanza es un tema central a varios modelos teóricos en las áreas de las ciencias del desarrollo y las ciencias de la educación.

Hay otro elemento central en torno a la conceptualización del constructo DPE que refiere a cómo se operacionaliza la adecuada transición escolar y el éxito en los ciclos educativos posteriores. El debate sobre esto es intenso, y no hay una respuesta unívoca. De hecho, conforme el actor al que se le consulta esta definición puede cambiar. Es más, responder esta pregunta es un trabajo arduo, que también va a depender del posicionamiento de los actores sobre el rol que debe cumplir el sistema educativo (incluida la educación parvularia) en la formación de las personas (ver Pregunta para el debate ¿La escuela debe formar para lo académico o debe formar para la vida?).

Si bien hoy en día es ampliamente aceptado que el rol del sistema educativo no debe ceñirse en educar en exclusividad en los aspectos académicos, es verdad que las posiciones son variables respecto a en qué medida la escuela debe formar integralmente para los distintos aspectos que hacen a la vida de los niños y adolescentes. Por ejemplo, cada vez más actores de la educación otorgan mayor peso a la formación de buenos vínculos entre los alumnos, o al desarrollo de habilidades blandas, como la creatividad y el pensamiento crítico. Sin embargo, el rol que debe tener la escuela en cuanto a la prevención en salud mental de niños y adolescentes es más debatido. De hecho, si observamos los programas de estudio y el lugar que ocupa este aspecto en las políticas educativas, vemos que su importancia es puntual.

En función de cómo han respondido esta pregunta los diversos actores del sistema educativo y los investigadores, es que la operacionalización de la DPE en políticas, instrumentos de evaluación o formas de intervención ha variado en el tiempo y entre regiones. Esto se debe a que esta operacionalización se relaciona estrechamente con los resultados educativos que se intentan predecir a través de las diferencias individuales en desarrollo infantil, antes del ingreso a la escuela. Por ejemplo, si el foco está puesto en aspectos académicos, las variables que se intentarán predecir son las de rendimiento (o notas) en pruebas de matemática, lengua o ciencia. Si el foco está puesto en el bienestar, los aspectos del desarrollo social cobran relevancia (e.g.: integración 
social con los pares). Si los aspectos de salud mental están sobre el tapete, intentaremos predecir la depresión infantil en cuarto año, el aislamiento, la impulsividad clínicamente relevante, o si el niño es objeto de acoso escolar, a través de diversos indicadores de desarrollo del niño cuando tenía 4 o 5 años de edad.

Nuestra postura es que la definición del componente "buena transición" o del "éxito escolar" debe ser holística e incluir los siguientes aspectos:

(a) El progreso académico y cognitivo, ya sea en notas, grado académico alcanzado, rendimiento, o desarrollo de aspectos de la inteligencia (científicamente entendida).

(b) Establecimiento de vínculos positivos y de integración social con los pares y los maestros.

(c) Prevención de aspectos relevantes de la salud mental de niños y adolescentes

(d) Desarrollo de actitudes positivas e involucramiento hacia el propio proceso de aprendizaje.

Concebido de esta manera, los antecedentes del desarrollo temprano con los que intentaremos explicar el éxito escolar, tenderán a ser más variados que si se considerase uno solo de ellos. Sobre este punto, es relevante hacer notar que estos aspectos en general están interrelacionados. Por ejemplo, sobre la base de actitudes negativas hacia el aprendizaje ("estudiar historia/matemática no sirve para nada") es menos probable alcanzar altos grados académicos o un mayor rendimiento en esas áreas. Por lo tanto, incluso aquellos que definen el éxito escolar centrados en el aspecto (a), verán que los puntos (b), (c) y (d) se correlacionan con esos resultados y ayudan, en grados diversos, a explicarlo.

\section{${ }^{\star * *}$ PREGUNTAS PARA EL DEBATE***}

¿La escuela debe formar para lo académico o debe formar para la vida?

Muchos actores del sistema educativo piensan que la escuela posee ciertos objetivos académicos y de aprendizaje formal que debe priorizar. Consideran que ese es el objetivo central de la escuela como institución y que los aspectos de formación sociales y emocional deben ser trabajados primordialmente por las familias $u$ otros grupos de pertenencia (clubes o actividades deportivas, actividades religiosas, etc.).

En cambio, otros actores consideran que la formación de los niños en aspectos actitudinales, socioemocionales y de salud personal (mental o física) es de mayor importancia para la adaptación de los niños y bienestar a lo largo de la vida y por lo tanto, los objetivos académicos que a veces demandan mucho esfuerzo y tensión para su aprendizaje, pueden no necesariamente ser prioritarios.

Si bien estas posiciones pueden resultar extremas, es común ver que algunas personas se decantan más para un polo que para el otro. ¿Tú qué piensas? ¿Cuál sería el adecuado balance entre ambas posturas? ¿Esto varía en función del ciclo educativo o del nivel que se esté cursando? 
Hay dos formas de analizar las diferencias en los niveles de DPE (Boivin \& Bierman, 2008). Puede concebirse como un umbral o como un conjunto de niveles mínimos de desarrollo que permitirán atender adecuadamente las demandas de la educación primaria. Alternativamente, puede entenderse en términos probabilísticos, esto es, que la finalización de la educación inicial con ciertos niveles de desarrollo hace más probable o menos probable el éxito en el pasaje a primaria y la trayectoria educativa posterior. Esto se relaciona también con el trabajo en la identificación de perfiles de DPE, esto es, las diferentes combinaciones de niveles de desarrollo que se relacionan con una transición saludable (Sabol \& Pianta, 2017). Por ejemplo, un niño puede compensar niveles disminuidos en un área mediante habilidades fortalecidas en otra área (e.g.: capacidad de cooperar o una alta persistencia pueden permitir que el niño busque ayuda oportunamente para resolver problemas de matemáticas ante los que presenta cierta dificultad, aunque sean simples para el nivel). Entendemos que salvo para compromisos de mayor riesgo y multidimensionales en el desarrollo muy específicos, el enfoque probabilístico debe preponderar en la conceptualización de la DPE y su traducción hacia políticas educativas.

\subsection{Estudios clave en DPE}

Las afirmaciones sobre las trayectorias educativas que realizamos en base al concepto de DPE demandan un tipo de enfoque metodológico específico: el longitudinal. Este se debe a que estamos intentando predecir (de forma probabilística) qué va a suceder con la trayectoria de las personas cuando tienen 8, 10, 15 o 22 años de edad, en base a sus niveles de desarrollo de cuando tenían 4, 5 o 6 años.

Con este fin predictivo, las investigaciones de mayor envergadura en PPE poseen el siguiente enfoque. Primero, se evalúan a los niños antes o al inicio de primaria en habilidades vinculadas a la DPE (e.g.: desarrollo social, lenguaje, o matemática). Luego se hace un seguimiento de los niños durante algún periodo de tiempo, que puede variar según el estudio, de un año (por ejemplo, para analizar el logro o rendimiento en el primer año de primaria) a más de 20 años (para analizar el logro o rendimiento en la universidad). Con estos datos, es posible analizar cuáles son los aspectos del desarrollo infantil temprano que, con el tiempo, se van a relacionar con variables educativas como el rendimiento, calificaciones o logro. Para ejemplificar esto, veamos algunos de los estudios emblemáticos en este sentido.

Duncan y colaboradores (Duncan et al., 2007) sistematizaron los resultados de seis investigaciones longitudinales previas, en lo que se llama un meta-análisis. Para esto, unificaron los datos provistos por seis estudios longitudinales previos, basados en datos gubernamentales de Estados Unidos, Canadá y Reino Unido. Estos estudios tenían la particularidad de tener varios elementos en común. Como ya mencionamos, todos eran de naturaleza longitudinal, y por lo tanto, poseían datos de cuando las personas están entrando a la escuela o kindergarten (nivel 5) y medidas posteriores en rendimiento académico en lectura y matemática, a los 8, 10 o 13 años. Las medidas vinculadas a la DPE eran lenguaje (ya sea lectura o habilidad verbal), habilidades matemáticas, 
capacidad atencional y comportamiento socioemocionales, como los problemas de comportamiento (internalizados y externalizados) y las habilidades sociales. Los resultados muestran que luego de controlar por otras variables de interés, los mejores predictores de rendimiento en matemática y en lenguaje en la educación primaria o inicios de la secundaria fueron, ordenadas según la magnitud de su efecto: las habilidades iniciales de matemática, luego el lenguaje y la lectura y por último la atención. En este estudio, el comportamiento socioemocional al ingreso a la escuela no tuvo un efecto significativo para predecir el rendimiento ni en matemáticas ni en lenguaje varios años después.

Este estudio, por su rigor metodológico y las implicaciones que tiene debido a resultados algo discrepantes con algunos teóricos influyentes en la literatura de DPE, ha llevado a nuevos estudios, extensiones y/o reanálisis total o parcial de las bases de datos empleadas en dicho trabajo. Por ejemplo, Watts, Duncan, Siegler y Davis-Kean (2014) analizaron los datos de 1364 niños de Estados Unidos y su relación entre rendimiento en matemáticas a los 54 meses y su rendimiento académico a los 15 años. Mostraron cómo, tanto el rendimiento a los 54 meses como la tasa de crecimiento entre los 54 meses y el primer año de primaria, se relacionaron con el rendimiento a los 15 años. La magnitud de esta asociación entre el crecimiento a la entrada a la escuela fue importante y de peso similar a las medidas de nivel obtenidas posteriormente (e.g.: en tercer año). Esto sugiere que los estudiantes que logran mejorar su desarrollo en los momentos cercanos al ingreso a primaria (más allá de su punto de partida), también logran mantener esa dinámica posteriormente en su tránsito académico.

Otros trabajos que extienden los hallazgos de Duncan et al. (2007) son los de Romano, Babchishin, Pagani y Kohen (2010) y el de Grissmer et al. (2010). En el primer caso, Romano et al. (2010) logran una replicación de los principales hallazgos de Duncan et al. (2007), en el sentido del efecto de las matemáticas tempranas, el lenguaje y la atención en el desempeño en tercer grado, pero también encuentran efectos de las competencias socioemocionales en dicho desempeño. Por otro lado, resulta de interés su hallazgo sobre un efecto contrario: las competencias matemáticas y de lenguaje explicaron el desempeño socioemocional en tercer grado de primaria. Estos resultados, son interpretados desde el punto de vista de la retroalimentación entre aspectos cognitivos y socioemocionales para el bienestar en el tránsito escolar. Por su parte, Grissmer et al. (2010), reanalizaron tres de los seis estudios empleados por Duncan et al. (2007). Encontraron que las habilidades motoras finas, la atención y el conocimiento general, tomados en su conjunto, son predictores más fuertes del rendimiento académico posterior que el lenguaje y la matemática tomados por su cuenta. El conocimiento general a la entrada a la escuela fue el mejor predictor del rendimiento en ciencia y lenguaje, así como también contribuyó para explicar el rendimiento en matemática varios años después. Estos resultados complementan los resultados de Duncan y cols., señalando la importancia de tomar a la motricidad fina y el conocimiento general como indicadores de DPE.

Uno de los estudios más reveladores sobre las consecuencias académicas a largo plazo de los rezagos del desarrollo en primera infancia es el de Feinstein (2003), en el que se analizan las trayectorias de una muestra de individuos desde el nacimiento hasta los 26 años a partir del Birth Cohort Study del Reino Unido. A los 22 meses, a los 42 
meses y a los 5 años se contó con medidas del desarrollo y a los 26 años con información sobre el máximo nivel de estudios adquirido (universitario, terciario o intermedio y sin estudios terciarios). El desempeño en tareas cognitivas y motoras en la primera infancia predijo, con efectos estadísticos grandes, el nivel de estudios alcanzado. Por ejemplo, entre quienes se desempeñaron en el cuartil 4 (el de mejor desempeño) a los 22 meses, el 43,3\% completó la universidad, mientras que entre quienes estaban en el cuartil 1 (el de desempeño más bajo), lo hicieron el 32.3\%. Si bien estos datos ya marcan una tendencia, veamos cómo se consolidan sobre el final de la primera infancia. A los 5 años, entre los niños que se desempeñaron en el cuartil 4, un 58,5\% había terminado la universidad 21 años después, mientras que sólo un $18 \%$ de los que se habían desempeñado en el cuartil 1, logró hacerlo.

Otro aspecto importante del trabajo de Feinstein (2003) es que señala que las diferencias en el desarrollo a los 22 meses de edad, si bien tienden a relacionarse menos con los logros posteriores, son bastante definitorias a largo plazo para los niños de niveles socioeconómicos más bajos. Esto es, los niños que se desempeñaron en el cuartil 1 a los 22 meses y provenían de contextos de pobreza tuvieron $60 \%$ de probabilidad de seguir en ese mismo cuartil en rendimiento educativo a los 10 años y siguientes. Estos resultados deben llamar a la reflexión sobre la necesidad de generar intervenciones de gran calado en primeria infancia para reducir los ciclos de reproducción de la desigualdad asociada al nivel socioeconómico y educativo de las familias de origen.

Por último, reseñamos el trabajo de Hattie (2008) que realizó una revisión metaanalítica de varios estudios longitudinales (aclaremos, no exclusivamente centrados en DPE). Mediante la misma llegó a la conclusión que el desarrollo o el logro académico previo es uno de los predictores más fuertes del logro educativo (con un efecto estadístico de mediano a alto). Sin embargo, señala que el $52 \%$ de la varianza en los resultados, no puede explicarse por el desarrollo o el logro temprano. Esto constituye un margen de maniobra muy significativo que tienen los actores del sistema educativo para intervenir en procura de transformar las condiciones de aprendizaje de los niños y lograr una mayor equidad de oportunidades en las trayectorias educativas.

\section{***PUNTO PARA LA DISCUSIÓN***}

Hattie (2008) en su revisión escribió: "uno de los resultados más fascinantes de esta síntesis de metaanálisis es que existen medidas que las escuelas pueden implementar que son más influyentes que este efecto del logro previo."

- ¿Te animas a pensar mediante qué mecanismos las escuelas pueden ser capaces de revertir los efectos de las características individuales con que los niños llegan a los centros educativos?

- ¿Cuán de acuerdo estás con la idea de que el sistema educativo contribuye a equiparar las oportunidades? 


\subsection{Dimensionalidad de la DPE}

Las competencias generalmente señaladas como fundamentales para lograr esta transición adecuada se centran en aspectos cognitivos como el desarrollo del lenguaje, el conocimiento general (semántico) y las matemáticas, aspectos atencionales y de regulación, el desarrollo motor, el desarrollo social y emocional, así como las actitudes que los niños van desarrollando hacia su propio proceso de aprendizaje. Si bien el peso otorgado a cada uno de estos elementos puede ser diferente según el profesional que la brinda (i.e., no necesariamente piensan de la misma forma los maestros de inicial, maestros de primaria, padres, agentes políticos o los investigadores basados en resultados de investigaciones longitudinales), sin duda estas son las principales áreas del desarrollo en las que se enfoca la acción y la investigación en DPE.

Los modelos y concepciones de la DPE han variado a lo largo del tiempo. Como parte de los antecedentes del concepto, antes de que se hablara de DPE, los esfuerzos de Binet y el desarrollo de los tests de habilidades para el aprendizaje, pueden ser considerados precursores de la evaluación y dimensionalidad del concepto. Binet fue el responsable científico de diseñar los primeros tests de edad mental, a pedido del ministerio de Educación francés, para identificar niños con problemas de aprendizaje (a veces denominados en los textos originales como "aprendizaje lento"). El objetivo era poder ofrecerles apoyos extraescolares o educación especial a los niños con un rendimiento por debajo de su edad mental. Esta evaluación se implementó en general en niños de edad primaria, pero con frecuencia también antes de ingresar a la primaria (de hecho, el Binet-Simon fue usado con niños de hasta tres años). Aunque Binet evitó llamarlo así, bien podríamos decir hoy en día que evaluaba algunos aspectos centrales de la inteligencia. Su idea caló muy profundo, por lo que generó toda una línea de investigaciones centradas en la idea que evaluando ciertos aspectos de la inteligencia infantil se lograría predecir el desempeño académico. Esto fue un eje central de la investigación entre desarrollo psicológico y educación hasta la constatación de la brecha entre habilidad y rendimiento académico en la década de 1950, sobre el cual profundizaremos en el Capítulo 3.

Posteriormente el concepto de DPE empezó a emerger estar en conformación, y se lo pensó inicialmente como una anticipación de los contenidos curriculares y de rutinas vinculados a los primeros años de la primaria. Surge así la idea de "preparatorio" como el año del jardín anterior al ingreso a la escuela primaria. Este modelo perseguía dos objetivos fundamentales: (1) familiarizar a los niños que tenían poca experiencia de contacto fuera del hogar con las rutinas y contenidos de los primeros años de primaria (especialmente en temas de oralidad, escritura y matemática, manejo en grupos de aula) y; (2) servir para valorar la necesidad de educación especial (y globalmente de salud) que podrían tener algunos niños antes de su ingreso a primaria. Es claro que esta concepción de la DPE responde a contextos donde el porcentaje de la población que asistía a los centros de atención en primera infancia era baja y donde los modelos de educación especial se imponían como forma de atender a la diversidad. 
Varios procesos sociales vinculados a la educación en primera infancia (e.g.: las concepciones sobre la diversidad educativa que apuestan a la integración, la cobertura de educación inicial que ha ido tendiendo a la universalización) así como el conocimiento científico del que disponemos hoy sobre los factores más influyentes en las trayectorias educativas, favorecieron un cambio de concepción sobre la DPE y un refinamiento del concepto. En este sentido, un punto de inflexión es la publicación del National Education Goals Panel, un comité de expertos que generó orientaciones para cumplir con los objetivos de aprendizaje de Estados Unidos para la década de 1990. La propuesta de Kagan y cols (1995) significó la consolidación formal de visiones más holísticas de la DPE, marcando la transición hacia la multidimensionalidad del concepto, que se mantiene hasta nuestros días. Su estructura, de una forma u otra, atraviesa a casi todas las conceptualizaciones de DPE más recientes (Vásquez Echeverría \& Moreira, 2016).

Kagan, Moore y Bredekamp (1995) propusieron un modelo de DPE basado en cinco grandes competencias. La primera dimensión es crecimiento y desarrollo físico. En esta dimensión se incluyen aspectos del crecimiento como talla o peso para la edad, la aptitud física y la fisiología corporal, en un sentido que permitan un funcionamiento integrado en el contexto educativo (e.g.: baja visión o audición), así como otros problemas de salud física o patologías. Desde un punto de vista más amplio, esta dimensión implica atender a la salud familiar, los antecedentes de nacimientos (salud perinatal) y el acceso a los cuidados sanitarios por parte de los padres, incluyendo los controles pediátricos rutinarios.

La segunda dimensión en el modelo de Kagan es el desarrollo socioemocional. En cuanto a lo social, implica a las habilidades para relacionarse con las otras personas generando confianza de forma cooperativa. En cuanto al desarrollo emocional, implica comenzar a reconocer y canalizar adecuadamente consigo mismo y en el vínculo con los demás las emociones primarias (alegría, miedo, enojo, dolor), las provenientes del intercambio social (disfrute, desagrado, horror) y las auto-evaluativas (vergüenza, orgullo, culpa).

La tercera dimensión es la disposición para el aprendizaje, que refiere a un amplio conjunto de hábitos, actitudes y estilos de vínculo con el propio proceso de aprendizaje. Existen antecedentes o predisposiciones como el género, el temperamento y los patrones de actividades que se desarrollan en las familias y comunidades de los niños. Segundo, se incluyen los estilos o formas con los que los niños se aproximan al conocimiento (los estilos de aprendizaje). Tiene que ver con tendencias iniciales de la personalidad, como la curiosidad, la apertura a las nuevas experiencias, iniciativa, persistencia, reflexividad, imaginación, entre otras. Tercero, se incluyen los estilos cognitivos, que son formas o tendencias de procesar la información con diferentes características (e.g.: más focalizados o más amplios; de respuesta rápida o más cautelosa, etc.).

La cuarta dimensión es el desarrollo lingüístico, ampliamente entendido, incluyendo la competencia comunicativa (expresión del pensamiento propio, reconocimiento de los diversos registros del habla) y las competencias vinculadas al código escrito (e.g.: conciencia de lo impreso, formas de preescritura) y la conciencia fonológica. 
Por último, la quinta dimensión es el desarrollo de la cognición y el conocimiento general. Esta dimensión refiere al conjunto de conocimientos socialmente compartidos que se espera que un niño domine al momento de ingresar a la primaria y los procesos cognitivos subyacentes que permiten que maneje esa información. Dentro del conocimiento general, se incluyen el conocimiento físico, el conocimiento lógico matemático y el conocimiento social, el conocimiento acumulado por las sociedades a través del tiempo y puede hacer referencia a tipos muy diversos de conocimientos relevantes (aspectos históricos, conductas preventivas, etc.).

El Early Development Instrument (EDI) es el instrumento para evaluar la DPE más utilizado en Norteamérica (Janus \& Offord, 2007). También está basado en una estructura multidimensional de la PPE que tiene raíces en el modelo de Kagan et al (1995). Sus cinco dimensiones son: (a) salud física y bienestar, que refiere a la preparación del niño para el día escolar en términos de alimentación, descanso, nivel de energía, así como aspectos motrices; (b) competencia social, que refiere a aspectos que facilitan la interacción y la cooperación, (c) madurez emocional, que refiere al buen manejo de las emociones, baja presencia de conductas ansioso-evitativas, hiperactivas o de agresión-frustración, (d) lenguaje y desarrollo cognitivo y (e) comunicación y conocimiento general, que refiere a la capacidad de transmitir su pensamiento de forma clara y comprensible así como el manejo de conocimientos básicos del mundo y de la sociedad (e.g.: nombres de colores).

Más recientemente, han surgido propuestas que intentan integrar los diferentes modelos multidimensionales de DPE bajo el paraguas del concepto autorregulación o de funcionamiento ejecutivo. Por ejemplo, Blair y Raver (2015) han sugerido que las competencias básicas que los maestros de inicial encuentran como cruciales para la transición a primaria (como ser escuchar, colaborar, cooperar, pedir ayuda, esperar turnos, ser persistente, tener iniciativa) son esencialmente de naturaleza autorregulatoria. Desde esta concepción, se entiende que los niños están dispuestos para ingresar a la escuela primaria cuando ha llegado un momento en su desarrollo en que están suficientemente maduros para manejar los distintos tipos de estimulación ambiental y su atención hacia ella, de forma que les permita regular sus emociones y mantener la atención de modo sostenido para su involucramiento escolar. Se entiende que detrás de todos los procesos de los modelos previos de DPE (actitud hacia el aprendizaje, competencias proto-aritméticas, desarrollo del lenguaje, etc.) está la función ejecutiva y la autorregulación (Blair, 2002; Blair \& Raver, 2015).

Existen otros modelos para conceptualizar la DPE de forma multidimensional, que no podemos detallar en profundidad en este capítulo, pero en general, están de una u otra manera basados en los componentes anteriormente presentado, en diferentes combinaciones o agrupamientos, fundamentados ya sea en razones teóricas o empíricas. Por ejemplo, una dimensión de la DPE propuesta es el ajuste comportamental, que colapsa contenidos de regulación, comportamiento prosocial e involucramiento en clase (Hughes et al., 2015).

Valga decir entonces que estas son las conceptualizaciones más relevantes al día de hoy de la multidimensionalidad de la DPE y que luego, en los distintos contextos regionales o nacionales de trabajo en DPE, los agrupamientos pueden variar en función 
de razones métricas o de evaluación del constructo, así como del foco o impronta que tenga la política pública de referencia.

Un paso importante en la concepción de la multidimensional del concepto es la importancia cada vez mayor que están recibiendo aspectos no necesariamente centrados en el niño. La evaluación de aspectos como el apoyo familiar hacia la escolarización de sus hijos (o lugar que le otorgan a los procesos escolares), la calidad del ambiente familiar y la calidad del ambiente escolar y cómo este se ajusta a las comunidades de referencia, son algunos temas que se deben considerar cuando se diseñan políticas de evaluación o intervención en DPE. Estos aspectos serán tratados en el apartado siguiente.

¿La DPE es del niño, de la familia o de la escuela?

Cualquier propuesta de intervención o política pública en DPE debe considerar, además de las características individuales del niño, los principales sistemas con los que éste interactúa: la familia y la escuela. Por lo tanto, y en consonancia con un informe reciente de UNICEF, la disposición para la escuela debe ser entendida en tres dimensiones: "la preparación de los niños para la escuela; preparación de la escuela para niños; y la disposición de las familias y las comunidades para ayudar a los niños a hacer la transición a la escuela" (UNICEF, 2012, p. 2).

Entender las características del niño es importante, pero el peso de las variables individuales va a variar en función de este ajuste con los principales sistemas de interacción infantil. Por ejemplo, las escuelas pueden desarrollar un conjunto de acciones cruciales para mejorar esta transición: acciones preparatorias durante el año anterior y/o el verano, establecimiento de vínculos previos y posteriores a la transición entre las escuelas y los jardines, o promover atención especializada a los niños que presentan menor DPE. Algunas características de las familias (y las características del ambiente familiar) son elementos

Es importante tener en cuenta que el nivel de desarrollo del niño es solo un aspecto del complejo cuadro de la DPE. Las políticas o intervenciones en DPE también deben focalizarse en la organización y salud de los principales sistemas de interacción del niño (como lo son el familiar y educativo), además de en los factores individuales. que explican buena parte de la variabilidad que presentan los niños en su desarrollo cognitivo y socioemocional. Por lo tanto, su involucramiento para promover o eventualmente cambiar ciertas prácticas en el ambiente del hogar es de mucha relevancia, así como su disposición para acompañar a los niños a los servicios especiales de apoyo (e.g.: en el contexto pediátrico), o para sostener al niño emocionalmente frente a los cambios de prácticas y las nuevas demandas inherentes al pasaje a la educación primaria. Variables como la atención a la salud mental de los padres deberían ser reforzadas especialmente frente a esta transición, debido al peso que tienen sobre el bienestar y el desarrollo del niño. 
Debido a su importancia para las trayectorias educativas, una parte importante de las intervenciones en DPE se están focalizando en el trabajo referido a los ambientes familiares y educativos. Presentamos en la Tabla 1.1, a modo de ejemplo y sin intención de exhaustividad, algunas de las principales dimensiones consideradas para su evaluación. En Uruguay existen antecedentes de generación de instrumentos de evaluación del ambiente escolar. Un ejemplo de esto es el Inventario de Caracterización de Ambientes para la Educación Inicial (INCA-EI). EI INCA-EI fue validado en un grupo de 142 aulas de Nivel 3, 4 y 5 de educación Inicial de Montevideo y está disponible para su utilización (más información en el sitio de compañía del libro).

Tabla 1.1

La evaluación del ambiente familiar y escolar en la primera infancia.

Ambiente familiar

Promoción del desarrollo. ¿Los padres estimulan a los niños a jugar y les dirigen la palabra de forma que los incentivan a involucrarse más en un juego o tarea?

Formas de regulación del comportamiento. Este indicador pone especial foco hacia los estilos, si los mismos son democráticos o violentos.

Diversidad de experiencias. Indaga las formas en que los padres fomentan que el niño tenga diversas experiencias y actividades que promuevan su desarrollo (ej. Ida a museos, plazas, visita a familiares).

Estrés parental. ¿En qué medida la crianza aumenta el estrés de los padres, por dificultades económicas, de acceso al cuidado sustituto o por problemas en las estrategias de afrontamiento?

Uso del tiempo. Estudia las horas frente a las pantallas, el tiempo compartido en las comidas, etc.
Estructura. Involucra aspectos que hacen a las condiciones materiales en que los niños reciben las clases: ratio alumnoniño, ventilación, mobiliario, recursos materiales para facilitar el aprendizaje, ruido externo.

Proceso. Implica aspectos interactivos que suceden entre el docente y los niños en contextos de aula. Incluye indicadores como:

Tiempo destinado a actividades pedagógicas, en porcentaje

Retroalimentación

Posibilidad de regulación del comportamiento

Vínculo familia-escuela. Si bien es un aspecto interactivo, el foco se introduce en la promoción por parte de las escuelas del involucramiento familiar. 


\title{
Capítulo 2.
}

\section{La evaluación del desarrollo en primera infancia: comprendiendo el funcionamiento de los tests}

\author{
Alejandro Vásquez Echeverría, Mónica Pérez y Maite Liz
}

\section{Objetivos de aprendizaje}

Al finalizar este capítulo el lector será capaz de:

1. Dar cuenta de las diferencias y similitudes entre la evaluación educativa y la evaluación del desarrollo.

2. Comprender las características principales de la evaluación psicológica.

3. Conocer y diferenciar los distintos tipos de estándar (norma o criterio) a los que puede estar referido un test.

4. Definir y explicar los atributos esenciales que determinan la calidad de un test.

5. Entender algunas particularidades de los procesos de evaluación en primera infancia.

\section{Ideas fuerza}

- Si bien las evaluaciones de DPE son implementadas en el ámbito educativo, son esencialmente evaluaciones del desarrollo psicológico.

- La evaluación psicológica y la evaluación educativa presentan elementos claramente diferenciables. Sin embargo, comparten un gran número de cualidades vinculadas a la teoría de la evaluación, a la estadística y a la psicometría, lo que se refleja en los estándares de calidad que se exigen para ambos tipos de evaluación

- Los tests en psicología refieren a un procedimiento sistemático para evaluar el funcionamiento de la persona y para interpretarlo de acuerdo a algún estándar, ya sea de norma o criterio.

- Los tests referidos a norma (TRN) permiten comparar el funcionamiento de un individuo con su grupo de referencia y los tests referidos a criterio (TRC) permiten determinar niveles de logro según estándares pre-establecidos.

- La psicometría es la ciencia que se encarga de evaluar los atributos de los tests e instrumentos psicológicos y educativos, especialmente en cuanto a la confiabilidad y la validez. 


\subsection{La evaluación de la DPE: ¿es un ámbito psicológico o educativo?}

La ciencia y la práctica de la evaluación está presente en todas las disciplinas del conocimiento. Por lo tanto, la evaluación, como foco de interés es un tema que comparten tanto la psicología (y otras ciencias del desarrollo humano) como las ciencias de la educación, cada una con sus particularidades.

Pero hay una pregunta frecuente que siempre se nos hace cuando intentamos hablar de evaluación de la DPE. ¿Se trata de evaluación psicológica o de evaluación educativa? Esta es una pregunta difícil de responder. La DPE generalmente se evalúa en contextos educativos, su constructo tiene un componente directamente vinculado a la evaluación educativa (nivel educativo alcanzado, rendimiento, repetición, etc) y es considerada para tomar decisiones en relación a las políticas educativas de los países (edad de ingreso a primaria, existencia y calidad de la atención preprimaria, etc).

Sin embargo, las evaluaciones que se suelen implementar en los sistemas educativos antes o durante el ingreso a la primaria son esencialmente del desarrollo psicológico (o eventualmente de aspectos pediátricos, si indagan información como bajo peso al nacer o de salud física) ya que los principales factores identificados por los diversos modelos vistos en el Capítulo 1 son inherentes a este. Varias puntualizaciones deben hacerse sobre esto:

La investigación sobre DPE es interdisciplinaria. Como vimos, la investigación sobre DPE combina áreas, y por lo tanto, es necesaria la articulación de conocimiento entre ambas disciplinas, no solo para generar modelos estadísticos de los efectos del desarrollo temprano sobre el logro posterior, sino para darle sentido teórico y generar explicaciones causales sobre los mecanismos de acción por lo que eso sucede. También es necesario conocer bien cómo se evalúa y define el logro académico y cómo los distintos actores lo operacionalizan para hacer investigación longitudinal de calidad en DPE.

La intervención y la evaluación sobre DPE es mayoritariamente llevada a cabo por actores educativos o se realiza en contextos educativos. En la enorme mayoría de las situaciones, las prácticas de intervención para la promoción de la DPE son implementadas por el cuerpo de los profesionales docentes, ya sea en el contexto de aula, como mediante maestros de apoyo, o a nivel de la dirección fortaleciendo la comunicación y trabajo con las familias. Asimismo, la evaluación de la DPE se realiza frecuentemente en contextos educativos ( ¡lo que no quiere decir que necesariamente sea evaluación educativa!), tanto porque la informante es la maestra como porque la evaluación la realiza un profesional externo en la escuela.

La evaluación psicológica y la educativa tienen muchos puntos en común. Si bien existen aspectos específicos, hay muchísimos elementos vinculados a la teoría de la evaluación, a la estadística y al uso de la psicometría que son compartidos. De hecho, muchas declaraciones y estándares de calidad sobre la construcción y elaboración de tests han sido firmados en forma conjunta por asociaciones de educación y de psicología. 
Por ejemplo, los estándares más utilizados para el desarrollo de tests tanto educativos como psicológicos, esto es, los Standards for educational and psychological testing, fueron desarrollados de forma conjunta por la Asociación Estadounidense de Investigación Educativa (conocida por sus siglas en inglés AERA), la Asociación Estadounidense de Psicología (APA) y el Consejo Nacional de Medición en Educación (NCME) de los Estados Unidos (AERA, APA, NCME, 2014), así como otras guías de adaptación de instrumentos (e.g.: Hambleton, Merenda \& Spielberger, 2005).

El apartado que sigue a continuación entonces estará enfocado en exponer los aspectos fundamentales sobre la evaluación del desarrollo, que es el punto de partida de la evaluación de la DPE y de la mayoría de los instrumentos diseñados para su evaluación sistemática. Pero esto no excluye que muchas de estas nociones sean también útiles para comprender temas de evaluación educativa. Comenzaremos presentando aspectos generales de la evaluación psicológica, para pasar a exponer sobre temas de tests psicológicos y cerrar con algunas consideraciones de la especificidad de la evaluación del desarrollo.

\subsection{Características de la evaluación psicológica}

Basados en el trabajo de académicos que nos anteceden (Groth-Marnat, 2003), definimos a la evaluación psicológica como el proceso mediante el cual un psicólogo u otro profesional con formación equivalente y habilitante (frecuentemente también puede tratarse de un equipo de profesionales) intenta responder preguntas específicas sobre la situación vital de una persona o grupo humano. Las respuestas a estas preguntas permiten ayudarle en la toma de decisiones y en la mejora de su salud y calidad de vida, en uno o más contextos de actividad (e.g.: personales, educativos, organizacionales, sanitarios, legales).

De esta definición se desprenden varios elementos. El primero, refiere a la idea de proceso. Indica que la evaluación es algo que debe llevar un tiempo, y por lo tanto posee una estructuración temporal (o fases). Como segundo punto, realizar una evaluación psicológica demanda formación específica que permita, no solo llevar adelante las estrategias de trabajo que nos planteemos para hacer la valoración, sino también interpretarla de forma correcta y que resulte en un beneficio para la persona evaluada. EI tercer punto refiere a los objetivos de la evaluación que es responder ciertas preguntas concretas, específicas, que vamos a implementar en la evaluación para entender alguna situación vital de la persona. Un proceso de evaluación, por tanto, nunca se trata de una valoración global de todos los aspectos de la vida del evaluado, sino de aquellos que son relevantes para comprender un momento o situación dada. Cuarto y último, un elemento central de la definición hace a la posibilidad de ayudar a las personas a mejorar su salud, su calidad de vida y acompañar la toma de decisiones en relación a procesos relevantes que afectarán sus trayectorias vitales.

Algunas puntuaciones importantes. Esta definición que proponemos, tiene el cuidado de no referirse específicamente a personas, ya que cada vez más las unidades a las que se realiza una evaluación refieren a grupos humanos: parejas, familias, grupos de 
trabajo o instituciones (como una escuela, empresa, etc.). Por otro lado, como el lector habrá notado, esta definición no menciona nada sobre diagnóstico psicológico, clínico o psicopatológico. Evaluar y diagnosticar son procesos diferentes, aunque comúnmente confundidos. Evidentemente, un buen proceso psicodiagnóstico requiere de una buena evaluación psicológica (esto es, un subtipo dentro de esta), pero un porcentaje reducido del trabajo en evaluación psicológica es de carácter psicodiagnóstico.

En la evaluación psicológica en general se trabaja con tres técnicas centrales: (a) la entrevista; (b) la observación del comportamiento y (c) los tests psicológicos. Una cuarta estrategia refiere al uso de registros como históricas clínicas, informes, documentos escritos, que en general son menos usados, por lo que no haremos referencia aquí. La entrevista suele ser utilizada/implementada al inicio del proceso de evaluación para establecer las hipótesis y los objetivos de trabajo, así como sobre el final, para confirmar e interpretar algunas informaciones recabadas con los otros procedimientos y para hacer la devolución. Las entrevistas pueden realizarse también con otras personas que no sean directamente parte del proceso de evaluación. Esto ocurre más frecuentemente con niños y personas en situación de vulnerabilidad. Hay diferentes formas de entrevistar, lo que incluye estrategias abiertas, semidirigidas 0 cerradas. En general, en un proceso de valoración debe usarse una combinación de todas ellas, e implica procesos de formación específica para un buen manejo de la herramienta.

La evaluación comportamental, por su parte, se basa en la idea sistémica de que el comportamiento ocurre en un contexto dado. Entonces, se entiende que es necesario evaluarlo en esa interacción y que las medidas deben contextualizarse en términos de antecedentes, las características situacionales que ocurren al momento de la conducta y sus consecuencias. Como estrategia, un psicólogo evaluador puede solicitar a la persona durante la semana que complete una ficha cada vez que, por ejemplo, tenga un pensamiento perturbador $x$ o cada vez que no se acuerde dónde dejó algo. Saber qué pasó antes, qué estaba haciendo en el momento, que estrés sentía y cuáles fueron las consecuencias de ello es de suma relevancia para valorar por qué se presenta una conducta. En un contexto de tecnologías digitales cada vez más presentes, también puede ser sencillo incorporar mediciones de tasa cardíaca o procesos de actividad física que ayudan a contextualizar las conductas.

Los tests psicológicos es la tercera estrategia a la que se puede recurrir en un proceso de evaluación y, en la mayoría de los casos es la más utilizada en conjunto con la entrevista. Por su relevancia para pensar la evaluación sistemática del desarrollo en contextos Los tests en psicología refieren a un procedimiento sistemático para obtener muestras de comportamiento, relevantes para el funcionamiento cognitivo $o$ afectivo, y para puntuar $y$ evaluar esas muestras según algún estándar ya sea de norma o criterio. educativos, objetivo importante de este libro, aquí profundizaremos en los fundamentos de los tests psicológicos en el contexto de la evaluación psicológica. 
Los tests psicológicos han sido definidos como "un procedimiento sistemático para obtener muestras de comportamiento, relevantes para el funcionamiento cognitivo o afectivo, y para puntuar y evaluar esas muestras de acuerdo con estándares" (Urbina, 2014, traducción libre). Esta definición tiene cinco aspectos centrales que ameritan una profundización:

a) Procedimiento sistemático. Refiere a que los test psicológicos demandan una planificación y uniformidad para su uso. Las condiciones y reglas de administración deben ser homogéneas para toda la población.

b) Muestras de comportamiento. Refiere a que, en tanto la evaluación es específica, los test también evalúan una parte del todo que configura el psiquismo humano. Esa parte ha sido seleccionada en función de los objetivos de la evaluación.

c) Relevantes para aspectos cognitivos, afectivos o ambos. Esto implica que son aspectos de la vida mental humana que se han asociado significativamente con el bienestar de los individuos, ya sea en su funcionamiento cognitivo y/o afectivo

d) Evaluados y puntuados. Este componente de la definición refiere a que los test poseen algún sistema por el cual se le asignan números o categorías a las respuestas de los indicadores o ítems.

e) Interpretados de acuerdo a estándares. Quizás este es uno de los elementos que demanda mayor explicación. Refiere a la necesidad de contar con procedimientos de tipificación de las puntuaciones como prerrequisito indispensable para interpretar los resultados de un test de forma útil para un proceso de evaluación. Esto es, se necesita una suerte de "vara de comparación" o un criterio de referencia para traducir la puntuación bruta que se obtiene mediante los indicadores de la prueba, a otra unidad o categoría que nos permite hacer una valoración del rendimiento del sujeto. Por su importancia, estos aspectos serán profundizados en el apartado 2.3.

\section{${ }^{* * *}$ PUNTO PARA EL DEBATE***}

Urbina (2014) afirmó, en consonancia con la definición de evaluación psicológica, que "Los tests psicológicos se utilizan frecuentemente para evaluar a las personas en algún punto de inflexión o coyuntura importante de sus vidas". Piensa en sí, a lo largo de tu vida, tú o alguna persona cercana a ti han pasado por un proceso de evaluación psicológica que implicara el uso de tests (vocacional, laboral, clínico, etc.).

- ¿Sucedió en un momento o coyuntura importante de tu vida?

- ¿Cómo fue ese proceso?

- ¿Tuviste una devolución de dicha evaluación?

- ¿Con qué sensaciones o aprendizajes te fuiste de ese proceso? 
Difícilmente podamos decir que estamos frente a un test psicológico si no posee los cinco elementos detallados más arriba. Quizás el punto más debatido sea la necesidad de estandarizaciones, 0 sea, si las herramientas psicológicas sin estandarización pueden ser llamados tests. Volveremos sobre este debate más adelante.

\subsection{Cómo hacer interpretables los resultados de un test: referencia a la norma y referencia a criterio}

Una de las características relevantes de los test es que proporcionan procedimientos estandarizados para la interpretación de las puntuaciones y, dependiendo del propósito de la aplicación del mismo, la interpretación de las puntuaciones puede clasificarse en test referidos a norma (TRN) o test referidos a criterio (TRC).

\section{Interpretación referida a Norma (TRN)}

La interpretación referida a norma permite responder a la pregunta acerca de cómo es la puntuación de un individuo, en comparación con los individuos que componen su grupo de referencia (ej. la población de un país o un grupo etario determinado). La norma es el resumen de las puntuaciones del test (por lo general pautado en percentiles, deciles, etc.) construida a partir de la evaluación de un grupo, denominado muestra normativa. A través de la referencia que nos brinda la norma se puede establecer el status o posición de ese individuo con respecto del grupo que integra. El objetivo primario de los TRN es, por tanto, diferenciar entre individuos o grupos en términos del atributo o atributos evaluados por el test y ofrecer una medida de posición. En este sentido, el logro obtenido por un individuo en el test será relativo a su grupo de pertenencia, ya que los resultados se valoran en función de cómo ese atributo se distribuye en la población de referencia (Martínez-Arias, Chacón-Gómez \& Castellanos-López, 2014; Tovar, 2007).

En el caso de los TRN es de suma importancia que la muestra normativa sea representativa de la población de individuos a los que se les aplicará el test. Tanto la descripción de la muestra normativa, así como el proceso de construcción de la norma deben estar debidamente reflejados en el manual del test y servir de insumo a quien lo va a utilizar para determinar su aplicabilidad. Las normas deben ser revisadas por los implementadores de los tests periódicamente, ya que las puntuaciones pueden variar debido a procesos históricos o culturales (e.g.: el efecto Flynn, visto en el capítulo 1).

Interpretación referida a criterio (TRC)

En la interpretación referida a criterio no se compara la puntuación de un individuo con las puntuaciones de su grupo de referencia (baremo), sino que se compara con un criterio o estándar previamente definido. Estos estándares se definen en términos de niveles de logro preestablecidos, con puntos de corte que determinan el nivel de habilidad o competencias indispensables que el individuo debe poseer para desempeñarse adecuadamente en relación a ese criterio. Los criterios deben estar claramente especificados en el manual del test y haber sido validados mediante algún procedimiento empírico o de jueces expertos. Así, el objetivo primario de los TRC es evaluar el logro obtenido por un individuo en uno o más atributos en términos absolutos, y en función de 
su grado de adecuación o consecución del criterio establecido (Tovar, 2007; Meneses et al., 2014; Martínez-Arias, Chacón-Gómez \& Castellanos-López, 2014). Para lograr esto, la puntuación bruta del test debe transformarse a niveles de desempeño ofrecidos en categorías (e.g.: nivel excelente, adecuado o inaceptable de percepción visual nocturna para conductores profesionales de vehículos).

Los objetivos de los TRN y TRC no son mutuamente excluyentes y es posible interpretar desde ambas perspectivas el rendimiento de las personas en un mismo test (Martínez-Arias, Chacón-Gómez \& Castellanos-López, 2014). Por esto mismo, muchas veces encontraremos tests que presentan, a la vez, estándares de norma y de criterio. La Figura 2.1 caracteriza y sintetiza los TRN y TRC en sus diferencias. En los TRN los sujetos se comparan entre sí, por lo que la noción de distribución (en la parte izquierda de la figura: la distribución normal) es de suma relevancia. En los TRC, los sujetos se comparan con un criterio, como puede ser las expectativas de desempeño en términos de puntuación derivadas de un programa de estudios (en la parte derecha de la figura: los niveles excelente, adecuado o inaceptable).
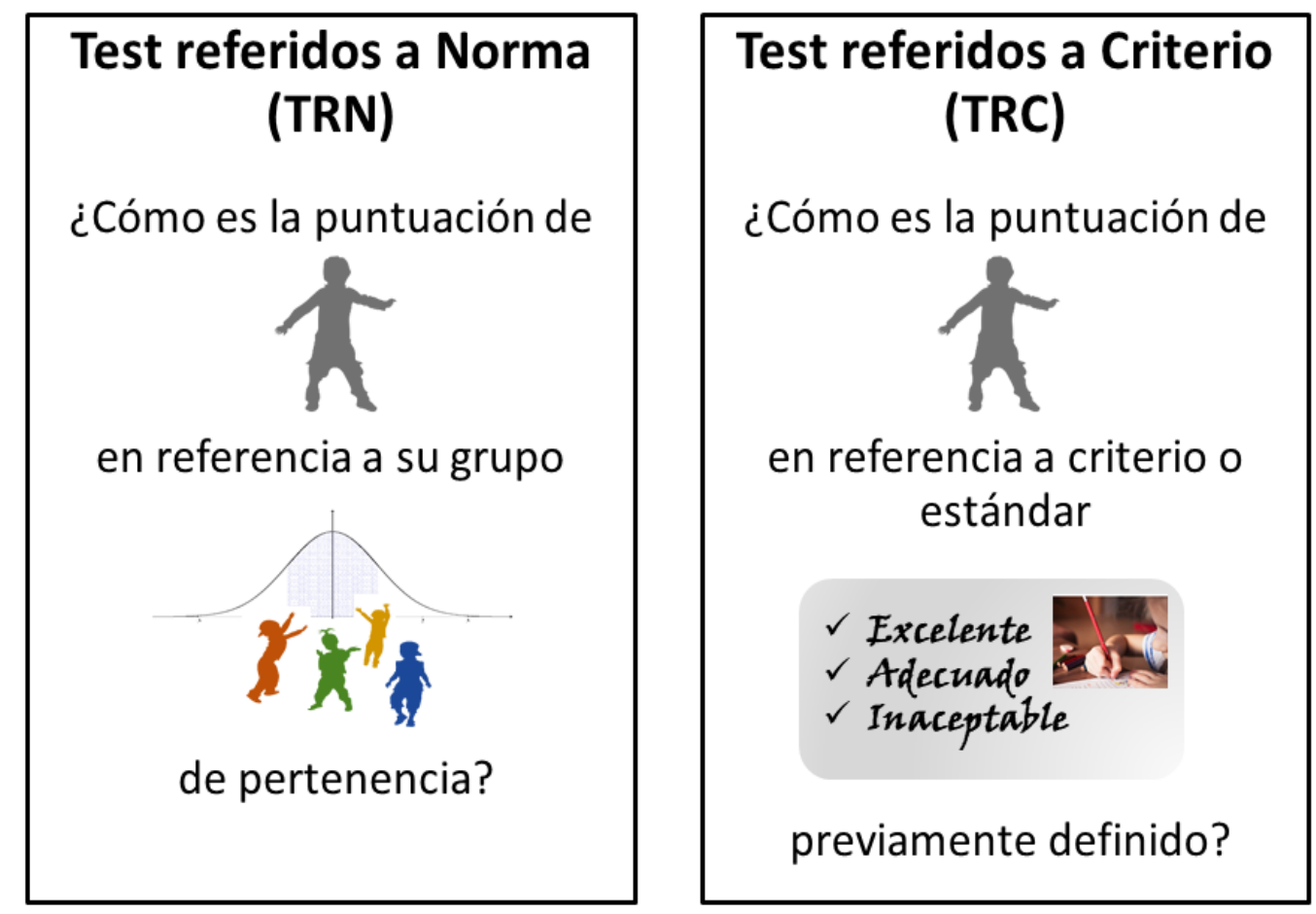

Figura 2.1. Caracterización de los test referidos a norma (izquierda) y los test referidos a criterio (derecha). 


\subsection{La calidad de los tests y la psicometría. Confiabilidad y validez}

Llegados a este punto, una pregunta que puede hacerse el lector es, ¿cómo podemos llegar a saber que un test mide lo que quiere medir?, ¿cómo reconozco si lo puedo usar en mi ámbito profesional? Este es un tema crucial, máxime en el ámbito de la psicología y de la educación donde, por el objeto de estudio de estas disciplinas, nos interesamos por aspectos no tangentes $u$ observables a simple vista, llamados las variables latentes (ver recuadro: Las variables latentes).

La calidad de las medidas que se tiene en psicología, ya sean consideradas tests o instrumentos, ha sido una preocupación importante desde el inicio de los esfuerzos de medición en psicología. El saber de qué forma las respuestas de un sujeto a ciertas preguntas o problemas se relaciona con su forma de ser, su rendimiento académico o su salud mental, estuvo en la preocupación originaria de quienes comenzaron el desarrollo de la medición sistemática en psicología. Con el tiempo, eso condujo a la especialización de un cuerpo de conocimientos específico, o una subdisciplina dentro de la psicología llamada psicometría.

La psicometría puede definirse de manera descriptiva como una subárea de la Psicología "cuya tarea fundamental es la medición o cuantificación de las variables psicológicas con todas las implicaciones que ello conlleva, tanto teóricas (posibilidades y criterios de medición) como prácticas (cómo y con qué se mide)." (Barbero, Vila Abad \& Holgado, 2015).

Sin embargo, nos basaremos en Furr \& Bacharach (2013) para definir a la psicometría como la ciencia que se encarga de evaluar los atributos de los tests e instrumentos de medición psicológicos y con frecuencia, los educativos. Esta definición es más simple que la anterior y funcional. Se enfoca en el verdadero cometido de

La psicometría es la ciencia
que se encarga de evaluar los
atributos de los tests e
instrumentos psicológicos y
educativos.
la psicometría: informar sobre los atributos relevantes de los tests psicológicos en tanto objetos pasibles de ser medidos y analizados en cuanto a su calidad.

Existen tres atributos esenciales de los tests psicológicos que podemos analizar mediante la psicometría: (a) el tipo de información generada por los test; (b) la confiabilidad de las puntuaciones logradas por los test y (c) la validez de los datos producidos por los test, siendo estos dos últimos los atributos centrales de los que se encarga la psicometría.

\section{Confiabilidad.}

Definiremos por confiabilidad el grado en que las puntuaciones obtenidas en un test son robustas o consistentes a variaciones irrelevantes a lo que se pretende medir. En otras palabras, cuando analizamos la confiabilidad nos interesa saber cuánto error tiene una medida. Por lo tanto, la confiabilidad es una estimación del rango de error aleatorio que puede tener una medida. Pongamos un ejemplo. Supongamos que un grupo de 
personas den valores de respuestas más bajos a un ítem de una prueba de autoestima, por el hecho de ser el último ítem en el test. Eso puede significar que el ítem es una fuente de error ya que, en principio, al desarrollador del test no le interesa evaluar la fatiga frente a la realización de la prueba, sino el nivel de la variable latente autoestima de esos sujetos. Lo mismo sucedería con una prueba de lenguaje receptivo (comprensión). Si la misma se aplicara dos veces en un período de tiempo acotado (por ejemplo, un lunes y jueves de la misma semana) a una persona de 25 años, el investigador esperaría un rendimiento similar sin variaciones bruscas, ya que su habilidad para entender la lengua es en teoría estable en periodos cortos de tiempo para esa edad. Por tanto, para estar seguros de que las diferencias entre las personas se deben a una variación en la variable y no a artefactos metodológicos en general aleatorios (ej. posición del ítem en el test o momento del día en el que se administra), nos debe interesar usar instrumentos con poco error de medición. Existen varios tipos de confiabilidad, pero destacamos los siguientes:

Consistencia interna. Es una de las formas de confiabilidad más analizada de los tests. Intenta responder a la pregunta de si los indicadores o ítems diseñados para medir el mismo constructo, producen puntuaciones similares. Dicho de otra forma, se analiza en qué medida las puntuaciones de un ítem se relacionan con la puntuación total. No sería consistente que los dos primeros ítems de una escala de seis, tengan baja relación con los últimos dos. En este caso, quizás haya un efecto (irrelevante) de la posición de los ítems, que esté afectando su aporte a la puntuación total.

Confiabilidad test-retest. Dependiendo de la estabilidad esperada de las puntuaciones en el tiempo, la confiabilidad test-retest es crucial de ser analizada. Por ejemplo, para los rasgos de personalidad, es de esperar cierta estabilidad en el tiempo, sin importar si la evaluación se realiza en invierno o en verano, en la planta baja o en el segundo piso del local de trabajo. Si llega a suceder que las puntuaciones varían de manera considerable, el efecto debe ser atribuido a un error en la generación de las puntuaciones debido al momento del año o al lugar en dónde se realiza la evaluación. Para analizar la confiabilidad test-retest se administra el instrumento a la misma persona dos veces en un periodo corto de tiempo (en general, dos, cuatro o cinco semanas) y se analiza la correlación entre la primera y la segunda puntuación obtenida. En el caso de los tests de desarrollo, especialmente en primera infancia, las puntuaciones son muy sensibles al paso del tiempo, por lo que es necesario diseñar con cuidado el intervalo de tiempo entre evaluaciones y las expectativas de fuerza y dirección de la correlación.

Confiabilidad entre jueces. Las puntuaciones, en un número significativo de tests, se generan en base al juicio del evaluador, ya sea mediante la observación o mediante la codificación de material cualitativo (e.g.: producciones textuales). Dado que lo que nos interesa evaluar son las características del sujeto en la variable de interés, las variaciones relacionadas a cómo puntúan los distintos evaluadores deberán incidir de manera irrelevante en los resultados. Esto requiere que el test describa minuciosamente la forma en la que los distintos evaluadores deben puntuar un indicador, intentando reducir al mínimo posible el espacio para interpretaciones personales. Para analizar esta fuente de error, se obtienen datos de un evaluando y dos o más jueces o evaluadores, con la suficiente formación y entrenamiento, responden a los indicadores, según las 
instrucciones del test. Estos resultados se analizan mediante correlaciones, que se espera que sean elevadas.

\section{Correlación: la relación entre dos variables}

El coeficiente de correlación es una medida que permite conocer el grado de asociación entre dos variables cuantitativas. A modo de ejemplo podríamos analizar la relación existente entre la altura y el peso de los niños y determinar si a mayor altura corresponde, en general, un mayor peso. Una correlación no implica causalidad, es decir no nos permite afirmar que una variable es causante del efecto en la otra variable.

Cuando observamos el grado de relación entre dos variables debemos tener en cuenta dos aspectos: (a) el sentido o dirección de la relación (positiva o negativa) y (b) la fuerza de la relación (desde perfecta, fuerte a débil o incluso nula). Una correlación será positiva si a medida que crece el valor de una variable la otra también lo hace. En cambio, será negativa, si cuando crece el valor de una variable la otra disminuye.

El valor de una correlación puede oscilar entre 1 (positiva perfecta) y -1 (negativa perfecta), reflejando los valores cercanos a 0 la ausencia de relación entre las dos variables, Los diagramas de dispersión que pueden verse a continuación nos proporcionan una aproximación visual a las correlaciones incluyendo sentido y fuerza.

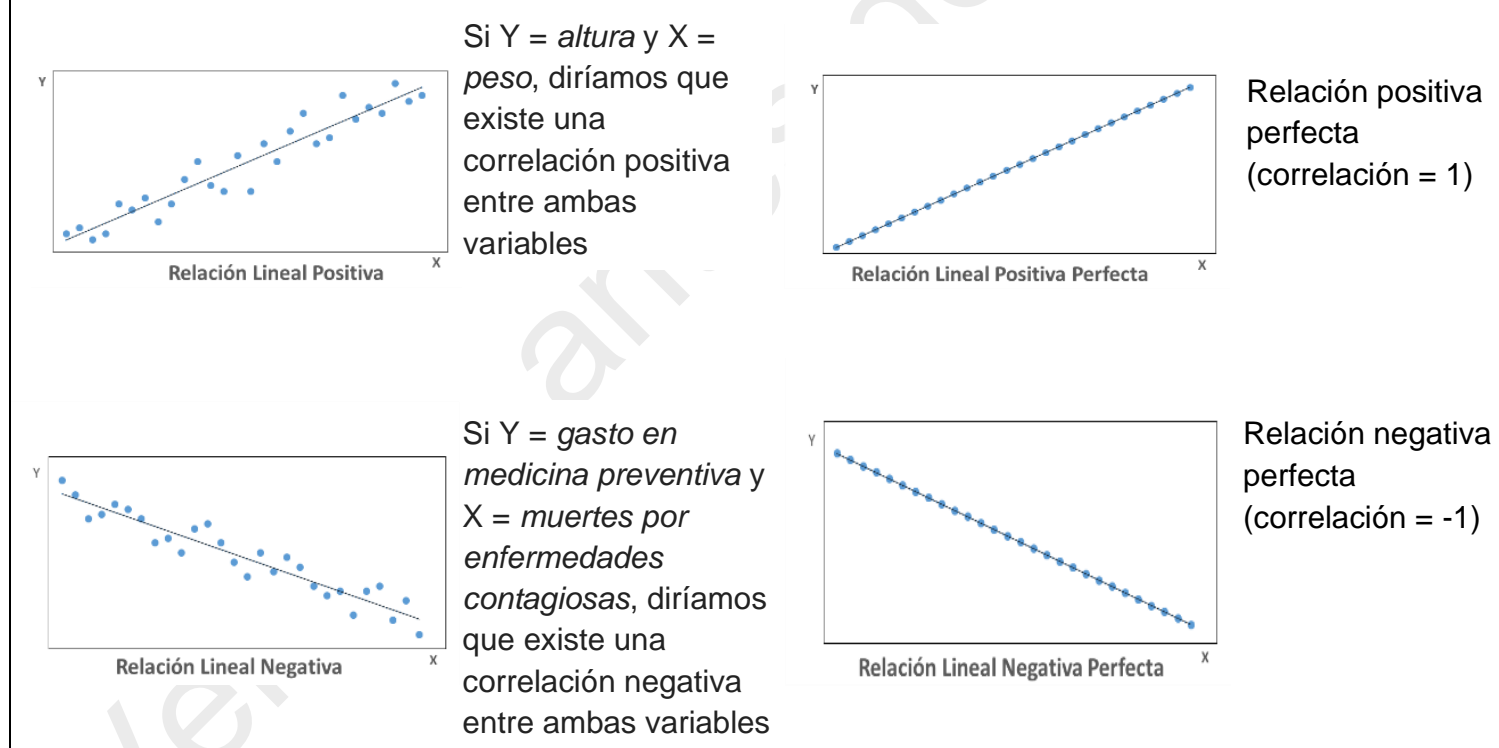

Sin embargo, puede no existir ningún grado de asociación entre variables

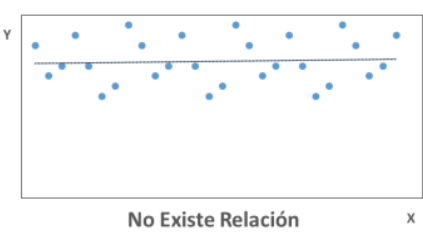


Validez

Analizar la validez de un test es el segundo de los atributos sobre los que versa la psicometría. La validez ha sido definida como "... el grado en el cual la evidencia y la teoría apoyan las interpretaciones de los resultados de un test según su uso propuesto" (AERA, APA \& NCME, 2014, p. 11, traducción libre). Veamos algunos aspectos relevantes que se desprenden de esta definición.

Una medida no es "válida o no válida" en sí misma, sino que depende de sus interpretaciones. Por lo tanto, la validez tiene que relacionarse estrechamente con cómo los desarrolladores de una prueba interpretan una puntuación alta, baja o media en esa escala y qué implicaciones puede tener para el sujeto esa puntuación otorgada. Por un lado, hay propiedades estadísticas de distribución de las puntuaciones, pero por otro, hay elementos teóricos a considerar cuando se analizan las posibles interpretaciones de los resultados con fines de validez. Este punto está emparentado con el punto siguiente, ya que las interpretaciones, tienen que ver con los usos propuestos.

Está relacionada a los usos propuestos por los desarrolladores del test. Para hacer justicia con los autores de un instrumento o test, es necesario evaluar su validez en función de su uso propuesto originalmente. Por ejemplo, si un test está diseñado para determinar la agudeza visual de los pilotos de avión para la conducción segura, no puede estimarse su validez usando muestras de jugadores de baloncesto y su tasa de acierto. Para cada nuevo uso propuesto, debe generarse un programa de validación adecuado a los objetivos.

La validez es un continuo. Este punto es especialmente relevante, en la medida en que es frecuente escuchar por parte de profesionales decir " $x$ test está validado". En realidad, esa expresión debemos traducirla como "el test $x$ tiene evidencias de validez que permiten usarlo para $x$ de manera segura”. Es importante, por tanto, pensar la validez como un continuo, un grado progresivo en donde los test tienen mayor o menor validez, en función de la investigación realizada en torno a ellos y en función de cada uso propuesto. Puede darse la situación de que un test tenga mucha validez en torno a un uso, y poca o incipiente validez en torno a otro.

Está basada tanto en datos y como en la teoría. Ambos son muy importantes para determinar la calidad del test. Conocer los marcos teóricos de referencia es indispensable para dar sentido y probar posibles modelos conceptuales alternativos como explicación a los resultados de los análisis psicométricos, y por sobre todas las cosas, para diseñar programas de validación de alta calidad.

Se trata de un constructo unitario. La validez de un test se nutre de diversas fuentes, pero la valoración global de la validez es única para cada uso propuesto y debe combinar la información de, idealmente, todos esos tipos de fuentes. Siguiendo a los Standards (AERA, APA \& NCME, 2014), los tipos de evidencia de validez son los siguientes:

1. Evidencias basadas en el contenido. Refiere a la adecuación con la que el contenido de los ítems del test representa al dominio o constructo que pretenden 
evaluar, y a la relevancia de estos contenidos en función de la interpretación propuesta de las puntuaciones del test. Aquí es importante determinar que los indicadores reactivos que la persona responde, están realmente relacionados en sus aspectos cualitativos con la variable latente (no observada) sobre la que se pretenden generar puntuaciones. De particular importancia es determinar: (a) la infra-representación del constructo en los reactivos a evaluar, esto es, cuantos aspectos relevantes al constructo no están siendo evaluados y (b) la representación en los reactivos de aspectos irrelevantes al constructo, esto es, aspectos que se evalúan mediante los indicadores que, en realidad, no tienen que ver con la variable latente. Este tipo de evidencia frecuentemente se logra mediante el análisis de los ítems por parte de personas calificadas en el área (juicio de expertos), las observaciones sistemáticas o las revisiones sistemáticas de literatura.

2. Evidencia basada en los procesos de respuesta. Todo instrumento o test psicológico asume que hay ciertos procesos cognitivos implicados en la forma en que se responde a los reactivos. Por lo tanto, es crucial analizar en qué medida las personas a las que se les administra el test procesan la información para responder a ellos y qué demanda cognitiva tiene, más allá del contenido que se pretende evaluar, comprender las instrucciones y ejecutar la respuesta. Un ejemplo de esto puede referir a cierta dificultad para la comprensión de las instrucciones de una prueba que busca evaluar matemática, pero que tiene una alta demanda de la capacidad de memoria de trabajo para comprender la consigna que da el evaluador. Por otro lado, si hay límites temporales muy estrictos por las condiciones en las que se administra un test (ej. en un salón de clases los maestros disponen de 20 minutos para evaluar 60 indicadores), entonces quizás se esté evaluando velocidad de procesamiento en mayor medida que la comprensión lectora.

3. Evidencias basadas en la estructura interna. Esta fuente de evidencia refiere a la relación entre los ítems y/o los componentes de un test con los constructos que pretenden medir y sobre los que se basarán las interpretaciones de los resultados. En general, este tipo de evidencia demanda trabajos empíricos analizando las relaciones formales (estadísticas) del comportamiento de los ítems. Por ejemplo, si un instrumento declara que está diseñado para medir únicamente motricidad fina, será de interés comprobar la homogeneidad de los indicadores para representar dicho constructo latente. En cambio, si un instrumento se basa en el pasaje de niveles de dificultad creciente para su cumplimentación, va a interesar demostrar qué evidencia se obtuvo de la dificultad de los indicadores para armar la secuencia de administración de los ítems.

4. Evidencias basadas en la relación con otras variables. Las implicaciones que tienen los resultados de los tests demandan conocer en qué medida éstos se 
relacionan con otras variables (no derivadas del test), tanto por las consecuencias prácticas que puedan tener como para confirmar las relaciones teóricamente esperadas del constructo sobre el que se ofrecen puntuaciones. Un ejemplo de esto puede ser el conocer si los resultados de una prueba de motricidad gruesa que aplica el profesor de educación física tienen una relación afín y esperada con, por ejemplo, una evaluación que realice otro profesional en el espacio de psicomotricidad. Por lo tanto, la relación con otras variables ofrece evidencia fundamental en torno a si las relaciones del constructo evaluado son consistentes con el uso propuesto para los resultados del test. Estas variables, externas al test, pueden ser: (a) un criterio que se supone el test debe predecir; (b) las puntuaciones de otro test (como en el ejemplo anterior) o (c) variables categóricas (o de membresía a grupo) como, por ejemplo, el sexo o la profesión. En todos los casos, se entiende que para que esta relación sea fuente de validez, además de los datos empíricos, deben existir expectativas teóricas por detrás que justifiquen y anticipen la dirección de los efectos.

Cuando hablamos de evidencias de criterio, nos referimos a una medida de un atributo o resultado comportamental que es diferente conceptualmente a la puntuación del test. Por ejemplo, cuando intentamos relacionar las puntuaciones que una persona tuvo en una prueba de personalidad, supongamos, en un rasgo como la extroversión, con el grado de satisfacción con la atención que recibió por parte de los empleados de una empresa. El criterio puede ser predictivo o concurrente, dependiente del punto temporal en el cual se obtiene la evidencia de criterio. Para el caso de las evidencias de validez predictivas, es necesario que los resultados de test se obtengan significativamente antes en el tiempo que se obtenga la información del criterio. Por ejemplo, los resultados en una prueba de comprensión lectora obtenidos en cuarto año de liceo se relacionan con el promedio de calificaciones en el tercer año de la Universidad. En el caso de las fuentes de criterio concurrentes, la evidencia debe obtenerse al mismo tiempo o con una diferencia de tiempo que no sea teóricamente relevante.

Por su parte, las fuentes de validez convergente o divergente relacionan las puntuaciones de un test con puntuaciones de otros tests sobre los que existen expectativas teóricas de presentar cierta similitud (convergencia) o relación negativa o nula (divergencia). Esto es, si un equipo de investigación quiere introducir un instrumento de detección rápida vía web de la impulsividad clínicamente relevante, intentará relacionar esas puntuaciones con los otros test que estén usando los profesionales del ámbito de la salud mental; aunque estos últimos sean administrados en contextos clínicos, hay una convergencia teórica en cuanto a los constructos que existen por detrás de las puntuaciones y por lo tanto, debería existir una convergencia empírica cuando se analicen los datos.

5. Evidencias basadas en las consecuencias del uso del test. Muchas veces, la administración de un test tiene consecuencias de diversa índole, algunas previstas y otras no previstas por los desarrolladores de un test. El análisis de las evidencias de validez basadas en el contexto o políticas de su uso es de mucha 
importancia. El análisis de estas posibles consecuencias, debe formar parte de un plan de validación integral. Para esto, el monitoreo continuo de la administración y uso del test es esencial, así como analizar experiencias similares de evaluación a nivel local o internacional y sus consecuencias. Por ejemplo, si un test se administra para mejorar las condiciones educativas de una población de riesgo, y en base a las puntuaciones se asignan a los estudiantes a programas de educación especial, ese hecho requiere de evidencias de validez específicas de que la educación especial mejorará la educación de esos niños, porque, de hecho, podría ser el caso contrario (que la empeore). Otro ejemplo de consecuencia no prevista en el uso de un test, es el uso de los nombres asignados a las categorías de desempeño y que eso derive en procesos que afecten la moral o autoestima de los niños y sus familias (por ejemplo, "Juan está en rojo"). El desarrollo de estrategias formativas y de mitigación de estos posibles impactos es crucial y debe realizarse en conjunto entre los desarrolladores del test, los implementadores de la política y los usuarios.

\section{LAS VARIABLES LATENTES}

En gran parte, tanto en la psicología como en la educación, se intenta medir aspectos o atributos que no son directamente observables (constructos teóricos). Para ello se recurre a indicadores indirectos que se manifiestan en conductas observables y que están conectados con el constructo teórico a través de las teorías que lo definen (Martínez-Arias, Chacón-Gómez \& Castellanos-López, 2014).

Es así que las conductas observables pueden recogerse a través del ítem de un test. De acuerdo a Martínez-Arias, Chacón-Gómez \& Castellanos-López (2014) la idea que subyace a la utilización de un test es la existencia de un constructo, que el instrumento intenta medir, y que utilizando las puntuaciones obtenidas en el test permite situar al individuo respecto a ese atributo. Por tanto, podemos señalar que los tests no son un fin en sí mismos, sino que son instrumentos al servicio del proceso de evaluación psicológica y educativa.

\subsection{Particularidades de la evaluación del desarrollo en primera infancia.}

La evaluación del desarrollo psicológico en la primera infancia presenta algunas particularidades que son específicas de esta etapa o, eventualmente, las comparten con la evaluación en la infancia y la adolescencia.

Las evaluaciones directas presentan como dificultad la fatiga, el cansancio o diversas características de personalidad o temperamento del niño (ej. grados de timidez). Esto se puede reflejar en evaluaciones que pueden quedar incompletas o ser poco 
fiables. Es muy importante analizar las demandas cognitivas y emocionales que presenta la administración de una tarea directa a un niño para comprender su validez.

Otra particularidad en primera infancia es la necesidad de establecer versiones y/o normas específicas para un test, según los grupos de edad. Esto se debe a la rápida variabilidad en las habilidades y competencias de los niños en el transcurrir del tiempo. Especialmente en la primaria infancia, estos cambios pueden ser vertiginosos y bastante notorios en períodos de pocos meses. Es entonces una tarea ardua, pero imprescindible, desde los aspectos teóricos, empíricos y prácticos, establecer cuál es la mejor unidad mínima de edad para establecer dichas normas (es decir, establecer los períodos de tiempo evolutivo dentro de los cuales las características comunes en una variable conforman un grupo normativo) y en qué rango de edades establecer versiones con los reactivos específicos para dichos grupos de edad.

\subsection{Las particularidades de la evaluación de la DPE.}

La evaluación de la DPE presenta algunas particularidades y preguntas que han sido el centro del debate por varios años. Específicamente el debate se ha centrado en relación a cuándo y quiénes deben realizar estas evaluaciones. Analicemos cada uno de estos puntos:

¿Cuándo debe realizarse la evaluación de la DPE? En general, las investigaciones y las políticas de DPE se han orientado, como es evidente al momento transicional. De todos modos, allí tenemos dos opciones: realizarlo al ingreso a la escuela primaria o realizarlo el año antes del ingreso a primaria (Nivel 5, en el caso uruguayo). Debido a las potencialidades preventivas que permite, la evaluación de DPE es oportuno realizarla en los niveles relativos al preescolar (educación inicial en Uruguay), en un formato que permita el monitoreo y la intervención oportuna, integrados a modelos de respuesta de intensidad graduada (ver capítulo siguiente).

¿Quiénes deben realizar la evaluación de la DPE? En el fondo, esta pregunta remite a las fuentes de información mediante las cuales podemos entender el desarrollo del niño en contextos educativos. Cada fuente (como estrategia de información) tiene sus ventajas y sus desventajas y en ese contexto es importante ponderar los fines que se persiguen en una política de evaluación sistemática de la DPE, para analizar cuál fuente o fuentes seleccionar (Vásquez-Echeverría \& Moreira, 2016). Como nota previa, es necesario aclarar que la relación entre fuentes de información, por ejemplo, entre padres y educadores, suele ser moderada, a veces tendiendo a baja (Grietens et al., 2004). Esto se debe principalmente a que el comportamiento del niño es muy sensible a los contextos y no tanto a diferencias en el funcionamiento de los instrumentos o a diferencias entre los informantes. Así un niño puede presentar ciertas conductas de forma menos frecuente (o no manifestarlas en ningún caso) en un contexto que, en otro, dónde se manifiesta con mucha frecuencia. Por otra parte, las características del test pueden hacer que algunas 
de las ventajas o desventajas que analicemos para seleccionar uno u otro informante, se potencien.

La evaluación directa del niño mediante tests con alto grado de protocolización y realizados por evaluadores destinados exclusivamente a tal fin (e.g: la Escala Weschler para preescolares, WPPSI) tiene como ventaja que puede lograr altos niveles de especificidad sobre las funciones de desarrollo evaluadas, así como reducir a mínimos, los sesgos del evaluador. Sin embargo, presentan algunas limitaciones. La primera es que los niños pequeños son muy sensibles a la fatiga, cansancio y vínculo con el evaluador, en tanto es una persona desconocida. Es muy común enfrentarse a situaciones en donde la evaluación no puede desarrollarse porque el niño no dirige la palabra o responde evidentemente sin ganas o al azar. Revertir este tipo de situaciones puede llevar varias instancias de trabajo en la generación de vínculo que permita el trabajo de evaluación (lo cual es costoso y demanda perfiles profesionales). Esto introduce un sesgo muy importante en los resultados: ¿qué desempeño tiene este perfil de niños? Por otro lado, tiene el problema de los costos: existen licencias para la administración de este tipo de instrumentos y necesita profesionales calificados para tal fin. Adicionalmente, son evaluaciones que suelen demandar un mayor tiempo de administración. Por todos estos motivos es muy impensado usar evaluaciones directas para evaluaciones masivas.

Los padres son una fuente de información muy importante. El ambiente familiar es donde el niño suele pasar la mayor parte de su tiempo en la primera infancia y por lo tanto, los padres son privilegiados informantes acerca de cómo se comporta el niño en un contexto íntimo y más proximal, difícil de observar tan en detalle de otro modo. Sin embargo, la información provista por los padres a veces presenta menor confiabilidad (el acuerdo inter-jueces entre una madre y un padre suele ser menor que entre dos educadores) debido a sesgos parentales en la interpretación del comportamiento de sus hijos. Esto incluye, por un lado, la incidencia que el lazo afectivo con el niño (desde aspectos como expectativas o deseos parentales) puede tener a la hora de querer brindar medidas "lo más objetivas posibles" y, por otro, a que tienen menores referencias del comportamiento esperado de los niños a ciertas edades. Para un adulto común, los contactos con niños frecuentes suelen limitarse a sus hijos y eventualmente algún otro familiar, por lo que su patrón de comparación para responder a si algo es "esperado", sucede "mucho" o con "frecuencia" puede resultar bastante idiosincrático. Por otro lado, en situaciones de violencia, negligencia 0 abuso es posible que alguno o ambos progenitores tienda a dar respuestas socialmente más deseables para encubrir la situación.

A diferencia de los padres, las maestras están en contacto con gran cantidad de niños de la edad de referencia desde que son estudiantes de magisterio. Esto, junto a su formación, les permite tener una expectativa más precisa sobre los patrones de comportamiento esperados para cierta edad y contexto (Winsler \& Wallace, 2002). Por otro lado, al tener los niños encuadres de trabajo y contextos de interacción más amplios en los centros educativos, la regulación social de la conducta, así como las habilidades interpersonales pueden apreciarse con más claridad en contextos escolares, frente al ambiente más íntimo que es la familia. Por tanto, la información obtenida a través de los docentes es en general valorada como confiable, y que permite acceder a un sistema de 
interacción privilegiado como es el escolar, donde la manifestación del desarrollo cognitivo y socioemocional se da en contextos naturales. Asimismo, las evaluaciones en contextos educativos suelen valorarse como medidas más eficientes en términos de costo público y de tiempo (aunque con fines distintos) que las de tipo exhaustivo y/o de carácter individual. El ámbito escolar es, por tanto, un contexto propicio para la evaluación de áreas del desarrollo que implican aspectos vinculares y relacionales, así como para evaluaciones del primer nivel (o de tamizaje, cribado o screening - ver capítulo 3) ya que la mayoría de sus indicadores pueden evaluarse en pequeños y/o grandes grupos para facilitar la administración. Es claro que esta fuente de información no está exenta de sesgos. Los docentes pueden sobrevalorar el rendimiento de algunos niños por un perfil de funcionamiento determinado (ej. aquellos que cumplen todas las consignas que se les brindan y colaboran con el funcionamiento del aula). Asimismo, los docentes pueden sentir presión por parte de autoridades educativas o superiores en relación a la evaluación misma o sus resultados, o, simplemente, tener un estilo de respuesta particular (p.ej.: condescendiente, sea por empatía, amabilidad, consideración, complacencia, etc.).

Valoradas en su conjunto, podemos afirmar que cada fuente de información aporta elementos valiosos para la evaluación integral del desarrollo y, en condiciones óptimas, sería deseable poder contar con todas ellas. Sin embargo, cada condición debe ser considerada según los objetivos de la evaluación que se está llevando adelante y las decisiones que deban tomarse en función de los resultados de la misma. 


\title{
Capítulo 3.
}

\section{La relación entre la evaluación y la intervención: el modelo de respuesta de intensidad graduada.}

\author{
Maite Liz y Alejandro Vásquez Echeverría
}

\section{Objetivos de aprendizaje}

Al finalizar lectura de este capítulo el lector será capaz de:

1. Comprender qué es y cómo implementar un modelo de respuesta de intensidad graduada.

2. Identificar los desafíos y los desafíos asociados a la implementación de un modelo RIG en la práctica educativa.

3. Comprender al modelo RIG como una forma de articular la evaluación y la intervención, basada en evidencia, en contextos educativos y de salud en primera infancia.

4. Definir los principales componentes del modelo RIG, diferenciando aquello que el modelo propone de algunos "mitos" que se le han asociado históricamente.

\section{Ideas fuerza}

- La evaluación y la intervención son un continuo que se debe retroalimentar constantemente en la práctica educativa. La evaluación en primera infancia constituye el primer paso para promover la estimulación oportuna.

- La intervención profesional especializada e individualizada debería ser la última opción a seleccionar a la hora de pensar las intervenciones en un sistema educativo y/o sanitario.

- El docente es quien conduce y organiza la implementación del modelo RIG en su grupo, ya que su experticia pedagógica y didáctica es el pilar sobre el cual se deben articular las propuestas "a medida de las necesidades" de los niños.

- El modelo RIG privilegia una mirada del funcionamiento contextualizado del niño, por sobre el diagnóstico o el "etiquetado" de las dificultades. Asimismo, brinda elementos para evaluar cómo responden los niños a las distintas intensidades de las intervenciones realizadas (educativas o sanitarias).

- La implementación de un modelo RIG puede variar en escala y alcance, desde un grupo o centro educativo concreto hasta servir a una política pública para toda una población (por ejemplo, la primera infancia).

- Algunos de los desafíos que presenta la implementación sistémica de los modelos RIG son: disponer de instrumentos de tamizaje de calidad, formación docente y técnica y compromiso político de los actores clave. 
En el capítulo anterior vimos que la evaluación tiene por objetivo ayudar a las personas en un momento importante, o de inflexión en sus vidas. Pero ¿cómo lo logra? Existen dos formas de responder esta pregunta. La primera, es la premisa de que la evaluación en sí misma tiene objetivos terapéuticos, en tanto hace visibles aspectos que eran difíciles de visualizar o representar anteriormente y que dicho insight y valoración ayuda a la persona a mejorar (Groth-Marnat, 2003). La segunda, es usando los resultados de la evaluación para una orientación de las personas o grupos hacia las intervenciones o servicios de atención más eficientes, de acuerdo a su coyuntura particular.

En este capítulo presentamos una forma de entender las interrelaciones entre la evaluación y la intervención, que es el modelo de respuesta de intensidad graduada. En resumidas cuentas, se trata de un modelo que afirma que la intervención profesional especializada e individualizada debería ser la última opción a seleccionar en un sistema educativo. Este tipo de intervención intensiva y personalizada debe suceder luego de implementarse (y nutrirse de la información obtenida de) múltiples estrategias de intervención previas, en un contexto que analice sistemáticamente la respuesta a las experiencias de aprendizaje y a las intervenciones específicas.

\section{1. ¿Qué es el modelo de respuesta de intensidad graduada y cómo surge?}

La respuesta de intensidad graduada (RIG) es un modelo que permite concebir de forma integral la evaluación y la intervención en contextos educativos. Valorar el estado de situación en un momento del desarrollo permite establecer nuevos desafíos y objetivos evolutivos sobre los cuales intervenir en caso de ser necesario. Específicamente en relación a la primera infancia, la evaluación configura el primer paso de una estrategia preventiva para la estimulación oportuna. Estas estrategias pueden ir direccionadas a la promoción del desarrollo de funciones que se encuentran en estado incipiente, hasta la intervención sobre rezagos en el desarrollo o dificultades adaptativas o de integración social.

Específicamente en el contexto educativo es relevante intervenir en áreas que son predictoras de mejores trayectorias escolares y logros académicos, entre otras. Las estrategias, sin embargo, deben diversificarse en base a las diferentes necesidades de los niños, para que tengan un sentido y una dirección clara. Detectar estas necesidades en tiempo y forma y atenderlas de manera equitativa favorece la igualdad de condiciones de aprendizaje, partiendo cada uno de las posibilidades que brinda su estado actual del desarrollo. Desde este lugar, se han desarrollado en las últimas décadas los modelos de respuesta de intensidad graduada (del inglés response to intervention o $R T I$ ) que brindan un marco organizativo de las intervenciones en niveles estratificados de intervención dinámica. Presenta grados de intensidad variable según las necesidades que van mostrando los niños en los distintos momentos y áreas en sus trayectorias escolares (Fletcher \& Vaughn, 2009).

Este enfoque surge de considerar los distintos procesos de aprendizaje que hay en el aula, intrínsecamente heterogénea, y que pueden verse interrumpidos por distintas circunstancias, sean transitorias o persistentes. El modelo RIG incorpora, por tanto, una 
fuerte mirada desde la prevención primaria y privilegia el funcionamiento del niño frente a la intervención, por sobre una mirada diagnóstica.

Si bien es una práctica que surge desde el ámbito de las dificultades del aprendizaje escolar (Fuchs \& Fuchs, 2006), hoy forma parte de iniciativas más generales de los sistemas educativos. Esto es debido a que brinda una manera eficiente de atender a las diversas necesidades en el aula, incluyendo pero no exclusivamente, a la detección e intervención temprana frente a indicadores de dificultad, riesgo o rezago escolar. Asimismo, permite optimizar los recursos educativos existentes organizando su distribución en base a una evaluación inicial y a la detección de las necesidades. Por trabajos previos del equipo en esta línea ver Liz \& Vásquez Echeverría (2020).

\section{Algo de historia sobre los modelos de Respuesta de Intensidad Graduada.}

El modelo RIG o más conocido por su sigla en inglés como RTI (response to intervention) fue propuesto en sus orígenes como contrapartida al modelo clásico que utilizaba el cociente intelectual $(\mathrm{Cl})$ como forma de determinar si un niño necesitaba educación de tipo especial. Este enfoque, se basó en los trabajos sobre la medición de la inteligencia de Alfred Binet (1857-1911), pedagogo y psicólogo francés, pero mostró ser inconsistente debido a la frecuente discrepancia entre el cociente intelectual y el rendimiento escolar (Kavale \& Flanagan, 2007). El modelo de discrepancia evalúa si existe una diferencia sustancial (de por lo menos dos desvíos estándar a partir de la referencia a norma) entre el puntaje de un estudiante en una prueba de inteligencia general (es decir, una prueba de $\mathrm{Cl}$ como las escalas Weschler, por ejemplo) y su puntaje en pruebas que evalúan áreas de rendimiento académico, como el PROLEC (Cuetos, Rodríguez \& Ruano, 1996) para lectura. Este modelo de discrepancia Clrendimiento (también llamado de "wait to fail" o "modelo basado en la espera al fracaso") perdura hasta nuestros días como criterio para determinar si existe una dificultad específica de aprendizaje. Sin embargo, el modelo RIG (como "modelo basado en las respuestas a las intervenciones") ha comenzado a representar una propuesta alternativa más consistente, abarcativa e inclusiva para los sistemas educativos en las últimas décadas. Su implementación cobra fuerza desde su inclusión en el "Acta para la educación de individuos con discapacidades" (IDEA, 2004) en Estados Unidos, la cual permite a los estados y distritos escolares elegir y/o complementar las decisiones entre el modelo de discrepancia Cl-rendimiento y el método RTI, para determinar la elegibilidad de los estudiantes con dificultades de aprendizaje para la educación especial. Esto permite dirimir las situaciones que requieren de atención tanto porque haya o no una diferencia significativa de $\mathrm{Cl}$-rendimiento, como porque respondan o no a intervenciones probadas en eficacia en el aula. Asimismo, permite contrastar la mirada del técnico o profesional externo al aula (generalmente encargado de los procesos de evaluación diagnóstica con pruebas estandarizadas de $\mathrm{Cl}$ y rendimiento) con la mirada del maestro de educación general, responsable y evaluador de la respuesta de los estudiantes a las intervenciones en el aula. Esto ha favorecido el debate y la postura de quienes insisten en la idea de una complementariedad entre ambos modelos a la hora de pensar el trabajo educativo (sobre todo en niveles de educación primaria y/o secundaria) con estudiantes con dificultades de aprendizaje. En niveles iniciales del sistema educativo, sin embargo, en donde muchas habilidades se encuentran 
emergiendo, posicionarnos desde el modelo RIG nos permite pensar en las dificultades para aprender, desde una perspectiva de prevención y de atención temprana y oportuna de las diferencias.

\section{2. ¿Cómo se lleva a la práctica un modelo RIG?}

El modelo RIG presenta tres niveles dinámicos de distribución de la población, para su intervención y monitoreo. Estos niveles pueden pensarse para un agrupamiento determinado (ej. la población de un aula, de un centro o de una jurisdicción) o para el sistema educativo global. Las respuestas que los niños presentan ante las intervenciones diseñadas para cada nivel y tipo de necesidad brindan insumos para planificar de forma dinámica las experiencias de aprendizaje (ver Figura 3.1 por sugerencias en la organización de las respuestas, según las necesidades presentes de los niños). De esta manera, se optimizan los recursos existentes para hacer coincidir las intensidades de las propuestas y estrategias de intervención, con la severidad de las necesidades detectadas (Saeki et al., 2011).

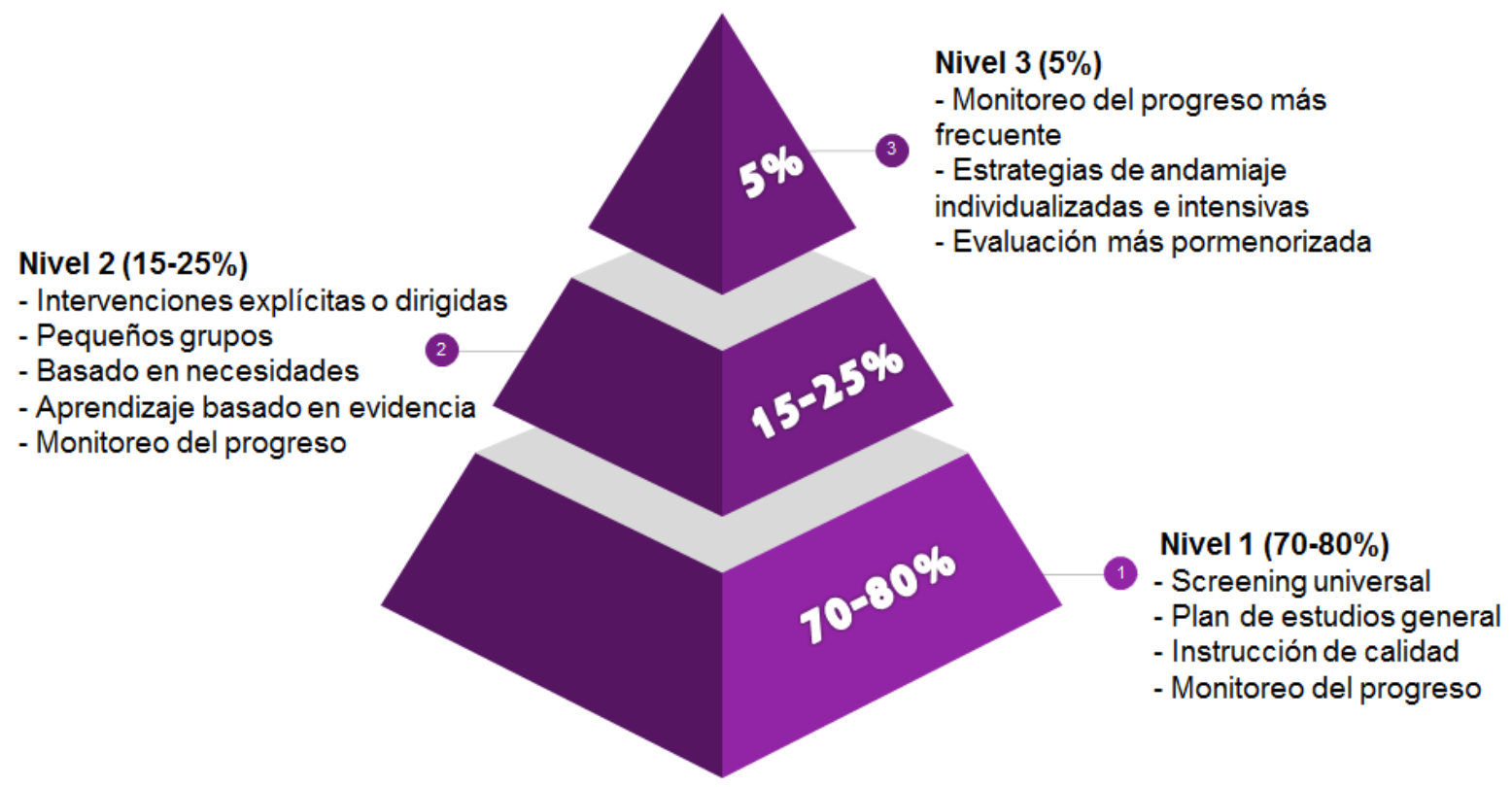

Figura 3.1. Modelo de Respuesta de intensidad graduada (RIG). Adaptada de Buysse \& Peisner-Feinberg (2010). Tomado de Liz \& Vásquez Echeverría (2020).

En el nivel 1 y como punto de partida, se sugiere la realización de evaluaciones estandarizadas de tamizaje (a veces también llamados de cribado o screening) a toda la población. Los instrumentos de tamizaje son aquellos que permiten despistar de forma rápida, a bajo costo, de implementación sencilla a gran escala y con adecuados niveles de sensibilidad y especificidad, el posible riesgo que tiene una persona de estar atravesando una situación considerada negativa. 
Una evaluación de tamizaje le permite al docente conocer más detalladamente las necesidades que presentan todos los niños dentro del aula. Esto implica inicialmente poder monitorear a aquellos que responden sin mayores dificultades al plan de estudios general para el nivel educativo (la llamada "respuesta a la instrucción"). Esto incluye el Es necesario disponer de
instrumentos de tamizaje
estandarizados y calibrados para la
población de referencia para cumplir
con sus fines métricos y ser una
fuente confiable en casos detectados
como de posible riesgo. Una
evaluación de tamizaje
multidimensional, tal como lo es el
INDI, permite una descripción del
estado de desarrollo de las
habilidades de los niños, en las
distintas áreas de incidencia
educativa análisis de la respuesta al programa oficial, a metodologías específicas para los procesos de enseñanza y aprendizaje propuestas por los docentes, a experiencias de aprendizaje generales, entre otros. Pero además y principalmente, las evaluaciones de tamizaje permiten detectar en tiempo y forma a aquellos estudiantes que posiblemente no tengan una buena respuesta natural al proceso educativo.

Dentro de la diversidad de un aula se estima que entre un 20 y un $25 \%$ de los niños podrían requerir de otro tipo de enseñanza en algún área particular. Para estos casos será necesaria la implementación de un segundo nivel de intervención para atender a las necesidades de este grupo de niños. En este nivel 2 se sugiere que el docente evalúe la pertinencia de desarrollar experiencias de aprendizaje en pequeños grupos, tanto dentro como fuera del aula, mediante procesos de enseñanza más explícita y dirigida. La experiencia de los modelos RIG recomienda incluir la implementación de programas específicos de intervención para el desarrollo y aprendizaje, basados en evidencia (ej. Chicago School Readiness Project'). La propuesta de este tipo de experiencias responde a la necesidad de abordar procesos intensos de estimulación específica en un corto período de tiempo para favorecer el fortalecimiento de las áreas detectadas como de mayor debilidad. Se recomiendan procesos de monitoreo continuo e intensivo del progreso según las intervenciones, en base a criterios previamente establecidos por el docente (indicadores de logro, metas de aprendizaje, entre otros). Se estima que la mayoría de los niños de este nivel responderá favorablemente a este tipo de intervenciones diseñadas "a medida de sus necesidades".

Si bien estas propuestas educativas resultan específicas y son orientadas en base a la detección de necesidades, se ha encontrado que un grupo de niños qque se configura en el entorno del $5 \%$ de la población inicial) suele demandar otro tipo de experiencias de aprendizaje para atender adecuadamente a sus necesidades educativas. En este caso, el modelo establece que podrá ser necesario implementar el nivel 3 de intervención educativa frente a situaciones en las cuales, a pesar de las intervenciones del nivel 2, las dificultades persistan y las respuestas no presenten el progreso esperado por los docentes. Para estos niños el modelo RIG propone que se beneficiarán de la implementación de estrategias de andamiaje individualizadas e intensivas, con un monitoreo en alta frecuencia semanal del desempeño y los avances. Las intervenciones se sugieren de mayor intensidad y frecuencia que las del nivel 2, fuera del aula o dentro de ella, según criterio del docente y/o del equipo RIG, con un referente personalizado

${ }^{2}$ https://steinhardt.nyu.edu/ihdsc/projects/csrp 
apoyando la labor docente y según parámetros previamente establecidos con él. En estas situaciones se podrá aconsejar la realización de evaluaciones pormenorizadas de algún área que presente indicadores de un desarrollo con alto nivel de riesgo, de dificultad o rezago, o por su escasa respuesta de progreso a pesar de las intervenciones graduadas, personalizadas y diseñadas a medida por su docente desde un modelo RIG. Para estas situaciones será de relevancia la información que brinda el proceso transitado por estos niños y sus docentes en los tres niveles de implementación del modelo RIG. Estos serán insumos de relevancia para la evaluación pormenorizada y para planificar las propuestas educativas, lo cual puede incluir la sugerencia de diferentes estrategias pedagógicas a ser valoradas por los docentes y el sistema, en el escenario educativo presente o futuro del niño.

\section{Distintas denominaciones, un mismo modelo conceptual.}

En la literatura sobre modelos de respuesta de intensidad graduada se han utilizado diferentes nombres para establecer distinciones en cuanto al foco de las perspectivas conceptuales. Todas refieren, sin embargo, a sistemas de intervención dinámicos y multinivel, con diferencias sutiles según sus orígenes o foco. Las denominaciones más frecuentes son:

- Multi-Tiered Systems of Support (MTSS) o Sistema de Apoyo de Múltiples Niveles para referirse de modo genérico a las estructuras multinivel de intervención y monitoreo educativo (incluye a las siguientes, pero es más abarcativa en cuanto a áreas del desarrollo y métodos que integra). Desde nuestra perspectiva, se trata del enfoque más próximo a cómo concebimos el modelo RIG.

- Response to intervention (RTI) o Respuesta a la Intervención solía utilizarse históricamente y por sus orígenes para denominar modelos multinivel de respuesta, generalmente asociados a áreas académicas y/o cognitivas como lengua o matemática (hoy en desuso con esta connotación específica y suele referirse a modelos más globales también).

- Positive Behavior Interventions and Supports (PBIS) o Intervenciones y apoyos conductuales positivos para designar modelos que ponen el foco en establecer expectativas de conducta y en brindar apoyos graduales para que los estudiantes puedan acercarse al cumplimiento de las mismas.

Se pueden distinguir cinco componentes transversales en el funcionamiento de un modelo RIG (Flanagan, Ortiz, Alfonso \& Dynda, 2006; Saeki et al., 2011), que hacen a procesos de sistematicidad en la evaluación e intervención:

(1) un continuo de intervenciones de calidad o basadas en evidencia empírica. Esto refiere a que en cada nivel los docentes puedan presentar a los niños experiencias de aprendizaje enriquecidas a partir del estado de la información inicial (resultados de la evaluación de tamizaje) de las necesidades individuales y que en la búsqueda de la atención a la diversidad éstos diseñen intervenciones para favorecer el desarrollo de las áreas específicas. 
(2) monitoreo constante del progreso de los niños. Esto incluye (aunque no exclusivamente) el uso de tests con referencia a norma, de forma tal que los parámetros de evolución esperada se puedan establecer según la propia población con la que se implementa. Desde esta perspectiva es necesario que los docentes delineen criterios evaluativos de la forma en la que los niños van respondiendo a las intervenciones que planifican para cada nivel, como monitoreo de los objetivos de aprendizaje que se haya propuesto el docente y como insumo para su planificación, frente a la necesidad de adecuar, de ser necesario, la enseñanza y las experiencias previstas, de manera dinámica.

(3) proceso sistemático de establecimiento de criterios para la toma de decisiones y la determinación del progreso de los niños. En todos los niveles de intervención propuestos será indispensable que los docentes establezcan sistemáticamente los criterios que les permitan la toma de decisiones basada en la evidencia del funcionamiento de los niños. Esto debido al hecho de que deberán decidir desde qué niños pasar al siguiente nivel por su escasa respuesta a las experiencias propuestas (e.g. de nivel 1 a 2 o de nivel 2 a 3), así como valorar la posibilidad de que sea necesario solicitar una evaluación pormenorizada de un área específica, para un niño que no logra progresos en el nivel 3. Asimismo, los criterios le permiten al docente dar cuenta de cuándo un niño ha respondido de manera favorable a las intervenciones por éste propuestas y presenta progresos en el área estimulada. En estos casos, el docente podrá considerar si es pertinente favorecer al niño con otro tipo de experiencias (ej. pasar de nivel 3 a nivel 2, o de nivel 2 a nivel 1) en ese momento y en esa área. Es decir, el proceso sistemático de establecimiento de criterios le permite al docente el establecimiento de un funcionamiento dinámico a la hora de tomar decisiones relativas a las necesidades que los niños de su aula presentan en los distintos momentos del año y en las diferentes áreas del desarrollo. Asimismo, le permite ir ajustando la intensidad de las respuestas dadas en cada momento y para cada niño, optimizando los recursos de los que dispone y enfocándolos hacia las necesidades detectadas.

(4) intervenciones de intensidad creciente cuando no se observan mejoras en respuesta a las experiencias propuestas. La intensidad de las propuestas educativas que el docente va sugiriendo para los niños en los distintos niveles tiene una base recomendada desde un proceso progresivo de aumento en la personalización, en la intensidad de la propuesta de intervención y/o en la frecuencia de las experiencias de aprendizaje hechas "a medida". De esta forma, el docente puede discriminar con mayor certeza si la falta de progreso esperado responde a: (a) que es necesario determinar mejor las áreas a atender, (b) que la intensidad de respuesta resultó insuficiente o (c) que hubo un inadecuado ajuste de las propuestas a las necesidades del niño. La posibilidad de evaluar constantemente las intervenciones que el docente se propone en los distintos niveles del modelo responde a una concepción dinámica del continuo monitoreoevaluación-intervención, base del modelo RIG.

(5) una evaluación más pormenorizada de aquellos niños que no presenten mejoras, a pesar de la implementación de las intervenciones de intensidad creciente. Cuando llegado el momento el docente y/o equipo RIG ha evaluado que el área a atender era la que se consideró necesaria, que la intensidad con la que se propusieron las intervenciones y experiencias de aprendizaje fue la adecuada y que las propuestas respetaron y atendieron a las necesidades detectadas de los niños, pero aún 
así el docente no visualiza el progreso esperado, estaremos frente a una situación en la que es necesario determinar más profundamente a qué se debe la falta de respuesta por parte del niño u obtener mejores insumos sobre cómo es necesario intervenir para promover mayores logros en esa área. La evaluación profunda de un área implicará la necesaria coordinación con agentes externos al aula, que pueden pertenecer o no al sistema educativo. En la mayoría de los sistemas educativos se cuenta con actores formados en áreas específicas del aprendizaje o equipos conformados por profesionales que puedan observar con mayor detenimiento las áreas comprometidas, en un trabajo coordinado con el docente de aula. Asimismo, o de no contar con estos recursos en el sistema, la situación puede requerir la interconsulta con un profesional de la salud o especialista (psicólogo, psicomotricista, fonoaudiólogo) para evaluar más profundamente el estado de las habilidades y/o el compromiso en la evolución de los aprendizajes. Dado el momento evolutivo en el que nos encontramos esta mirada tiene un fuerte sentido de prevención, buscando anticipar la instalación de una dificultad mayor o de una situación de rezago crónico. Los procesos de evaluación en estos niveles están pensados para brindar insumos a los docentes y al sistema educativo para generar la puesta en marcha de intervenciones adicionales intra o extra aula cuando así se requieran.

\section{Modelo RIG en primera infancia.}

Dado que los modelos de respuesta a la intervención surgen básicamente de la atención a las dificultades de aprendizaje, su implementación ha sido frecuente en sistemas de educación primaria y/o secundaria. Sin embargo, atendiendo a su gran capacidad de prevención y a la optimización que conlleva - tanto de los procesos de enseñanza y aprendizaje como de los recursos institucionales-, se ha buscado en los últimos años adaptar su implementación para contextos de primera infancia (Buysse \& Peisner-Feinberg, 2013).

Estas adaptaciones incluyen, principalmente, el foco en aspectos del desarrollo más que de aprendizajes académicos per se. Esto implica considerar dos factores de relevancia para el desarrollo infantil, sobre todo en niños pequeños: la edad en meses y las áreas de fortaleza en cuanto a habilidades y competencias. Desde esta perspectiva entonces, el nivel 2 de implementación del modelo RIG se definirá como apropiado para el nivel de desarrollo del niño, más que en base a sus logros de orden académico. Asimismo, las evaluaciones sugeridas para el nivel 3 y las intervenciones diseñadas para acompañar estas situaciones más complejas, deberán atender a aspectos globales del desarrollo más que a áreas académicas específicas, dada la plasticidad en el desarrollo que encontramos en esta etapa de la vida. El modelo RIG implementado de forma temprana para la primera infancia puede colaborar así en la prevención de rezagos o desvíos en el desarrollo -así como en la detección de áreas de fortaleza-, brindando insumos sólidos desde los inicios de la trayectoria escolar, para el acompañamiento y diseño de propuestas educativas diversificadas. 


\subsection{Desafíos para la implementación de un modelo RIG}

La implementación de modelos RIG puede llevarse a cabo en diferentes niveles. Puede suceder dentro de un aula, un centro educativo, una región o un país, como parte de una política educativa y sociosanitaria bien delimitada. Si bien la puesta en práctica de modelos RIG pone a los países en la avanzada a nivel de políticas públicas, su implementación puede ser difícil ya que demanda altos niveles de coordinación entre los docentes, los prestadores de servicios de atención más específica y los investigadores.

Algunos de los desafíos que pueden presentarse para la implementación de un modelo RIG a mediana o gran escala son los siguientes:

- Disponibilidad de instrumentos de tamizaje y evaluación específica adecuados a la población de referencia. Este es el primer "cuello de botella" que presentan los modelos RIG. El modelo descansa en el supuesto de que los resultados del cribado poblacional funcionan adecuadamente, esto es, que los niños que son identificados con áreas de riesgo, realmente lo sean. La credibilidad de los instrumentos del primer nivel es un paso fundamental para que docentes y actores de los servicios especiales activen los mecanismos necesarios según los perfiles de desarrollo de los niños.

- Formación docente en RIG y prácticas basadas en evidencia. En general, los modelos RIG implican la activación, en los puntos de mayor compromiso, de medidas de respuesta protocolizadas según las dificultades que el niño presenta en su proceso de desarrollo o educativo. Se basa en el principio por el cual las medidas son más eficaces cuando su diseño está más cercano a las necesidades y/o problemas particulares que enfrentan los niños. Adecuar el tipo, nivel e intensidad de respuesta en función de las alertas demanda procesos de investigación y formación sobre los modelos de intervención más eficaces para cada necesidad. Asimismo, la implementación de un modelo RIG demanda que los actores del sistema educativo (y eventualmente del sistema sanitario), estén fuertemente formados en temas de evaluación, modelos RIG e intervenciones basadas en evidencia, para poder activar los protocolos de intercambio y dialogar fluidamente.

- Compromiso político. La administración de toda evaluación requiere de recursos económicos y humanos. La elaboración de protocolos de atención coordinada y comunicación entre unidades o divisiones de un organismo, o intersectorialmente, demanda horas de trabajo, coordinación y búsqueda de consensos. La formación continua de los recursos humanos (en este caso, docentes en sus distintos roles como ser maestro a cargo de grupo, en la dirección o en la inspección) en paradigmas de trabajo que permitan la reflexión colectiva y el intercambio interdisciplinar, es costosa y difícil de concretar. Por lo tanto, la maquinaria de inputs de evaluación y la articulación de actores y prestaciones que recibe el niño depende de un compromiso político sostenido en el tiempo que haga visible la implementación a largo plazo del proceso RIG y permita superar las resistencias iniciales. Un ejemplo de prácticas de articulación a nivel nacional lo constituye la implementación desde 2019 de la Hoja de ruta de coordinación intersectorial entre 
CEIP y el MSP, a partir de los resultados de la evaluación con INDI. Mediante este protocolo se estableció y priorizó la atención en el sector sanitario, de los niños que tienen indicadores de riesgo en más de un área evaluada por el INDI. Se sugiere la lectura del capítulo 5 para un mayor detalle en relación a esta Hoja de ruta.

\section{***PUNTO PARA LA DISCUSIÓN***}

Siguiendo las tres grandes líneas de desafíos propuestos en este capítulo, intenta identificar características nacionales (ej. del funcionamiento del sistema educativo o de alguna política que conozcas dirigida hacia la primera infancia) que puedan funcionar como facilitadores o como obstáculos para implementar el modelo RIG. Intenta, por ejemplo, responder a las siguientes preguntas para pensar opciones:

1. ¿Qué instrumentos de tamizaje y de evaluación específica del desarrollo adecuados a la primera infancia existen o se implementan en Uruguay? ¿Funcionan adecuadamente?, ¿han sido validados para nuestro medio y nuestra población?

2. ¿Qué instancias de formación para docentes conoces, en temas vinculados al modelo RIG? ¿Conoces prácticas o programas de intervención basados en evidencia que se trabajen en Uruguay? ¿Estás en conocimiento de medidas de respuesta protocolizadas para atender a población de riesgo en primera infancia en nuestro país?

3. ¿Qué conocimiento tienes en relación al compromiso político nacional hacia la primera infancia? ¿Qué puntos evalúas como fortalezas y cuáles como debilidades de las políticas dirigidas a la primera infancia que conoces?

\subsection{Algunos mitos asociados a la implementación de los modelos RIG.}

Históricamente se ha asociado a los modelos basados en la respuesta a la intervención, con una serie de premisas o preconceptos, muchos de los cuales persisten hasta hoy (Greenwood et al., 2011). En varias oportunidades esto se ha debido también a ciertas denominaciones que se suelen incluir cuando se abordan estas temáticas. Puntualizamos a continuación las premisas más frecuentes y sus respectivas aclaraciones, en la búsqueda de esclarecer los propósitos, intenciones y fundamentos básicos del modelo RIG, expuestos a lo largo de este capítulo.

- El modelo RIG es un programa específico de intervención o un método de enseñanza: como hemos visto, el modelo RIG ofrece una estructura teórico-práctica desde la cual el docente y los actores educativos pueden pensar, diseñar y evaluar de forma sistemática las prácticas educativas, globalmente entendidas; esto abarca desde prácticas pedagógicas hasta políticas educativas a gran escala

- Existen programas de intervención basados en evidencia (PBE) para dar respuesta a todas las necesidades educativas: si bien existe una amplia variedad de programas 
para muchas áreas académicas, los procesos educativos son un campo en constante desarrollo. Aunque se dispone de un cúmulo importante de investigación que sustenta muchos programas de intervención existentes, aún es necesario continuar indagando áreas menos exploradas, sobre todo en relación a la primera infancia

- Los niños son "etiquetados" según categorías diagnósticas: como hemos presentado en este capítulo la idea de la estructura en niveles que propone el modelo RIG es dinámica, buscando favorecer un tránsito ágil de los niños entre los niveles y valorando primordialmente la forma en que los niños responden a las experiencias de aprendizaje. Las evaluaciones de tamizaje y de monitoreo del progreso que el docente realiza desde el modelo RIG tienen objetivos que distan de los que persiguen las evaluaciones de diagnóstico clínico, de uso frecuente en psicología

- Genera expectativas de desempeño de los niños que no son apropiadas para el momento evolutivo: las proposiciones de este modelo presentan como aspecto relevante el hecho de contemplar el nivel de desarrollo (en educación inicial incluso por sobre las áreas académicas y según la edad en meses del niño) para el diseño docente de las intervenciones "a medida de las necesidades". Como hemos visto en el capítulo 2, además, es importante que las evaluaciones implementadas refieran a normas poblacionales según la edad y el momento evolutivo de los niños, lo que da soporte técnico a las percepciones —rara vez erradas - de los docentes

- Refuerza la idea de agrupar niños por nivel de habilidad la mayor parte de la jornada escolar y en detrimento de la autoestima: lejos de fomentar una exigencia que vaya en detrimento del potencial de desarrollo de los niños, las intervenciones diseñadas a partir de la detección de las necesidades individuales, favorece el bienestar educativo y social de los mismos. El modelo RIG, adecuadamente $n$ implementado, fomenta la sensación de eficacia de los niños y es una alternativa saludable, como vimos, a los modelos basados en la espera al fracaso. Esto es debido a que previene el malestar al proponerle al niño intervenciones dinámicas de manera temprana y "hechas a medida". Como se ha descrito las propuestas educativas no necesariamente se realizan fuera del aula regular y en muchos casos no implican tiempo educativo adicional. Cuando así lo requieren, se respetan de todos modos los tiempos de aula compartidos con pares y se suman intervenciones breves pero intensivas en instancias extracurriculares.

- RIG implica una educación individual e intensiva para todos los niños: como hemos visto sólo aproximadamente un $5 \%$ de los niños requerirán en algún momento, de este tipo de intervenciones durante un período de tiempo acotado. Asimismo, se promueve la idea del trabajo subgrupal y en pequeños grupos como prioritaria previo a un diseño individual, de último orden y para un número muy limitado de niños.

- RIG "desautoriza" al maestro como profesional educativo: lejos de favorecer esta presuposición, el modelo RIG prioriza y pondera la mirada del maestro y su autoridad profesional dentro del aula y como referente del grupo, tanto para el diseño y la implementación de las intervenciones, como para el establecimiento de los criterios de progreso y la evaluación del proceso de los niños. Es el docente de aula quien conduce, dirige y organiza la implementación del modelo RIG referido a su grupo, ya que su experticia pedagógica y didáctica es el pilar sobre el que se deben articular las propuestas "a medida de las necesidades" de los niños. 
Para ilustrar algunas de las características más importantes del modelo trabajadas en este apartado en la Tabla 3.1 ofrecemos una síntesis de las mismas, comparando los mitos con las expectativas teóricamente ajustadas sobre el modelo.

Tabla 3.1

¿Qué no es (mitos) y qué es el modelo RIG?

\begin{tabular}{|c|c|}
\hline $\begin{array}{c}\text { MITOS - Cómo NO debe ser concebido el } \\
\text { modelo RIG }\end{array}$ & Qué SÍ esperar del modelo RIG \\
\hline $\begin{array}{l}\text { Como un programa específico de } \\
\text { intervención o un método de enseñanza }\end{array}$ & $\begin{array}{l}\rightarrow \text { Un marco teórico genérico para pensar y } \\
\text { diseñar las intervenciones }\end{array}$ \\
\hline $\begin{array}{l}\text { Como promotor del etiquetado y el } \\
\text { sobre diagnóstico de los niños }\end{array}$ & $\begin{array}{l}\rightarrow \text { Procura evitar el etiquetado y el } \\
\text { sobrediagnóstico evaluando la } \\
\text { responsividad a las experiencias de } \\
\text { aprendizaje, con foco en el funcionamiento. }\end{array}$ \\
\hline $\begin{array}{l}\text { Para generar expectativas de } \\
\text { desempeño no apropiadas al momento } \\
\text { evolutivo o de aprendizaje }\end{array}$ & $\begin{array}{l}\rightarrow \text { Reconoce que, en niños de edades } \\
\text { similares, existen niveles de desarrollo y } \\
\text { aprendizaje diferentes, y que las } \\
\text { intervenciones deben ser apropiadas a ese } \\
\text { nivel. }\end{array}$ \\
\hline $\begin{array}{l}\text { Como reforzador del modelo de } \\
\text { agrupamiento de niños por nivel de } \\
\text { habilidad en el tiempo escolar }\end{array}$ & $\begin{array}{l}\rightarrow \quad \text { La agrupación de niños con cierta } \\
\text { homogeneidad en su desarrollo puede ser } \\
\text { útil y costo-eficiente como apoyo brindado } \\
\text { de forma extra-curricular. }\end{array}$ \\
\hline $\begin{array}{l}\text { Como un modelo de educación } \\
\text { individual e intensiva para todos los } \\
\text { niños }\end{array}$ & $\begin{array}{l}\rightarrow \text { Los recursos para la educación individual e } \\
\text { intensiva deben ser puestos en juego para } \\
\text { los niños identificados como más } \\
\text { vulnerables, que no respondieron a otras } \\
\text { estrategias menos intensivas e, idealmente, } \\
\text { por periodos cortos de tiempo. }\end{array}$ \\
\hline $\begin{array}{l}\text { Para desautorizar al docente, ya que } \\
\text { impone visiones diseñadas por otros }\end{array}$ & $\begin{array}{l}\rightarrow \text { Ofrece una estructura general que valoriza } \\
\text { y pondera el trabajo docente y le brinda un } \\
\text { marco para el abordaje interdisciplinario. } \\
\text { Asimismo, ofrece garantías para que los } \\
\text { niños y docentes reciban el apoyo } \\
\text { necesario. }\end{array}$ \\
\hline
\end{tabular}

\subsection{Importancia de la atención temprana: aspectos educativos y de salud}

Como hemos visto, la evaluación del desarrollo en esta etapa aporta información sobre la variabilidad entre los niños. Esta información puede ser utilizada para generar 
programas educativos, comunitarios o sanitarios de calidad para atender a la población en los distintos ámbitos (escuelas, hogares, consultas pediátricas) según las necesidades detectadas.

En edades tempranas la evaluación del desarrollo humano persigue varios objetivos. Entre otros, permite desarrollar conciencia a nivel público sobre la importancia de la detección precoz y la actuación oportuna, ante ciertas dificultades de alta prevalencia en la población general. La detección precoz implica la posibilidad de identificar problemas o patologías en una población determinada y aún asintomática. El objetivo de esto es prevenir la posterior emergencia de dificultades, mitigar su aparición, o disminuir su incidencia o posible cronicidad. Estas acciones se sustentan en el entendido de que gran parte de estas dificultades presentarán un mejor desarrollo y menores consecuencias futuras en el mismo, cuanto antes sean detectadas y atendidas.

La evaluación del desarrollo en estas etapas permite además identificar dificultades o necesidades específicas en áreas que conforman los procesos básicos que permiten los aprendizajes. Su integración al ámbito educativo, por tanto, brinda la oportunidad de crear experiencias de aprendizaje acordes a los procesos que se encuentran transitando los niños e identificar a aquellos que necesitan una evaluación adicional. En estos casos, permite diseñar espacios para apoyos adicionales y significativos a los niños en riesgo y que así lo requieran. Esto es relevante ya que se puede intervenir de manera temprana en el desarrollo de las funciones psicológicas, dada la plasticidad cerebral de este período evolutivo.

Contar con información acerca de la diversidad y variabilidad entre los niños que se encuentran realizando el tránsito entre los niveles iniciales del ciclo escolar puede favorecer la labor de los docentes, pues les brinda información que los aproxima más a entender las necesidades y capacidades de su clase actual y de las singularidades heterogéneas que la conforman. Las intervenciones oportunas a partir de la evaluación promueven procesos de inclusión educativa y equidad en el desarrollo. Como consecuencia de una buena atención al desarrollo en la primera infancia colaboran en la prevención del rezago o la repetición escolar, incidiendo así en las trayectorias escolares.

Asimismo, los resultados de la evaluación permiten el diseño de intervenciones coordinadas con otros actores como la familia, la comunidad o el sistema de salud, promoviendo la integralidad de la atención a la primera infancia. Esto tendrá particular importancia para los niños que presenten dificultades en algún área, sea por el incipiente desarrollo de una dificultad propiamente dicha o porque los niños carezcan de experiencias favorecedoras en su entorno familiar o sociocultural. De esta forma, permite coordinar esfuerzos de los actores y aunar criterios de acompañamiento para favorecer mejores experiencias de aprendizaje desde los inicios del ciclo escolar. 


\section{PARTE 2}

\section{El Inventario de Desarrollo Infantil: creación e implementación en Uruguay}


PÁGINA INTENCIONALMENTE EN BLANCO 


\title{
Capítulo 4.
}

\section{El Inventario de Desarrollo Infantil: creación, estructura y administración.}

\author{
Clementina Tomás, Ana Inés Mandl, Maite Liz y Alejandro Vásquez Echeverría
}

\section{Objetivos de aprendizaje}

Al finalizar este capítulo el lector será capaz de:

1. Recuperar los principales hitos en el proceso de creación, validación e implementación nacional del INDI.

2. Describir a nivel teórico la estructura dimensional y componentes del INDI, así como su pertinencia en la evaluación del desarrollo.

3. Conocer los aspectos prácticos para la adecuada administración del INDI en sus versiones para Nivel 3 y Niveles 4-5.

\section{Ideas fuerza}

- Desde su versión inicial en 2015, el INDI ha sido sometido a análisis de confiabilidad y validez para comprobar la pertinencia de sus contenidos y su capacidad de ofrecer información de calidad.

- El INDI es un instrumento de tamizaje y seguimiento del desarrollo (no de diagnóstico clínico), baremado para población infantil uruguaya, que es administrado por el docente en un periodo de tres semanas de observación en el contexto natural del centro educativo.

- Se estructura en cuatro dimensiones: Cognitiva (cuatro componentes), Motora, Socioemocional (tres componentes) y Disposición para el aprendizaje.

- El INDI incluye ítems "fáciles" y "difíciles" con el objetivo de detectar perfiles extremos (muy descendidos o de fortaleza) en las dimensiones y componentes.

- Una misma puntuación directa adjudicada por el docente corresponderá a distintos perfiles de desarrollo según la edad y el nivel educativo del niño evaluado. Esto permite asimismo que existan ítems en común entre las versiones para Nivel 3 y Nivel 4 y 5 .

- Por tanto, alcanzar la puntuación máxima en los indicadores (6) no es necesariamente un objetivo de desarrollo para el nivel educativo que se está evaluando. 
Este capítulo que da comienzo a la Parte II de esta obra, tiene por objetivo introducir el Inventario de Desarrollo Infantil (en adelante INDI), como un instrumento de evaluación de la DPE confiable, válido y diseñado para su administración en contextos educativos. Para ello, haremos un repaso histórico de los primeros cinco años de desarrollo del INDI, desde su creación hasta su implementación nacional en el sistema de educación inicial de CEIP. Luego pasaremos a describir su marco teórico y realizar diversas consideraciones sobre su forma de administración.

\subsection{Aspectos históricos del proceso de creación, validación y universalización del INDI.}

EI INDI surge a partir de la percepción de una demanda: atender de manera temprana y desde una perspectiva de derechos e inclusión educativa a las diferencias en el desarrollo entre los niños que afectan su bienestar actual y se relacionan con su bienestar futuro y las trayectorias educativas posteriores.

En tanto la evaluación de la DPE contribuye a identificar y reducir la brecha de aprendizajes (Unicef, 2012) y debido a la inexistencia en aquel entonces de instrumentos de evaluación confiables y válidos para nuestra región, se presentó en 2013 un proyecto de investigación en inclusión social a la Comisión Sectorial de Investigación Científica de la UdelaR que tenía por objetivo la creación y validación de una escala para evaluar aspectos del desarrollo vinculados a los procesos educativos y que son predictores del desempeño posterior. Este proyecto fue aprobado en 2014 y se comenzó a ejecutar y se conformó el equipo de desarrollo del INDI a comienzos de 2015. En 2019, se cumplieron cinco años de presencia del INDI en las aulas uruguayas (Vásquez Echeverría \& Liz, 2019). Presentamos a continuación un resumen de los puntos destacados de este quinquenio, año a año.

\section{Año 2015}

Como primer paso del proyecto, se realizó una revisión exhaustiva de literatura en torno al concepto de DPE, incluyendo una revisión sistemática de estudios longitudinales (Arrivillaga et al., 2016). Este conjunto de revisiones indicó la conveniencia y necesidad de un abordaje multidimensional del concepto. En paralelo, se comenzó un trabajo de corte cualitativo mediante entrevistas a informantes calificados y expertos en las distintas áreas del desarrollo infantil. Esto permitió determinar cuál era el estado del arte en aspectos teóricos básicos y en temas aplicados para la implementación de políticas en torno a la evaluación de la DPE. En este proceso participaron actores tanto de la academia como del ámbito profesional de las ciencias del desarrollo humano, incluido maestros. Este proceso condujo a la elaboración del marco de referencia de INDI, delimitando su estructura dimensional y principales contenidos a ser evaluados. En el apartado 4.2 detallamos las características de este marco.

Tras ello, se trabajó en desarrollar el primer conjunto de indicadores, que condujo a una versión piloto del INDI, con muchos más ítems de los deseados para una versión final. Esta primera propuesta de ítems fue testeada con expertos en desarrollo y actores de los distintos niveles del sistema educativo (e.g.: cuerpo de Inspección de Educación Inicial, maestras, etc.). A partir de allí, se realizó el primer trabajo de campo (como 
estudio piloto) en colaboración con instituciones y actores de la Educación Inicial pública y privada del país. Este estudio, además de ser crucial para realizar los primeros análisis de confiabilidad y validez del instrumento, permitió analizar la usabilidad del INDI en territorio, específicamente para los contextos educativos uruguayos. Para esto se promovió, bajo metodologías cualitativas, el intercambio y la retroalimentación con las maestras que lo utilizaron. Esto permitió alcanzar, por un lado, la máxima claridad posible en el uso del INDI y, por otro, que los actores de la educación Inicial del Uruguay fueran partícipes de un proceso de co-construcción, en tanto usuarios finales del instrumento en sus prácticas.

Año 2016

Durante 2016 se puso un fuerte énfasis en el perfeccionamiento del inventario y se ampliaron los estudios de confiabilidad y validez (estos conceptos fueron definidos en el capítulo 2). Estos incluyeron análisis de consistencia interna para cada una de las subescalas y dimensiones, así como estudios de confiabilidad de test - retest luego de tres semanas de aplicado inicialmente el INDI, e interjueces con dos informantes calificados dentro del aula (maestra y auxiliar de clase o ATPI). En cuanto a los estudios de validez, se realizaron análisis de validez convergente a nivel ítems, subescalas y/o dimensiones mediante evaluaciones directas con instrumentos estandarizados y de validez predictiva, específicamente de la subescala de Funcionamiento ejecutivo (Liz, Vásquez-Echeverría \& Canet-Juric, enviado). A partir de ello se realizaron procesos de ajuste psicométrico y nuevos análisis de confiabilidad y validez en una muestra mayor. Un mayor detalle técnico en relación a los valores de confiabilidad y validez de las distintas muestras y años se presenta en la Tabla 4.1. Finalmente, se llevaron a cabo nuevos análisis de usabilidad por docentes y se comenzó el diseño de propuestas de intervención (e.g. "Jugate").

Año 2017

Durante 2017 sucedieron algunos hitos muy significativos. Se trabajó en conjunto con el sistema educativo para la construcción de la referencia a la norma nacional con una muestra representativa uruguaya ${ }^{3}$. Para esto, se contó con el apoyo desde las autoridades de ANEP para la implementación del INDI en los centros educativos sorteados aleatoriamente, a partir de los cuales se realizó el sorteo de niños (muestreo por conglomerados en dos pasos). En el mismo año se adaptó y realizó el pilotaje del INDI para Nivel 3 de educación inicial ${ }^{4}$. Asimismo, se realizó la digitalización del INDI en la plataforma GURI (Gestión Unificada de Registros e Información) de CEIP, a través de la articulación entre las distintas disciplinas. Esto permitió diseñar y poner en marcha un sistema automático para la emisión de reportes del INDI (Liz \& Vásquez Echeverría, 2018), inicialmente por niño y por grupo y complementados actualmente con reportes a nivel de Centro educativo y de Jurisdicción (ver recuadro Construcción de los reportes automáticos del INDI). Los mismos brindan una interpretación técnica y ajustada de las puntuaciones que los docentes asignan en la evaluación (por más detalle en relación a los reportes ver capítulo 5), buscando atender a las necesidades de intervención de manera inmediata tras cada evaluación con el INDI.

\footnotetext{
${ }^{3}$ Fondos concursables I+D CSIC (UdelaR) y convenio Fac. de Psicología (UdelaR) - CODICEN

${ }^{4}$ Financiamiento a través del fondo concursable María Viñas de la ANII
} 
Año 2018: Inicio de la evaluación sistemática en Educación Inicial mediante el INDI

En 2018 se produce la universalización de la evaluación con el INDI en los Niveles 4 y 5 de educación inicial pública, pasando a formar parte de la política educativa del CEIP ${ }^{5}$. Esta implementación a nivel país del INDI demandó niveles de respuesta e intercambio fluido con los actores para el monitoreo de la evaluación. La creciente articulación de recursos desde la Universidad y desde ANEP fue imprescindible para la mejor atención de las demandas del sistema educativo (ej. formación de capacitadoras de GURI para replicar a nivel país instancias de capacitación presenciales y diálogo con docentes sobre el uso de la evaluación en la plataforma). Asimismo, se hizo necesaria la sistematicidad de instancias de formación en los días administrativos a comienzos de cada año lectivo y la creación de recursos digitales por parte del equipo de desarrollo del INDI (ej. desarrollo de un sitio web, tutoriales, guías en pdf, publicaciones) que faciliten el acceso a información e insumos, para acompañar la evaluación y el uso de sus resultados. Como parte del monitoreo y tras resolución de CODICEN ${ }^{6}$ comienza a funcionar en 2018 una Comisión de coordinación y articulación interinstitucional e intersectorial de seguimiento a la implementación y los resultados del INDI, bajo la órbita de la Unidad de Análisis e Intervención (UNAI) de CODICEN, para el diseño de modelos de respuesta a partir de los resultados del instrumento. Esta Comisión ha buscado articular los distintos niveles de respuesta que se hacen necesarios brindar a los usuarios del sistema educativo (niños, familias, docentes) en base a las demandas y las necesidades detectadas, tras la evaluación con el INDI. En el capítulo 5 se ofrece más detalle en relación al funcionamiento de este grupo de trabajo.

\section{Año 2019}

El año 2019 fue el segundo de evaluación universal mediante el INDI y presentó niveles de adhesión más elevados por parte de los maestros respecto a 2018. Esto incluyó la evaluación de forma extensiva para Nivel 3, incluso cuando en la primera evaluación del año no había aún disponible una emisión de reporte para este Nivel. En la Tabla 4.1 se presenta la evolución de la cobertura de la evaluación mediante el INDI en Educación Inicial Pública hasta este año.

Tabla 4.1

Cantidad de niños evaluados y grupos que cumplimentaron el INDI por nivel y año.

\begin{tabular}{|c|c|c|c|c|c|c|c|c|}
\hline & \multirow{2}{*}{$\begin{array}{l}2015 \\
\text { N4-N5 }\end{array}$} & \multirow{2}{*}{$\begin{array}{c}2016 \\
\text { N4-N5 }\end{array}$} & \multicolumn{2}{|c|}{2017} & \multicolumn{2}{|c|}{2018} & \multicolumn{2}{|c|}{2019} \\
\hline & & & N3 & N4-N5 & N3 & N4-N5 & N3 & N4-N5 \\
\hline Niños/as & 674 & 2404 & 1031 & 11039 & 2301 & 72924 & 14620 & 74935 \\
\hline Grupos & 24 & 121 & 63 & 364 & 144 & 4142 & 869 & 4252 \\
\hline
\end{tabular}

Nota. No incluye segundas evaluaciones regulares del año ni evaluaciones interjueces o testretest.

\footnotetext{
${ }^{5}$ Resolución №4, Acta № 62, 14/12/2017, CEIP-ANEP

${ }^{6}$ Resolución № 4 , Acta № 3, 7/2/2018, CODICEN-ANEP
} 
El número creciente de evaluaciones realizadas año a año da cuenta de un aumento progresivo en el nivel de adhesión hacia un proceso de evaluación sistemática mediante el INDI. De hecho, en 2019 los docentes a completar las evaluaciones de más del $94 \%$ de la población que asiste a los centros de educación inicial pública. El $6 \%$ restante se divide en aproximadamente un $4 \%$ de las evaluaciones que quedaron en estado "pendiente" (se comenzó a evaluar, pero diversas razones el docente no dió su finalización) y entre un 1,5 y $2 \%$ de la población que no fue evaluada con el INDI.

En cuanto a la evaluación para el Nivel de 3 años, el alto grado de adhesión permitió realizar la norma de referencia nacional en óptimas condiciones, así como comenzar con la emisión de los reportes. Por esto, ya en la segunda evaluación de Nivel 3 en 2019 se emitió por primera vez y de forma piloto el reporte individual. En 2020 quedaron disponibles el reporte de grupo y se incluyeron los datos de Nivel de 3 años al reporte de Centro y de Jurisdicción ya existentes (que hasta entonces sólo recogían la información para Nivel 4 y 5).

En la segunda toma de 2019 quedó disponible también el reporte individual de trayectoria para Nivel 4 y 5 (ver apartado 5.3.2. del capítulo 5 para más conocer más sobre este tipo de reporte) con información de carácter dinámica respecto del proceso del niño entre la primera y la segunda evaluación. Se incluyeron los reportes de INDI en las fichas de información digital de los niños en GURI. Esto permitió que los docentes de Nivel 4 y 5 de Ed. Inicial y de 1er año de Primaria (Educación Común) pudiesen acceder a los resultados de las evaluaciones realizadas con el INDI en años anteriores. Esta mirada diacrónica del niño a lo largo de las evaluaciones brinda información relevante a los docentes para la planificación del trabajo áulico y son insumos importantes para promover el diseño de intervenciones a la medida de las necesidades de cada niño, grupo, centro o región.

Para finalizar este apartado, en la Tabla 4.2 mostramos los principales análisis de confiabilidad y validez convergente del INDI realizados durante este periodo de trabajo. 
Tabla 4.2

Estudios de validez y confiabilidad del INDI

\begin{tabular}{|c|c|c|c|c|c|}
\hline $\begin{array}{l}\text { Dimensión - } \\
\text { Componentes }\end{array}$ & Nivel & Validez convergente & $\begin{array}{r}\text { Test- } \\
\text { Retest }^{\underline{a}}\end{array}$ & $\begin{array}{l}\text { Inter- } \\
\text { jueces }{ }^{\mathrm{a}}\end{array}$ & $\begin{array}{l}\text { Fiabi- } \\
\text { lidad }\end{array}$ \\
\hline & & $r$ & $\mathrm{CCl}$ & $\mathrm{CCl}$ & $\alpha$ \\
\hline \multirow[t]{2}{*}{ Cognitiva } & 3 & $\begin{array}{l}\text { [a] Lenguaje receptivo } .55, .43 \text { [b] Habilidad cognitiva } .55 \text { (Discriminación perceptiva } .32 \text {, } \\
\text { Memoria } .47 \text {, } \\
\text { Razonamiento y habilidades escolares } .49 \text {, Desarrollo conceptual } .50 \text { ) [c] DPE .49 [d] } \\
\text { Razonamiento no verbal } .38\end{array}$ & .95 & .96 & .95 \\
\hline & 4-5 & [a] Lenguaje receptivo .51 [e] Razonamiento no verbal $.51, .31$, Vocabulario expresivo $.52, .52$ & .99 & .85 & .96 \\
\hline \multirow[t]{2}{*}{ Lenguaje } & 3 & [a] Lenguaje receptivo $.51 ; .38$ [c] DPE .41 [d] Razonamiento no verbal .32 & .88 & .96 & .90 \\
\hline & $4-5$ & [a] Lenguaje receptivo $.50, .48$ [e] Vocabulario expresivo .51 & .97 & .95 & .92 \\
\hline \multirow{2}{*}{$\begin{array}{l}\text { Hab. lógico } \\
\text { matemáticas }\end{array}$} & 3 & [f] Aritmética .66 & .90 & .90 & 82 \\
\hline & $4-5$ & $\begin{array}{l}\text { [g] Matemática informal } .64, .67 \text {, Matemática formal } .59, .62[\mathrm{e}] \text { Razonamiento no verbal } .50 \\
\text { [h] Atención sostenida y velocidad de procesamiento } .45 \text {, Flexibilidad cognitiva } .48\end{array}$ & .98 & .87 & .92 \\
\hline \multirow[t]{2}{*}{ Descentramiento } & 3 & $\begin{array}{l}\text { [i] Teoría de la mente .28 [j] Pensamiento futuro } .15 \text { ns. [k] Representación simbólica objetos } \\
.27 \text { ns. }\end{array}$ & .86 & .91 & .86 \\
\hline & $4-5$ & [i] Teoría de la mente $.30, .31$ [j] Pensamiento futuro $.22 \mathrm{~ns}$. & .96 & .80 & .90 \\
\hline \multirow[t]{2}{*}{ Func. ejecutivo } & 3 & [m] Autorregulación cognitiva .29 [l] Flexibilidad cognitiva .18 ns. & .86 & .87 & .89 \\
\hline & $4-5$ & $\begin{array}{l}\text { [h] Razonamiento fluido y flexibilidad cognitiva } .37 \text { [m] Autorregulación cognitiva . } 38-.44 \text {, } \\
\text { Autorregulación emocional .49-.67 [n] Atención y control impulsos .47, .40 } \\
\text { [o] Autorregulación-Z } .19 \mathrm{~ns} \text {. }\end{array}$ & .95 & .71 & .86 \\
\hline Motor & 3 & [b] Habilidad motora .69 (Coordinación .54, Motricidad fina .61, Percepción .63, Locomoción & .90 & .92 & .81 \\
\hline
\end{tabular}


$.35)$

4-5 [b] Coordinación .51, Motricidad fina .36, Percepción .54

Socioemocional

Prosocial

3 [p] Observación prosocialidad .46 $4-5$

Internalizante

Externalizante

[p] Observación comportamiento internalizante .32

3

[p] Observación comportamiento externalizante .49

4-5

Disp. para el aprendizaje
3

4-5 [h] Atención sostenida y velocidad de procesamiento .39, Razonamiento fluido y flexibilidad cognitiva .40, Información general .28 [m] Autorregulación cognitiva .37 - .44, Autorregulación emocional .45 - .47 (con ítem D2) [n] Atención y control inhibitorio .49

cognitiva .40, Información general .28 [m] Autorregulación cognitiva .37 - .44, Autorregulación
emocional $.45-.47$ (con ítem D2) [n] Atención y control inhibitorio .49

Nota. ns. = no significativo. $\mathrm{m}=$ meses. $\mathrm{CCl}=$ coeficiente de correlación intraclase. Confiabilidad test-retest (año 2016 n=123, 2018 n aprox.=128). Confiabilidad Inter jueces (año $2016 n=111,2018 n=24-55$ ). a Concordancia a nivel ítem cercana o superior a k=.50. Estudios validez concurrente INDI Nivel 3: años 2017 y 2018, estudios INDI Niveles 4-5: años 2015, 2016 y 2017. Fiabilidad INDI: 2019 (Nivel 3 n aprox.=14000, Niveles 4-5 n aprox. $=75400$ ). [a-p] Detalle de instrumentos y muestras empleadas para estudios de validez concurrente disponibles en Anexo 1 al final del libro. 


\section{Construcción de los reportes automáticos del INDI}

El proceso de construcción de los reportes automáticos del INDI se inició en 2017, mediante un trabajo de articulación entre profesionales de distintas disciplinas (e.g.: psicología, magisterio, informática), posibilitado por su digitalización en GURI y la existencia de una referencia a la norma uruguaya. A través de este sistema de reportes automáticos se buscó informar sobre los perfiles de fortalezas y debilidades en el nivel de la DPE de los niños, grupos, centros y jurisdicciones (ver capítulo 5 para mayor detalle sobre los reportes).

Para su construcción y diseño, se efectuó una revisión de literatura específica en torno a la producción de reportes automáticos de instrumentos de evaluación del desarrollo. Las experiencias y recomendaciones de la literatura fueron articuladas con las necesidades y demandas del sistema educativo nacional y del posicionamiento científico-técnico del equipo de desarrollo del INDI sobre cómo transmitir información de un test y los usos posibles del instrumento en función de su diseño técnico y las evidencias de validez.

Seguidamente se implementaron dispositivos cuanti-cualitativos de intercambio con docentes para entender las experiencias de usabilidad de la versión digital del INDI. Asimismo, se realizaron entrevistas semiestructuradas con docentes y directores, para comprender su perspectiva en cuanto a la información de interés sobre los resultados de la evaluación. Se indagaron sus apreciaciones sobre los contenidos que consideraban necesarios a incluir en un reporte (individual, grupal y de centro), que fuera de utilidad para su labor. Finalmente, se realizó un grupo focal con el objetivo analizar la comprensibilidad y recibir retroalimentación en relación a la estructura y el contenido específico de cada nivel de reporte. Se realizaron procesos de testeo de los reportes individuales y grupales. Una vez validados, se procedió al testeo y emisión de los reportes de centro dentro del contexto de la plataforma.

Para el diseño e implementación del reporte de Jurisdicción se mantuvieron intercambios con la Inspección Nacional de Inicial y con las autoridades del sistema educativo uruguayo. Se estableció un diseño por región, intentando ayudar visualmente en su interpretación con algunos recursos básicos de geolocalización. Del mismo modo, se mantuvieron intercambios con los actores de GURI, para articular las mejores propuestas de diseño y de contenido de los reportes, en base a las posibilidades del sistema informático.

Finalmente, en 2019 se diseñaron y testearon los reportes individuales de trayectoria. Para éstos se realizaron entrevistas individuales, grupos focales y capacitaciones para su interpretación, con maestras y directores en centros piloto. 


\subsection{Marco de referencia del INDI: estructura dimensional y componentes.}

Este apartado tiene por objetivo presentar el marco de referencia del INDI, en base a su estructura dimensional y su operacionalización. El conjunto de dimensiones, constructos e indicadores planteado es fruto de procesos de revisión sistemática de modelos teóricos, juicio de expertos, evidencia empírica y la revisión crítica de diversos instrumentos de evaluación del desarrollo y su funcionamiento en contexto local. En su aspecto teórico, este modelo conceptual está basado fuertemente en la literatura sobre DPE presentada en el capítulo 1. En este apartado pretendemos definir y discutir específicamente sobre los constructos que el INDI pretende medir.

En la Tabla 4.3 se detallan las dimensiones, subdimensiones (o componentes) y contenidos del INDI para cada una de las versiones (Nivel 3 y Nivel 4 y 5 de Educación inicial), así como los contenidos transversales a ambas.

Tabla 4.3

Especificación de contenidos evaluados en Nivel 3 y Niveles 4 y 5, según dimensiones y componentes del INDI.

\section{Contenidos N3}

\section{Desarrollo cognitivo}

Lenguaje

Habilidades
lógico-
matemáticas

Descentramiento

\section{Contenidos N4-5}

Aspectos articulatorios

Aspectos pragmáticos

\author{
Conciencia fonémica \\ Conciencia silábica \\ Conocimiento de las letras - código \\ escrito
}

Contenidos transversales: Lenguaje receptivo, Lenguaje expresivo
Conteo y cardinalización
Comparación de magnitudes
Clasificación

\author{
Comparación de números \\ Operaciones
}

Contenidos transversales: Recitado serie numérica, Notación simbólica del número, Conocimiento geométrico inicial
Uso simbólico de objetos
Teoría de la mente (inferir emociones e intenciones)
Cognición temporal
(autoproyección, anticipación de eventos futuros) Cognición temporal (nociones
temporales, autoproyección,
anticipación de necesidades y
eventos futuros)
Juego sociodramático (roles adultos)

Contenidos transversales: Memoria episódica, Teoría de la Mente, Cognición temporal, Juego sociodramático 
Funcionamiento ejecutivo
Flexibilidad cognitiva

Planificación

Contenidos transversales: Autorregulación, Control atencional, Control inhibitorio,

\section{Desarrollo motor}

Unidimensional Motricidad gruesa

(Proyección e interceptación

de móviles)

Contenidos transversales: Motricidad gruesa (Locomoción), Motricidad fina (Prensión, coordinación óculo-manual)

\section{Desarrollo socioemocional}

Prosocialidad Contenidos transversales: Conductas de cooperación, Gestión asertiva de emociones, Empatía

Comportamiento Contenidos transversales: Conductas evitativas, Ansiedad, internalizante Retiro social

Comportamiento Contenidos transversales: Agresividad física, Agresividad verbal, externalizante Conducta desafiante

Disposición para el aprendizaje

Unidimensional Autonomía
Motivación intrínseca

Creatividad

Contenidos transversales: Adaptación escolar (rutinas, hábitos de higiene), Actitudes hacia el aprendizaje, Persistencia

\subsubsection{Desarrollo cognitivo}

La dimensión Desarrollo cognitivo del INDI, se estructura en función de indicadores que se agrupan en los siguientes cuatro componentes: Lenguaje, Habilidades lógicomatemáticas, Descentramiento y Funcionamiento ejecutivo. A continuación, se describen los contenidos para cada uno de ellos.

\section{Lenguaje}

Las habilidades lingüísticas tempranas han sido identificadas como uno de los principales predictores del desarrollo en los primeros años de vida, incidiendo de modo sustantivo en las habilidades académicas en la educación primaria (Bernier, McMahon, y Perrier, 2016; Dearing, McCartney, y Taylor, 2009; Duncan et al., 2007; Fewell y Deutscher, 2004; Fiorentino y Howe, 2004; Jerrim y Vignoles, 2013; Prior, Bavin, y Ong, 2011). 
De acuerdo a lo reportado en la literatura especializada, en el INDI se incluyen aspectos de desarrollo del lenguaje, con especial énfasis en la función comunicativa. Es por ello que, de modo transversal a las dos versiones, se proponen indicadores que evalúan la capacidad de comprender y expresarse a través de la oralidad (lenguaje receptivo y productivo) como, por ejemplo: Comprende un cuento breve y Cuenta una historia apoyándose en imágenes o dibujos.

Para el caso de nivel 3, se incluyen por una parte aspectos lingüísticos pragmáticos, evaluando el uso del lenguaje y su adecuación a las situaciones comunicativas (BaixauliFortea, Roselló y Miranda-Casas, 2004), así como la observación de los aspectos articulatorios del lenguaje. Algunos ejemplos de indicadores específicos son Se comunica adecuadamente a través del lenguaje y Presenta buena dicción.

Por su parte, en la versión para nivel 4 y 5 se incorporan aspectos analíticos asociados al lenguaje, como por ejemplo las habilidades metafonológicas. Este es el caso de la conciencia fonológica, que consiste en la habilidad de operar de modo intencional y mediante procesos explícitos sobre unidades léxicas - palabras - y subléxicas — sílabas, unidades intrasilábicas y fonemas- (Defior y Serrano, 2011a). Para el caso del castellano, existe sólida evidencia respecto al poder predictivo de las habilidades fonológicas desarrolladas en la etapa prelectora sobre los procesos de lectura y escritura en la etapa de educación primaria, siendo además aspectos entrenables (Andrés, Urquijo, Navarro, y García-Sedeño, 2010; Cuadro y Trías, 2008; Defior y Serrano, 2011a; 2011b; Defior, Serrano, y Marín-Cano, 2008; Prior et al., 2011). Es por ello que a través del INDI se evalúa la capacidad de manipular y segmentar sílabas (conciencia silábica) y fonemas (conciencia fonémica). En este sentido, algunos ejemplos de indicadores incluidos son Identifica la sílaba final de una palabra e Identifica el sonido final de una palabra.

Finalmente, la versión para los niveles 4 y 5 incluye la evaluación del dominio inicial del código escrito a través de la decodificación y la escritura de palabras simples. Se incorpora el reconocimiento de letras, factor también reportado como predictor de los procesos de la adquisición del principio alfabético (Bravo-Valdivieso, Villalón \& Orellana, 2006; Diuk y Ferroni, 2014). Algunos ejemplos son los indicadores Ante una letra escrita es capaz de producir su sonido y Es capaz de escribir palabras simples (ej. pan, mesa).

\section{Habilidades lógico-matemáticas}

Los estudios referidos a la DPE, alguno de ellos ya referidos en el Capítulo 1, identifican al desarrollo de habilidades numéricas tempranas como otro de los predictores destacados, sino el más importante, en relación a las trayectorias académicas (Duncan et al. 2007; Geary, 1994; Ginsburg, Baroody, del Río y Guerra, 2007; Pagani et al., 2010; Romano et al., 2010; Watts et al., 2014). Específicamente, en la etapa de Educación inicial son de particular relevancia las habilidades matemáticas informales como conocimiento fundante para el desarrollo de habilidades matemáticas más avanzadas (Davis y Ginsburg, 1993). El concepto de matemática informal se sustenta en la evidencia de que existe un conocimiento temprano e intuitivo de las matemáticas que está presente en niños de distintas culturas, que se adquiere a través de situaciones de la vida cotidiana y tiene origen incluso previo al ingreso al sistema educativo. Un desarrollo débil de las matemáticas informales aumenta la probabilidad de presentar dificultades en el pensamiento matemático formal que será exigido en etapas posteriores. Este último se caracteriza por el aprendizaje 
de convenciones, el dominio de hechos numéricos y el cálculo formal, entre otros procesos de complejidad y sistematización creciente (Ginsburg et al., 2007; Howell y Kemp, 2005).

Respecto al conocimiento matemático informal, se ha postulado que algunos de los principales dominios que lo componen son la Numeración, las Relaciones y las Operaciones aritméticas (Purpura y Lonigan, 2013). En este sentido las habilidades de Numeración refieren al conocimiento de las reglas de conteo y la cantidad. Algunos ejemplos son el conteo verbal, conteo estructurado - contar elementos de una colección uno a uno-, la cardinalidad, el conteo de subcolecciones, la subitización -identificar rápidamente la cantidad sin contar - y la estimación —aproximación sin conteo-, entre otros. Siguiendo con la clasificación de Purpura y Lonigan (2013), las habilidades de Relación implican conocer la asociación entre elementos (colecciones o números), por ejemplo, a través de la comparación de cantidades y números, la asociación o secuenciación de colecciones, la asociación de cantidades y numerales, el orden, entre otros. Por último, las Operaciones aritméticas refieren a la habilidad de comprender la composición y descomposición de colecciones y subcolecciones, por ejemplo, a través de las acciones de añadir y sustraer empleando material concreto.

En la versión para nivel 3 del INDI se introduce la evaluación de habilidades de conteo y cardinalización, la comparación de magnitudes y la clasificación. Algunos ejemplos de indicadores son: Cuenta objetos de una colección mayor a tres elementos y Compara magnitudes (ej. grande-chico, lleno- vacío). Para el caso de nivel 4 y 5 se introducen otros indicadores referidos a relaciones entre números y a operaciones. Algunos ejemplos son: Identifica cuál de dos números entre el 1 y el 9 tiene mayor valor y Suma números menores a 5. De modo transversal a las dos versiones del INDI encontramos otros indicadores de numeración como por ejemplo Recita la serie numérica hasta 30, Reconoce números entre el 1 y el 10, así como indicadores de conocimiento geométrico inicial: Identifica y señala un cuadrado, un triángulo y un círculo para nivel 3, y Dibuja figuras geométricas básicas frente a la instrucción verbal de hacerlo (no copia) para los niveles 4 y 5.

\section{Descentramiento}

Durante los primeros años de vida se produce un aumento en la capacidad de las personas de distanciarse de sus propias percepciones, cogniciones y emociones, para desplazarse mentalmente hacia otro lugar, tiempo o perspectiva. Esta capacidad se vincula en buena medida al desarrollo de la capacidad representacional, permitiendo el mencionado distanciamiento temporal, espacial y psicológico entre sí mismo (self) y el objeto, a la vez que engloba procesos de diferenciación objeto-símbolo e idea-acción (Sigel, 1968). Se trata de un logro cognitivo crucial que se produce habitualmente entre los 3 y los 6 años y se sofistica en etapas posteriores del desarrollo.

Si bien en general, el descentramiento no es un constructo específicamente incluido en las evaluaciones o estudios de DPE, optamos por su inclusión en el INDI debido a la presencia, más bien reciente, de argumentos teóricos (e.g.: Astington y Pelletier, 2005) y empíricos (e.g.: Cavadel y Frye, 2017) que asocian algunos aspectos del descentramiento (específicamente la teoría de la mente) con la DPE, así como por la importancia dada por maestros del sistema educativo a procesos de desarrollo que pueden englobarse en torno al desarrollo de la noción del yo (self) y la diferenciación yo-otro. Para seleccionar los 
componentes de descentramiento a evaluar, optamos por seguir de forma amplia a Buckner y Carroll (2007), que proponen englobar teoría de la mente, memoria episódica y pensamiento futuro episódico dentro de un mismo constructo de proyección del yo (self) hacia otros lugares o tiempos (también denominado como proceso de auto proyección). Estos procesos demandan además cierto manejo de nociones temporales y capacidad imaginativa para construir mentalmente escenarios de lo que puede estar sintiendo o viendo otra persona, o uno mismo, en otro lugar o tiempo.

Basado en esto, el INDI evalúa la capacidad de descentramiento a través de indicadores que refieren al distanciamiento interpsicológico. Este punto se enmarca en el constructo teoría de la mente (Wellman y Liu, 2004), el cual refiere a la capacidad de atribuir estados mentales (pensamientos, creencias, intenciones, entre otros) a otros agentes, diferenciados de los estados mentales propios. El INDI recupera este aspecto en indicadores tales como Infiere emociones básicas e intenciones de los personajes de historias o cuentos, Comprende intenciones de los demás, y Reconoce ideas, emociones y/o puntos de vista de sus pares.

Adicionalmente, el INDI evalúa la capacidad de distanciamiento temporal, esto es, la capacidad de autoproyectarse y rememorar episodios pasados, así como desplazarse mentalmente hacia episodios y escenarios futuros. En psicología estos procesos se han enmarcados en los constructos memoria episódica (Perner, Kloo y Gornik, 2007; Tulving, 1984) y pensamiento futuro episódico (Atance y O’Neill, 2005; Suddendorf y Corballis, 2007). Algunos ejemplos son los indicadores Comenta con detalles lo que le sucedió en un momento pasado (ej. el fin de semana, el día anterior) y Anticipa lo que necesitará/vivirá en un momento futuro (ej. recreo, excursión).

Por último, el componente Descentramiento del INDI incluye indicadores de observación del juego sociodramático en el contexto educativo, entendiéndolo como actividad rectora en la etapa de educación inicial. En este sentido, a lo largo de esta etapa los niños avanzan hacia formas más complejas de juego, aspecto observable a través del uso simbólico e imaginario de los objetos, adopción de roles adultos bien definidos, variados y coordinados entre participantes (adoptando las acciones, registros de habla y expresión esperable según el personaje), enriquecimiento de los escenarios de juego y presencia de marcos temporales extendidos (persistencia de las historias de juego en el tiempo), entre otros. Por tanto, el desarrollo de formas maduras de juego da cuenta de ganancias a nivel de la capacidad de descentramiento, entre otros logros a nivel lingüístico y de autorregulación (Bodrova, 2008; Leong y Bodrova, 2012). En el INDI el descentramiento es también evaluado a través de la observación de las características del juego, por ejemplo: En el juego utiliza los objetos de manera simbólica y En el juego adopta roles adultos claramente definidos (incluye personajes de series televisivas y deportistas).

\section{Funcionamiento ejecutivo}

Las funciones ejecutivas son un conjunto amplio de procesos que permiten gestionar el pensamiento y la conducta para dirigirlos hacia una meta u objetivo (Diamond, 2013). Entre los distintos modelos que se han ofrecido para su operacionalización, Diamond (2013) identifica tres procesos psicológicos involucrados: el control inhibitorio, la memoria de trabajo y la flexibilidad cognitiva. El control inhibitorio refiere a la posibilidad de inhibir una 
respuesta automática para dar lugar a otra menos impulsiva. Esta capacidad está presente, por ejemplo, en la supresión de pensamientos o respuestas comportamentales que no son apropiados en un determinado entorno o situación. Por su parte, la memoria de trabajo permite mantener operativa la información que se necesita manipular para realizar una tarea o alcanzar un determinado fin (como, por ejemplo, recordar una secuencia de acciones para la consecución global de una tarea). Por último, la flexibilidad cognitiva refiere a la capacidad de alternar entre distintos abordajes, criterios o respuestas, ajustadas a las variaciones en las demandas del entorno (por ejemplo, probar distintas posiciones en las que una pieza de un puzzle puede encajar en el espacio disponible para insertarla). Estos procesos dan lugar al desarrollo de las funciones ejecutivas superiores tales como la planificación, resolución de problemas y la capacidad de adaptarse a situaciones nuevas, habilidades que mantienen vínculo estrecho con las demandas que caracterizan a la actividad escolar (Diamond, 2013).

Como vimos en el capítulo 1, las funciones ejecutivas han sido postuladas por algunos académicos como un elemento central de la DPE (Blair y Diamond, 2008; Blair y Raver, 2015; Shaul y Schwartz, 2014; Ursache, Blair, y Raver, 2012). En el INDI, su operacionalización incluye aspectos básicos del funcionamiento cognitivo tales como el control inhibitorio y la capacidad atencional global y de concentración. Asimismo, el contenido de esta subescala también aborda características autorregulatorias generales asociadas a este constructo - como la capacidad de esperar por algo que se desea- y cualidades que involucran funciones ejecutivas superiores como el despliegue de estrategias para la resolución de conflictos o la planificación.

Algunos ejemplos de indicadores de funcionamiento ejecutivo son Inicia e inhibe movimientos en respuesta a una instrucción (ej. Simon dice, Juego de las estatuas), Es capaz de esperar turnos y Despliega diferentes estrategias de resolución ante desafíos o problemas.

\subsubsection{Desarrollo motor}

El desarrollo motor refiere a la progresiva adquisición de control y coordinación corporal, que van desde movimientos básicos hasta habilidades que implican altos niveles de precisión. En este proceso los sustratos biológicos de maduración neuromuscular y características de crecimiento (tamaño y proporciones corporales) interactúan con las experiencias del ambiente físico, social y cultural (Malina, 2005). A través de esta articulación el niño se vincula con el ambiente, percibe, extrae información y opera sobre él. Esto repercute sobre un incremento en el repertorio conductual y en la adquisición de conocimiento, produciendo efectos de aprendizaje respecto a las características y regularidades del entorno (Vereijken, 2005).

De acuerdo a lo antedicho, el desarrollo motor es un componente clave en el desarrollo infantil y de particular relevancia en el contexto de la educación inicial; esto se explica por su mediación en el desarrollo de los dominios perceptivos, cognitivos y sociales (Vereijken, 2005). En la literatura de DPE, estudios longitudinales dan cuenta de la contribución del desarrollo motor temprano sobre el logro académico posterior (Grissmer et 
al., 2010; Pagani et al., 2010), destacando su rol específico en los procesos de aprendizaje formal.

EI INDI incorpora indicadores para la observación de aspectos de motricidad fina y gruesa en el contexto educativo. La motricidad fina (también llamada selectiva) refiere a la capacidad de realizar movimientos pequeños que requieran precisión y coordinación entre la manipulación manual y la vista (coordinación mano-ojo u óculo-manual). Estas habilidades incluyen el dominio motor gráfico, la destreza manual y el uso de herramientas (Kagan et al., 1995). El rol de la motricidad fina ha sido específicamente abordado en la literatura sobre desarrollo infantil y escolarización debido a su intersección con los procesos de desarrollo de la lectoescritura (Grissmer et al., 2010). En el INDI la observación de estos aspectos se realiza a través de indicadores tales como Toma el lápiz adecuadamente o Rasga y troza papel, entre otros.

Por su parte, la motricidad gruesa (o también llamada global) refiere a la capacidad de realizar movimientos amplios que involucren grandes segmentos del cuerpo, como brazos y piernas. Se incluyen entre estas habilidades las locomotrices como caminar y correr (que requieren coordinación simétrica), habilidades como saltar en un pie (que requiere el balanceo repetido en un apoyo) y habilidades de proyección (lanzar un móvil) e interceptación (recibir un móvil). Esta progresión de habilidades ha sido descrita como hitos del desarrollo motor en la infancia (Clark, 2005; Malina, 2005). En el INDI estos aspectos son evaluados a través de indicadores como, por ejemplo, Camina adecuadamente sobre una línea recta, Se desplaza saltando en un pie, y Lanza y recibe una pelota con sus manos.

\subsubsection{Desarrollo socioemocional}

Desde una perspectiva multidimensional del desarrollo, existe actualmente un fuerte consenso respecto a la incidencia de la competencia socioemocional en el bienestar del niño, en las trayectorias educativas, así como en su articulación con otros dominios del desarrollo. El desarrollo socioemocional comienza a forjarse desde las primeras interacciones del niño con sus adultos significativos y demás vínculos tempranos, y su curso continúa a lo largo del ciclo vital (Housman, Denham y Cabral, 2018). Estas interacciones iniciales sientan las bases para el desarrollo posterior en otros contextos de socialización, entre los que se destaca el centro escolar. En cuanto a la disposición para la escolarización, el desarrollo socioemocional se vincula al relacionamiento positivo con pares y adultos en el contexto educativo, actitudes positivas hacia el aprendizaje escolar, niveles incrementados de participación en la actividad escolar y mejor desempeño académico (Denham, 2006). Algunos de los aspectos que han sido identificados como constitutivos de la competencia socioemocional son: la expresividad emocional, la comprensión de emociones, la regulación emocional y comportamental, y las habilidades de relacionamiento y resolución de problemas a nivel social (Denham, 2006).

Por tanto, concebimos al desarrollo socioemocional desde un enfoque adaptativo, donde la expresión de las emociones primarias y secundarias juegan un rol crucial en la regulación y mediación del intercambio social en tanto señales que se quieren transmitir y funciones (adaptativas) que se quieren alcanzar. Esto es particularmente importante en esta etapa de 3 a 6 donde el intercambio con pares se vuelve paulatinamente cada vez más 
preponderante y necesario para la adaptación y para el fortalecimiento de otras funciones del desarrollo, particularmente, las cognitivas (e.g.: el aprendizaje entre pares).

La dimensión Desarrollo socioemocional en el INDI se operacionaliza de forma tripartita, tratando de identificar los aspectos vinculados a la manifestación de intención de interacción social positiva como la manifestación de emociones negativas. Por un lado, seguimos la caracterización de las conductas prosociales propuesta en Eisenberg y Miller (1987; 1990) y, por otro, una de las clasificaciones más extendidas de los problemas emocionales-comportamentales, que separa problemas internalizados de externalizados (Achenbach, 1966; Achenbach y Rescorla, 2000; Rescorla, 2005). La dimensión socioemocional del INDI se compone, por tanto, de una subescala de prosocialidad, y dos subescalas correspondientes a los perfiles comportamentales externalizante e internalizante. Las mismas se describen a continuación.

\section{Prosocialidad}

La prosocialidad refiere a un conjunto de conductas voluntarias que tienen por intención beneficiar a otro de forma desinteresada. Esto implica cooperar, compartir, ayudar, consolar, demostrar compasión de modo altruista, entre otras manifestaciones posibles. Eisenberg y Miller $(1987 ; 1990)$ han señalado que el desarrollo de la prosocialidad depende en buena medida de la capacidad de empatía, de la capacidad de realizar inferencias sobre los estados emocionales y cognitivos de otros agentes, y del razonamiento moral. Sostienen que el desarrollo de la prosocialidad es asimismo estimulado por la socialización por parte de los adultos de las conductas orientadas hacia otros. Algunos de los mecanismos a través de los cuales lo anterior ocurre son: la exposición a modelos de conducta prosocial, la implementación de claves que evocan respuestas empáticas, las atribuciones prosociales -construir una autoimagen prosocial-, y el señalamiento explícito de las consecuencias de las acciones. Cabe asimismo destacar que bajos niveles de prosocialidad pueden explicarse por factores como la percepción de falta de competencia para asistir al otro o falta de asertividad social, y no necesariamente a intenciones individualistas (Eisenberg, 2015; Eisenberg y Miller, 1987; 1990).

Por tanto, intentamos que el componente de habilidades sociales del INDI recogiera información sobre aspectos básicos cooperación, colaboración y consolación, algunos de ellos con demanda de empatía. Algunos indicadores son, por ejemplo, Ayuda a sus compañeros cuando lo necesitan, Comparte juguetes y materiales y Está atento a los sentimientos de los otros.

\section{Problemas comportamentales de tipo internalizado y externalizado}

Estas denominaciones agrupan una serie de aspectos diversos entre sí que tienen en común la gestión disfuncional del malestar. Por una parte, el perfil internalizante agrupa casos con una o varias de las siguientes manifestaciones: emocionalmente reactivo, ansioso, deprimido, presencia de quejas somáticas y conductas evitativas o de retraimiento (Achenbach y Rescorla, 2000; Rescorla, 2005). Durante la primera infancia esperamos trayectorias estables respecto a este componente, a excepción de las situaciones que presentan niveles clínicamente significativos de estas conductas. 
Por su parte, el perfil comportamental externalizante se caracteriza por manifestaciones agresivas (físicas y/o verbales), actitudes desafiantes y de frustración direccionada hacia otros, conducta destructiva, hiperactividad y problemas atencionales (Achenbach y Rescorla, 2000; Rescorla, 2005). Cabe destacar que algunas de estas conductas son empleadas en etapas tempranas del desarrollo para el afrontamiento de conflictos, siendo que con el desarrollo de recursos para regular la emoción y otras ganancias cognitivas las mismas tienden a disminuir durante la educación inicial y los primeros años de la etapa de educación primaria (Fanti y Henrich, 2010). El desarrollo de los perfiles internalizante y externalizante es sensible, a la vez, a aspectos individuales como el temperamento y características neuropsicológicas- y ambientales del desarrollo del niño (Fanti y Henrich, 2010; Pesenti-Gritti et al., 2008). Cabe observar que es posible que varias de las manifestaciones que caracterizan cada perfil co-existan, en mayor o menor medida. Asimismo, la co-ocurrencia de perfiles internalizantes y externalizantes se encuentra documentada (Caron y Rutter, 1991; Fanti y Henrich, 2010; Pesenti-Gritti et al., 2008) y existe evidencia de que los problemas de tipo externalizante e internalizante pueden influenciarse mutuamente tanto en un momento específico del ciclo vital como también a lo largo del tiempo. Un ejemplo específico de lo anterior es la presencia temprana de problemas de tipo externalizante que conducen a un contexto de relacionamiento social debilitado y se asocian a un riesgo incrementado de desarrollar a futuro problemas de ansiedad y depresión (Van Lier \& Koot, 2010). Esto reafirma la importancia de la detección de perfiles de riesgo en los primeros años de vida con fines preventivos, ya que su persistencia en el tiempo puede asociarse a la aparición de otros aspectos disfuncionales del desarrollo socioemocional y/o cognitivo en el niño.

En el INDI operacionalizamos a los problemas de comportamiento de forma amplia, para poder capturar algunas de las principales manifestaciones de la conducta internalizada y externalizada que con distinta frecuencia pueden observarse en el contexto áulico de nuestro país, según lo reportado por la literatura especializada y la información provista por los informantes calificados. Para el caso del Comportamiento internalizante, procuramos evaluar niveles de ansiedad, inhibición y retiro social (aislamiento). Para el caso del Comportamiento externalizante, intentamos capturar manifestaciones comportamentales de agresividad (tanto física como verbal), rabia y frustración, tanto hacia los pares como hacia el personal docente.

Algunos ejemplos de ítems para la evaluación del componente Comportamiento Internalizante del INDI son: Evita relacionarse con otros, Pasa el tiempo solo, aislado del grupo y Tiene un aspecto triste, cansado y/o preocupado. Para el caso del componente Comportamiento Externalizante se presentan los siguientes indicadores a modo ilustrativo: Agrede verbalmente a sus compañeros (ej. insulta, grita, se burla), Tiene una postura desafiante hacia las maestras y Se frustra y/o enoja con facilidad.

\subsubsection{Disposición para el aprendizaje}

La inclusión de esta dimensión en el INDI se sustenta en la idea de que una buena transición entre la educación inicial y la escuela primaria no depende exclusivamente de la asimilación de conocimientos, sino que es un proceso bidireccional, que se apoya en las distintas actitudes que tiene el niño hacia la escuela y hacia el proceso de enseñanza y 
aprendizaje. Por tanto, la dimensión Disposición para el aprendizaje del INDI nuclea un conjunto amplio de características y rasgos que inciden sobre los modos en que los niños se aproximan cognitiva, afectiva y comportamentalmente a las experiencias de aprendizaje en el contexto escolar. Se ha planteado que la inclusión de este tipo de aspectos es crucial para conocer la predisposición del sujeto para desplegar los conocimientos y capacidades que porta, lo que es sensible a factores como el género, el temperamento y los patrones culturales y expectativas respecto a las dinámicas de enseñanza-aprendizaje (Kagan, Moore y Bredekamp, 1995).

La dimensión Disposición para el aprendizaje del INDI se operacionaliza, por tanto, incluyendo aspectos motivacionales, actitudinales y cognitivos. Por una parte, se incluyen indicadores de adaptación al centro escolar, actitud de apertura a la experiencia educativa y persistencia, de modo transversal a los tres niveles de educación inicial. En este contexto la persistencia refiere a la capacidad de adherir y sostener una tarea o intento, y resulta fundante en el contexto de los aprendizajes académicos en ciclos posteriores (Kagan, Moore y Bredekamp, 1995). Específicamente en lo que respecta al INDI para Nivel 3, se evalúa además la adquisición de autonomía en las situaciones cotidianas de aula. Para el caso de los Niveles 4 y 5 se incorpora la valoración de la motivación intrínseca, lo que refiere al involucramiento en una tarea por el valor que en sí mismo representa el dominio de la misma, por curiosidad o porque representa un desafío (Pintrich, Smith, García, y McKeachie, 1991). Finalmente, se considera el desarrollo del pensamiento creativo, el cual puede ser entendido a través de rasgos cognitivos como la capacidad progresiva de ofrecer respuestas originales y flexibles — pensamiento divergente- (Torrance, 1966), así como rasgos de personalidad como la apertura a experiencias o ideas novedosas (Garaigordobil y Pérez, 2005).

Algunos ejemplos de indicadores de la dimensión Disposición para el aprendizaje son Se adapta a las rutinas de clase, Muestra curiosidad e interés en la clase y Prefiere actividades que le supongan un reto.

\subsection{Conociendo mejor el Inventario de Desarrollo Infantil}

En los apartados anteriores de este capítulo hemos recorrido el proceso histórico de creación y validación del INDI, lo que nos permite contextualizar sus fines y su desarrollo. Seguidamente, hemos profundizado sobre el marco de referencia conceptual del INDI para comprender con mayor detalle que constructos pretenden capturar los distintos indicadores de las subescalas y dimensiones. En este apartado se presentarán los aspectos prácticos para administrar y completar adecuadamente el Inventario de Desarrollo Infantil (INDI), tanto en sus versiones para Nivel 3, como para Nivel 4 y 5 . Ambas versiones comparten la misma estructura dimensional, con sus respectivas subescalas o componentes, existiendo ítems que se conservan e ítems que varían entre ambas versiones. Mantener varios ítems comunes entre versiones permite hacerlas comparables entre sí, permitiendo a futuro el seguimiento longitudinal de las trayectorias a través de los tres niveles educativos del ciclo Inicial. Por otro lado, que existan ítems diferentes permite contemplar las características propias del desarrollo en cada tramo evolutivo, otorgando mayor grado de especificidad para su análisis. 


\subsection{1. ¿Cómo administrar el INDI?}

El INDI, como instrumento de evaluación del desarrollo infantil para el contexto educativo, es aplicado por el docente del grupo, en el aula, así como en otros espacios institucionales (ej. patio, comedor, sala de psicomotricidad, sala de música) donde se desarrollan las distintas experiencias educativas de los niños de Nivel 3, 4 y 5 de Educación Inicial. El docente es el evaluador calificado para este fin ya que, por su idoneidad y cotidianeidad, puede realizar valoraciones de procesos de desarrollo de cada niño en particular y de sus procesos de aprendizaje. El docente puede discriminar avances y retrocesos en ciertas adquisiciones, así como determinar la frecuencia con la que cada niño pone en juego una determinada habilidad o comportamiento. No sería posible que un observador externo realizara esta tarea en un momento específico, pues no es viable evaluar de manera procesual sin tener un vasto conocimiento del niño en situación.

A nivel técnico, se sugiere realizar la primera evaluación al menos un mes luego de comenzado el año lectivo, para poder contar con insumos suficientes de experiencias de aprendizaje de los niños y facilitar su adaptación al grupo. Asimismo, se recomienda la realización de dos evaluaciones anuales (separadas por un período de al menos 6 meses) lo que permite monitorear la trayectoria de desarrollo a lo largo del ciclo lectivo, analizando su nivel de respuesta a las experiencias de aprendizaje (idealmente, adaptadas a los niveles de desarrollo mostrados en la primera evaluación).

¿De qué insumos se vale el docente para evaluar?

Los insumos de evaluación se obtienen a partir de la observación de las actividades cotidianas de los niños en el centro educativo, siendo la mayoría de los ítems sugeridos para ser evaluados en modalidad grupal o subgrupal. Existe, sin embargo, un porcentaje menor de indicadores que se sugieren ser evaluados a nivel individual. Estos requieren de un breve tiempo personal con cada niño y sirven como ítems de anclaje para reducir el sesgo del evaluador. Asimismo, la evaluación de algunos ítems podrá requerir de la observación en actividades particulares, no restringidas exclusivamente al espacio de aula (ej. clase de Educación Física o Taller de Plástica). Para algunos de los ítems podrá también ser necesario el uso de un soporte (cuaderno $u$ hoja), pizarrón u otros recursos didácticos específicos (por ejemplo, en el trabajo con figuras, palabras o números en forma colectiva).

\section{Ética de la evaluación}

"La enseñanza y la evaluación no son tareas neutrales, se trata de procesos que tienen un fuerte componente político-ideológico y ético-moral, que inevitablemente afecta las vidas de las personas implicadas." (Moreno, 2011; p. 131)

La evaluación con el INDI, como práctica de evaluación en contexto educativo, forma parte de las tareas docentes dentro del aula. Para ello, requiere del compromiso de las maestras (y del sistema educativo todo) en diferentes niveles. Por un lado, en la necesidad de 
familiarizarse con el instrumento para que los aspectos técnico-instrumentales no resulten una interferencia al momento de la evaluación, ni afecten sus resultados. En segundo término, demanda progresivos esfuerzos de formación docente respecto a contenidos teóricos y aspecto prácticos que sirven de marco al INDI, posibilitando el uso responsable de los resultados como insumos para la intervención. Asimismo, la evaluación procesual que propone el INDI implica la posibilidad de observar a los niños en su actividad cotidiana en contexto escolar. Estas observaciones requieren de la mayor precisión posible por parte del docente para evitar sesgos, entendiendo que no siempre las condiciones del ambiente serán las más favorables para la evaluación (ej. grupos numerosos). Por último, la ética en la evaluación, como proceso que inevitablemente afecta a quienes están siendo evaluados, nos interpela a permanecer alerta y procurar el mayor logro en cada acción evaluativa para el bienestar de los evaluados. EI INDI, en consonancia con estos principios, surge desde una perspectiva de derechos de la primera infancia y busca mediante la evaluación temprana del desarrollo, favorecer la atención oportuna para el bienestar de cada uno de los niños.

Sugerencias antes de comenzar a evaluar.

Dada la responsabilidad y el compromiso ético que debe asumir el docente al momento de evaluar, resulta menester tener en cuenta algunos aspectos antes de disponerse a la aplicación del INDI: (a) la importancia de conocer a fondo el contenido de cada uno de los ítems, así como los recursos necesarios para su correcta evaluación. Esto refiere, por un lado, a qué debe ser observado para puntuar el ítem y por otro, a cómo hacerlo, utilizando como guía las especificaciones para su evaluación (ver Guía de aplicación de aula, disponible en sitio web aquí); (b) aggiornarse con el instrumento será clave para planificar actividades que permitan observar con acierto y precisión habilidades y/o comportamientos a evaluar y (c) tener presente el carácter económico, a nivel de trabajo y tiempo invertido, de orientar la planificación hacia actividades —grupales y/o sub grupales - que permitan al docente obtener la mayor cantidad de insumos para completar el INDI durante las tres semanas de evaluación previstas.

\section{¿En qué período de tiempo debe realizarse la evaluación?}

El tiempo estipulado para aplicar y sistematizar toda la información se adecuará a las posibilidades de cada docente, teniendo en cuenta las condiciones contextuales de la clase y de la institución. Sin embargo, es conveniente que los datos de un mismo grupo se completen dentro del periodo regular de evaluación de tres semanas, para evitar efectos de la maduración natural que afectarían la puntuación entre dos momentos de observación. El establecimiento de un lapso de tiempo acotado - tres semanas- permite realizar una evaluación de procesos, acordar y mantener el encuadre para todos los niños del país, y controlar el paso del tiempo y la maduración del niño a lo largo de la evaluación, intentando evitar interferencias en los resultados obtenidos. 
Las tres semanas dispuestas para llevar a cabo las actividades de evaluación con el INDI deben ser valoradas como período de oportunidad, como espacio de observación y recolección de evidencia sobre el estado de desarrollo de las habilidades, los comportamientos y las actitudes de los niños, como ambiente de aprendizaje. Este tiempo pedagógico de calidad será base y también motor para planificar intervenciones oportunas, contextualizadas en cada aula particular, respetando la individualidad de cada niño.
¿Dónde se asignan las puntuaciones del INDI?

Los datos de la evaluación se ingresan digitalmente a la plataforma (GURI), estando a disposición para usuarios docentes y equipo de dirección. Además, el INDI también se encuentra a disposición para ser descargado en formato PDF (Figura 4.1) desde el sitio web de este libro, pudiendo imprimirse y utilizarse como apoyo para su administración en el aula, tanto el inventario como la Guía de aplicación de aula (también disponible para descarga).

Desarrollo Cognitivo (Dimensión C)
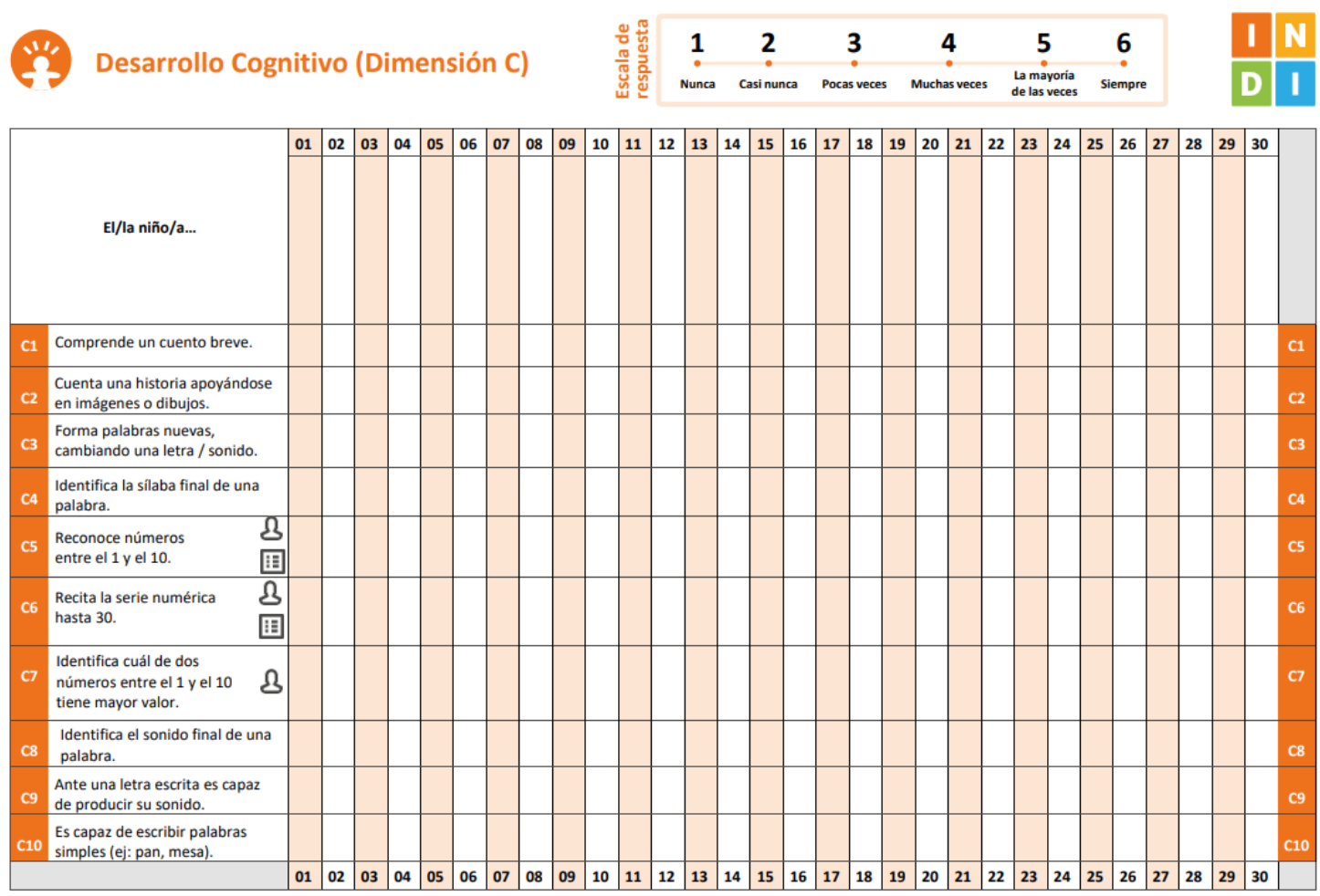

Figura 4.1. Página del INDI imprimible para Nivel 4 y 5

\subsection{2. ¿Cómo se puntúa?}

Las puntuaciones serán asignadas de acuerdo a dos tipos de escalas: de frecuencia y específica. La gran mayoría de los ítems responden a una escala de frecuencia, que se organiza desde el 1: Nunca, hasta el 6: Siempre (ver Fig. 4.2). Cada una de las seis puntuaciones refiere a la frecuencia con la que el niño presenta la habilidad a la que alude el ítem. 


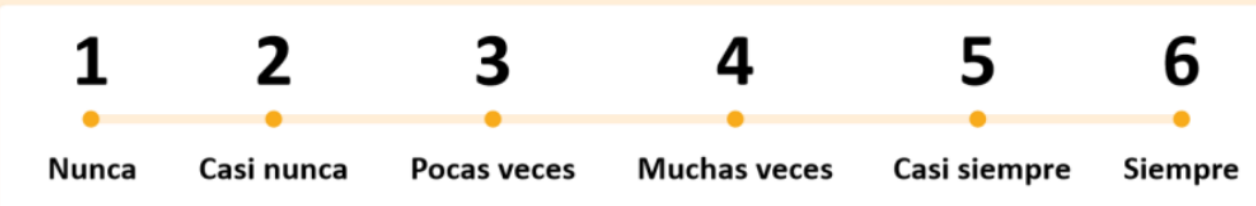

Figura 4.2. Escala de respuesta del INDI en base a frecuencia

Tomando en consideración que la fidelidad de las respuestas es crucial para recabar datos precisos y generar intervenciones oportunas que beneficien a los niños en su desarrollo, resulta imprescindible que el docente escoja para cada ítem, la respuesta que mejor describa el comportamiento del niño. Para esto, es importante considerar las manifestaciones de manera procesual, evaluando las conductas a través del tiempo y no en una única oportunidad. Como criterio general se sugiere que se seleccione:

Nunca (1): si el niño no manifiesta, en ninguna oportunidad, la habilidad, comportamiento o actitud a la que refiere el ítem evaluado.

Casi nunca (2): si el niño excepcionalmente da muestras de cierto grado de adquisición de la habilidad, comportamiento o actitud a la que alude el ítem.

Pocas veces (3): si el niño demuestra en ciertas oportunidades la habilidad, comportamiento o actitud que evalúa el ítem, sin alcanzar una consistencia tal que la represente como adquirida.

Muchas veces (4): si el niño manifiesta en reiteradas oportunidades la habilidad, el comportamiento o la actitud que refiere al ítem, pero ha presentado errores o ciertas imprecisiones, necesitando de apoyo externo.

Casi siempre (5): si el niño presenta la mayoría de las veces la habilidad, comportamiento o actitud mencionada, salvo en ocasiones excepcionales en las que no logra realizarlas o para las cuales requiere de la ayuda de terceros (ej. adulto o un par con mayores niveles de desarrollo).

Siempre (6): Si el niño siempre manifiesta la habilidad, comportamiento o actitud a que hace mención el ítem, sin ayuda de terceros y sin cometer errores.

Así, si existen dudas en los matices de frecuencia se adjudicará el menor valor entre las puntuaciones que se consideren. Por ejemplo: si al evaluar el ítem Es capaz de esperar turnos se duda entre que lo logre muchas veces (4) o que lo logre casi siempre (5), se le asignará en esta evaluación la categoría muchas veces (4) y se valorarán los avances en el próximo período de evaluación.

Para un número menor de ítems que por su naturaleza no son posibles de evaluar con escala de frecuencia se les ha asignado una escala de evaluación específica que varía en función del ítem y del logro esperado. Un ejemplo de esto es el ítem Reconoce números del 1 al 10 para el cual la escala tomará un valor que dependerá de la cantidad de números que el niño logre reconocer. Se le asignará 1 si el niño no logra reconocer números o 
reconoce solamente un número, se le asignará 2 si reconoce entre dos y tres números, y así sucesivamente hasta la puntuación máxima (6) si reconoce todos los números. Por mayor detalle sobre las especificaciones de los ítems del INDI se sugiere consultar las Guías de aplicación de aula para Nivel 3 y para Nivel 4 y 5, disponibles en el sitio web del INDI.

\subsubsection{Algunas precisiones en torno a la puntuación}

Hay distintos tipos de ítems en el INDI, lo que permite determinar distintos perfiles de desarrollo. Es importante aclarar que no se espera que todos los niños alcancen el máximo de puntuación en los ítems, ya que la opción siempre para escala de frecuencia o su equivalente en las escalas específicas, no necesariamente representa un momento esperado en el desarrollo de un niño, ni se trata de un objetivo de salida para el nivel. En este sentido, el INDI tiene ítems que pueden ser considerados sencillos, pero que aún así es necesario que sean evaluados para poder detectar a aquellos niños que poseen perfiles de riesgo en el desarrollo en alguna dimensión o componente. Del mismo modo, contiene otros ítems que pueden parecer difíciles, que existen como forma de discriminar fortalezas en el desarrollo de los niños y/o funcionamiento destacado.

Las puntuaciones otorgadas por los docentes son ponderadas y contrastadas contra un baremo poblacional uruguayo. Dado que los resultados en las puntuaciones de los niños son contrastados contra una referencia a norma (baremo) nacional por edad en meses y nivel educativo, los valores otorgados a los ítems son ponderados en el cálculo de los resultados finales. De esta forma, si un docente puntúa con pocas veces en un ítem determinado, el valor asociado a esa respuesta podrá representar distintos funcionamientos según la edad en meses y el nivel educativo en que se encuentra el niño. Es decir, una misma puntuación en una dimensión o en un componente del niño puede significar distintos niveles de desarrollo en un niño del primer semestre de Nivel 4 que uno del segundo semestre o de Nivel 5.

EI INDI no evalúa la labor docente ni los contenidos curriculares. Es relevante recordar que el INDI evalúa la disposición para la escolarización, a través de indicadores del desarrollo en contexto educativo. Por este motivo y dado que el desarrollo del niño sucede también en ámbitos por fuera de lo escolar puede implicar observar aspectos que no han sido explícitamente trabajados en el contexto escolar, o que no forman parte del programa. Sin embargo, sus manifestaciones resultan de extrema relevancia para el proceso educativo y el logro de los aprendizajes académicos. De esta forma, su observación y evaluación puede igualmente realizarse en este ámbito y su aporte al proceso educativo ser muy relevante. 
Es importante tener en cuenta al momento de completar el INDI:

- La puntuación máxima de un ítem no tiene relación con los objetivos de salida (ni de ingreso) de ningún nivel.

- Las puntuaciones no pueden interpretarse de forma directa (esto es, sumando los puntajes asignados a los indicadores y comparando los totales de las distintas subescalas entre sí) ya que las mismas sufren procesos de conversión antes de ser interpretadas por el sistema.

- Los baremos están ajustados según la edad (en meses) del niño, por lo que, al administrarlo, el docente no debe realizar ninguna calibración en este sentido (ej. compensar la puntuación de algunos niños por ser los de menor edad del grupo).

- No es un uso previsto del INDI, ni una consecuencia deseable, su utilización para evaluar la labor docente.

\subsubsection{2. Íconos de especificación para algunos ítems}

Existen tres íconos de especificación a los que es necesario prestar atención para algunos ítems del INDI (ver Figura 4.3 para detalle de imágenes). El primero refiere a que ese ítem se sugiere sea de observación individual. Es decir, requiere de atención focalizada sobre el desempeño de cada niño, en una observación mediante un breve tiempo personal con cada niño. Por ejemplo, el ítem Identifica cuál de dos números entre el 1 y el 10 tiene mayor valor.

El segundo de estos íconos hace referencia a que es necesario utilizar imágenes adjuntas para evaluar esos ítems. Hay dos ítems con estas características en el INDI:

- El ítem M1 Toma el lápiz adecuadamente presenta una imagen para cada puntuación, correspondiente a posibles formas en las que los niños suelen realizar la prensión de este tipo de utensilio (lápiz, marcador, crayón).

- El ítem M3 Toma la tijera adecuadamente igualmente sugiere una imagen para puntuar según distintos tipos de prensión de la tijera.
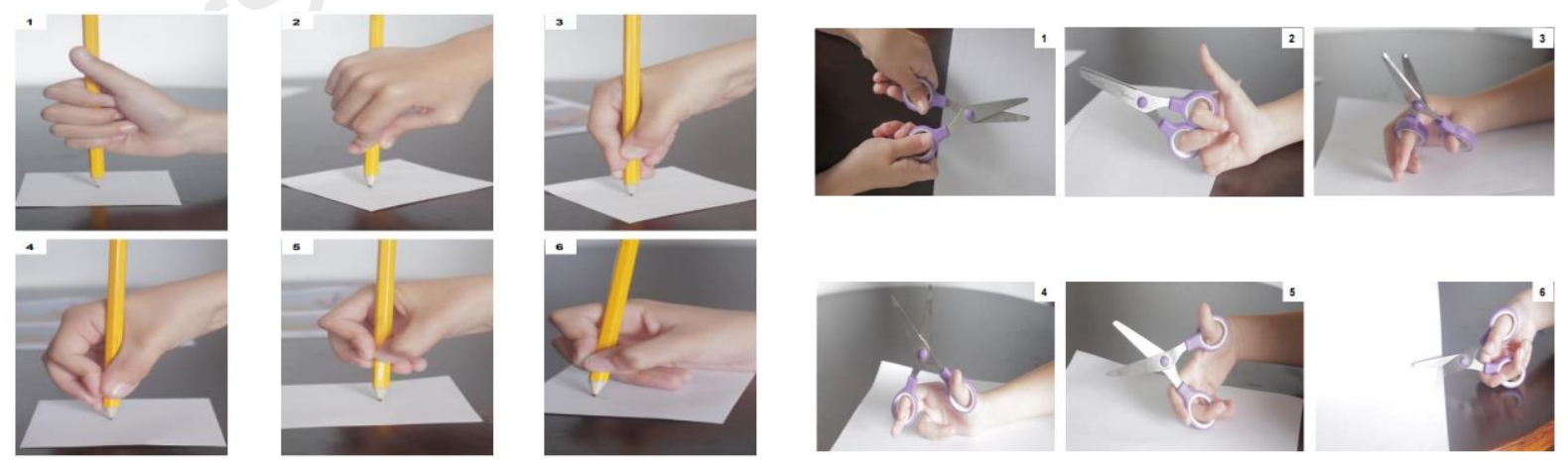

Figura 4.3. Imágenes de referencia para la evaluación de los ítems M1 (izquierda) y M3 (derecha). 
Si bien las imágenes de prensión del lápiz o de la tijera no contemplan la infinidad de posibilidades, son seis puntos de corte entre los cuales el docente se deberá guiar a la hora de puntuar. En ambos casos se buscará puntuar al niño de acuerdo a la forma más cercana dentro de las 6 posibilidad que se brindan. Si se presenta una situación de alternancia entre una forma de prensión y otra, se recomienda seleccionar la de menor valor, entendiendo que aún está en transición a la siguiente, sin lograrlo completamente.

El tercer ícono que puede presentar un ítem es el que refiere a que debe ser puntuado con una escala específica. En estos casos, como se señaló con anterioridad, no aplica la escala de frecuencia (de nunca a siempre), sino que es necesario atender detenidamente a las especificaciones existentes en las Guías o en el desplegable de la plataforma, para asignar cada puntuación.

\begin{tabular}{|c|c|c|c|}
\hline Ícono & Especificidad & Ítems INDI 3 & Ítems INDI 4 y 5 \\
\hline$\Omega$ & Ítem de observación individual & $\begin{array}{c}\text { C11, C12, C13, } \\
\text { C17, C18, M1, M3 }\end{array}$ & $\begin{array}{c}\text { C5, C6, C7, M1 } \\
\text { M4, M5 }\end{array}$ \\
\hline 四 & $\begin{array}{l}\text { Uso de imágenes para evaluar este } \\
\text { ítem }\end{array}$ & M1, M3 & M1, M3 \\
\hline 困 & Escala específica & $\begin{array}{c}\text { C11, C12, C13, } \\
\text { C17, C18, C19, } \\
\text { M1, M3, M4 }\end{array}$ & $\begin{array}{c}\mathrm{C} 5, \mathrm{C} 6, \mathrm{M} 1, \mathrm{M} 5 \\
\mathrm{M} 6\end{array}$ \\
\hline
\end{tabular}

Figura 4.3. Íconos de especificación para algunos ítems del INDI

Criterios para aplicar INDI en caso de niños que presenten discapacidad o que por alguna razón no sea posible evaluar alguna dimensión(es) o ítem(s) particular.

A veces, los docentes se encuentran con obstáculos para evaluar uno o varios ítems del INDI. Esto puede suceder por la diversidad de situaciones que se presentan en las aulas de los jardines o escuelas y/o relacionado a las políticas de educación inclusiva. Por ejemplo, algunos docentes cuentan en sus grupos con niños que presentan alguna discapacidad a nivel del desarrollo global

Sugerimos que se deje de administrar un ítem solo en las situaciones en que no es posible seguir las instrucciones debido a la situación de desarrollo del niño. La falta de un solo ítem provoca que no sea posible ofrecer el resultado para todo el componente y/o dimensión. o en algún área puntual, o que por alguna razón no sea posible observar alguna de las habilidades, comportamientos 0 actitudes $-\mathrm{e}$ incluso dimensiones completas-, aunque no se cuente con un diagnóstico específico realizado por un profesional de la salud. 
En estos casos descritos sugerimos, siempre que sea posible, tender a evaluar la mayor cantidad de ítems que puedan ser observados y permitan ser puntuados, pero, por sobre todo, intentar completar la mayor cantidad de componente y/o dimensiones del INDI. En los casos que presenten esta condición, será fundamental que se le asigne la opción "no se puede evaluar por diagnóstico o dificultad severa" a los ítems que no puedan ser evaluados para permitirle al docente dar por finalizada la evaluación. Si no se le asigna ninguna puntuación u opción, al sistema no le será posible: (a) calcular los perfiles de desarrollo para los demás componentes de la dimensión, (b) calcular los perfiles de desarrollo de las demás dimensiones, (c) emitir los reportes de resultados para ese niño (reporte individual estático, incluir al niño en el reporte de grupo ni emitir el reporte de trayectoria luego de la segunda evaluación anual) y (d) incluir a los niños con estas particularidades en la Hoja de ruta de coordinación interinstitucional entre CEIP y MSP (ver capítulo 5 para profundizar sobre este punto).

\subsubsection{INDI en versión digital}

La evaluación con el INDI, para los centros públicos de Educación Inicial, se realiza a través de la plataforma GURí, en el sitio web guri.ceip.edu.uy. Para ingresar al módulo de evaluación INDI es necesario disponer de un usuario y grupo a cargo. La evaluación digital puede realizarse ingresando de a un niño a la vez (evaluando cada ítem para ese niño), para el grupo entero (evaluando un ítem para todos los niños del grupo) o alternando entre ambas opciones. Esto permite al docente planificar la evaluación según las características del ítem, de un niño y/o del grupo. Para obtener más información acerca del procedimiento para la evaluación digital, puede consultarse la página web de INDI: indi.psico.edu.uy. Allí se encuentran tutoriales que explican el acceso correcto a la plataforma y guían el proceso de evaluación.

La versión digital del INDI permite que, una vez finalizada la evaluación el docente, acceda de manera inmediata a los resultados contextualizados. Esto se realiza mediante la emisión automática de reportes (uno para cada niño y un reporte de grupo), a los que el docente puede acceder a través de la carpeta "reportes" en el sistema. El análisis de los distintos formatos de resultados (reportes) y sus usos se abordará en el capítulo 5 de esta obra. 


\title{
Capítulo 5.
}

\section{Reportes automáticos del Inventario de Desarrollo Infantil y su interpretación}

\author{
Maite Liz, Mónica Pérez, Clementina Tomás, Juan I. Rodríguez, Ana Inés Mandl y \\ Alejandro Vásquez Echeverría
}

\section{Objetivos de aprendizaje}

Al finalizar este capítulo el lector será capaz de:

1. Comprender los perfiles de desarrollo que se emiten como resultado de la evaluación con el INDI.

2. Leer e interpretar adecuadamente los reportes del INDI en sus distintos niveles: individual, de trayectoria, grupal, de centro y de jurisdicción.

3. Conocer la existencia de una política nacional basada en el modelo de respuesta de intensidad graduada (RIG), a partir de los resultados del INDI.

\section{Ideas fuerza}

- La puntuación directa que otorga el docente es interpretada por el sistema de reportes automáticos en función de la edad en meses y nivel educativo de los niños.

- Los reportes del INDI son recursos pedagógicos que fueron creados para uso exclusivo por parte del personal docente. Sin embargo, pueden ser una fuente relevante de información para la comunicación con otros actores (ej. familias, profesionales de la salud).

- El destinatario de los reportes individuales (estáticos y de trayectoria) y grupal es el maestro de aula, el reporte de centro va dirigido al director y el de jurisdicción a la inspección.

- El INDI brinda como resultado un perfil de desarrollo o de DPE para cada dimensión y subescala evaluada. En los reportes, estos perfiles se expresan con 4 categorías de funcionamiento: "muy descendido", "descendido", "esperado" y "destacado".

- Los dos criterios por los que un niño puede integrar los listados de la Hoja de ruta para la coordinación interinstitucional ANEP-MSP son: (a) la preexistencia de un diagnóstico del desarrollo y/o dificultad severa que impidió la evaluación de algún área con el INDI y/o (b) 2 o las 3 dimensiones cognitiva, motora y/o socioemocional con funcionamiento "muy descendido" en la primera evaluación anual. 


\subsection{Características generales de los reportes}

Los reportes de INDI fueron creados con el fin de identificar perfiles de fortaleza y debilidad en las distintas áreas de la DPE de los niños, grupos, centros y jurisdicciones. Por este motivo, brindan información descriptiva del funcionamiento de los niños a partir de la interpretación que se realiza de las puntuaciones que los docentes asignan a los ítems en las distintas áreas evaluadas con el INDI. Los reportes intentan colaborar en la realidad educativa presente de los niños, siendo un insumo relevante a la hora de pensar en la estimulación temprana del desarrollo. Por este motivo, fueron creados para uso exclusivo por parte del personal docente, pero pueden ser una fuente relevante de información para la comunicación con otros actores (ej. familias, profesionales de la salud).

Los reportes del INDI se emiten de manera automática una vez que el docente finaliza la evaluación. Este sistema de emisión automática permite:

- brindar acceso a los docentes, directores e inspectores a la información sobre los resultados de la evaluación de manera inmediata en todo el país.

- garantizar que las puntuaciones que los docentes otorgan a los diferentes ítems del INDI sean interpretadas de manera acertada para brindar información en relación a los niveles de DPE de los niños, grupos, centros y jurisdicciones.

- utilizar los resultados de la evaluación de manera inmediata como orientadores para las prácticas educativas en acciones de tipo preventivas o de atención.

- utilizar los resultados de la evaluación para promover acciones de coordinación intra sistema o intersectorial, de ser necesario.

Luego de cada evaluación finalizada con el INDI se emiten automáticamente distintos formatos de reportes para actores educativos. Estos son: un reporte individual de cada niño y un reporte grupal dirigidos al docente de aula, un reporte de centro dirigido al director del centro escolar y un reporte de jurisdicción dirigido a los inspectores (zonales y departamental). Luego de la segunda evaluación del año se emite también, desde 2019, un reporte individual de trayectoria para cada niño, dirigido al docente de aula actual y, como veremos más adelante en este capítulo, particularmente al docente del año siguiente. El mismo integra información relevante acerca de las dos evaluaciones del año y del perfil de trayectoria que el niño muestra entre ellas. Esto se reporta para cada una de las áreas evaluadas con el INDI.

\section{Destinatarios de los reportes.}

Los reportes de INDI son recursos pedagógicos dirigidos a los actores del sistema educativo. Por tanto, están destinados para uso exclusivo de los docentes, directores e inspectores. Fueron creados y diseñados en conjunto con el magisterio, con el objetivo de apoyar la toma de decisiones respecto a la intervención educativa. Emplea lenguaje técnico dirigido a los profesionales de la educación (quienes además reciben formación específica en el instrumento y en la interpretación de los resultados) y no es adecuado, por tanto, para su entrega directa a otros actores (familias, profesionales de la salud). 
La información contenida en los reportes es un insumo adicional para mejorar las experiencias de aprendizaje y la planificación de la comunicación con las familias y otros actores de referencia para los niños. Su uso implica un compromiso ético por parte de los docentes, para el manejo adecuado de la información y de los resultados de la evaluación.

En la línea de trabajo a futuro con los reportes del INDI no se descarta la posibilidad de generar informes dirigidos a otros destinatarios como la familia y los profesionales de la salud.

\subsection{Perfiles de desarrollo en base a los resultados de la evaluación}

Los resultados de la administración del INDI se presentan en un formato de perfiles, establecidos según el nivel de desarrollo o DPE de los niños. Los criterios para determinar los distintos perfiles de desarrollo o perfiles de DPE fueron establecidos en base a la referencia a norma uruguaya (baremo) realizada en 2017. De esta forma, los resultados del INDI permiten comparar el nivel de desarrollo de un niño con el de los niños uruguayos de su misma edad en meses y nivel educativo. Con base en esta referencia a la norma, se establecieron distintos puntos de corte asociados a percentiles de rendimiento con los que se determinan los niveles de riesgo, funcionamiento esperado y funcionamiento destacado.

Dado que, como hemos visto, el INDI es de carácter multidimensional, cada reporte presenta los distintos perfiles de desarrollo de los niños considerando las múltiples áreas evaluadas. En este sentido, se describen perfiles de riesgo, de funcionamiento esperado o de áreas destacadas para cada una de las dimensiones y para cada uno de los componentes o subescalas del INDI. En la primera infancia se considera relevante poder discriminar el funcionamiento específicamente por área (más que un perfil de desarrollo global) para atender de manera precisa y oportuna las necesidades tanto individuales como grupales en las distintas áreas del desarrollo.

En los reportes de INDI se definen 4 perfiles descriptivos del nivel de DPE de los niños, según los resultados de la evaluación. Se denominan "Zona de riesgo", "Zona de monitoreo", "Perfil esperado y "Perfil destacado" y se calculan en base a las puntuaciones en los ítems del INDI. Dadas algunas

EI INDI brinda como resultado un perfil de
desarrollo o de DPE para cada dimensión
y subescala evaluada. En los reportes,
estos perfiles se expresan con 4
categorías de funcionamiento: "muy
descendido", "descendido", "esperado" y
"destacado".
características evolutivas y contextuales de Nivel 3, como ser el incipiente desarrollo de algunas funciones y la más costosa adaptación al jardín en este nivel, para la primera evaluación del año no se reporta el perfil "Zona de riesgo". En su lugar, se engloba en el perfil "Zona de monitoreo" a ambos perfiles y se discrimina entre un funcionamiento "muy descendido" o "descendido" únicamente para la segunda evaluación anual (Ver Tabla 5.1.). 
Tabla 5.1

Perfiles y categorías descriptivas de INDI para Nivel 3

\begin{tabular}{|c|c|c|c|}
\hline \multicolumn{4}{|c|}{ Perfiles y categorías descriptivas de INDI para Nivel 3} \\
\hline \multicolumn{4}{|c|}{ Primera evaluación } \\
\hline $\begin{array}{r}\text { Zona de } r \\
\text { Funcionamien } \\
y \text { Muy de } \\
\text { Percel }\end{array}$ & $\begin{array}{l}\text { lonitoreo } \\
\text { o Descendido } \\
\text { scendido } \\
\text { til }<21\end{array}$ & $\begin{array}{l}\text { Perfil esperado } \\
\text { Funcionamiento } \\
\text { Esperado } \\
\text { Percentil 21-80 }\end{array}$ & $\begin{array}{c}\text { Perfil destacado } \\
\text { Funcionamiento } \\
\text { Destacado } \\
\text { Percentil }>80\end{array}$ \\
\hline \multicolumn{4}{|c|}{ Segunda evaluación } \\
\hline $\begin{array}{c}\text { Zona de } \\
\text { monitoreo } \\
\text { Funcionamiento } \\
\text { Muy Descendido } \\
\text { Percentil <6 }\end{array}$ & $\begin{array}{c}\text { Zona de } \\
\text { monitoreo } \\
\text { Funcionamiento } \\
\text { Descendido } \\
\text { Percentil 6-20 }\end{array}$ & $\begin{array}{l}\text { Perfil esperado } \\
\text { Funcionamiento } \\
\text { Esperado } \\
\text { Percentil 21-80 }\end{array}$ & $\begin{array}{c}\text { Funcionamiento } \\
\text { Destacado } \\
\text { Percentil >80 }\end{array}$ \\
\hline
\end{tabular}

Por otra parte, para los Niveles 4 y 5 años los perfiles y categorías descriptivas del funcionamiento son las que se presentan en la Tabla 5.2. Recordamos que los resultados del INDI son contrastados contra una norma nacional que permite estimar el percentil de desempeño en comparación con la población uruguaya de los niveles 3, 4 y 5.

Tabla 5.2

Perfiles y categorías descriptivas de INDI para Nivel 4 y 5

Perfiles y categorías descriptivas de INDI para Nivel 4 y Nivel 5 (ambas evaluaciones)

\begin{tabular}{|c|c|c|c|}
\hline $\begin{array}{c}\text { Zona de } \\
\text { monitoreo } \\
\text { (riesgo) }\end{array}$ & $\begin{array}{c}\text { Zona de } \\
\text { monitoreo }\end{array}$ & Perfil esperado & Perfil destacado \\
$\begin{array}{c}\text { Funcionamiento } \\
\text { Muy Descendido }\end{array}$ & $\begin{array}{c}\text { Funcionamiento } \\
\text { Descendido }\end{array}$ & $\begin{array}{c}\text { Funcionamiento } \\
\text { Esperado }\end{array}$ & $\begin{array}{c}\text { Funcionamiento } \\
\text { Destacado }\end{array}$ \\
Percentil $<6$ & Percentil 6-20 & Percentil 21-80 & Percentil >80 \\
\hline
\end{tabular}


El INDI entonces reportará que un niño presenta Riesgo en una dimensión o componente cuando el perfil de sus resultados en esa área de la evaluación se corresponde con un percentil poblacional menor o igual a 5 . Esto quiere decir que su funcionamiento se encuentra dentro del $5 \%$ de la población con nivel más descendido del país o, lo que es lo mismo, que el $95 \%$ de la población uruguaya de su misma edad en meses y nivel educativo tiene un funcionamiento por encima de lo que ese niño presenta en ese

El percentil representa el resultado obtenido en la evaluación en una distribución del 1 al 100, lo que permite atribuir una posición al desempeño según lo que es más o menos típico para la población de referencia., "descendido", "esperado" y "destacado". componente o dimensión del INDI. La categoría descriptiva del nivel de desarrollo de esa área para este perfil se muestra en el reporte bajo la denominación de "muy descendido".

Cuando un área (dimensión o componente del INDI) muestra un perfil que la ubica en Zona de monitoreo se debe a que el funcionamiento del niño en la evaluación lo posiciona entre los percentiles 6 y 20 de la población de referencia ${ }^{7}$. Esto quiere decir que su

\section{EI INDI está baremado para} población uruguaya desde 36 meses de edad (3 años, 0 mes) hasta los 79 meses (6 años y 7 meses) de edad. Distintos baremos se aplican según la edad en meses y nivel educativo. nivel de desarrollo en ese componente 0 dimensión se encuentra por encima de entre 6 hasta el $20 \%$ de la población del Uruguay de su misma edad en meses y nivel educativo. Descriptivamente denominamos que el funcionamiento del niño en esta área presenta un funcionamiento "descendido".

Un perfil de funcionamiento Esperado en una dimensión o componente del INDI se expresa cuando las puntuaciones posicionan el nivel de desarrollo del niño entre los percentiles 21 y 80 de la población uruguaya. En estas situaciones describiremos su funcionamiento como "esperado" para su edad en meses y nivel educativo.

Por último, se reporta que un niño presenta un perfil Destacado en una dimensión o componente del INDI cuando, comparado con la población de referencia, su funcionamiento en esa área se encuentra dentro del $20 \%$ de la población con mayores puntuaciones 0 mejor rendimiento. En estas situaciones su funcionamiento se describe como "destacado".

\footnotetext{
Nota técnica. Como vimos en el Capítulo 4, el INDI presenta una estructura de subescalas para algunas de sus dimensiones, entre ellas la socioemocional, con los componentes Prosocialidad, Comportamiento externalizante y Comportamiento internalizante. Dado que estas dos últimas subescalas refieren a aspectos de conducta problemática (Achenbach, 1966), no es conveniente describir un desempeño como un perfil Destacado. Esto repercute, en consecuencia, en que los perfiles de resultados de la dimensión $S$ globalmente entendida sólo puedan ser "muy descendido", "descendido" o "esperado". Por tanto, sólo para el componente de Prosocialidad se describe el funcionamiento "destacado".
}

\footnotetext{
${ }^{7}$ Como vimos en la Tabla 5.1, esto no se cumple para la primera evaluación anual de Nivel 3, para la cual no se emite el perfil "Zona de riesgo". En cambio, el perfil "Zona de monitoreo" engloba todo el funcionamiento hasta el percentil 20.
} 
Grupo de trabajo intersectorial y Hoja de ruta para la coordinación entre educación y salud.

En el marco de la universalización del INDI se conforma en 2018 un grupo de trabajo intersectorial ${ }^{8}$ denominado Comisión de coordinación y articulación interinstitucional e intersectorial de seguimiento a la implementación y los resultados del INDI. El mismo funcionó inicialmente bajo la órbita de la Unidad de Promoción Intervención y Desarrollo Educativo (UPIDE) del CODICEN, la cual pasa a formar parte de la Dirección de Derechos Humanos (CODICEN) en 2019 y cambia su denominación a Unidad de Análisis e Intervención (UNAI).

Desde sus inicios, este grupo ha estado integrado por referentes de CODICEN, CEIP y del equipo de desarrollo del INDI y se ha abocado al logro de un primer acuerdo entre ANEP y MSP — como organismo rector de los prestadores de salud pública y privada en Uruguay - que asegure el camino más efectivo para la atención prioritaria y oportuna de los niños con riesgo elevado en el desarrollo, de acuerdo a los resultados de la evaluación. Para esta población que presenta compromisos en múltiples áreas del desarrollo, se determinó la atención prioritaria para una evaluación más pormenorizada por parte de profesionales de la salud, mediante consulta inicial con pediatra tratante o médico de familia. Para ello, se ha elaborado una hoja de ruta (ver documento Hoja de ruta para la coordinación interinstitucional ANEP-MSP) que ordena la coordinación entre el sector educativo y sanitario, en función de los resultados que el INDI brinda, complementando lo que el docente observa desde su práctica cotidiana.

El propósito principal de esta Hoja de ruta $(\mathrm{HdR})$ es el de generar un protocolo de actuación que garantice la intervención y seguimiento de la población infantil que asiste a la educación inicial (CEIP-ANEP) y presenta alguno de los dos criterios (no excluyentes) siguientes: (1) la coocurrencia de un perfil "muy descendido" en por lo menos dos de las tres dimensiones C, M y/o S del desarrollo evaluadas por el INDI y/o (2) la preexistencia de un diagnóstico o dificultad severa que impidió realizar la evaluación con el INDI en por lo menos un área específica del desarrollo (componente o dimensión).

En el documento de la HdR se pautan las acciones a implementar para el logro de una coordinación exitosa, desde el sistema educativo y desde el sanitario. Algunas de estas líneas involucran:

1) Un análisis inicial por parte de los docentes, directores e inspectores en relación a la población que requiere de esta atención cumpliendo con los criterios de asignación para ser incluidos en la HdR. Se establece que desde el sector educativo se realicen las acciones necesarias para favorecer la comunicación con las familias acerca de la integración de los listados, de modo tal que todos los actores involucrados en la estimulación y acompañamiento del desarrollo de los niños se encuentren alineados. Los lineamientos generales que se brindan en la $\mathrm{HdR}$ incluyen, además, implementar acciones de orientación hacia la familia y de intervención en el aula, y la elaboración de un informe pedagógico en conocimiento de la familia, que incluya la

\footnotetext{
${ }^{8}$ Resolución № 4, Acta № 3, 7/2/2018, CODICEN-ANEP
} 
información acerca de las áreas muy descendidas en el INDI y pueda acompañar la derivación al sector de la salud.

2) Desde el sector sanitario y mediante referentes designados para la coordinación interinstitucional se deberá corroborar si el niño está siendo asistido de manera regular o no en los centros de salud y realizar acciones en consecuencia. Esto involucra, entre otras: (a) la comunicación por parte de los referentes con el prestador de salud que atiende al niño, a fin de conocer el estado de la misma, (b) si el niño se encuentra en situación de monitoreo (ej. asiste a controles en salud, recibe tratamiento/s, etc.) se indicará el estado actual de la atención del niño y si existe algún diagnóstico del desarrollo que esté siendo atendido y (c) si el niño no se encuentra siendo asistido de manera regular en el prestador de salud se brindará prioridad para una consulta pediátrica en un período comprendido entre 30-45 días a partir de la recepción del listado.

3) Se realizará un intercambio interinstitucional mediante planillas de información actualizada por los referentes de salud y por la UNAI, como organismo encargado de la coordinación entre ambos. Se espera que la articulación sistemática de trabajos en torno al niño colabore en abrir canales de comunicación progresiva entre ambos sectores siendo referentes del desarrollo para las familias tanto los docentes como los profesionales de la salud.

$\mathrm{Si}$ bien consideramos que el logro de esta articulación intersectorial e interinstitucional constituye un gran hito para llegar a modelos de respuesta de intensidad graduada (ver capítulo 3 para mayor detalle) para el logro de una optimización de los recursos y miradas dirigidos al niño, debemos recordar que el INDI no pretende constituirse en un instrumento enfocado en la derivación a otros profesionales. Más allá de que el niño requiera de una atención profesional desde otros ámbitos, la función que desarrolla el docente en el aula a partir de los resultados de la evaluación es clave para el desarrollo de su potencial. Para continuar fortaleciendo este camino es necesario apelar al compromiso del docente como profesional, comprendiendo el valor de la evaluación como herramienta que ordena, otorga parámetros de interpretación de los resultados y optimiza las acciones y los recursos implementados desde el contexto educativo.

\subsection{Tipos de reportes del INDI según sus destinatarios}

En este apartado profundizaremos en los diferentes tipos de reportes del INDI, que actualmente son cinco. Los reportes del INDI fueron pensados para facilitar el uso de los resultados, promoviendo las intervenciones educativas y sanitarias, en varios niveles del sistema educativo. Primero, los reportes individuales y grupales están dirigidos a los docentes para su trabajo a nivel del aula o clase. Existen dos tipos de reportes individuales, los estáticos (presentados en el subapartado 5.3.1) y los de trayectoria (subapartado 5.3.2). El reporte de grupo (subapartado 5.3.3) caracteriza la situación a nivel del aula en base a los datos agregados de los niños.

Los reportes de centro (subapartado 5.3.4) están dirigidos a los directores o equipos de dirección de los centros para pensar acciones de trabajo o políticas a nivel del jardín o escuela. Por su parte, los reportes de jurisdicción (subapartado 5.3.5) están dirigidos al 
cuerpo de inspectores, para colaborar en la toma de decisiones a nivel de la gestión y las políticas a desenvolver en su región. Su emisión de forma automática una vez que el docente finaliza la evaluación en el sistema informático, permite que la información calibrada e interpretada sea recibida en tiempo real.

\subsubsection{Reporte individual estático}

Este reporte se emite automáticamente para todos los niños, luego de cada evaluación realizada con el INDI. Presenta una introducción que contextualiza la evaluación (quién la realiza, en dónde y qué evalúa) describiendo brevemente las dimensiones y componentes incluidos en el INDI. Luego se presentan los datos descriptivos del Centro, de la clase y del niño cuyos resultados se muestran en el reporte. Se incluye además la fecha en que fue realizada la evaluación (inicio y fin), período al que hace referencia la información que se describe. En la Figura 5.1 se puede observar un modelo de este tipo de reporte o se puede visitar el sitio https://indi.psico.edu.uy/librovol1 para acceder a modelos en formato PDF de todos los reportes de INDI.

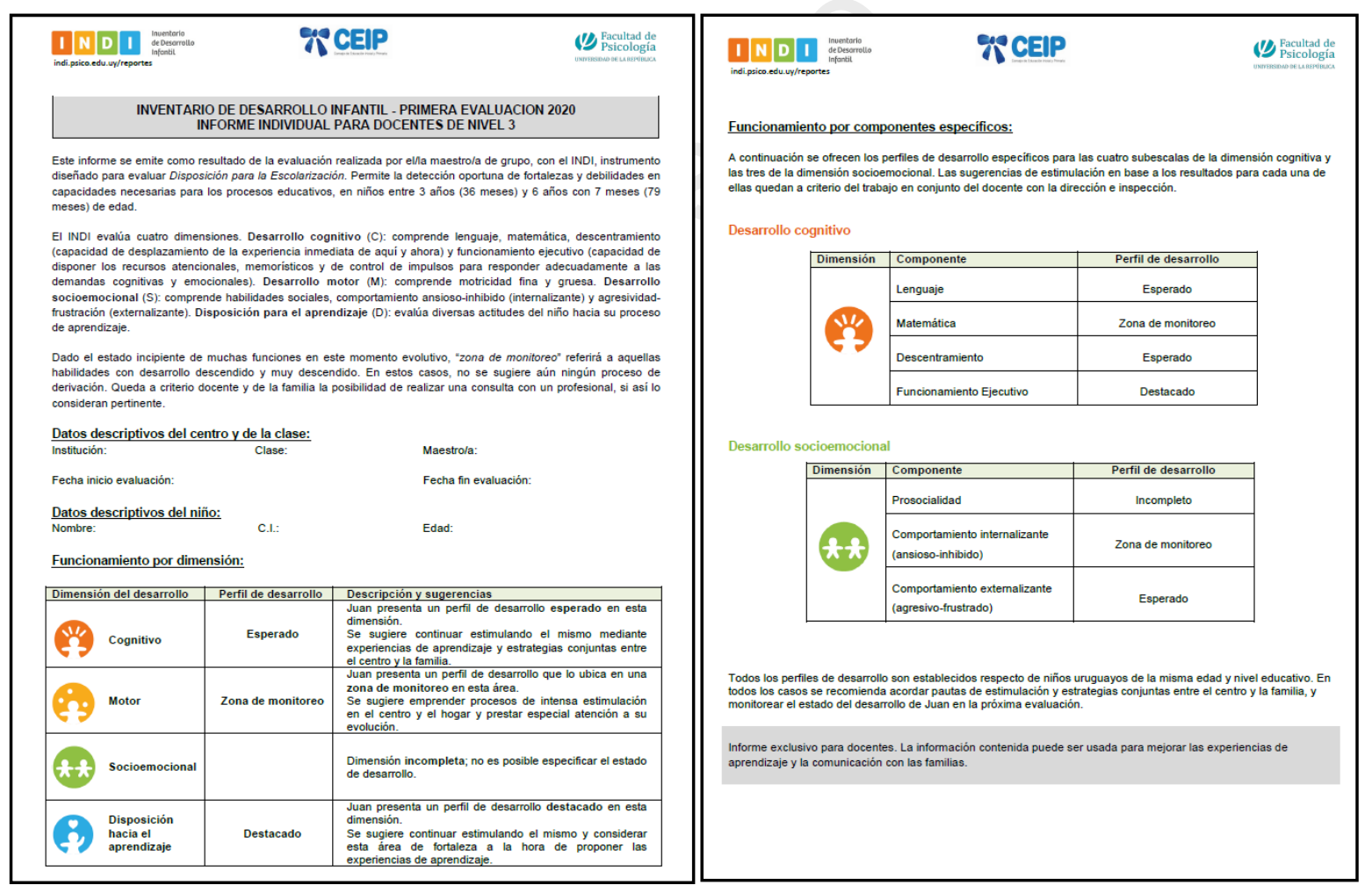

Figura 5.1. Modelo de reporte individual del INDI

Luego de esta parte introductoria, el reporte presenta dos tablas. La primera refiere al funcionamiento por dimensión y describe el perfil de desarrollo del niño para cada una de las dimensiones evaluadas por el INDI: cognitiva, motora, socioemocional y de disposición 
hacia el aprendizaje. La segunda tabla muestra el funcionamiento del niño en los distintos componentes específicos o subescalas: Lenguaje, Matemática, Funcionamiento ejecutivo y Descentramiento para la dimensión cognitiva y Prosocialidad, Comportamiento internalizante (ansioso-inhibido) y Comportamiento externalizante (agresivo-frustrado) para la dimensión socioemocional. Recordamos que, como se puntualizó en el capítulo 4, la dimensión motora y de disposición hacia el aprendizaje no presentan subescalas.

\section{Tabla de funcionamiento por dimensión}

En la tabla de "Funcionamiento por dimensión" (Fig. 5.2) se presentan en la primera columna las 4 dimensiones del desarrollo evaluadas por el INDI (cognitiva, motora, socioemocional y de disposición hacia el aprendizaje). En la columna central se muestra la categoría descriptiva del perfil de desarrollo de cada una de ellas, según los resultados de la evaluación. Finalmente, sobre la derecha, se señala en un breve texto descriptivo el perfil de desarrollo asignado y se indican algunas acciones que se sugieren realizar con el niño en las distintas dimensiones del INDI, según el perfil de resultados de cada una de ellas.

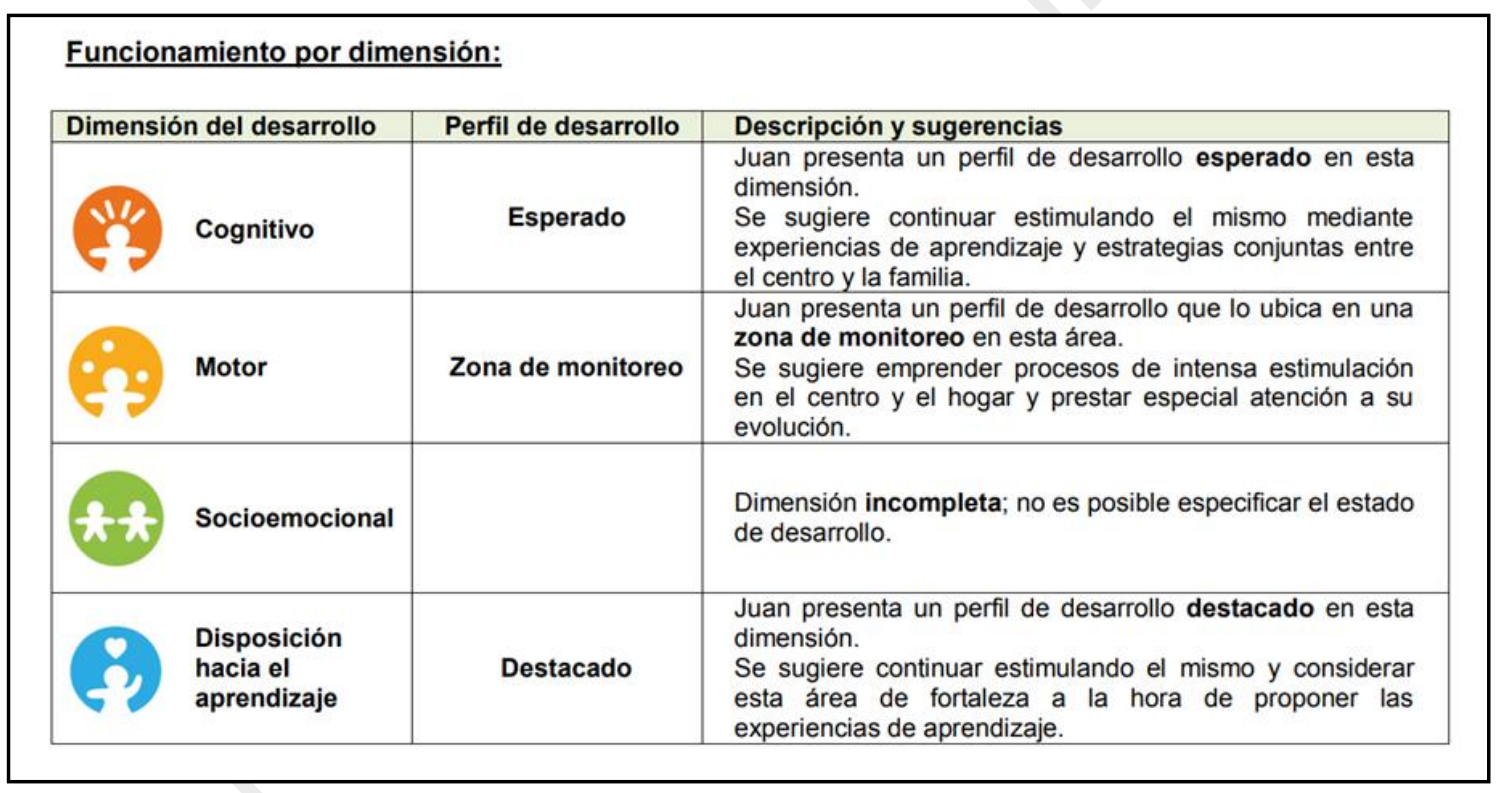

Figura 5.2. Ejemplo de tabla de Funcionamiento por dimensión en el reporte individual.

De modo genérico, para las dimensiones $C, M$ o S que presenten un funcionamiento muy descendido (perfil "Zona de riesgo") se propondrá realizar interconsultas con profesionales para un estudio más pormenorizado de esa área, sobre todo en situaciones en las que no se disponga de información o evaluaciones diagnósticas previas. Para ello, se sugerirá considerar en conjunto con los actores del centro educativo (ej. maestro/a, dirección, inspección, profesionales) y con la familia, la pertinencia de realizar la consulta en ese momento, ya que pueden existir factores contextuales (ej. mudanza, fallecimiento de familiar, ruptura de núcleo familiar, entre otros) incidiendo en el desarrollo actual del niño. De considerarse realizar la interconsulta, se sugiere acompañar la misma con un informe pedagógico que incluya aspectos descriptivos y observacionales del funcionamiento del 
niño en el aula y un detalle específico sobre las áreas que se presentan muy descendidas en la evaluación con el INDI.

En el caso de las dimensiones que presenten un funcionamiento descendido (perfil "Zona de monitoreo") se propondrá emprender procesos conjuntos de intensa estimulación de esa área, en el centro y en el hogar. En estos casos, se insta al docente a prestar especial atención al perfil de desarrollo de esa área en el niño en la siguiente evaluación. Esto se realiza con el fin de que si no se presenta una mejoría en el funcionamiento $-\mathrm{y}$ tras analizar factores contextuales que puedan estar incidiendo de manera temporal- el docente pueda optar por otros recursos (ej. solicitar la realización de una interconsulta para una evaluación más pormenorizada de esa área).

En cuanto a las dimensiones que presenten un funcionamiento esperado o destacado se sugerirá continuar estimulando el desarrollo mediante experiencias de aprendizaje y estrategias conjuntas entre el centro y la familia, así como considerar las áreas de fortaleza en el desarrollo como soporte del potencial del niño, a la hora de diseñar las propuestas áulicas.

\begin{abstract}
Excepciones: No se emite una categoría descriptiva para un área del desarrollo (componente y/o dimensión) únicamente si el docente no ha podido evaluar algún ítem, componente o dimensión. Las causas para esto pueden ser: (a) que el niño presentó una elevada inasistencia durante el período regular de la evaluación (más de dos tercios del período) o (b) porque evidencia una dificultad o diagnóstico clínico que impidió realizar la evaluación de uno o más de los indicadores. Frente a estas situaciones el reporte emitirá un recordatorio de que esa área se encuentra incompleta y que no es posible, por tanto, especificar el estado de desarrollo de la misma. Para aquellas situaciones en las que no se asigne una de las causas anteriores y la evaluación quede incompleta, el sistema no podrá calcular los resultados a partir de las puntuaciones y, por tanto, la maestra no podrá consultar los reportes del INDI.
\end{abstract}

\title{
Tablas de funcionamiento por componentes específicos
}

En la sección de "Funcionamiento por componentes específicos" (ver Fig. 5.3) se presentan las 7 subescalas del desarrollo que contempla el INDI. En una primera tabla se agrupan las 4 correspondientes a la dimensión cognitiva: Lenguaje, Matemática, Funcionamiento Ejecutivo y Descentramiento, y en una siguiente las 3 subescalas de la dimensión socioemocional: Prosocialidad, Comportamiento Internalizante y Comportamiento Externalizante. Al igual que para las dimensiones, se describe el perfil de desarrollo obtenido como resultado para cada uno de los componentes, en base a la interpretación de las puntuaciones asignadas. 


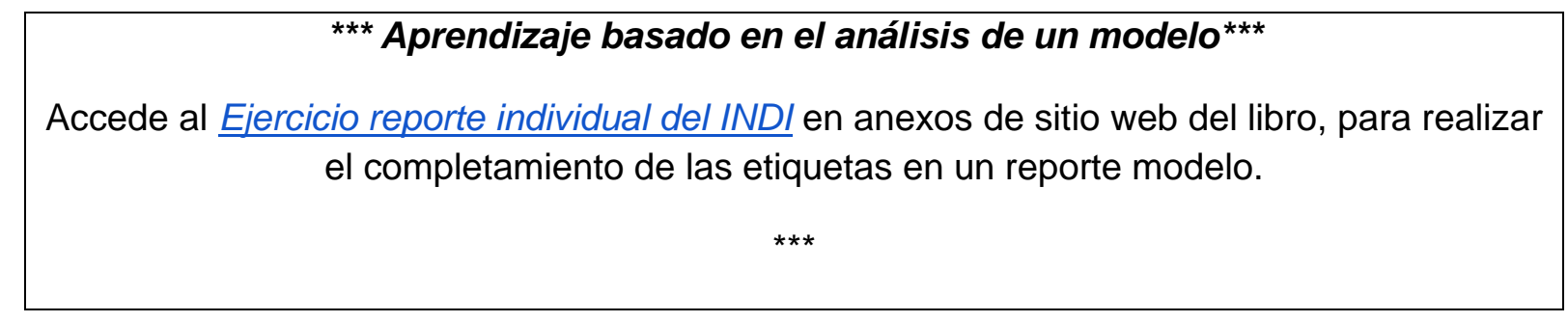

Desarrollo cognitivo

\begin{tabular}{|l|l|c|}
\hline Dimensión & Componente & Perfil de desarrollo \\
\hline \multirow{4}{*}{} & Lenguaje & Esperado \\
\cline { 2 - 3 } & Matemática & Zona de monitoreo \\
\cline { 2 - 3 } & Descentramiento & Esperado \\
\cline { 2 - 3 } & Funcionamiento Ejecutivo & Destacado \\
\hline
\end{tabular}

Desarrollo socioemocional

\begin{tabular}{|c|c|c|}
\hline Dimensión & Componente & Perfil de desarrollo \\
\hline & Prosocialidad & Incompleto \\
\hline & $\begin{array}{l}\text { Comportamiento internalizante } \\
\text { (ansioso-inhibido) }\end{array}$ & Zona de monitoreo \\
\hline & $\begin{array}{l}\text { Comportamiento externalizante } \\
\text { (agresivo-frustrado) }\end{array}$ & Esperado \\
\hline
\end{tabular}

Figura 5.3. Ejemplo de cuadro de Funcionamiento por componentes específicos en el reporte individual.

\section{${ }^{* * *}$ Situación problema ${ }^{* * *}$}

Interpretación de los resultados de un reporte individual (estático) del INDI.

Observa el Reporte individual ficticio de un niño de Nivel 3 en los materiales anexos al capítulo en la web de INDI y trata de responder a las siguientes preguntas:

1. ¿Qué información brinda en cuanto a los perfiles de desarrollo por dimensión?

2. ¿Qué información brinda en cuanto a los perfiles de desarrollo por componentes o subescalas?

3. ¿Por qué no emite perfil de desarrollo para la Dimensión Cognitiva ni para el componente de Lenguaje? Intenta explicar por qué puede haber sucedido esto.

4. ¿Qué áreas del desarrollo se pueden identificar como de fortaleza o de debilidad para este niño? 

5. ¿Qué indicaciones se describen como sugerencias para el área socioemocional? ¿En qué medida son diferentes a las de las otras dimensiones?
6. De acuerdo a las características que muestran los perfiles de Comportamiento Externalizante e Internalizante, ¿qué tipo de intervenciones áulicas podrían pensarse para favorecer el desarrollo socioemocional de este niño?

\subsubsection{Reporte individual de trayectoria}

El reporte individual antes visto, nos permite comparar entre niños para determinar el estado de algunas funciones del desarrollo a nivel poblacional. Pero hemos visto, asimismo, que el desarrollo no es un proceso lineal y puede presentar, por tanto, cierta variabilidad intraindividual, o cambio, a lo largo de períodos breves de tiempo. El reporte individual de trayectoria del INDI es un documento adicional a los reportes individuales estáticos, que se emite luego de realizada la segunda evaluación del año. Tiene por objetivo informar sobre la variabilidad intrapersonal en el desarrollo para las áreas evaluadas por el INDI.

Existen por lo menos tres motivos relevantes para considerar el estudio del cambio en el desarrollo infantil y emitir, en consecuencia, un reporte de trayectoria del INDI. En primer lugar, permite evaluar el impacto que tiene en el desarrollo del niño algún cambio de tipo ambiental o de salud que esté presente entre las tomas. En segundo lugar, permite detectar situaciones de cronicidad o de rezago persistente (aunque haya variabilidad la misma no es suficiente para los parámetros esperados) que, de no ser atendidas a tiempo, presentan mayores probabilidades de consecuencias negativas a largo plazo para el niño. Por último, desde el modelo de respuesta de intensidad graduada, presentado en el capítulo 3 , permite evaluar la responsividad del niño ante las intervenciones educativas, familiares 0 sanitarias, que se hayan implementado entre ambas evaluaciones. La no responsividad es una señal de alarma adicional.

Los resultados que se presentan en este reporte individual de trayectoria refieren a: (a) los perfiles de desarrollo del niño en las distintas áreas evaluadas por el INDI en la primera y segunda evaluación del año, (b) las características de la trayectoria en el desarrollo de las distintas áreas evaluadas por el INDI y (c) un detalle de las áreas a las que, según la interpretación de la información de trayectoria, es necesario prestar especial atención. La información que ofrece el reporte individual de trayectoria es, por tanto, diferente y complementaria a la que contienen los reportes de la primera y segunda evaluación anual.

Vemos entonces que este reporte integra la información de las dos evaluaciones del año (a) y analiza la variabilidad entre los dos momentos (b), determinando la magnitud del cambio entre ellos y ofreciendo información de carácter dinámica respecto al proceso del niño a lo largo del año. Esta información se presenta en formato de tablas y gráficos que detallan los resultados de las dos evaluaciones del año y se describe, en un texto breve, cómo ha sido el cambio en esa área del desarrollo entre ambas tomas. 
Debido a las características propias de las diferentes áreas del desarrollo y al tiempo que transcurre entre la primera y segunda evaluación (aproximadamente 6 meses) se esperan cambios de mayor magnitud en algunas dimensiones y componentes del INDI que en otros. Por tanto, los parámetros de cambio esperados han sido establecidos para cada dimensión y componente del INDI de manera diferenciada y según el perfil de la población uruguaya, para periodos de seis meses.

A continuación (Tabla 5.3) se presenta un cuadro comparativo entre algunas propiedades del reporte individual estático y del reporte individual de trayectoria (dinámico) En esta tabla comparativa se puede apreciar que la información contenida en ellos es adicional y complementaria.

Tabla 5.3

Cuadro comparativo de algunas propiedades del reporte individual estático y del dinámico

\begin{tabular}{|c|c|c|}
\hline & $\begin{array}{l}\text { Reporte individual de } \\
\text { evaluación (estático) }\end{array}$ & $\begin{array}{l}\text { Reporte individual de trayectoria } \\
\text { (dinámico) }\end{array}$ \\
\hline $\begin{array}{l}\text { Tipo de } \\
\text { información }\end{array}$ & $\begin{array}{l}\text { "Foto" de un momento (período de } \\
\text { evaluación) }\end{array}$ & $\begin{array}{l}\text { Información "dinámica" de la magnitud del } \\
\text { cambio entre evaluaciones }\end{array}$ \\
\hline $\begin{array}{l}\text { Baremo de } \\
\text { comparación } \\
\text { de resultados }\end{array}$ & $\begin{array}{l}\text { Estático: compara con nivel de } \\
\text { desarrollo según edad en meses y } \\
\text { nivel educativo }\end{array}$ & $\begin{array}{l}\text { Dinámico: compara con magnitud del } \\
\text { cambio según edad en meses y nivel } \\
\text { educativo }\end{array}$ \\
\hline Sugerencias & $\begin{array}{l}\text { De intervención y posible } \\
\text { interconsulta (en áreas "muy } \\
\text { descendidas") }\end{array}$ & $\begin{array}{l}\text { De áreas de especial atención basado } \\
\text { únicamente en la trayectoria de cambio }\end{array}$ \\
\hline Destinatario & $\begin{array}{l}\text { docente actual (para intervención y } \\
\text { comunicación) }\end{array}$ & $\begin{array}{l}\text { Docente actual y, especialmente, del año } \\
\text { próximo ya que permite ver proceso anual }\end{array}$ \\
\hline Emisión & Luego de cada evaluación & $\begin{array}{l}\text { Únicamente después de la } 2 \text { da evaluación } \\
\text { anual }\end{array}$ \\
\hline
\end{tabular}

El reporte individual de trayectoria presenta una primera página en la que se encuentran los datos descriptivos del niño y del centro educativo, así como una breve explicación de la información contenida en el reporte (ver Modelo de reporte INDI individual de trayectoria en recursos anexos para acceder a una vista completa del modelo). A continuación de esta página, el reporte muestra una serie de gráficos y tablas para cada una de las dimensiones y componentes del desarrollo evaluados por el INDI. En la Figura 5.4 podemos observar un ejemplo de ellos. 


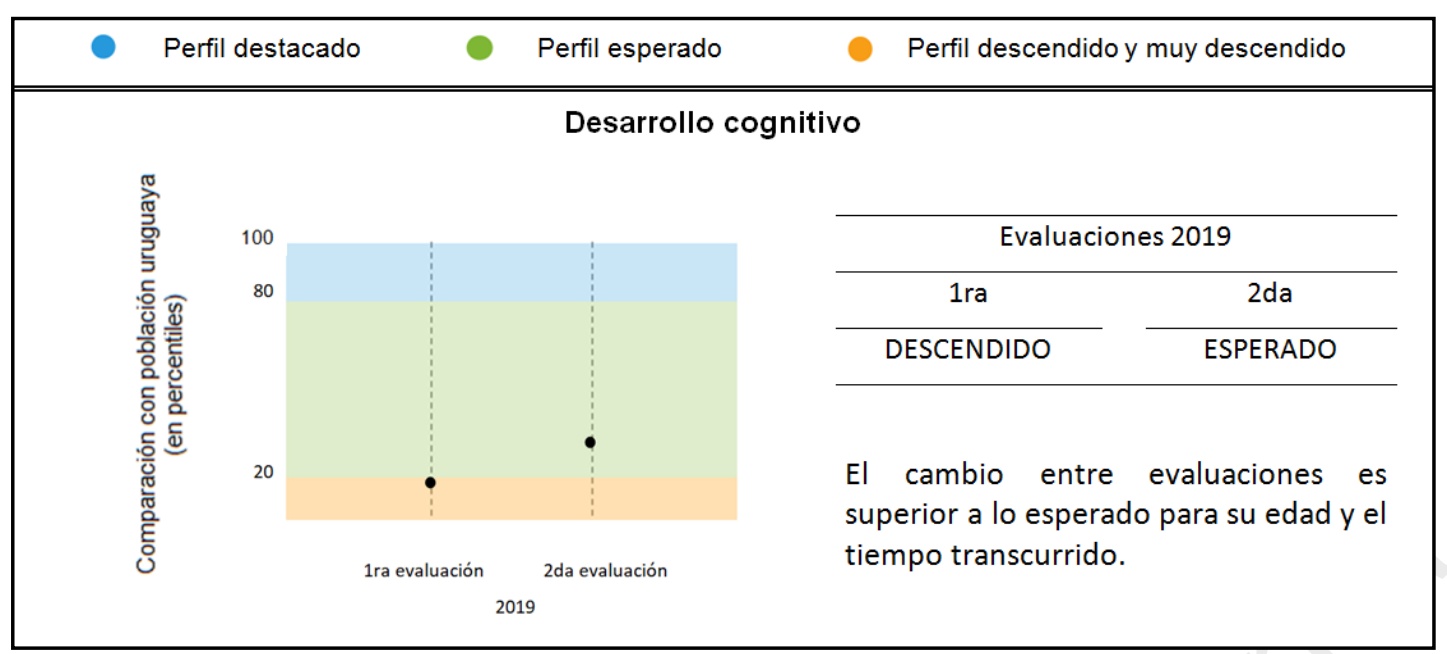

Figura 5.4. Representación de la información de una dimensión o componente del desarrollo en el reporte de trayectoria

Cada dimensión o componente del desarrollo evaluado es presentado en un área compuesta por: (a) un gráfico, (b) una tabla y (c) un texto descriptivo.

En el gráfico se encuentran representados mediante franjas de color, los posibles perfiles de desarrollo que emite el INDI como resultado: Zona de riesgo y de monitoreo agrupados en la franja de color anaranjado, perfil Esperado determinado por la zona de color verde y el perfil Destacado representado en la zona de color celeste. En el eje vertical del gráfico se establecen los puntos de corte para estos perfiles de resultados, según vimos en el apartado 5.2., en base a los percentiles poblacionales de la norma uruguaya: percentil menor a 20 para los resultados que indican un funcionamiento "descendido" o "muy descendido", percentil entre 21 y 80 para el desarrollo esperado y superior a 80 para la zona de funcionamiento destacado9. El eje vertical indica entonces la posición aproximada del niño comparado con la población uruguaya de su misma edad en meses y nivel educativo. En el eje horizontal del gráfico se detallan dos momentos en el tiempo, que se corresponden con las dos evaluaciones anuales El gráfico del reporte de
trayectoria es una representación
aproximada de los resultados. Se
recomienda su interpretación más
precisa basándose en la
información contenida en la tabla
a la derecha y en el texto
descriptivo correspondiente. realizadas con el INDI. Para favorecer la lectura del gráfico éstas se representan a lo largo de las zonas de color con líneas verticales punteadas y permiten determinar la posición aproximada del perfil de desarrollo del niño mediante un punto.

La tabla a la derecha bajo el rótulo "Evaluaciones (año)" (ej. "Evaluaciones 2019" en Fig. 5.4) indica el año sobre el cual se informa en ese reporte individual de trayectoria. Se señala el perfil de desarrollo obtenido en esa dimensión o componente específico, para cada una de las evaluaciones anuales. De esta forma, se recupera aquí información presentada en el primer y segundo reporte individual del año, mostrando ambos resultados juntos. Debajo de la misma podrá encontrarse un texto (ver más adelante casos en los que

\footnotetext{
${ }^{9}$ Recordamos que ésta no aplica a la dimensión $S$ globalmente ni a sus componentes Comportamiento internalizante (ansioso-inhibido) y externalizante (agresivo-frustrado).
} 
puede aparecer en blanco) que refiere a la variabilidad observada entre la primera y segunda evaluación. Este "cambio" puede ser: (a) acorde a lo esperado, (b) por debajo de lo esperado o (c) superior a lo esperado. Como hemos visto y debido al tiempo que transcurre entre ambas evaluaciones, la variabilidad esperada a nivel del desarrollo puede ser de mayor o menor magnitud en algunas dimensiones y/o componentes. Por tanto, se han establecido parámetros de cambio diferentes para cada dimensión y componente, mediante baremos dinámicos específicos para cada área del desarrollo, según la población de referencia y para periodos de seis meses.

Texto referido a la variabilidad entre evaluaciones.

Este texto introduce la información más relevante del reporte individual de trayectoria. Esto se debe a que describe cómo ha sido el cambio intraindividual entre ambas evaluaciones, más allá de los resultados de cada evaluación del año por separado. En este texto el reporte destaca lo más relevante del estudio de la trayectoria: determina la magnitud del cambio entre las evaluaciones y expresa si esa variabilidad sigue un patrón esperado en el desarrollo, más allá de las categorías descriptivas de los resultados de cada una de las evaluaciones e incluso dentro de un mismo perfil de resultados. Esto quiere decir que, por ejemplo, un niño puede haber obtenido en ambas evaluaciones anuales un perfil de desarrollo "descendido" para un área determinada $\mathrm{y}$, sin embargo, el texto sobre la variabilidad entre ellas puede expresar que su evolución se encuentra acorde o es incluso superior a lo esperado, según los parámetros para el momento evolutivo (edad en meses) y el área del desarrollo.

Existen múltiples posibilidades de variabilidad en los resultados entre las evaluaciones y, a su vez, el patrón de evolución esperado es diferente para las distintas áreas del desarrollo que evalúa el INDI. Por este motivo, se han generado categorías descriptivas de posibles resultados de trayectoria mediante textos sujetos a: (a) el área del desarrollo a la que refieren y (b) el tipo de trayectoria que muestra la variabilidad entre ambas evaluaciones. Se presenta en la Tabla 5.4 los posibles textos de salida emitidos en el reporte.

Existen dimensiones del INDI (ej. desarrollo cognitivo o motor) para las cuales podemos esperar una curva de desarrollo creciente, con mayor o menor pronunciación. Sin embargo, hay áreas del desarrollo para las cuales esperamos una disminución de sus manifestaciones (ej. comportamiento internalizante y externalizante). En este sentido, como vemos en la Tabla 5.4, para las dimensiones $C, M$ y $D$ y para la subescala de Prosocialidad de la dimensión $\mathrm{S}$ se reportan determinadas categorías descriptivas y para las subescalas de Comportamiento internalizante y Comportamiento externalizante de la dimensión $\mathrm{S}$ se reportan otras. Por esto mismo, se presentan a continuación ciertas puntualizaciones en relación a algunos de los textos descriptivos del perfil de trayectoria que se presentan en la Tabla 5.4. 
Tabla 5.4

Textos emitidos en los reportes individuales de trayectoria que describen el perfil de la variabilidad entre evaluaciones

\begin{tabular}{l|cc}
\hline \multirow{2}{*}{ Perfil de trayectoria } & \multicolumn{2}{|c}{ Área/s del desarrollo evaluadas por INDI: } \\
\cline { 2 - 3 } & $\begin{array}{c}\text { Dimensiones C, M y D; } \\
\text { Prosocialidad (S) }\end{array}$ & $\begin{array}{c}\text { Comportamiento internalizante y } \\
\text { externalizante (S) }\end{array}$ \\
\hline
\end{tabular}

Ambos resultados de las evaluaciones anuales se encuentran dentro de

"Ver áreas de especial los percentiles mínimos atención al final del reporte" que el instrumento puede medir
"Indicadores de riesgo socioemocional muy elevados (persistencia de conducta ansiosaevitativa / agresiva-frustrada). Continúa requiriendo especial atención"
"El cambio entre

Por debajo de los esperada parámetros de evolución para su edad y el tiempo evaluaciones se encuentra por debajo de lo esperado transcurrido" o "Ver áreas de especial atención al final del reporte"*
"El cambio entre evaluaciones indica la aparición de niveles significativos de conducta ansiosaevitativa (internalizante) / agresiva-frustrada (externalizante)" o "El cambio entre evaluaciones indica un aumento significativo de la conducta ansiosa-evitativa (internalizante) / agresivafrustrada (externalizante). Continúa requiriendo especial atención" o "Persisten niveles poblacionalmente altos de conducta ansiosaevitativa (internalizante) / agresiva-frustrada (externalizante)"

"El cambio entre evaluaciones indica una

"El cambio entre disminución de la conducta ansiosa-evitativa evaluaciones es acorde a lo

Acorde a los parámetros de evolución esperada

esperado para su edad y el tiempo transcurrido" o "Ver áreas de especial atención" *

(internalizante) / agresiva-frustrada

(externalizante), si bien aún requiere de especial atención" o "El cambio entre evaluaciones es favorable, indicando la disminución significativa de la conducta ansiosa-evitativa (internalizante) / agresiva-frustrada (externalizante)"

\section{"El cambio entre}

Superior a los parámetros de evolución esperada evaluaciones es superior a lo esperado para su edad $y$ el tiempo transcurrido" o "Ver áreas de especial atención" *
No aplica dado que la tendencia esperada es hacia una expresión mínima (o ausencia) de las conductas de tipo ansioso-evitativo / agresivofrustrado

\footnotetext{
Ambos resultados de las evaluaciones anuales se

"Ha alcanzado el máximo encuentran dentro de los percentiles máximos que el instrumento puede medir
}

no se emite texto dado que muestra ausencia de conductas problemáticas de tipo ansiosoevitativo / agresivo-frustrado, en ambas evaluaciones anuales

\footnotetext{
Nota. *podrán existir situaciones -muy infrecuentes- en las que un niño pueda estar presentando una evolución favorable en su desarrollo (ej: acorde o superior a lo esperado) pero que, de todos modos sea un cambio insuficiente dentro de los parámetros mínimos esperados. En estos casos y aunque visualmente el gráfico pueda mostrar progresos, aparecerá la leyenda "Ver áreas de especial atención" debajo de la tabla de evaluaciones anuales y como texto descriptivo del perfil de trayectoria de cambio en esa área, indicando la atención necesaria.
} 
- "Ver áreas de especial atención al final del reporte": esta especificación (presentada para las dimensiones C, M, D y para el componente de Prosocialidad) presenta diferentes situaciones en las que puede figurar. Entre ellas, podrá aparecer (a) cuando el nivel de desarrollo en un área presenta los valores mínimos a nivel de percentiles captados por el instrumento o (b) cuando la variabilidad entre evaluaciones no alcance la magnitud deseada o sea marcadamente por debajo de lo esperado. Esto quiere decir que podremos encontrarnos frente a situaciones en las que un niño presente una "evolución" en su desarrollo, pero ésta no implique un cambio suficiente dentro de los parámetros mínimos esperados. Por este motivo, podrán existir situaciones de lectura del gráfico y del texto que resulten, a primera vista, contraintuitivas, en las que se visualice en el gráfico que el niño "progresa" pero el texto indique que no es una variabilidad suficiente dentro de los parámetros de cambio esperados y que, por tanto, es un área que requiere de especial atención. Veremos algún ejemplo de esto más adelante en esta sección.

- "Indicadores de riesgo socioemocional muy elevados. Continúa requiriendo especial atención": esta especificación (tanto para Comportamiento externalizante como internalizante) indica que nos encontramos ante situaciones en las que ha constatado a lo largo del año (esto es, en ambas tomas) una elevada presencia de problemas de conducta, ya sea de ansiedad-inhibición o de agresividad-frustración y requiere, por tanto, de especial atención a nivel educativo y familiar, para poder acompañar el desarrollo del niño.

- Para las áreas de Comportamiento internalizante y externalizante se brindará una alerta de variabilidad o cambio por debajo de los parámetros esperados cuando se indique la aparición, el aumento o la persistencia de conductas de tipo problemáticas (ansioso-evitativas o agresivo-frustradas). Esto quiere decir que cuando haya una mayor presencia de conductas de este tipo, el niño presentará un percentil menor en el desarrollo, ya que un mayor número de niños logra niveles más altos de desarrollo en esta área. Esta "inversión" de las puntuaciones para estos componentes del INDI se expresa en un gráfico de igual orientación que los demás, para facilitar su comprensión visual. Cuando la representación gráfica del perfil en las evaluaciones anuales se encuentra más arriba en relación al eje vertical, será porque se corresponde a un percentil poblacional más alto e indicará, por tanto, una menor presencia de conductas de tipo ansioso-evitativas o agresivo-frustradas. A nivel del texto de trayectoria esto se podrá expresar también como una trayectoria "favorable" si la disminución de las manifestaciones es acorde a los parámetros de evolución esperada.

Finalmente, puede suceder que no se emita un texto descriptivo del perfil de trayectoria. Esto sucede en las ocasiones en las que la información que brindaría resulta redundante (ej. ambas evaluaciones anuales con funcionamiento "esperado" y perfil de trayectoria acorde a los parámetros también "esperados"). 


\section{Ejemplos de la relevancia de la información de trayectoria.}

Es importante recordar que la información acerca de la trayectoria evolutiva en un área del desarrollo es complementaria y adicional a la información que brindan los reportes de las dos evaluaciones anuales. En este contexto, éstos son considerados como reportes "estáticos", ya que brindan información acerca de un "estado" momentáneo del desarrollo. Se presentan a continuación tres ejemplos en donde se aprecia la información adicional que puede brindar este reporte, tanto porque amplíe la información ofrecida por los reportes estáticos (Figura 5.5), como porque la resignifique (Figuras 5.6 y 5.7).

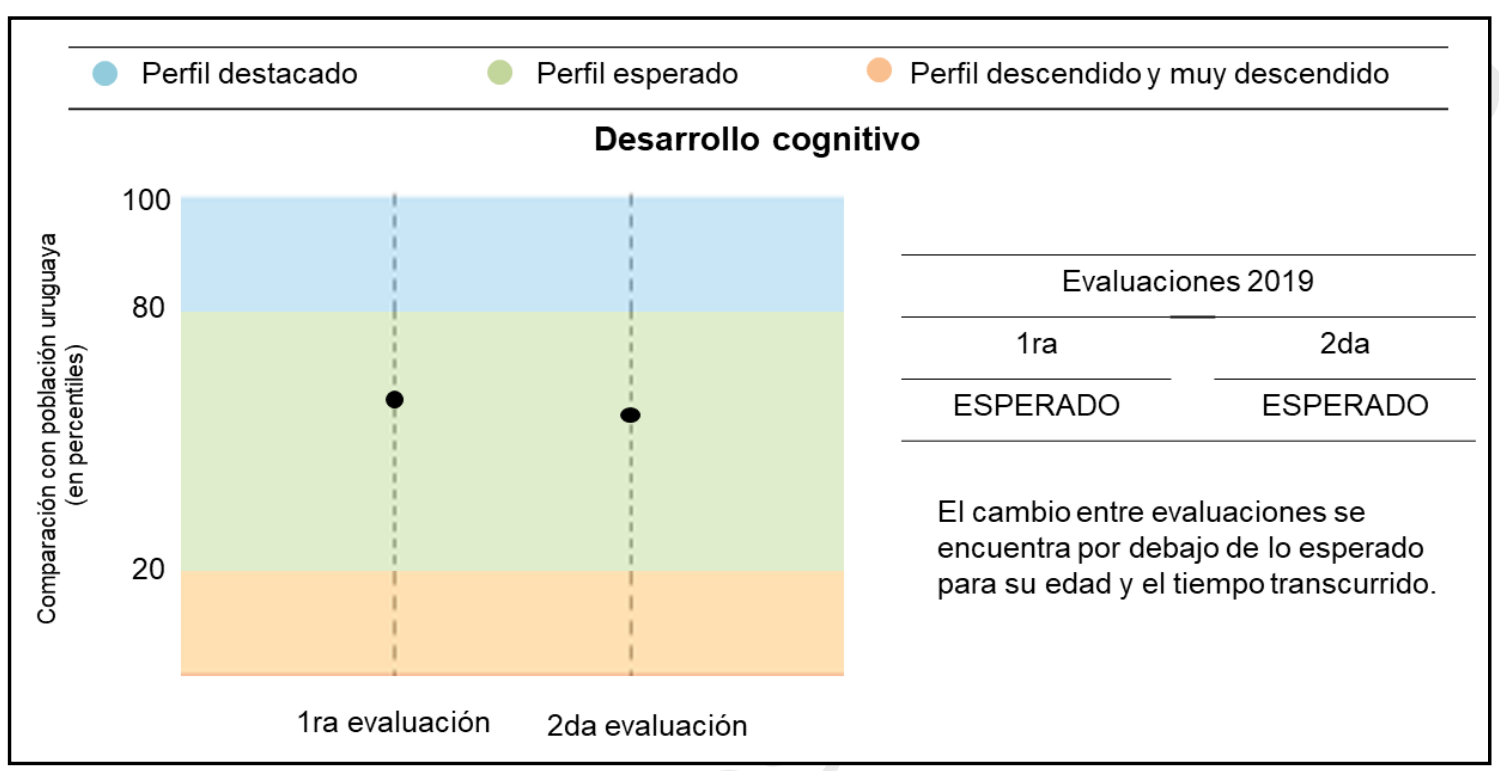

Figura 5.5. Ejemplo de cambio por debajo de lo esperado en el reporte de trayectoria

En el ejemplo de la figura 5.5, la información de la primera y segunda evaluación indica que este niño presentó un perfil de desarrollo esperado en la dimensión cognitiva en los dos momentos del año, comparado con la población de referencia. Sin embargo, cuando se analiza el cambio en el desarrollo entre la primera y la segunda evaluación se observa que ha progresado en menor medida de lo esperado. Es posible concluir que pese a mantenerse dentro del perfil esperado en ambas evaluaciones, no presenta el nivel de progreso que se espera para su edad en meses y nivel educativo. 


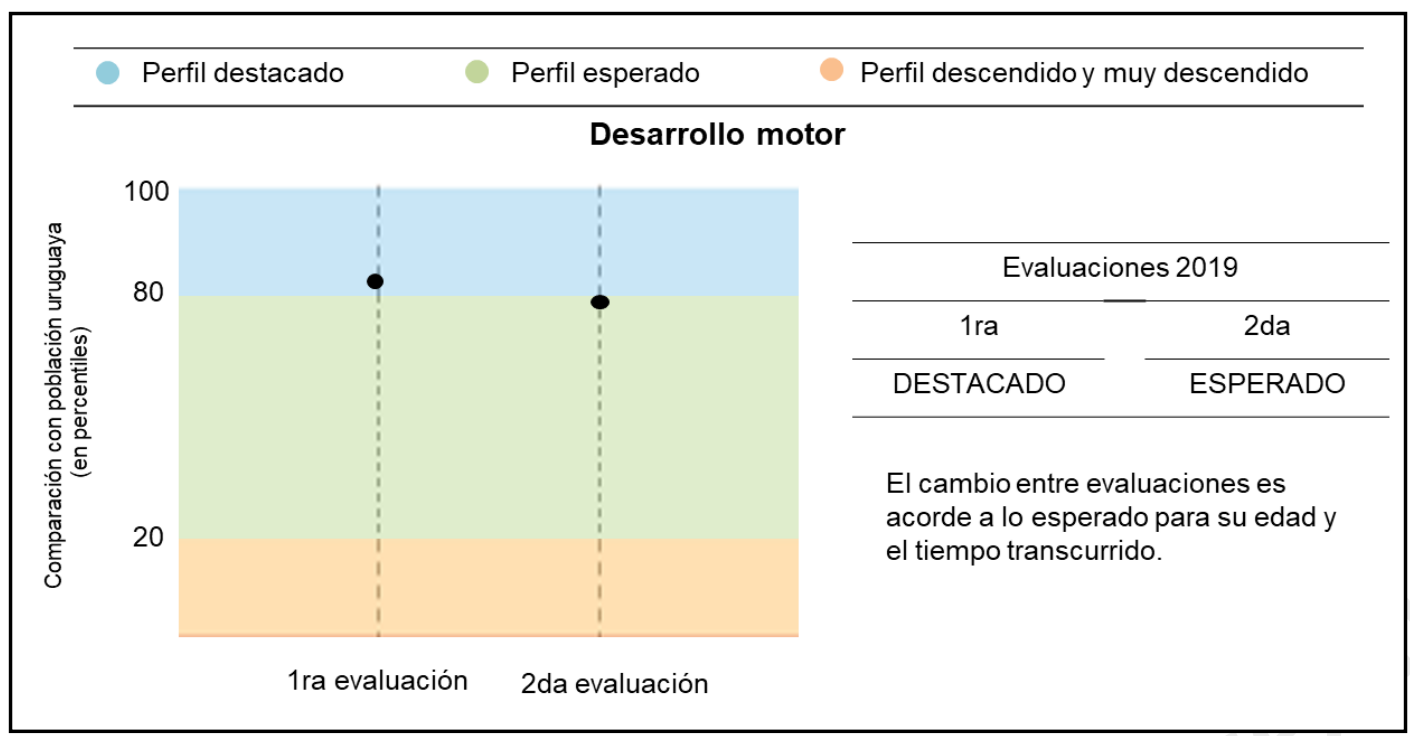

Figura 5.6. Ejemplo A de cambio esperado en el reporte de trayectoria

En el ejemplo de la figura 5.6 si bien el perfil de desarrollo en la primera evaluación fue de "destacado" y en la segunda evaluación fue de "esperado", la magnitud del cambio en esta dimensión resulta acorde a la tendencia de los niños de su edad en meses y nivel educativo. Por tanto, al considerar la información en conjunto, se estima que la trayectoria de desarrollo en esta dimensión es de todas formas favorable. La información de trayectoria, en este caso, permite al docente establecer cierto parámetro de relatividad en torno a los resultados de estas evaluaciones estáticas; esto puede pensarse tanto como por una sobreestimación por parte del docente al asignar las puntuaciones al momento de la primera evaluación, como por interpretar como un "descenso" el resultado de la segunda evaluación anual. Si el docente compara ambas evaluaciones con la información de los reportes estáticos únicamente, perdería de vista que la evolución respeta, igualmente, los parámetros de cambio esperados para el área del desarrollo y la edad del niño. Esto es relevante al momento de considerar las posibles intervenciones con este niño o niña en esta área del desarrollo.

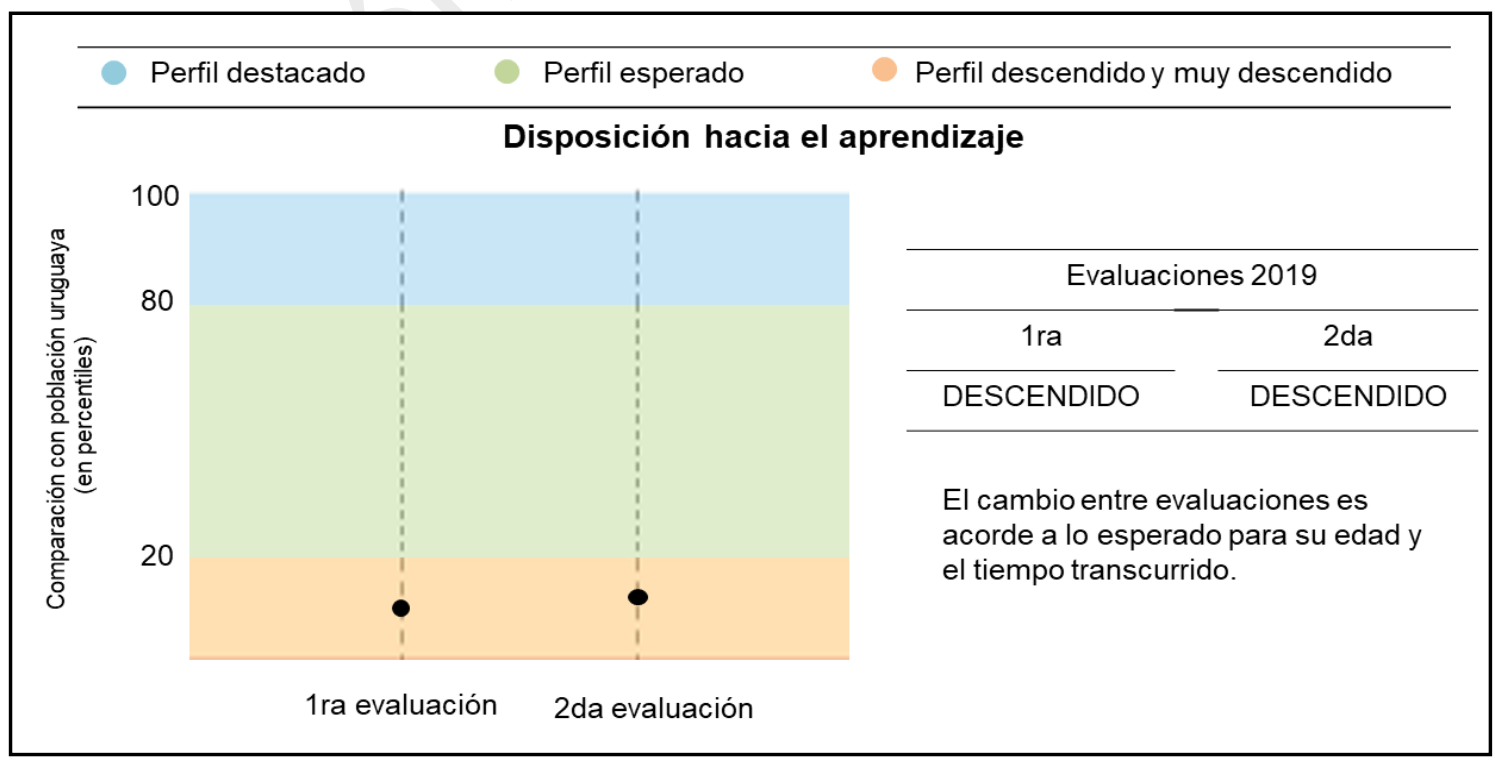

Figura 5.7. Ejemplo B de cambio esperado en el reporte de trayectoria 
En el ejemplo de la figura 5.7, a diferencia del anterior, la información de trayectoria indica que el desarrollo en el área Disposición hacia el aprendizaje presenta un cambio acorde a lo esperado. Sin embargo, la información de ambas evaluaciones estáticas indica que el mismo se encuentra "descendido" en ambos momentos de evaluación. En este caso, la información de trayectoria complementa la información estática indicando que el niño viene en una curva de desarrollo progresivo, dentro de lo esperado, en esta área. El análisis que el docente pueda realizar en torno a los factores presentes entre evaluaciones (ej. una situación familiar que pudiere estar incidiendo momentáneamente o la implementación de un dispositivo de intervención que se haya podido realizar entre evaluaciones, en el marco de un modelo RIG, podrá colaborar en las líneas para continuar estimulando esta área que comienza a mostrar responsividad y progresos.

Áreas de especial atención basadas en la información de trayectoria. Esta última sección del reporte de trayectoria refiere a las áreas a priorizar exclusivamente desde el punto de vista del análisis de la trayectoria o de la magnitud de la variabilidad entre la primera y segunda evaluación. Específicamente se incluirán aquí aquellas áreas para las cuales se establece que, desde el punto de vista de la trayectoria, no han progresado en la medida que se espera para la edad en meses del niño, para el tiempo transcurrido entre evaluaciones (6 meses) y para el área del desarrollo evaluada. Como hemos visto en los ejemplos más arriba, esta información puede diferir de las áreas a las cuales el docente debe prestar atención siguiendo los reportes estáticos. Por este motivo se sugiere consultar también el reporte individual de la segunda evaluación para ampliar la información sobre áreas a atender y para acceder a las recomendaciones específicas (por ejemplo, intensificar la intervención, derivación) para las diferentes áreas del desarrollo.

\section{Aprendizaje basado en el análisis de un modelo:}

Accede al Ejercicio reporte individual de trayectoria del INDI en anexos de sitio web del libro, para realizar el completamiento de las etiquetas en una sección de este tipo de reporte.

\subsubsection{Reporte grupal}

El reporte grupal, al igual que el individual estático, presenta al inicio una breve contextualización de la evaluación y de los objetivos de la misma. A continuación, se describe información de la clase (centro al que pertenece, denominación de grupo, nombre de la maestra a cargo y cantidad de alumnos inscriptos) sobre la cual se reportan los resultados de INDI. Se indica la fecha de inicio y fin de la evaluación grupal, período sobre 
el cual se reportan los perfiles de desarrollo. En la Figura 5.8, a continuación, se puede observar este reporte en su diseño general o se puede acceder a un Modelo de reporte INDI grupal en el hipervínculo a recursos del libro.

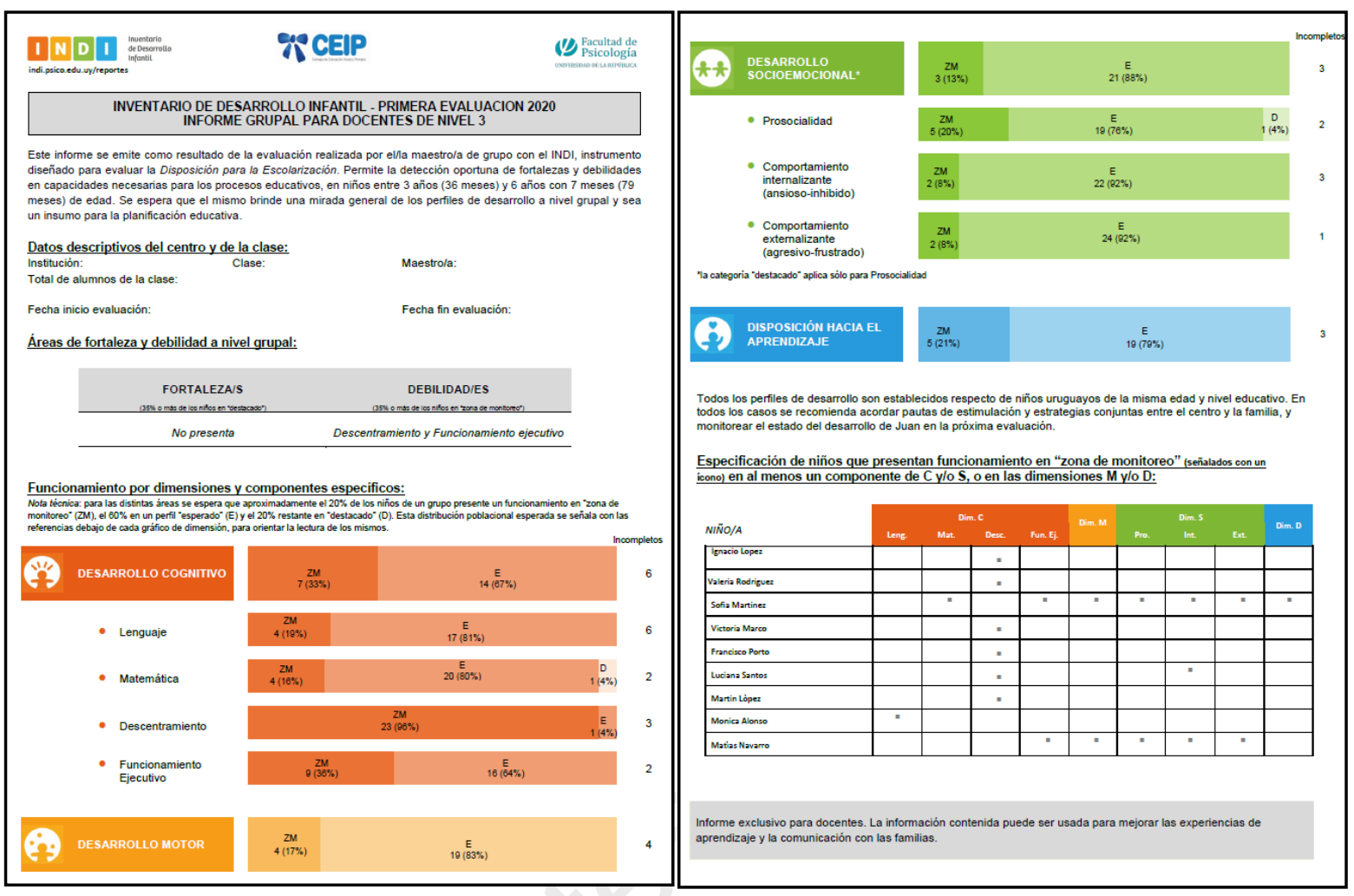

Figura 5.8. Modelo de reporte de grupo (aula) del INDI

\section{Sección Áreas de fortaleza y debilidad a nivel grupal}

En este apartado del reporte grupal se describen los componentes y dimensiones que destacan como fortalezas o debilidades a nivel de la clase. Esto es calculado por el sistema en base a la cantidad de niños del grupo que mostraron en esas áreas un funcionamiento "descendido" o "muy descendido" para el caso de las debilidades y un funcionamiento "destacado" para el caso de las fortalezas. Se determina que un área constituye una fortaleza a nivel grupal cuando el 35\% o más de los niños presenta un perfil "destacado" en esa área. Asimismo, se considera que un componente o dimensión del INDI constituye una debilidad a nivel grupal cuando el 35\% o más de los niños de la clase presenta un desarrollo "descendido" o "muy descendido" en esa área. En el ejemplo del grupo que se muestra en la Figura 5.9, puede observarse que el reporte indica que no se encuentran áreas de fortaleza grupal, ya que ningún componente o dimensión presenta más del $35 \%$ de los niños con desarrollo "destacado". Asimismo, se expresa que las subescalas de Descentramiento y Funcionamiento ejecutivo constituyen debilidades del grupo, ya que más del $35 \%$ de los niños presentaron un perfil de desarrollo de "Zona de monitoreo" en la evaluación. 


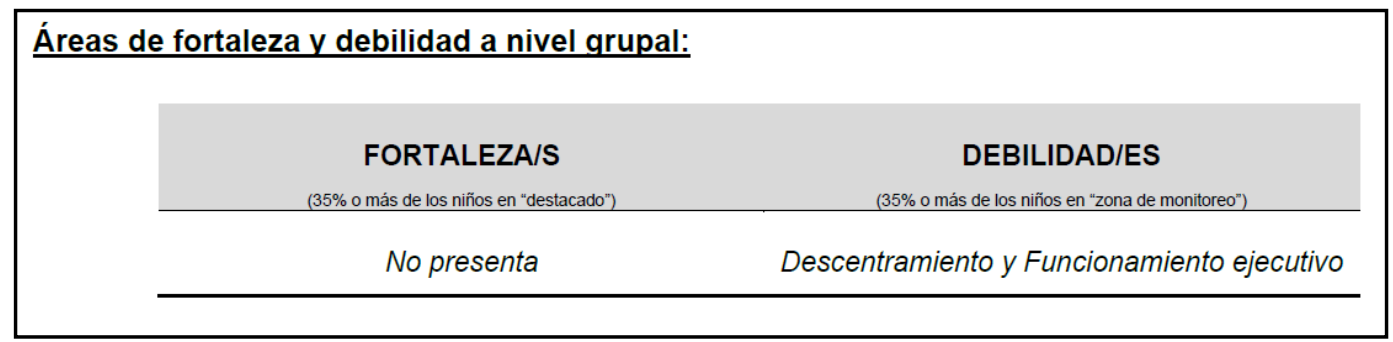

Figura 5.9. Ejemplo de la sección Áreas de fortaleza y debilidad a nivel grupal, en reporte de grupo del NDI

\section{Sección Funcionamiento por dimensiones y componentes específicos}

En este apartado del reporte grupal se presentan gráficos de barras agrupadas que dan cuenta de los resultados de la evaluación para cada área (dimensión y sus respectivos componentes, si corresponde) en base a la sumatoria de los resultados individuales del grupo. Ejemplos de la representación de estos gráficos pueden observarse en las Figuras 5.10 y 5.11 , a continuación.

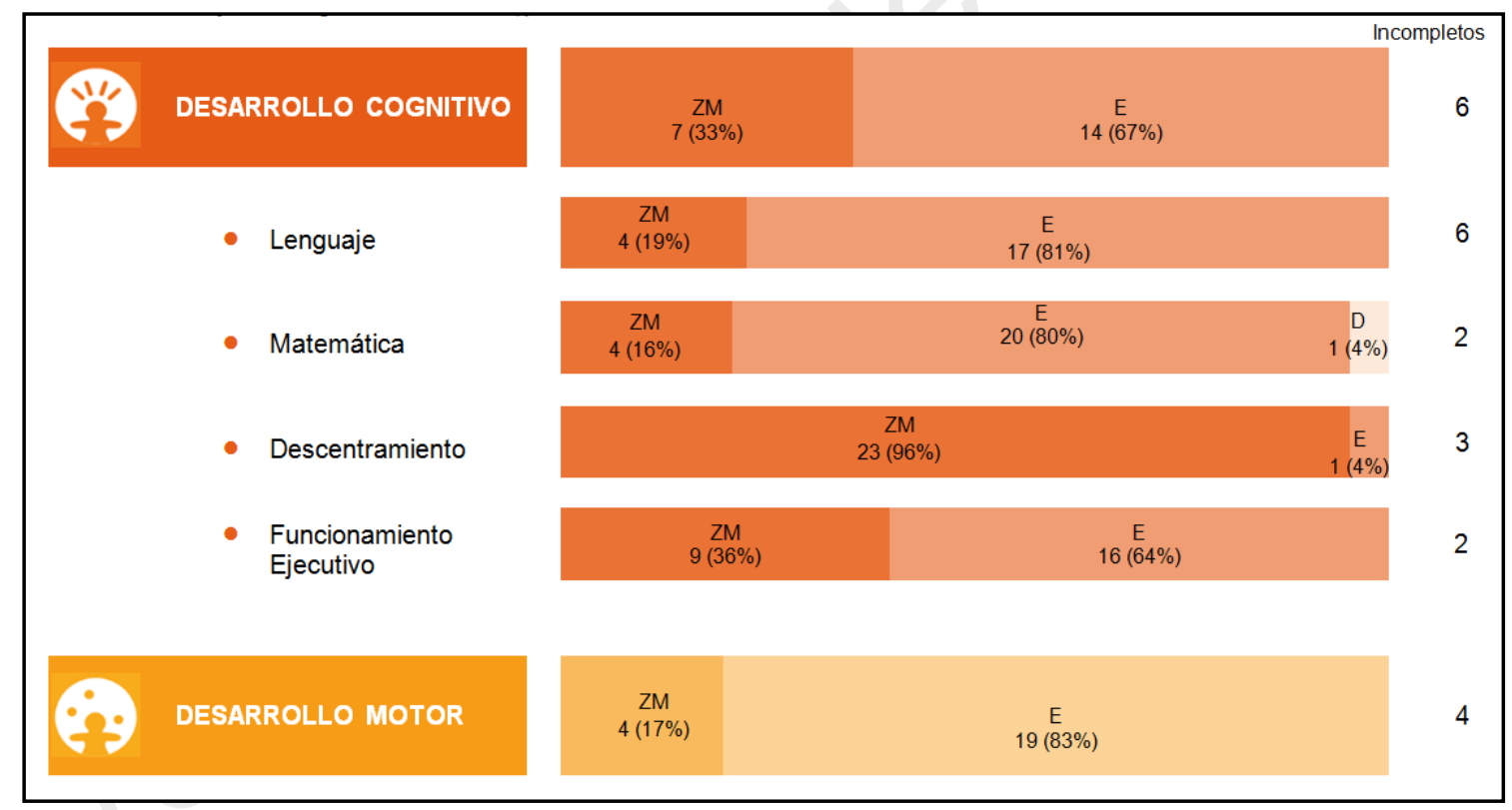

Figura 5.10. Ejemplo de representaciones gráficas del funcionamiento por dimensiones y componentes del reporte grupal, para la dimensión cognitiva y sus componentes y para la dimensión motora. 


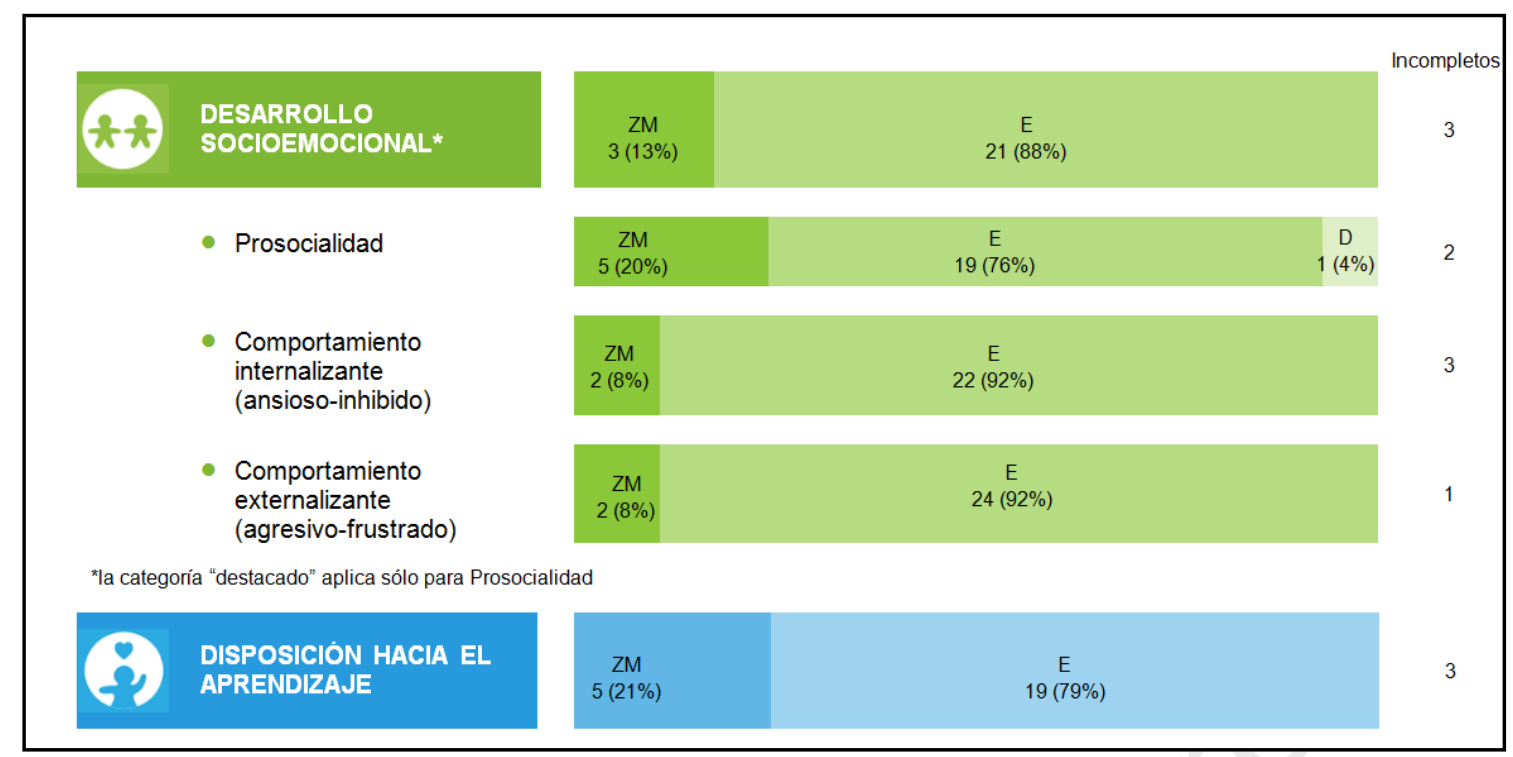

Figura 5.11. Ejemplo de representaciones gráficas del funcionamiento por dimensiones y componentes del reporte grupal, para la dimensión socioemocional y sus componentes y para la dimensión de disposición hacia el aprendizaje.

De esta forma, mediante áreas en el gráfico de mayor o menor tamaño y diferentes intensidades de color se expresan los distintos perfiles de desarrollo, para cada dimensión y componente del INDI. La configuración de los gráficos quedará determinada entonces de manera única para cada grupo, según los resultados de las evaluaciones individuales. Esto quiere decir que cuando una zona en un gráfico tiene un área más extensa, la misma da cuenta de una mayor cantidad de situaciones en el grupo con ese perfil de desarrollo como resultado y áreas de menor extensión reflejarán menor cantidad de situaciones individuales con ese perfil de desarrollo como resultado, para esa dimensión o componente. A su vez, la intensidad del color con la que se representa el área del gráfico expresa el tipo de funcionamiento de ese conjunto de niños en esa dimensión o componente: el grado de color más intenso referirá a un funcionamiento "descendido" y "muy descendido" (Zona de monitoreo y/o de riesgo dependiendo si se trate de nivel 3, 4 o 5), el grado de color intermedio representa al desarrollo "esperado" y el grado de color más suave al "destacado".

Dentro de cada zona del gráfico, a su vez, se expresa una leyenda que refiere al perfil de desarrollo que esa zona representa: ZM para "Zona de monitoreo" (lo que incluye los funcionamientos "descendido" y "muy descendido"), E para el desarrollo "esperado" y D para el "destacado". Junto a ésta, se encontrará una cifra que expresa la cantidad de niños del grupo que obtuvieron como resultado ese perfil de desarrollo en esa área, y el porcentaje que esa cantidad representa del total de los niños evaluados en el grupo. La sumatoria de las cifras de las distintas zonas del gráfico para una misma dimensión o componente refleja el $100 \%$ de los niños del grupo que fueron evaluados en esa área del desarrollo. Se excluyen para el cálculo aquellos niños que, por algún motivo, no pudieron ser evaluados en esa área y sus evaluaciones se encuentran, por tanto, incompletas. La cantidad de niños sin evaluar en cada una de las dimensiones y/o componentes se encuentra expresada en una columna a la derecha de cada gráfico, bajo el título "Incompletos". 


\begin{tabular}{|c|}
\hline Abreviaciones en el reporte de grupo. \\
ZM = Zona de monitoreo \\
(incluye los funcionamientos "descendido" y "muy descendido") \\
E $=$ Desarrollo esperado \\
D $=$ Desarrollo destacado
\end{tabular}

Realizaremos algunas puntualizaciones en relación a estos gráficos:

1. Las áreas de las distintas zonas de los gráficos son representaciones aproximadas a las mismas y no exactas.

2. Se incluye en el reporte una nota técnica en la que se especifica que, con base en la norma poblacional para las distintas áreas, se espera que aproximadamente el $20 \%$ de los niños de un grupo presente un funcionamiento en "Zona de monitoreo" (ZM con perfil "descendido" y/o "muy descendido"), el $60 \%$ con un funcionamiento "Esperado" (E) y el $20 \%$ restante con perfil "Destacado" (D). Esta distribución poblacional esperada se señala con referencias debajo de cada gráfico de dimensión, para orientar la lectura de los mismos.

3. Se recuerda también en el reporte que para la dimensión socioemocional la categoría "destacado" aplica sólo para el componente Prosocialidad (no así para Comportamiento Internalizante y Externalizante ni para la Dimensión S globalmente entendida, ver apartado 5.2.).

4. Se especifica que todos los perfiles de desarrollo representados en los gráficos son establecidos respecto de niños uruguayos de la misma edad en meses y nivel educativo.

Sección de especificación de niños que presentan funcionamiento descendido y/o muy descendido en algún área del desarrollo evaluada por INDI

En el último apartado del reporte grupal se ofrece un listado de los niños del grupo que presentan un funcionamiento en la categoría "descendido" o "muy descendido" (perfil de desarrollo en Zona de riesgo y/o Zona de monitoreo), en algún componente o dimensión. Este listado busca ser un resumen de aquellos casos en los cuales el reporte individual mostró algún área con funcionamiento descendido y a quienes resulta prioritario ofrecer recursos adicionales de apoyo. Su representación en el reporte grupal se muestra en la Figura 5.12. 


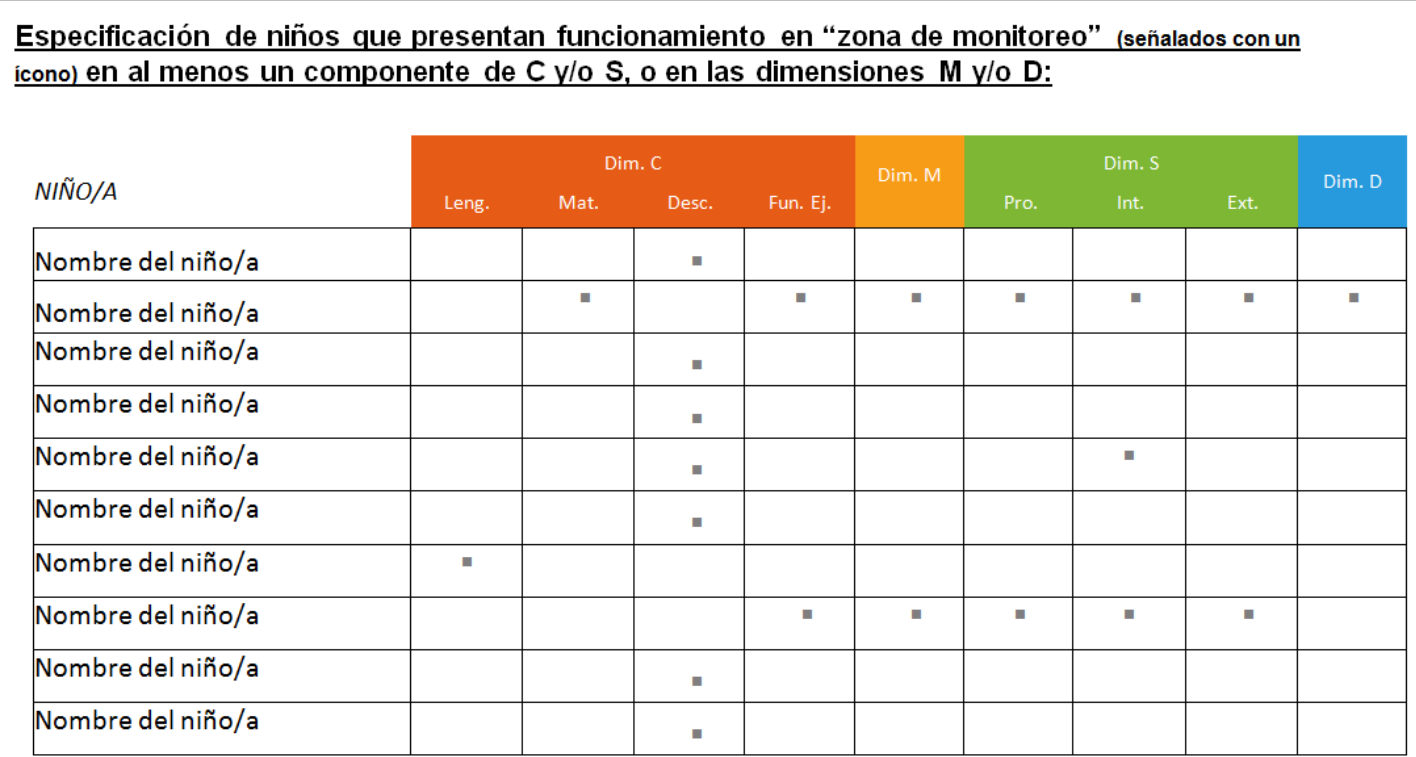

Figura 5.12. Ejemplo de tabla de especificación de niños con funcionamiento descendido o muy descendido en algún componente o dimensión del INDI

\section{${ }^{\star * \star}$ Aprendizaje basado en el análisis de un modelo***}

Accede al Ejercicio reporte grupal del INDI en anexos de sitio web del libro, para realizar el completamiento de las etiquetas en un reporte modelo de este tipo.

\section{${ }^{* \star *}$ INICIO EJERCICIO ${ }^{* * \star}$ Interpretación de los resultados de un reporte grupal del INDI.}

Observa el Reporte grupal ficticio de Nivel 4 en los materiales anexos al capítulo en la web de INDI y trata de responder a las siguientes preguntas:

1. ¿Qué información brinda el reporte en cuanto a los perfiles de desarrollo por dimensión y por componentes, a nivel grupal? ¿Qué conclusiones te permite sacar acerca del funcionamiento del grupo en las distintas áreas?

2. ¿Qué dimensión/es o componente/es identificas como de mayor fortaleza del grupo y cuál/es como de mayor debilidad del grupo? ¿Qué información del reporte te permite establecer esto?

3. ¿Por qué las barras de los componentes Matemática y Prosocialidad presentan tres grados de color mientras de las demás presentan sólo dos? ¿A qué se debe esto?

4. ¿Dirías que el funcionamiento del grupo para las subescalas de Comportamiento externalizante e internalizante se encuentran dentro de los parámetros de funcionamiento esperado para un grupo promedio? Justifica tu respuesta con información del reporte y del capítulo.

5. ¿Qué lineamientos de intervención pensarías a nivel individual, basado en la información de la tabla de especificación de niños con áreas en "Zona de monitoreo" (última sección del reporte de grupo)?

6. ¿Qué lineamientos de intervención se te ocurren para implementar en un grupo con las características que describe el reporte? 


\subsubsection{Reporte de centro}

Este reporte va dirigido al director (o equipo de dirección) del centro educativo y busca colaborar en la mirada global del estado de la población de niños que asiste al mismo. Para acceder a una visión completa de un Modelo de reporte INDI de Centro ver material adjunto en anexo del libro en sitio web de INDI.

Este reporte, al igual que los anteriores, presenta inicialmente una breve contextualización de la evaluación y de los objetivos de la misma y brinda a continuación los datos descriptivos del centro sobre el cual se informan los resultados de la evaluación. En la Figura 5.13, a continuación, se puede observar un ejemplo para esta primera sección del reporte, incluida la fecha de realización de la evaluación con el INDI y la distribución de la matrícula por grupo y nivel.

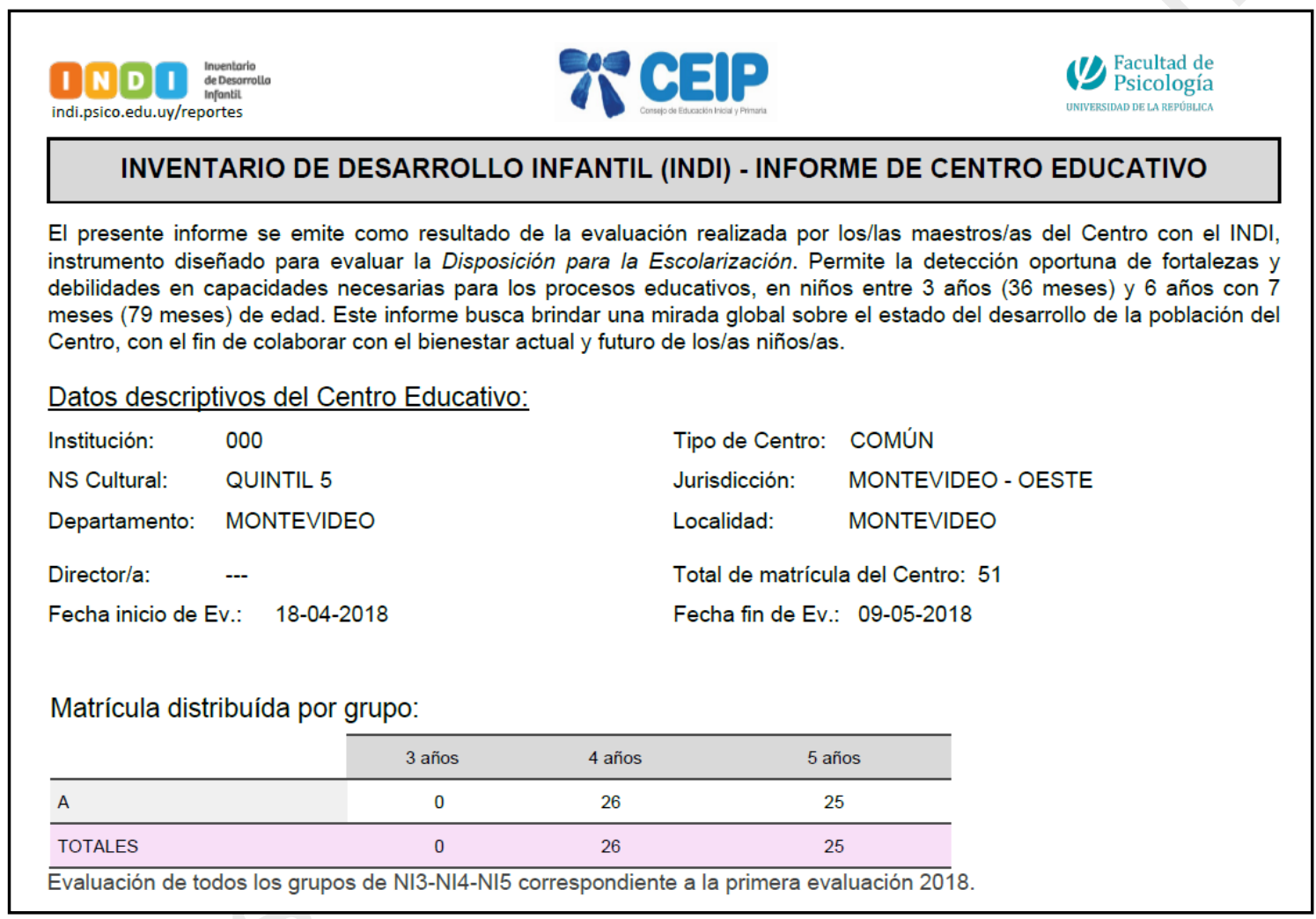

Figura 5.13. Captura de reporte de centro que incluye datos descriptivos del Centro

\section{$\underline{\text { Tabla de Funcionamiento por dimensión }}$}

A continuación, el reporte de Centro brinda una caracterización de la población del mismo según el nivel educativo al que pertenecen los niños y el estado del desarrollo de los mismos en las distintas dimensiones evaluadas por el INDI. Su formato de presentación en tablas puede observarse en la Figura 5.14, a continuación. 


\begin{tabular}{|c|c|c|c|c|}
\hline \multicolumn{5}{|c|}{ Desarrollo Cognitivo (C) } \\
\hline Nivel & Descendido & Esperado & Destacado & Incompleto \\
\hline $\mathrm{N} 14$ & $1(4.17 \%)$ & $21(87.50 \%)$ & $2(8.33 \%)$ & 2 \\
\hline N15 & $1(4.35 \%)$ & $16(69.57 \%)$ & $6(26.09 \%)$ & 2 \\
\hline Total & $2(4.26 \%)$ & $37(78.72 \%)$ & $8(17.02 \%)$ & 4 \\
\hline \multicolumn{5}{|c|}{ Nota: Cantidad de niños/as (\% sobre el nivel o total, según corresponda). } \\
\hline \multicolumn{5}{|c|}{ Desarrollo Motor (M) } \\
\hline Nivel & Descendido & Esperado & Destacado & Incompleto \\
\hline $\mathrm{N} 14$ & $2(9.09 \%)$ & $12(54.55 \%)$ & $8(36.36 \%)$ & 4 \\
\hline N15 & $2(8.00 \%)$ & $22(88.00 \%)$ & $1(4.00 \%)$ & 0 \\
\hline Total & $4(8.51 \%)$ & $34(72.34 \%)$ & $9(19.15 \%)$ & 4 \\
\hline
\end{tabular}

Figura 5.14. Tablas de caracterización del centro según estado del desarrollo de los niños.

Como puede observarse en el ejemplo de la figura 5.14, se detalla para cada dimensión y para cada nivel educativo (nótese que este centro no cuenta con Nivel 3) la cantidad de niños que obtuvieron como resultado un desarrollo descendido (incluye el funcionamiento "descendido" y "muy descendido"), un perfil esperado o un perfil destacado. Se detalla entre paréntesis el porcentaje que esa cantidad de niños representa del total de niños del nivel o del total de niños de la población del centro (línea inferior de la tabla), según corresponda. Para una lectura cualitativa de estos resultados se indica que se considera una fortaleza del nivel cuando una dimensión presenta un 35\% o más de los niños con desempeño en la categoría "destacado". Asimismo, se considerará como una debilidad de un nivel educativo cuando una dimensión presenta un 35\% o más de los niños de ese nivel con un funcionamiento en la categoría "descendido". Estas tablas se presentan para cada una de las dimensiones del desarrollo evaluadas por el INDI (C, M, S y D).

\section{$\underline{\text { Resumen detallado de funcionamiento por grupo }}$}

En este apartado del reporte se incluye el detalle de fortalezas y debilidades a nivel de los grupos del centro. Las diferentes dimensiones y componentes del INDI se distribuyen según el perfil de funcionamiento que los niños hayan obtenido como resultado para cada uno de ellos. El criterio de distribución de las categorías de "Fortalezas" y "Debilidades" sigue el mismo patrón que se mencionó en el apartado anterior. Es decir, se considera una fortaleza del grupo cuando en una dimensión o componente existe un 35\% o más de los niños del grupo con funcionamiento "destacado" y una debilidad cuando se presenta un $35 \%$ o más de los niños del grupo con funcionamiento "descendido". En la columna final sobre la derecha de la tabla se detallan los componentes para los cuales no fue posible realizar el cálculo, ya que presentan un $20 \%$ o más de los niños del grupo sin evaluar. En la Figura 5.15 puede observarse un cuadro de ejemplo de esta sección. 


\begin{tabular}{|c|c|c|c|c|c|}
\hline Nivel & Grupo & Debilidades & Esperado & Fortalezas & Sin evaluar \\
\hline 4 años & A & $\begin{array}{l}\text { Comportamiento } \\
\text { Internalizante, } \\
\text { Prosocialidad }\end{array}$ & \begin{tabular}{|c|} 
Desarrollo Cognitivo (C), \\
Disposición para el apren \\
dizaje (D), Desarrollo \\
socioemocional (S), \\
Descentramiento, \\
Comportamiento \\
Externalizante, \\
Funcionamiento \\
Ejecutivo, Lenguaje, \\
Matemática
\end{tabular} & Desarrollo motor (M) & \\
\hline 5 años & A & & \begin{tabular}{|c|} 
Desarrollo Cognitivo $(C)$, \\
Disposición para el apren \\
dizaje $(D)$, \\
Desarrollo motor $(M)$, \\
Desarrollo \\
socioemocional $(S)$, \\
Descentramiento, \\
Comportamiento \\
Externalizante, \\
Comportamiento \\
Internalizante, \\
Prosocialidad
\end{tabular} & $\begin{array}{c}\text { Funcionamiento } \\
\text { Ejecutivo, Lenguaje, } \\
\text { Matemática }\end{array}$ & \\
\hline
\end{tabular}

Figura 5.15. Cuadro de resumen de fortalezas y debilidades a nivel de los grupos en el reporte de centro.

\section{$\underline{\text { Tabla de especificación de niños que presentan descenso en alguna dimensión }}$}

En esta sección del Reporte de centro se muestra un listado de niños que tienen la particularidad de presentar alguna de las dimensiones del desarrollo evaluadas por el INDI con un perfil de funcionamiento "descendido" o "muy descendido", según los parámetros establecidos en la norma nacional de referencia. Como información relevante para el director o equipo director del centro, pero también para el trabajo con las maestras, se indica el grupo al que pertenece ese niño. Un ejemplo de esta tabla puede verse en la Figura 5.16, a continuación.

\begin{tabular}{|c|c|c|c|c|c|c|}
\hline Niño/a & Coord. MSP & Clase & Dim. C & Dim. M & Dim. S & Dim. D \\
\hline NOMBRE DEL NIÑO/A & $\checkmark$ & NI4A & MD & MD & D & \\
\hline NOMBRE DEL NIÑO/A & & NI4A & D & & D & D \\
\hline NOMBRE DEL NIÑO/A & & NI4A & & & D & \\
\hline
\end{tabular}

Figura 5.16. Tabla de especificación de niños con perfil "descendido" o "muy descendido" en alguna de las dimensiones del desarrollo evaluadas por el INDI.

Esta tabla incluye además una columna con el encabezado "Coordinación MSP" en la cual se encuentra señalado con un ícono si ese niño presenta un perfil que se corresponde con alguno de los criterios definidos para realizar una interconsulta con el sector sanitario. Uno de estos criterios refiere a la existencia de dos o las tres dimensiones C, M y $S$ evaluadas por el INDI, con un perfil de desarrollo "muy descendido" (especificado como "MD" en la tabla del reporte de centro). En el ejemplo proporcionado en la Fig. 5.16 se puede observar que el primer caso de la tabla presenta este perfil de "muy descendido" (MD) en las dimensiones cognitiva y motora cumpliendo, por tanto, con el criterio antes mencionado (ver recuadro Articulación intersectorial frente a la detección de más de un área en zona de riesgo más arriba en este capítulo para mayor detalle). Esto se encuentra indicado con el ícono $\checkmark$ en la columna designada. 
Listado de niños del Centro que cumplen con los criterios para integrar la Hoja de ruta de coordinación entre ANEP y MSP

La última sección del reporte presenta un listado de los niños del centro educativo que cumplen con alguno de los criterios asignados en la Hoja de ruta de coordinación entre ANEP y el MSP, para su atención prioritaria en el sistema sanitario. La tabla mediante la cual se brinda esta información de los niños en el reporte incluye la especificación de los dos criterios no excluyentes que pueden presentarse para que un niño sea incluido en los listados de la Hoja de ruta $(\mathrm{HdR})$ para atención prioritaria en el sistema sanitario. Como vimos en el apartado 5.2 acerca del funcionamiento de la Comisión intersectorial y la creación de la HdR, esto implica inicialmente consulta con pediatra tratante o médico referente (ver apartado Grupo de trabajo intersectorial y Hoja de ruta para la coordinación entre educación y salud en sección 5.2 de este capítulo más arriba o ver recuadro Criterios de la Hoja de ruta para la atención prioritaria de niños en el sistema sanitario más adelante por especificación de los criterios). Un ejemplo de esta sección se puede observar en la Figura 5.17.

\begin{tabular}{|l|c|c|c|}
\hline \multirow{2}{*}{ Niño/a } & \multirow{2}{*}{ Clase } & \multicolumn{2}{|c|}{ Criterios para integrar la HdR de coordinación ANEP-MSP } \\
\cline { 3 - 4 } & & Diagnóstico previo & Coocurrencia de funcionamiento MD $^{*}$ \\
\hline NOMBRE DEL NIÑO/A & NI4A & & $\checkmark$ \\
\hline NOMBRE DEL NIÑO/A & NI4A & $\checkmark$ & $\checkmark$ \\
\hline NOMBRE DEL NIÑO/A & NI4A & $\checkmark$ & $\checkmark$ \\
\hline NOMBRE DEL NIÑO/A & NI5A & & \\
\hline NOMBRE DEL NIÑO/A & NI5A & $\checkmark$ & \\
\hline NOMBRE DEL NIÑO/A & NI5A & $\checkmark$ & \\
\hline
\end{tabular}

Nota: *refiere a las dimensiones C, M y/o S

Figura 5.17. Ejemplo de tabla con listado de niños del centro que cumplen con alguno de los criterios para integrar la Hoja de Ruta $(\mathrm{HdR})$ de articulación ANEP-MSP.

\section{Criterios de la Hoja de ruta para la atención prioritaria de niños en el sistema sanitario}

Recordamos que los dos criterios no excluyentes que pueden presentarse para que un niño sea integrado en los listados de la Hoja de ruta $(\mathrm{HdR})$ para atención prioritaria en el sistema sanitario son: (1) la coocurrencia de un perfil "muy descendido" en por lo menos dos de las tres dimensiones C, M y/o S del desarrollo evaluadas por el INDI y/o (2) la preexistencia de un diagnóstico o dificultad severa que impidió realizar la evaluación con el INDI en por lo menos un área específica del desarrollo (componente o dimensión). 


\section{${ }^{* * \star A p r e n d i z a j e ~ b a s a d o}$ en el análisis de un modelo***}

Accede al Ejercicio reporte INDI de Centro en anexos de sitio web del libro, para realizar el completamiento de las etiquetas en un reporte de centro modelo.

\subsubsection{Reporte de jurisdicción}

Los reportes jurisdiccionales van dirigidos al cuerpo de Inspección Nacional (inspector zonal, departamental o nacional) y brindan una mirada global del estado de desarrollo de la población que asiste a los centros de educación inicial en esa región del país. Los distintos niveles de inspectores pueden acceder al reporte INDI de jurisdicción, de forma tal que la información allí contenida promueva acciones en variadas líneas posibles de intervención (ej. decisiones regionales y nacionales, educativas y políticas, entre otras). Para acceder a una visión completa de un Modelo de reporte INDI de Jurisdicción ver material adjunto a este libro en sitio web de INDI.

El reporte presenta inicialmente un párrafo descriptivo de la evaluación y del contexto de la misma y continúa con un apartado con información relevada de la jurisdicción (ej. cantidad y tipos de centros o distribución de la matrícula en los mismos por nivel y por grupo). En este apartado se incluye el detalle de la cantidad de niños por centro que no pudieron ser evaluados por presentar: (1) alta inasistencia durante el período regular de evaluación (señalados en la columna "Inasist.") y/o (2) un diagnóstico o dificultad severa preexistente que impidió la realización de la evaluación en por lo menos un ítem del INDI (señalados en la columna "Diag./Dif.").

\section{Tabla de Funcionamiento por dimensión}

En la siguiente sección del reporte se presenta un detalle del estado de desarrollo de los niños de la jurisdicción, según el nivel educativo al que asisten y la dimensión del desarrollo evaluada por el INDI. Un ejemplo de cómo se muestra esta información en tablas se puede observar en la Figura 5.18.

\begin{tabular}{|c|c|c|c|c|}
\hline \multicolumn{4}{|c|}{ Desarrollo Cognitivo (C) } & \multirow[b]{2}{*}{ Incompleto } \\
\hline Nivel & Descendido & Esperado & Destacado & \\
\hline $\mathrm{N} 13$ & no disponible & no disponible & no disponible & -- \\
\hline $\mathrm{N} 14$ & $161(15.45 \%)$ & $614(58.93 \%)$ & $267(25.62 \%)$ & 44 \\
\hline NI5 & $115(11.05 \%)$ & $666(63.98 \%)$ & $260(24.98 \%)$ & 12 \\
\hline Total & $276(13.25 \%)$ & $1280(61.45 \%)$ & $527(25.30 \%)$ & 56 \\
\hline
\end{tabular}

Figura 5.18. Ejemplo de tabla de caracterización de la población de la jurisdicción, por nivel educativo y dimensión del desarrollo evaluada por el INDI.

En una tabla para cada dimensión del desarrollo se detalla en números la cantidad de niños del Nivel 3, 4 o 5 del centro, que presentan los perfiles de funcionamiento 
"Descendido", "Esperado" y "Destacado", y el porcentaje que esa cantidad de niños representa del total de la población de la jurisdicción, para ese nivel educativo. En la línea inferior de la tabla se presenta el total de niños de la jurisdicción para cada perfil de desarrollo y su correspondiente porcentaje en relación a la población total de la jurisdicción. En la columna sobre la derecha se especifica la cantidad de niños por nivel y total, que presentan evaluaciones incompletas.

\section{$\underline{\text { Resumen detallado de funcionamiento por centro educativo }}$}

El siguiente apartado del reporte de jurisdicción presenta un detalle de la distribución por nivel y por centro educativo del perfil de desarrollo de los niños, para cada una de las dimensiones evaluadas por el INDI. Se detalla, asimismo, que se debe considerar una fortaleza del nivel cuando un $35 \%$ o más de los niños presenten funcionamiento en la categoría "destacado" y una debilidad cuando lo sea en la categoría "descendido / muy descendido". En la Figura 5.19. puede observarse cómo se presenta esta información en el reporte.

\begin{tabular}{|c|c|c|c|c|c|c|}
\hline \multicolumn{2}{|c|}{ Esperado } & \multicolumn{2}{|c|}{ Descendido/muy descendido } & ado (no aplica & (n S) & \\
\hline Centro & Nivel & Dimensión C & Dimensión M & Dimensión S & Dimensión [ & \\
\hline 1111 & 3 & No aplica & No aplica & No aplica & No aplica & \\
\hline 1111 & 4 & & & & & 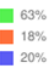 \\
\hline 1111 & 5 & & & & & 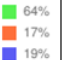 \\
\hline
\end{tabular}

Figura 5.19. Ejemplo de detalle de funcionamiento de los niños de un Centro, por nivel educativo y por dimensión del desarrollo.

\section{La categoría "Destacado" no aplica para la Dimensión S}

Para cada dimensión del desarrollo y nivel educativo el reporte muestra un gráfico de torta, identificando con un código de color los distintos perfiles de funcionamiento de los niños. Recordamos que esto se establece según el nivel de desarrollo en base a los resultados de la evaluación. Se indica con color anaranjado el perfil de niños que obtuvieron un funcionamiento "descendido" o "muy descendido" en esa área del desarrollo, con color verde quienes presentaron un funcionamiento "esperado" y en color azul se señala el porcentaje de niños que muestran un funcionamiento "destacado" en esa área del desarrollo. Los gráficos presentan entonces el porcentaje de la población del nivel para cada uno de los perfiles en las distintas dimensiones del desarrollo. 


\section{Mapas de calor por nivel de riesgo y dimensión del desarrollo}

En la siguiente sección del reporte se presenta un mapa de la jurisdicción para cada dimensión del desarrollo evaluada por el INDI (C, M, $S$ y D). En estos mapas se pueden observar indicadores para los diferentes centros educativos de la jurisdicción que presentan algún nivel de riesgo en esa área del desarrollo. Los distintos parámetros de riesgo se calculan según la cantidad de niños del centro que presentan un perfil "descendido" o "muy descendido" para esa área del desarrollo, según los resultados de la evaluación.

El porcentaje total sobre el cual se calculan los distintos perfiles por dimensión se basa en la cantidad de niños cuyas evaluaciones para esa dimensión se encuentran COMPLETAS.

Para su representación gráfica se establece un código de color cuyo detalle se puede observar en la Figura 5.20.

\footnotetext{
Entre el 30 y el $45 \%$ de los/as niños/as del centro presentan funcionamiento descendido o muy descendido en esta dimensión. Entre el 46 y el $60 \%$ de los/as niños/as del centro presentan funcionamiento descendido o muy descendido en esta dimensión. Entre el 61 y el $75 \%$ de los/as niños/as del centro presentan funcionamiento descendido o muy descendido en esta dimensión. Más del $75 \%$ de los/as niños/as del centro presentan funcionamiento descendido o muy descendido en esta dimensión.
}

Figura 5.20. Código de colores que determina el nivel de riesgo para un centro para cada una de las dimensiones evaluadas.

\section{Listado de niños de la jurisdicción que cumplen con los criterios para integrar la Hoja} de ruta de coordinación entre ANEP y MSP

La última sección del reporte presenta, al igual que el reporte de Centro, el listado de los niños que cumplen con alguno de los criterios asignados en la Hoja de ruta (HdR) de coordinación entre ANEP y el MSP, para su atención prioritaria en el sistema sanitario (ver apartado Grupo de trabajo intersectorial y Hoja de ruta para la coordinación entre educación y salud en sección 5.2 de este capítulo por mayor información). En esta oportunidad se detalla esta información para los niños de la jurisdicción completa, especificando el centro y la clase a la que pertenecen.

La tabla mediante la cual se brinda esta información de los niños en el reporte de jurisdicción incluye la especificación de los dos criterios no excluyentes que pueden presentarse para que un niño sea integrado en los listados de la Hoja de ruta (HdR) para atención prioritaria en el sistema sanitario (ver recuadro Criterios de la Hoja de ruta para la atención prioritaria de niños en el sistema sanitario). Un ejemplo de esta sección se puede observar en la Figura 5.21. 


\begin{tabular}{|c|c|c|c|c|}
\hline \multirow[t]{2}{*}{ Niño/a } & \multirow[t]{2}{*}{ Centro } & \multirow[t]{2}{*}{ Clase } & \multicolumn{2}{|c|}{ Criterios para integrar la HdR de coordinación ANEP-MSP } \\
\hline & & & Diagnóstico previo & Coocurrencia de MD' \\
\hline NOMBRE DEL NINNO/A & 000 & NI4A & & $\checkmark$ \\
\hline NOMBRE DEL NIÑO/A & 111 & NI4A & $\checkmark$ & \\
\hline NOMBRE DEL NIÑO/A & 222 & NI5A & $\checkmark$ & $\checkmark$ \\
\hline \multicolumn{5}{|l|}{ NOMBRE DEL NINNO/A } \\
\hline \multicolumn{5}{|l|}{ NOMBRE DEL NIÑO/A } \\
\hline NOMBRE DEL NIÑO/A & & & & \\
\hline
\end{tabular}

Figura 5.21. Ejemplo de tabla con listado de niños de la jurisdicción que cumplen con alguno de los criterios para integrar la Hoja de Ruta $(\mathrm{HdR})$ de articulación ANEP-MSP.

***INICIO RECUADRO***

Aprendizaje basado en el análisis de un modelo:

Accede al Ejercicio reporte INDI de jurisdicción en anexos de sitio web del libro, para realizar el completamiento de las etiquetas en un reporte modelo de este tipo.

${ }^{* * *}$ FIN RECUADRO*** 


\title{
Capítulo 6.
}

\section{El INDI y su relación con otros documentos uruguayos de referencia en primera infancia. Análisis Comparativo ${ }^{10}$}

\author{
Clementina Tomás y Alejandro Vásquez Echeverría
}

\section{Objetivos de aprendizaje}

Al finalizar este capítulo el lector será capaz de:

1. Situar al INDI en función de otros documentos rectores para el trabajo en la primera infancia en nuestro país.

2. Identificar las convergencias y divergencias entre los contenidos incluidos en documentos oficiales a nivel educativo (Marco curricular y Programa escolar) y el INDI, para el caso de la Educación inicial.

3. Visualizar puntos de correspondencia entre los indicadores evaluados en la GNVD V2 administrada en el ámbito sanitario y el INDI.

\section{Ideas fuerza}

- El INDI no tiene por objetivo evaluar la labor docente en la enseñanza de contenidos curriculares.

- Poner en diálogo las funciones del desarrollo evaluadas en el INDI y los lineamientos curriculares nacionales permite pensar el rol del desarrollo en los procesos educativos y facilita la incorporación de la evaluación en la planificación educativa.

- La GNVD V.2 es un instrumento de tamizaje del desarrollo aplicado en el ámbito sanitario.

- El análisis complementario a través de distintas fuentes de información (INDI y la GNVD V.2) puede potenciar la detección de segmentos de población que requieren atención prioritaria, y para la protocolización de acciones coordinadas a nivel educativo y sanitario.

10 Este capítulo tiene como antecedente las tablas de convergencia del INDI 4 y 5 (versiones previas) con el Marco curricular, el Programa escolar, y la GNVD V.1, desarrolladas oportunamente junto a Karen Moreira. 


\subsection{Contextualización del INDI en relación a otros marcos rectores del trabajo en primera infancia}

El INDI se inserta en el contexto educativo nacional como una política de evaluación sistemática del desarrollo infantil. Es por ello de suma relevancia conocer su nivel de articulación temática con dos de los documentos rectores a nivel curricular en el marco de la Educación inicial en nuestro país: el Marco Curricular para la atención y educación de niños y niñas uruguayos desde el nacimiento a los 6 años (en adelante Marco curricular; UCC CCEPI, 2014) y el Programa de educación inicial y Primaria (en adelante Programa escolar; ANEP-CEIP, 2008). Por otra parte, de acuerdo al aporte que representa la evaluación multiinformante para el estudio del desarrollo, y su potencial para la detección y mejor delimitación de perfiles de riesgo, resulta particularmente pertinente el análisis de congruencia de contenidos del INDI y la Guía Nacional para la vigilancia del Desarrollo del niño y la niña menores de 5 años (en adelante GNVD V.2; MSP, 2018). La GNVD V.2 es administrada en el contexto de la consulta pediátrica, coincidiendo con el INDI en su función de tamizaje respecto a una misma población objetivo.

Por lo antedicho, este capítulo tiene por objetivo analizar los niveles de convergencia entre el INDI y el Marco curricular, el Programa escolar y la GNVD V.2, a través de una revisión comparada. Este análisis se centró en la búsqueda de correspondencias en la operacionalización de las dimensiones y los contenidos de cada documento. Dadas las características y fines específicos de cada uno, la expectativa en torno a este análisis es identificar puntos de articulación más que tender hacia una correspondencia plena, así como distinguir las áreas para las cuales no se observan solapamientos. Como ejemplo de esto último, señalamos que el INDI incluye indicadores del desarrollo no necesariamente identificables como contenidos de aprendizaje en sí mismos, a diferencia de lo que ocurre con el Programa escolar, en tanto instrumento concebido para orientar las acciones educativas. Para el caso de la GNVD V.2, las especificidades del contexto sanitario para la evaluación del desarrollo, en comparación al contexto educativo, también explican algunas de las diferencias en los contenidos.

De modo de procurar la validez del estudio comparativo que a continuación se presenta, los apartados referidos al Marco curricular y al Programa escolar fueron revisados por profesionales de la educación con conocimiento del INDI, externos al equipo de investigación. Un miembro del equipo de investigación y un médico pediatra involucrado en el proceso de diseño e implementación de la GNVD V.2 emitieron su juicio respecto al apartado referido a la GNVD V.2. En todos los casos los juicios fueron independientes, y los autores consideraron estas observaciones para arribar a la versión aquí presentada ${ }^{11}$.

\footnotetext{
${ }^{11}$ Agradecemos especialmente la revisión de los contenidos de este capítulo realizada por Tania Presa (Marco curricular y Programa escolar), Maite Liz y Mercedes Pérez (GNVD V.2).
} 


\subsection{Marco Curricular para la atención y educación de niñas y niños uruguayos desde el nacimiento hasta los seis años}

El Marco Curricular es producto de un esfuerzo interinstitucional de articulación de los diseños curriculares existentes en primera infancia en Uruguay para los tramos educativos hasta los 3 años de edad (Diseño curricular básico para niños y niñas de 0 a 36 meses; MEC, 2006) y a partir de los 3 años (Programa de Educación Inicial y Primaria; ANEP-CEIP, 2008). Este documento funciona como marco referencial amplio para asegurar la coherencia y progresión curricular en la etapa inicial del ciclo vital, así como la mejora de la calidad de las acciones orientadas a la primera infancia. En este sentido el documento se presenta como lineamiento transversal a distintas instituciones y agentes -familia, docentes, actores comunitarios- (UCC - CCEPI, 2014).

De modo inicial, el Marco curricular introduce las siguientes ideas-fuerza para la atención y educación en esta etapa: (a) el niño como sujeto de derechos, (b) la familia como primer entorno educador, (c) la primera infancia como etapa fundante en el ciclo vital, (d) los principios pedagógicos y metodológicos propios de la educación en la primera infancia, y (e) el adulto como figura facilitadora del desarrollo y promotor de los aprendizajes (UCC CCEPI, 2014). Desde el punto de vista de su estructura, se delimitan cuatro áreas: Conocimiento de sí mismo, Comunicación, Conocimiento del ambiente y Bienestar integral. Para cada área se presentan ejes que agrupan competencias específicas de complejidad creciente. Propone asimismo un conjunto de competencias generales referentes al desarrollo infantil y los aprendizajes, de carácter transversal.

Para el análisis comparativo, se identificaron aquellos componentes del INDI involucrados en cada una de las competencias generales enunciadas en el Marco Curricular, como luce en la Tabla 6.1. Como se puede observar, cada competencia general adscribe a una combinación de componentes del desarrollo evaluados en el INDI, siendo particularmente destacable la presencia de elementos recogidos en los componentes Lenguaje, Habilidades lógico-matemáticas, los componentes socioemocionales y la dimensión Disposición para el aprendizaje del INDI.

Por su parte, a través del análisis de los objetivos generales correspondientes a los distintos ejes del Marco curricular, se observa que para la dimensión Desarrollo cognitivo del INDI, las congruencias refieren a los ejes Expresión y creatividad y Lenguaje pre verbal y verbal respecto al componente Lenguaje del INDI, eje Relaciones lógico-matemáticas respecto al componente Habilidades lógico-matemáticas del INDI, y eje Vida diaria en relación respecto a Funcionamiento ejecutivo del INDI. Por otra parte, asociados a la dimensión Desarrollo Motor del INDI, se identifican los ejes Corporeidad y Lenguaje preverbal y verbal del Marco. De modo general, el mayor nivel de congruencia se observa entre los ejes Identidad, Pertenencia, Expresión y creatividad, Contexto social y cultural, Vida diaria en relación, Convivencia y Espacio-ambiente respecto a los componentes socioemocionales y la dimensión Disposición para el aprendizaje del INDI. Para ésta última se observan adicionalmente correspondencias respecto a los ejes Autonomía y Contexto natural del Marco curricular. Cabe destacar que no se encontraron en cambio correspondencias directas entre el eje Lenguaje multimedial -cuyo objetivo es favorecer la 
comunicación mediada por distintas tecnologías- e indicadores específicos del INDI. EI detalle de estos contenidos se ofrece en la Tabla 6.2.

Lo anterior se complementa a través del análisis detallado de las competencias específicas descritas para las distintas áreas y ejes del Marco Curricular. Para el área Conocimiento de sí mismo se observa una fuerte presencia de componentes cognitivos del INDI (subescalas Lenguaje y Funcionamiento ejecutivo), componentes de Desarrollo socioemocional y de la dimensión Disposición para el aprendizaje. Para el área Comunicación la correspondencia preponderante es respecto a los componentes Lenguaje y Descentramiento del INDI, seguido de la dimensión Disposición para el aprendizaje, y en menor medida Desarrollo motor. Para el área Conocimiento del ambiente las correspondencias también se localizan mayoritariamente con respecto a la dimensión Cognitiva del INDI, con mayor preponderancia del componente Habilidades lógico matemáticas como cabe esperar en relación a los objetivos específicos del eje Relaciones lógico matemáticas que integra esta área. Por otra parte, cuando se analizan los objetivos específicos del área Bienestar integral, se encuentra mayor congruencia con las dimensiones Disposición para el aprendizaje y Socioemocional del INDI, seguido de los componentes cognitivos Funcionamiento ejecutivo y Descentramiento. El detalle del análisis según objetivos específicos del Marco curricular puede ser consultado en la Tabla Correspondencia objetivos específicos del Marco curricular - INDI, que está disponible en el sitio web de compañía de este libro.

Para concluir, considerando tanto los objetivos generales como específicos enunciados en el Marco curricular, se destaca que el INDI recupera buena parte de los lineamientos establecidos. Las correspondencias se observan en mayor medida a través de los componentes Descentramiento y Funcionamiento ejecutivo de la dimensión Cognitiva, y las dimensiones de Desarrollo socioemocional y Disposición para el aprendizaje. 
Tabla 6.1

Correspondencia de las competencias generales enunciadas en el Marco curricular (UCC - CCEPI, 2014) respecto a las dimensiones y componentes del INDI

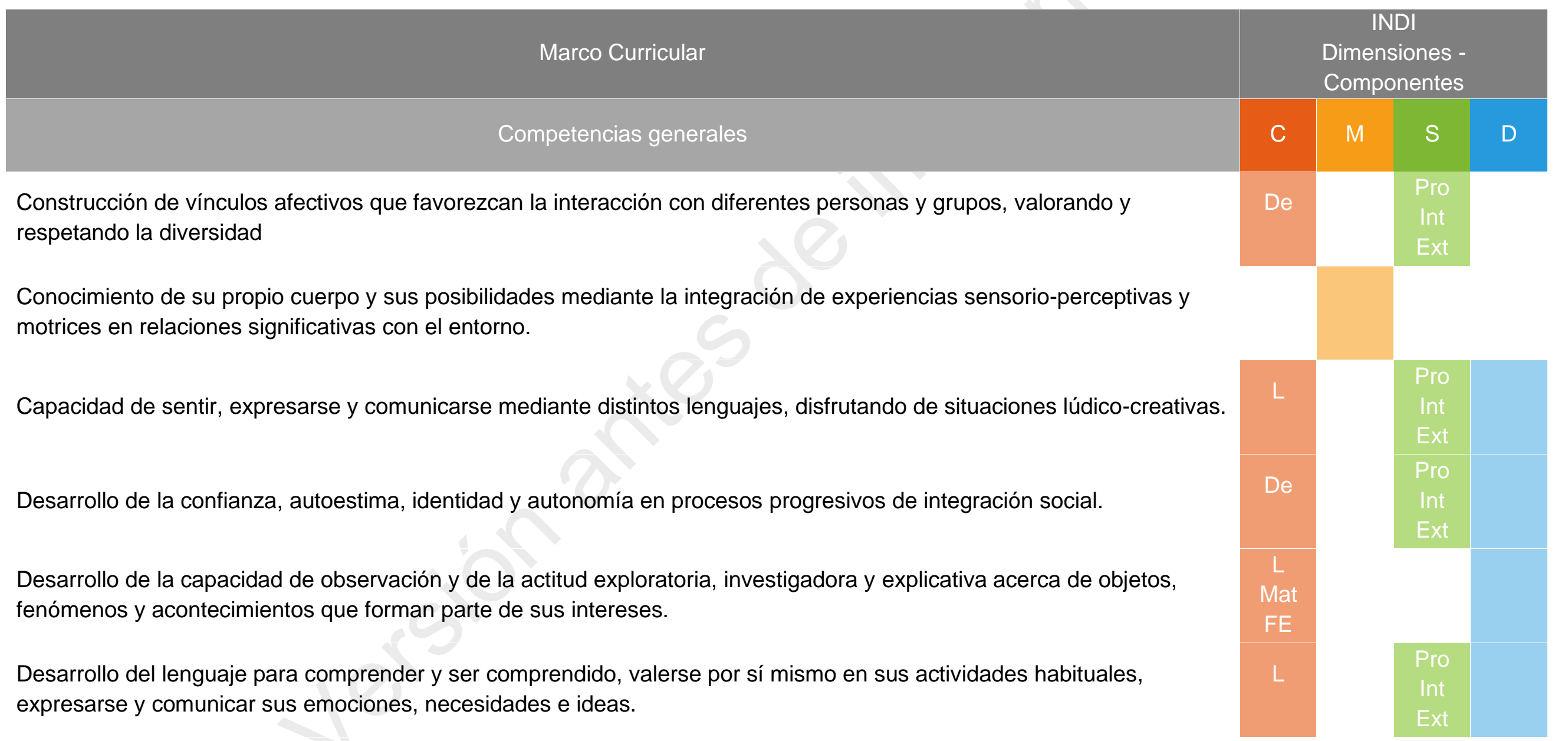


Identificación, comprensión y apropiación de diferentes tipos de símbolos, signos y códigos significativos para sí mismo y su vida en relación.

Descubrimiento, valoración y construcción personal de la lengua escrita, iniciando el proceso de apropiación de la escritura, a partir de su curiosidad, intereses y necesidades.

Construcción de relaciones y nociones lógico-matemáticas en interacción con los objetos, y en contextos significativos, aplicando un lenguaje específico y pertinente de forma paulatina.

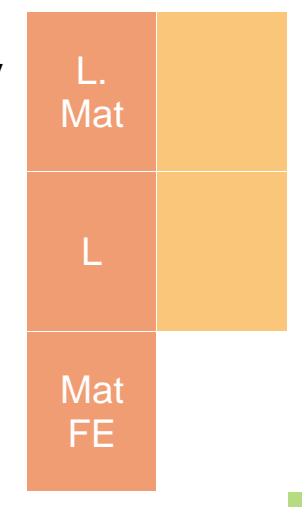

Desarrollo progresivo de habilidades y actitudes que promuevan estilos de vida saludables avanzando desde el cuidado hacia el autocuidado.

Identificación creciente de prácticas, estados, características y condiciones personales y ambientales que contribuyen a la conservación de la salud mejorando la calidad de vida.

Construcción progresiva de su ciudadanía en un marco de valores que contribuyan a la inclusión, la convivencia y el bien común.

Nota. $\mathrm{C}=$ Cognitiva. $\mathrm{M}=$ Motor. $\mathrm{S}=$ Socioemocional. $\mathrm{D}=$ Disposición para el aprendizaje. $\mathrm{L}=$ Lenguaje. Mat=Matemáticas. De=Descentramiento. $\mathrm{FE}=\mathrm{Funcionamiento}$ ejecutivo. Pro=Prosocial. Int=Internalizante. Ext=Externalizante. 
Tabla 6.2

Correspondencia de los objetivos generales según eje del Marco curricular (UCC-CCEPI, 2014) respecto a las dimensiones y componentes del INDI

\begin{tabular}{|c|c|c|c|c|c|}
\hline \multicolumn{2}{|r|}{ Marco Curricular } & \multicolumn{4}{|c|}{$\begin{array}{c}\text { INDI } \\
\text { Dimensiones - Componentes }\end{array}$} \\
\hline Eje & Objetivo & $\mathrm{C}$ & $\mathrm{M}$ & S & $\mathrm{D}$ \\
\hline Corporeidad & $\begin{array}{l}\text { Favorecer en cada niño/niña el conocimiento de su cuerpo y sus posibilidades, promoviendo el } \\
\text { dominio progresivo de las capacidades que le permiten interactuar vivencialmente consigo mismo, } \\
\text { con otras personas y con los objetos y elementos que conforman su entorno. }\end{array}$ & & & & \\
\hline Identidad & $\begin{array}{l}\text { Promover el proceso de construcción de la identidad personal por el cual niños y niñas desarrollan } \\
\text { su autoestima, reconociéndose como sujetos en una trama vincular que los habilita } \\
\text { progresivamente a ser parte de grupos más amplios. }\end{array}$ & De & & $\begin{array}{l}\text { Pro } \\
\text { Int } \\
\text { Ext }\end{array}$ & \\
\hline Autonomía & $\begin{array}{l}\text { Facilitar en niños y niñas la conquista de la autonomía progresiva para valerse por sí mismos en } \\
\text { todos los planos de forma activa con la seguridad y la confianza necesarias para la exploración } \\
\text { cada vez más compleja e interesante del entorno. }\end{array}$ & & & & \\
\hline Pertenencia & $\begin{array}{l}\text { Fortalecer sentimientos de pertenencia del niño/niña a una familia y a otros grupos humanos con } \\
\text { los cuales comparte y construye valores, costumbres y tradiciones generando lazos afectivos y } \\
\text { sociales. }\end{array}$ & & & $\begin{array}{l}\text { Pro } \\
\text { Int } \\
\text { Ext }\end{array}$ & \\
\hline $\begin{array}{l}\text { Expresión y } \\
\text { creatividad }\end{array}$ & $\begin{array}{l}\text { Promover exploraciones sensoperceptivas y experiencias afectivas, sociales y cognitivas que } \\
\text { habiliten y fomenten las potencialidades expresivas y creativas de los niños y niñas fortaleciendo } \\
\text { su singularidad, su autoconfianza y su autoestima. }\end{array}$ & L & & $\begin{array}{l}\text { Pro } \\
\text { Int } \\
\text { Ext }\end{array}$ & \\
\hline $\begin{array}{l}\text { Lenguaje pre } \\
\text { verbal y verbal }\end{array}$ & $\begin{array}{l}\text { Favorecer la progresiva ampliación de intenciones, contextos y contenidos de la comunicación } \\
\text { utilizando los lenguajes pre-verbal y verbal en interacción con diversos interlocutores mediante } \\
\text { gestos, sonidos, balbuceos, palabras, grafismos, dibujos y escrituras. }\end{array}$ & L & & & \\
\hline
\end{tabular}




\section{Lenguaje}

multimedial

Contexto social

y cultural

Contexto natural

\section{Relaciones}

lógico

matemáticas

\section{Vida diaria en} relación

\section{Convivencia}

\section{Espacio ambiente}

Favorecer la comunicación mediada por la tecnología en contextos de revalorización de los vínculos humanos utilizando diversos recursos multimediales.

Comprende los aprendizajes relacionados con sentirse parte de un contexto humano y físico al cual pertenece, asumiendo conocimientos y roles que le permitan interactuar, valorar, expresar y apropiarse de forma creativa de su cultura, respetando al mismo tiempo las de otros niños, niñas y comunidades.

Promover el interés por descubrir, investigar, conocer y comprender el mundo natural y físico desarrollando habilidades de observación, de exploración, de experimentación y de cuidado del ambiente.

Promover la construcción de relaciones lógico matemáticas favoreciendo su acción sobre los objetos que le permitan resolver problemas cotidianos e incorporar gradualmente el lenguaje matemático en sus actividades de juego.

Promover en niños y niñas la identificación y satisfacción de sus necesidades, favoreciendo los procesos de aprendizaje y autorregulación en acciones de su vida diaria relacionadas con las emociones, la alimentación, el descanso, la higiene, la seguridad personal.

Favorecer en niñas y niños la inserción activa y placentera a los grupos sociales de referencia manifestando su singularidad en relación con otros en procesos crecientes de comprensión e incorporación de rutinas, pautas, reglas y límites.

Promover la internalización de conductas de cuidado y respeto por los diferentes espacios y ambientes en los que desarrolla su vida, habitando los mismos con iniciativa y creatividad.
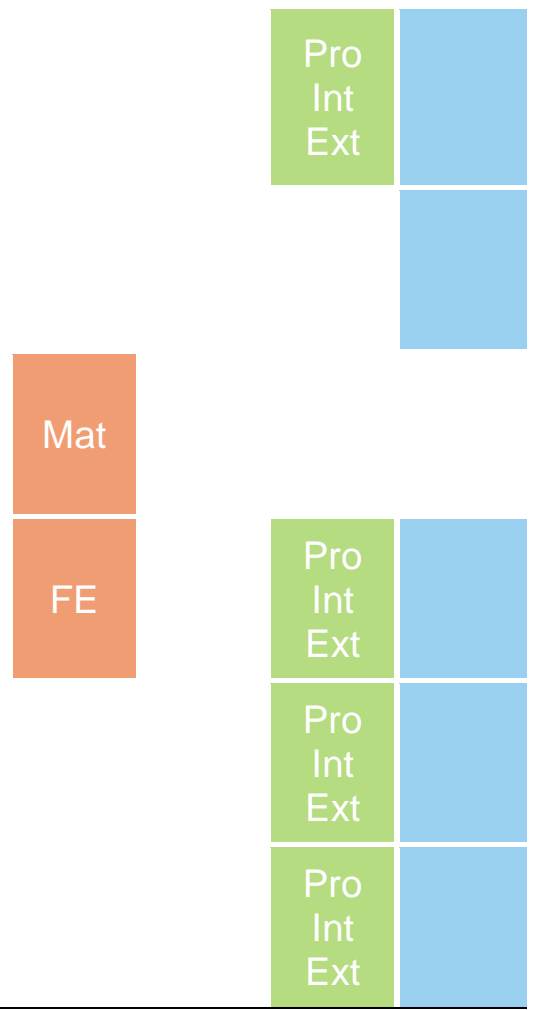

Nota. $\mathrm{C}=$ Cognitiva. $\mathrm{M}=$ Motor. $\mathrm{S}=$ Socioemocional. $\mathrm{D}=$ Disposición para el aprendizaje. $\mathrm{L}=$ Lenguaje. Mat=Matemáticas. De=Descentramiento. $\mathrm{FE}=$ Funcionamiento ejecutivo. Pro=Prosocial. Int=Internalizante. Ext=Externalizante. 


\subsection{Programa de Educación Inicial y Primaria}

El Programa escolar (ANEP-CEIP, 2008) reúne los contenidos curriculares a ser ofrecidos como contenidos de enseñanza a lo largo de los ciclos de Educación inicial y Educación primaria, con el objetivo de regular la práctica educativa en jardines, escuelas públicas y colegios privados habilitados de nuestro país. Su creación tuvo como propósito unificar los programas de Educación inicial, común, rural y especial bajo los lineamientos de una política educativa general, y un programa único y centrado en los Derechos Humanos. Desde el punto de vista de los contenidos programáticos, este documento se estructura en seis áreas de conocimiento: Lenguas, Matemáticas, Artística, Social, de la Naturaleza y Corporal. Cada área de conocimiento se conforma en función de disciplinas (por ejemplo, para el Área Conocimiento de la Naturaleza disciplinas tales como Astronomía, Geología, etc.), a través de las cuales se organizan y secuencian los contenidos de enseñanza desde Nivel 3 de Educación inicial hasta 6to año de Educación primaria.

El análisis comparativo respecto al INDI se basó en los contenidos programáticos especificados para los Niveles 3, 4 y 5 de Educación inicial. En tanto el INDI se compone de indicadores del desarrollo observables en términos de rasgos y conductas, el ejercicio consistió en asociar los contenidos de enseñanza a las habilidades y funciones evaluadas en el INDI. Como fue enunciado anteriormente, esto implica necesariamente reconocer los límites de contrastar indicadores de desarrollo y contenidos de aprendizaje.

Cabe destacar que, a partir de este análisis, se observa que los mayores niveles de correspondencia se encuentran en relación al área de conocimiento de Lenguas con respecto al componente Lenguaje del INDI, así como el área del conocimiento Matemático con respecto al componente Habilidades lógico-matemáticas de la dimensión Cognitiva del INDI. En relación al área del Conocimiento artístico, específicamente en lo que respecta a la disciplina Expresión Corporal, se encontraron algunas correspondencias con ítems de motricidad gruesa del INDI. Para la disciplina Teatro se identificaron requerimientos vinculados a la capacidad de descentramiento evaluada a través del INDI -en particular los ítems que refieren a juego socio-dramático-, así como respecto a la dimensión Socioemocional, de acuerdo a los requerimientos de interacción colectiva que caracterizan la disciplina. Por otra parte, para la disciplina Literatura las correspondencias refieren fundamentalmente al componente Lenguaje del INDI, aunque esta vez enmarcados en el trabajo sobre géneros literarios específicamente señalados.

En lo que respecta al área de Conocimiento Social, las disciplinas que presentaron mayores correspondencias con indicadores del INDI fueron Historia y Construcción de Ciudadanía. En el primer caso la correspondencia se observa en relación a las habilidades de descentramiento del INDI, en particular para aquellos contenidos programáticos que refieren a la percepción del tiempo, su periodización, así como los requerimientos cognitivos necesarios para acceder a los contenidos históricos propiamente dichos. En el segundo caso, las correspondencias refieren especialmente a los contenidos programáticos que incitan a la reflexión en torno a la convivencia en los espacios cotidianos, involucrando nuevamente habilidades de descentramiento, habilidades socioemocionales y de disposición para el aprendizaje recogidos en el INDI. Por su parte, no se encontraron correspondencias directas entre indicadores del INDI y los contenidos del Área del 
Conocimiento de la Naturaleza del Programa escolar. Este es un aspecto previsible si consideramos que es un área que porta un nivel de especificidad alto en la formulación de sus contenidos -en su mayoría formulado en términos de contenidos científicos-, que lo distancia de la formulación de los indicadores del INDI. Aun así, esto en ningún caso descarta que las competencias evaluadas en el INDI sienten las bases para el acceso a este tipo de conocimiento.

En las Tablas $6.3,6.4$ y 6.5 se presenta la revisión comparativa entre el INDI y el Programa escolar para los tres niveles de Educación inicial. 
Tabla 6.3

Convergencias identificadas entre el Programa escolar (Nivel 3 años) y el INDI en su versión para Nivel 3 de Educación inicial

\begin{tabular}{|c|c|c|c|c|c|c|}
\hline \multirow{2}{*}{ Área y disciplina } & \multirow{2}{*}{ Contenido curricular } & \multirow{2}{*}{ Ítems } & \multicolumn{4}{|c|}{$\begin{array}{l}\text { Dimensiones - } \\
\text { Componentes }\end{array}$} \\
\hline & & & $\mathrm{C}$ & $M$ & $\varsigma$ & $\mathrm{D}$ \\
\hline
\end{tabular}

\section{Conocimiento de Lenguas}

Oralidad La narración de vivencias.

La narración en los cuentos.

La descripción del personaje principal en los

cuentos.

La conversación sobre textos de interés científico

con apoyo icónico.

Las opiniones en situaciones cotidianas: entre pares y en clase.

Las fórmulas de cortesía en el contexto escolar.

Lectura

\section{La anticipación icónica.}

Las inferencias a partir de elementos paratextuales en textos de información.

La ampliación del reservorio lingüístico: la memorización de nanas.

\section{C1 Comprende cuento \\ C2 Cuenta historia}

C21 Infiere emociones 


\section{Geometría Los polígonos y no polígonos. \\ La composición de figuras.}

C18 Identifica cuadrado, etc.

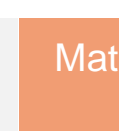

\section{Conocimiento Artístico}

Artes Visuales El color. Los colores primarios.

Expresión corporal

Teatro El reconocimiento del cuerpo.
Los límites y las dimensiones del espacio físico.

La representación de roles de la vida familiar. El juego de interacción con objetos en forma individual.

El cuento de tradición oral.

Las nanas, las rondas y las rimas

\section{C5 Identifica colores}

M5 Camina línea recta

M6 Salta (un pie)

M7 Lanza, recibe pelota

C19 Juego (uso simbólico objetos) C21 Infiere emociones

C1 Comprende cuento

C2 Cuenta historia

C6 Memoriza canciones

\section{Conocimiento de la Naturaleza}

Física

$$
\text { Los colores sustractivos. }
$$

C5 Identifica colores

\section{Conocimiento Social}

Historia La sucesión y ordenación del tiempo en las actividades cotidianas.

Construcción Las condiciones que posibilitan y obstaculizan la de ciudadanía - Ética

\section{convivencia. - El conflicto como parte de la vida} social.

- El lugar personal, el lugar del "otro" y de "nosotros".

\section{C20 Comenta momento pasado}

S1-S13 (Buen relacionamiento, Ayuda, Evita relacionarse, Aislado, Agrede, Expresión emocional

asertiva, Comparte, Atento a otros,

Tímido, Triste, preocupado,

Desafiante, Frustrado, enojado)
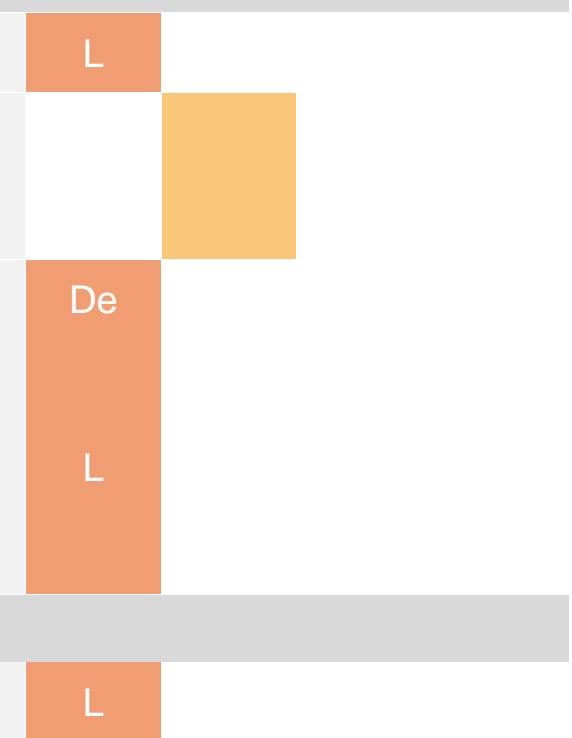

Nota. $\mathrm{C}=$ Cognitiva. $\mathrm{M}=$ Motor. $\mathrm{S}=$ Socioemocional. $\mathrm{D}=$ Disposición para el aprendizaje. $\mathrm{L}=\mathrm{L}$ enguaje. Mat=Matemáticas. De=Descentramiento. FE=Funcionamiento ejecutivo. Pro=Prosocial. Int=Internalizante. Ext=Externalizante. Los códigos de ítems del INDI corresponden a la versión para Nivel 4-5. 
Tabla 6.4

Convergencias identificadas entre el Programa escolar (Nivel 4 años) y el INDI en su versión para los Niveles 4 y 5 de Educación inicial

\begin{tabular}{|c|c|c|c|c|c|c|}
\hline \multirow{2}{*}{ Área y disciplina } & \multirow{2}{*}{ Contenido curricular } & \multirow{2}{*}{ Ítems } & \multicolumn{4}{|c|}{$\begin{array}{l}\text { Dimensiones - } \\
\text { Componentes }\end{array}$} \\
\hline & & & C & M & $\S$ & D \\
\hline
\end{tabular}

\section{Conocimiento de Lenguas}

Oralidad Las narraciones de anécdotas.

La organización en el cuento: marco, complicación

y resolución.

Los nexos temporales en la narración oral (al otro

día, al día siguiente, un día).

La descripción de: - La ubicación espacio temporal.

Lectura

Las inferencias textuales. - El tema global del cuento.

Las inferencias a partir de elementos

paratextuales.

La ampliación del reservorio lingüístico: la

memorización de rimas.

El nombre propio.

La secuencia nominal. - Lista de palabras.
C1 Comprende cuento

C2 Cuenta historia

C15 Nociones temporales

C1 Comprende cuento

C2 Cuenta historia

C3 Forma palabras nuevas

C4 Sílaba final

C8 Sonido final

C10 Escribe palabras

\section{Conocimiento Matemático}

Numeración

La relación entre cantidades.

La serie numérica oral (mínimo hasta 10).

Los números naturales (mínimo hasta 10).

Operaciones
La adición y la sustracción en contexto lúdico.

El cálculo pensado con dígitos.
C7 Identifica número mayor

C12 Reconoce doble

C6 Serie numérica

C5 Reconoce números

C11 Suma

C12 Reconoce doble
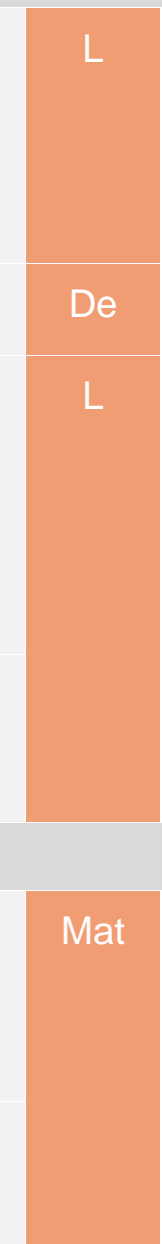
Geometría

El dibujo a "mano alzada" de polígonos.

C13 Dibuja figuras geométricas

Conocimiento Artístico

Artes Visuales Los colores secundarios.

Expresión

Corporal

Teatro

Literatura El cuento maravilloso.

Las jitanjáforas.

Las estructuras lúdicas: los trabalenguas.

\section{C14 Identifica colores}

M3 Camina línea recta M4 Salta (un pie) movimientos.

El reconocimiento y movimientos de las extremidades del cuerpo.

La representación de roles de la vida real. El juego de interacción en forma colectiva.
C22 Juego (roles adultos) C26 Juego (planificación)

C21 Reconoce puntos de vista S1-S14 (Buen relacionamiento, Ayuda, Evita relacionarse, Aprensivo, Agrede, Expresión emocional asertiva, Comparte, Atento a otros, Tímido, Triste, preocupado, Desafiante, Frustrado, enojado, Aislado) D4 Creativo

C1 Comprende cuento

C2 Cuenta historia

C3 Forma palabras nuevas

C4 Sílaba final

C8 Sonido final

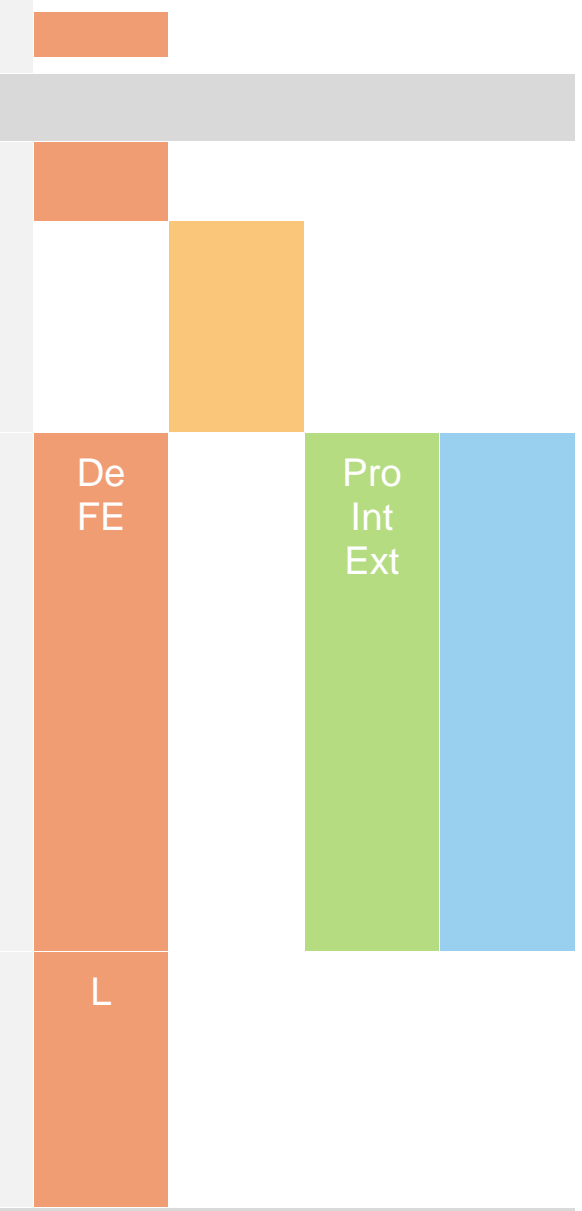

\section{Conocimiento de la Naturaleza}

Física

Los colores sustractivos secundarios.

\section{C14 Identifica colores}

C15 Nociones temporales

C17 Se anticipa del niño y en los objetos.

La duración del tiempo en la vida cotidiana. - Las costumbres familiares en el día y en la semana.
C20 Comenta momento pasado

C16 Sabe día y momento
De

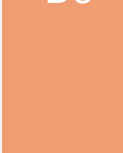


La periodización del tiempo: día, semana.

Las identidades a través de los juegos de roles.

Geografía El espacio cercano: - La representación gráfica de recorridos y mojones.

Construcción Las relaciones en la convivencia social: - La de ciudadanía identificación de conflictos en el aula.

- Ética

La convivencia en el hogar en la escuela. - Las palabras que ayudan en la convivencia ("por favor", "gracias").

Construcción Las reglas en el hogar y en la escuela.

de ciudadanía -

Derecho
C22 Juego (roles adultos)

M3 Camina línea recta M4 Salta (un pie)

C21 Reconoce puntos de vista C18 Diferentes estrategias resolución

S1-S14

C23 Espera por algo

C25 Espera turnos

S1-S14

D2 Adaptación rutinas

C23 Espera por algo

C25 Espera turnos

S1Buen relacionamiento

S5 Agrede físicamente

S6 Agrede verbalmente

S12 Desafiante

D2 Adaptación rutinas

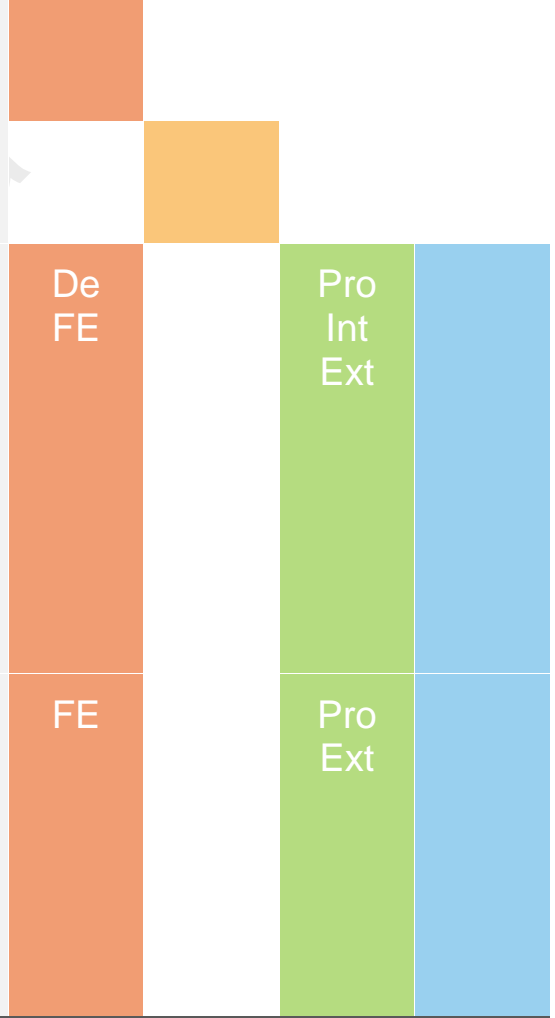

Nota. $\mathrm{C}=$ Cognitiva. $\mathrm{M}=$ Motor. S=Socioemocional. D=Disposición para el aprendizaje. L=Lenguaje. Mat=Matemáticas. De=Descentramiento. $\mathrm{FE}=$ Funcionamiento ejecutivo. Pro=Prosocial. Int=Internalizante. Ext=Externalizante. Los códigos de ítems del INDI corresponden a la versión para Nivel 4-5. (Esta nota también aplica para la tabla 6.5) 
Tabla 6.5

Convergencias identificadas entre el Programa escolar (Nivel 5 años) y el INDI en su versión para los Niveles 4 y 5 de Educación inicial

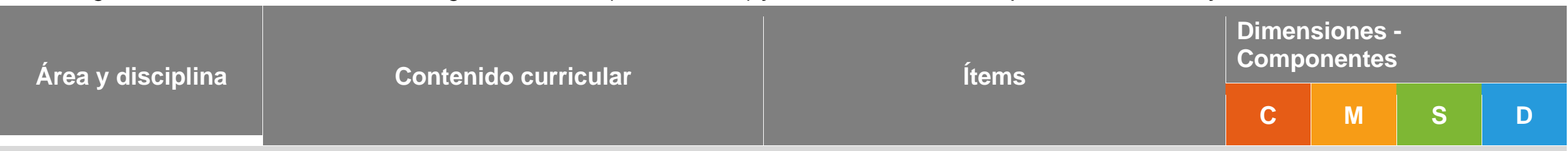

\section{Conocimiento de Lenguas}

Oralidad La narración de cuentos tradicionales. - La creación de cuentos a partir de personajes. El diálogo en el juego de roles.

C1 Comprende cuento

C2 Cuenta historia

C22 Juego (roles adultos)

C1 Comprende cuento

C2 Cuenta historia

C9 Sonido letras

C10 Escribe palabras

\section{Conocimiento matemático}

\section{Naturales La serie numérica oral (mínimo hasta 30).}

La relación de orden (mayor, menor e igual). La composición y descomposición aditiva de cantidades.

Las relaciones anterior, siguiente.

Racionales

La noción de mitad y mitades.

La representación numérica.

Operaciones La adición y la sustracción en contextos matemáticos.

El cálculo pensado. - El anterior y siguiente. - Los dobles.

Geometría polígonos.

C6 Serie numérica

C7 Identifica número mayor

C11 Suma

C12 Reconoce doble

C12 Reconoce doble

C5 Reconoce números

C11 Suma

C7 Identifica número mayor

C12 Reconoce doble

C13 Dibuja figuras geométricas 


\section{Conocimiento artístico}

Expresión Los cambios de dirección y sentido en los corporal desplazamientos espaciales.

El cuerpo y los movimientos corporales. Las posibilidades de movimiento de las articulaciones y los puntos de apoyo.

Literatura

El cuento tradicional: versión original y otras. Los limericks, las retahílas y las coplas.
M3 Camina línea recta M4 Salta (un pie)

\section{C1 Comprende cuento} C2 Cuenta historia C3 Forma palabras nuevas C4 Silaba final, C8 Sonido final

\section{Conocimiento Social}

Historia La sucesión y ordenación del tiempo en el paisaje (presente/pasado).

La duración del tiempo en el ámbito personal y escolar.

La periodización del tiempo: semanas, meses.

Construcción La valoración de la voz del "otro" en la de ciudadanía convivencia. El límite y el acuerdo.

- Ética - Los limites de los "otros" (pacíficos y violentos).

- Los límites en el juego. Las reglas.

Construcción de ciudadanía - Derecho

El derecho a tener una opinión. - El diálogo como estrategia. - La resolución de conflictos.

C20 Comenta momento pasado

C16 Sabe día y momento

C15 Nociones temporales

C21 Reconoce puntos de vista

C18 Diferentes estrategias resolución

C23 Espera por algo

C25 Espera turnos

S1 Buen relacionamiento, S2 Ayuda S5-

S9 (Agrede, Expresión asertiva

emociones, Comparte, Atento a otros),

S12 Desafiante,

S13 Frustrado, enojado

C21 Reconoce puntos de vista

C18 Diferentes estrategias resolución S1-S14*

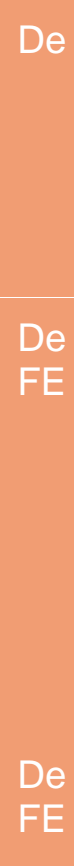

Nota. Ver contenidos abreviados en pág. 134 o en la Guía de Aplicación. 


\subsection{Guía Nacional para la vigilancia del Desarrollo del niño y la niña menores de 5 años del MSP}

La GNVD V.2 (MSP, 2018) es un instrumento de tamizaje para la detección de alteraciones del desarrollo aplicado por los profesionales médicos en el ámbito sanitario. Fue inicialmente creada en el 2010 por el Ministerio de Salud Pública (MSP) de nuestro país y sometido desde entonces a distintos procedimientos de revisión y validación.

La GNVD V.2 se estructura en descripciones de conductas agrupadas de modo ascendente en las siguientes áreas: Motora, Coordinación, Lenguaje y Social. Para cada conducta se especifican los percentiles 25,75 y 90 de la edad de cumplimiento del indicador, así como los criterios de logro y no logro. Las posibilidades de respuesta refieren a si ha adquirido o no la conducta, o si su adquisición se encuentra en duda. Asimismo, para las distintas edades, se presentan un conjunto de signos de alerta a considerar para la detección temprana de alteraciones del desarrollo.

El INDI y la GNVD V.2 son aplicadas por informantes diferentes, en distintos contextos de observación y en relación a una misma población. Debido al carácter multidimensional del desarrollo, el análisis integrado de los insumos que ambos instrumentos brindan posee un importante potencial para la detección de segmentos de población que requieren atención prioritaria debido a riesgo en el desarrollo, y para la protocolización de acciones coordinadas a partir de estas alertas. Es preciso entonces identificar los niveles de correspondencia y complementariedad del contenido en ambos instrumentos.

Desde el punto de vista de las características de administración de ambos instrumentos, existen algunas diferencias a considerar. Como sabemos, buena parte de los indicadores del INDI se basan en criterios de frecuencia en relación a las conductas y rasgos evaluados, ajustados a la frecuentación propia de la observación que se realiza en el contexto educativo. En cambio, la GNVD V.2 es un instrumento de evaluación directa y de observación acotada en el tiempo en el marco de las consultas clínicas, que recoge además información transmitida por el cuidador. Por otra parte, cabe señalar que para el caso de la GNVD V.2 no se computan puntuaciones correspondientes a subescalas. En cambio, como resultado de la aplicación de la GNVD V.2 se considera que "pasa" (cumple con todas las conductas esperadas) o "no pasa" (no cumple con al menos una), aspecto que se añade a la evaluación de presencia de signos de alerta y retroceso o pérdida de conductas adquiridas con anterioridad (MSP, 2018). La GNVD V.2 presenta un flujograma para la toma de decisión basado en las consideraciones anteriores.

Desde el punto de vista estructural, cabe considerar que la operacionalización de las dimensiones del desarrollo que ambos instrumentos proponen presenta algunas diferencias. En este sentido, las congruencias encontradas fueron las siguientes. Para el área Motor grueso de la GNVD V.2 se observó una clara correspondencia con los indicadores de motricidad gruesa de la dimensión Motora del INDI. Para el área Coordinación de la GNVD V.2 se destaca la correspondencia con indicadores de motricidad fina del INDI, en particular con referencia al dibujo de figuras y con ítems referidos a la manipulación de prendas de vestir. Por su parte, el área Lenguaje de la GNVD V.2 presentó congruencias con 
contenidos de los componentes Lenguaje y Habilidades lógico-matemáticas de la dimensión Cognitiva del INDI, especialmente en lo que respecta al desarrollo de las habilidades comunicativas, la conciencia fonológica, agrupamiento de objetos en función de sus cualidades, así como la habilidad de percibir magnitudes. Por último, para el área Social de la GNVD V.2, las correspondencias fueron más heterogéneas, involucrando contenidos recogidos en el componente Funcionamiento ejecutivo y la dimensión Disposición para el aprendizaje del INDI -por ejemplo, la capacidad de seguir normas y rutinas-, el componente Descentramiento -en particular en relación al juego socio-dramático, así como el relato de experiencias pasadas- y la dimensión Socioemocional del INDI en cuanto al reconocimiento de sus emociones. El detalle de las correspondencias de contenido para las distintas áreas se presenta en la Tabla 6.6.

En lo que respecta a los signos de alerta especificados en la GNVD V.2 para las edades 3, 4 y 5 años, se encontró un nivel alto de correspondencia respecto a indicadores incluidos en el INDI. La mayor parte de los signos de alerta de la GNVD V.2 se encuentran recogidos en los componentes Lenguaje de la dimensión Cognitiva, y los componentes Prosocialidad, Comportamiento internalizante y Comportamiento externalizante de la dimensión Socioemocional del INDI. Este detalle se ofrece en la Tabla 6.7. Por su parte, los signos de alerta de la GNVD V.2 para los cuales no se encontraron correspondencias directas en el INDI refieren a las dificultades asociadas al control de esfínteres, la alimentación y el sueño. Este resultado es esperable ya que, si bien el docente es un informante posible, se trata de aspectos específicamente evaluados en el contexto clínico.

Se concluye a partir de este análisis que los mayores niveles de congruencia con respecto a los indicadores de la GNVD V.2 se localizan en relación las dimensiones Cognitiva y Motora del INDI, mientras que los componentes socioemocionales del INDI tienen mayor presencia en las especificaciones de signos de alerta de la GNVD V.2. 
Tabla 6.6

Contenidos de la GNVD V.2 que presentan concordancia con el INDI, evaluados a partir o con posterioridad a la edad 3 años

\begin{tabular}{|c|c|c|c|c|c|c|c|c|}
\hline & & GNVD V.2 & \multicolumn{6}{|c|}{ INDI } \\
\hline \multirow[t]{2}{*}{ Área } & \multirow{2}{*}{$\begin{array}{c}\text { Percentiles } \\
(25-90) \\
\text { edad } \\
\text { meses }\end{array}$} & & & \multirow{2}{*}{$\begin{array}{l}\text { Nivel } \\
\text { Ed. } \\
\text { inicial }\end{array}$} & \multicolumn{4}{|c|}{$\begin{array}{l}\text { Dimensión - } \\
\text { Componente }\end{array}$} \\
\hline & & & & & C & M & S & $\mathrm{D}$ \\
\hline \multirow[t]{3}{*}{ Motor grueso } & $15-30$ & Lanza la pelota en una dirección & M7 Lanza, recibe pelota & 3 & & & & \\
\hline & $36-60$ & Camina talón punta & M5 M3 Camina línea recta & $3,4-5$ & & & & \\
\hline & $61-72+$ & Recorre $2 \mathrm{~m}$ saltando en un pie & M6 M4 Salta (un pie) & $3,4-5$ & & & & \\
\hline \multirow[t]{7}{*}{ Coordinación } & $17-33$ & Se quita alguna ropa & M8 Se desabriga & 3 & & & & \\
\hline & $18-39$ & Se pone ropa o zapato & M2 Manipula prendas & $4-5$ & & & & \\
\hline & $36-50$ & Abotona y desabotona & & & & & & \\
\hline & $48-62$ & Se viste y desviste sin ayuda & & & & & & \\
\hline & $30-54$ & Copia una línea recta & C13 Dibuja figuras geométricas & $4-5$ & & & & \\
\hline & $39-60$ & Copia una cruz & & & & & & \\
\hline & $54-71$ & Copia un triángulo & & & & & & \\
\hline \multirow[t]{2}{*}{ Lenguaje } & $36-50$ & Identifica tamaños (grande y chico) & C10 Compara magnitudes & 3 & Mat & & & \\
\hline & $43-48$ & Reconoce tres colores & C5 C14 Identifica colores & $3,4-5$ & & & & \\
\hline
\end{tabular}




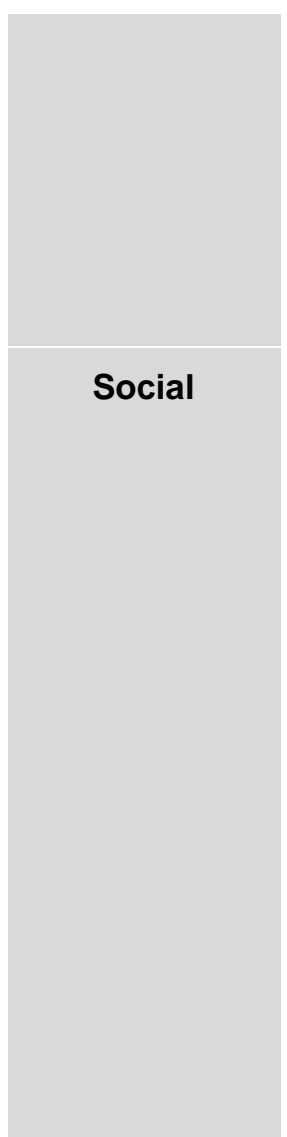

$48-72$

Aumenta el vocabulario. Utiliza frases de 5 o 6 palabras

53-66 Identifica sonidos iniciales

42-69 Clasifica teniendo en cuenta dos atributos (tamaño y/o forma y/o color)

18-30 Comienza a seguir normas sencillas de la casa, rutinas

21-30 Arma juegos de roles

36-57 Cuenta experiencias que le pasaron

48-62 Expresión de sentimientos (¿Cómo te sentís cuando...?)

60-72 Participa en juegos de competencia (ha comenzado a participar en juegos competitivos con otros niños disfrutando y aceptando reglas y turnos)

\section{C7 Comunica adecuadamente}

C8 Sonido final

C11 Clasifica objetos

C16 C25 Espera turnos

D1 D2 Adaptación rutinas

C19 Juego (uso simbólico)

C22 Juego (roles adultos)

C20 Comenta momento pasado

C21 Infiere emociones

C21 Reconoce puntos de vista S7 Expresión emocional asertiva

\section{C14 C23 Espera por algo} C16 C25 Espera turnos
3

4-5

3

$3,4-5$

3

$3,4-5$

3

4-5

3, 4-5

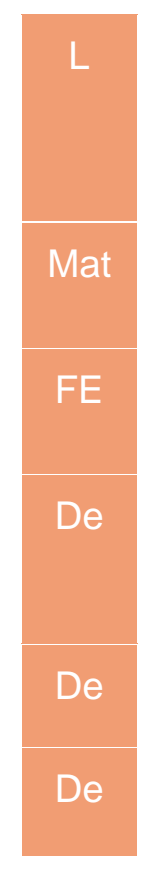

$3,4-5$

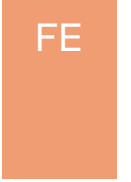

Nota. $\mathrm{C}=$ Cognitiva. $\mathrm{M}=$ Motor. $\mathrm{S}=$ Socioemocional. $\mathrm{D}=$ Disposición para el aprendizaje. $\mathrm{L}=\mathrm{L}$ enguaje. Mat=Matemáticas. De=Descentramiento. FE=Funcionamiento ejecutivo. Pro=Prosocial. Int=Internalizante. Ext=Externalizante. Cuando un ítem del INDI es común a las dos versiones del instrumento se señala en primer lugar el código correspondiente a la versión de Nivel 3 y a continuación el código de la versión 4-5. 
Tabla 6.7

Signos de alerta especificados en la GNVD V.2 para las edades 3, 4 y 5 que presentan concordancia con el INDI

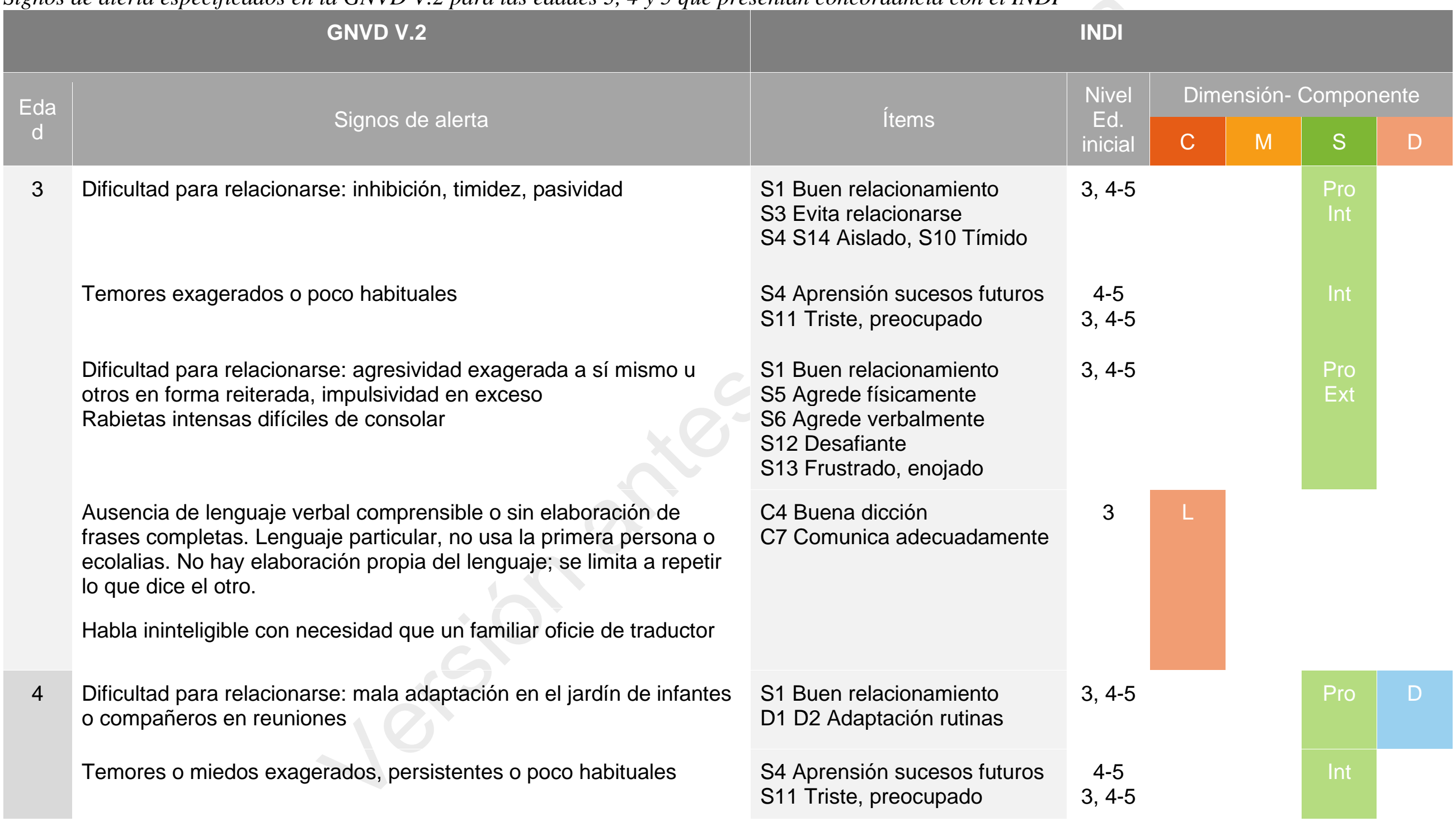


Ausencia de juego simbólico o poco elaborado y repetitivo

Habla ininteligible o con persistencia de errores (omisiones, sustituciones de fonemas como ser la sustitución de la /r/ por la /g/ Ej.: "pego" x perro, "goto" x roto, "ogeja" x oreja.) No establece diálogo

Inflexible, resistencia a los cambios

4-5 Impulsividad, inquietud, agresividad en exceso a sí mismo u otros en forma reiterada

5 Tendencia a aislarse en recreos o situaciones similares o a abandonar rápidamente los juegos con otros niños por falta de habilidad para comprender "su papel" en el juego

Miedos persistentes y generalizados

No manifiesta culpa. Realiza acciones que pueden generar disgusto en el otro, pero no puede percibir la sensación que genera en el otro

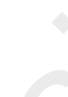

C19 Juego (uso simbólico)
C22 Juego (roles adultos)

C26 Juego (planificación)

C4 Buena dicción

C7 Comunica adecuadamente

C18 Diferentes estrategias resolución

S5 Agrede físicamente

S6 Agrede verbalmente

S12 Desafiante

S13 Frustrado, enojado

C22 Juego (roles adultos)

S3 Evita relacionarse

S4 S14 Aislado

S10 Tímido

S4 Aprensión sucesos futuros

S11 Triste, preocupado

C21 Reconoce puntos de vista

S9 Atento a otros

S5 Agrede físicamente

S6 Agrede verbalmente

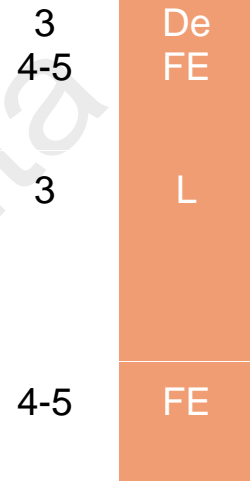

$3,4-5$

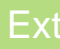

4-5

$3,4-5$

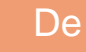

De

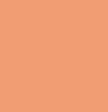

4-5

$3,4-5$

$3,4-5$

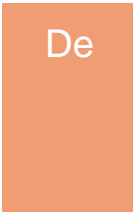

Nota. C=Cognitiva. M=Motor. S=Socioemocional. $\mathrm{D}=$ Disposición para el aprendizaje. L=Lenguaje. Mat=Matemáticas. De=Descentramiento. FE=Funcionamiento ejecutivo. Pro=Prosocial. Int=Internalizante. Ext=Externalizante. Cuando un ítem del INDI es común a las dos versiones del instrumento se señala en primer lugar el código correspondiente a la versión de Nivel 3 y a continuación el código de la versión 4-5. 


\subsection{Consideraciones finales}

Este capítulo tuvo por objetivo sistematizar las convergencias y divergencias de los indicadores evaluados a través del INDI, con respecto a los contenidos y lineamientos del Marco curricular y el Programa escolar, en tanto documentos oficiales del contexto educativo nacional. Conocer la articulación del INDI con respecto a los lineamientos curriculares vigentes es pertinente en dos niveles. Por una parte, se espera que la información aquí ofrecida sirva de insumo al momento de administrar el INDI, ya que corresponde al docente la planificación de las estrategias para la observación de los indicadores, en línea con los lineamientos curriculares y las especificidades del contexto de aplicación. Asimismo, se espera que este estudio comparativo sea de utilidad al momento de diseñar respuestas de intervención educativa en función de los perfiles de desarrollo identificados como resultado de la evaluación.

Como parte del objetivo, se estudió asimismo la congruencia entre el INDI y la GNVD V.2 en tanto instrumentos de tamizaje aplicados a una misma población objetivo. En función de las correspondencias de distinto nivel encontradas, se valora el potencial de la complementariedad de la evaluación de los profesionales de la educación y la salud, particularmente para tender hacia un sistema integrado de información para el seguimiento del desarrollo infantil a nivel interinstitucional. Actualmente, el estudio del valor predictivo que la articulación del INDI y la GNVD V.2 posee para la detección de perfiles de riesgo es parte de un proceso de investigación específico que proporcionará evidencia empírica al respecto. 


\section{***APRENDIZAJE BASADO EN PROBLEMA 1***}

Marco curricular, evaluación de la disposición para la escolarización y continuidad entre ciclos educativos

El Capítulo 5 del Marco Curricular (Orientaciones generales para la implementación del Marco curricular), en su apartado 5.5 (La vida en los centros de atención y educación en primera infancia) aborda específicamente el problema de la continuidad entre ciclos educativos, en especial la educación en primera infancia y la educación primaria. Del mencionado apartado seleccionamos el siguiente extracto:

"Es necesario identificar algunas líneas de continuidad que resultan fundamentales para acompañar el tránsito de niños y niñas desde la atención y educación de la primera infancia hacia la educación primaria (...). El análisis conjunto del Diseño Básico Curricular para niños y niñas de 0 a 36 meses (MEC, 2006) y del Programa de Educación Inicial y Primaria (ANEP-CEIP, 2008) en el proceso de elaboración del presente Marco Curricular hace visibles, relaciona y otorga significado a los cambios curriculares que ocurren durante la etapa, fortaleciendo las líneas de continuidad con educación primaria. Los administradores de la educación, los maestros y los educadores han de aportar al proceso constructivo por el cual cada etapa resulta posibilitadora de la siguiente, la cual recupera y resignifica los aprendizajes de la anterior. Es necesario avanzar en el proceso de construcción de una pedagogía de las oportunidades propia de la primera infancia basada en una imagen de niño/a potente, curioso y ávido por conocer y aprender (Peralta, 2002). Esto no debe confundirse con reformular hacia abajo la educación primaria, promoviendo adelantamientos o precocidades. Atender y educar oportunamente a niños y niñas desde el nacimiento a los seis años implica respetar la identidad de este período de la vida que es único, delicado y de corta duración" (UCC - CCEPI, 2014, pp. 7071).

A partir de esta lectura proponemos discutir los siguientes aspectos:

1. En el Capítulo 1 del presente libro abordamos la conceptualización teórica del constructo DPE. El fragmento del Marco curricular que hemos seleccionado recupera algunas de las ideas centrales que definen a la DPE y sus implicancias en el tránsito educativo. Identifica estas ideas en el fragmento y desarrollarlas tomando como insumo el Capítulo 1 del presente libro.

2. ¿Cuál es el potencial de la evaluación sistemática de la DPE para abordar el problema de la continuidad entre el ciclo de Educación inicial y Primaria?

Para una mayor profundización se recomienda la lectura del apartado 5.5 subapartado Continuidad con educación primaria (UCC - CCEPI, 2014, pp. 70-71) completo. 


\section{***APRENDIZAJE BASADO EN PROBLEMA 2***}

\section{Articulación entre lineamientos curriculares y evaluación del desarrollo}

Como hemos desarrollado en el Capítulo 4, el INDI se compone de una serie de indicadores y criterios estandarizados para la valoración del desarrollo infantil. Una característica del INDI es su anclaje en las situaciones escolares cotidianas, lo cual implica el diseño de propuestas de implementación o selección de situaciones de observación específica por parte de cada docente en su entorno.

En este capítulo hemos analizado las articulaciones entre el INDI y el Programa escolar, enfatizando que una diferencia relevante entre ambos es que el INDI no ha sido diseñado para la evaluación de los aprendizajes curriculares específicamente. No obstante, conocer la articulación entre el INDI y el Programa escolar resulta útil para pensar la implementación de la evaluación del desarrollo en el contexto educativo formal.

Tomando en consideración las especificaciones de las Tablas 6.3, 6.4 y 6.5 del presente capítulo, proponemos:

- Seleccionar un área de conocimiento, disciplina y contenido curricular incluidos en las mencionadas tablas según se trate de Nivel 3, 4 o 5.

- Observar la asociación planteada entre el contenido curricular seleccionado y los indicadores INDI (tomar en consideración que no se plantea como correspondencia plena, sino para analizar la articulación entre los lineamientos curriculares y las características del desarrollo relevantes en esta etapa).

- Enmarcado en el área de conocimiento, disciplina y contenido curricular seleccionado para el nivel, diseñar una actividad o situación de evaluación a través de la cual sea posible evaluar el indicador del INDI.

- Seleccionar una nueva área de conocimiento, disciplina y contenido curricular planteando esta vez una situación de evaluación que en sí misma capture la observación de más de un indicador del INDI.

- Identificar ítems del INDI que por referir a aspectos más globales del desarrollo no son directamente vinculables a disciplinas y contenidos curriculares explícitos del Programa. Plantear en qué situaciones educativas sería posible observarlos para su evaluación.

Para cada caso señalar además los patrones de interacción implicados (si se trata de situaciones de evaluación individual, subgrupal o grupal) y si consiste en una situación de evaluación promovida por el docente o de observación de situaciones espontáneas.

*** FIN APRENDIZAJE BASADO EN PROBLEMA*** 


\section{***APRENDIZAJE BASADO EN PROBLEMA 3***}

\section{La especificidad de la observación del desarrollo en el contexto educativo y la relevancia de la evaluación multi-informante}

En el Capítulo 2 de este libro hemos abordado la evaluación del desarrollo y las particularidades de la evaluación de la disposición para la escolarización. En este sentido, la observación naturalística presenta algunas ventajas frente a otras formas de evaluación del desarrollo. Del mismo modo, para la toma de decisión a nivel individual y colectivo resulta importante contrastar la información recogida por distintos agentes y en distintos contextos de evaluación, es decir emplear estrategias de evaluación multi-informante.

En este sentido, proponemos reflexionar en torno a los siguientes aspectos:

1. ¿Cuáles crees que son las ventajas que la evaluación del desarrollo en contextos educativos posee en comparación con otros contextos de evaluación?

2. Identifica, a modo de ejemplo, algunos indicadores del INDI para los cuales entiendas es particularmente necesaria la observación situada en el entorno escolar (o, dicho de otro modo, que serían menos observables fuera del ambiente escolar).

3. En este capítulo hemos analizado la articulación conceptual entre la GNVD V.2 y el INDI, mientras que en el Capítulo 3 abordamos la conceptualización de los modelos de respuesta de intensidad graduada. ¿Cuál crees que es el potencial de la articulación de las evaluaciones del desarrollo realizadas en contexto educativo y sanitario, desde la perspectiva de los modelos RIG?

*** FIN APRENDIZAJE BASADO EN PROBLEMA*** 


\section{Referencias Bibliográficas}

Achenbach, T. M. (1966). The classification of children's psychiatric symptoms: A factoranalytic study. Psychological Monographs: General and Applied, 80(7), 1-37. DOI:10.1037/h0093906

Achenbach, T. M., \& Rescorla, L. A. (2000). Manual for the ASEBA preschool forms and profiles (Vol. 30). Burlington, VT: University of Vermont, Research center for children, youth, \& families.

American Educational Research Association, American Psychological Association, \& National Council on Measurement in Education. (2014). Standards for educational and psychological testing. Autor.

Andrés, M. L., Urquijo, S., Guzmán, J. I. N., \& Sedeño, M. A. G. (2010). Contexto alfabetizador familiar: relaciones con la adquisición de habilidades prelectoras y desempeño lector. European journal of education and psychology, 3(1), 129-140.

ANEP-CEIP (2008). Programa de Educación inicial y Primaria. Montevideo: Rosgal.

Arrivillaga, C., Cuevasanta, D., Liz, M., Moreira, K., Schiappacasse, P., \& Echeverría, A. V. (2016). Preparación para la escolarización: una revisión sistemática de estudios longitudinales. PSIENCIA. Revista Latinoamericana de Ciencia Psicológica, 8(1), 1 12.

Astington, J. W., \& Pelletier, J. (2005). Theory of mind, language, and learning in the early years: Developmental origins of school readiness. En B. D. Homer \& C. S. Tamis-LeMonda (Eds.), The development of social cognition and communication (pp. 205-230). Mahwah, NJ: Erlbaum.

Atance, C. M., \& O'Neill, D. K. (2005). The emergence of episodic future thinking in humans. Learning and Motivation, 36(2), 126-144.

Baixauli-Fortea, I., Roselló, B., \& Miranda-Casas, A. (2004). Evaluación de las dificultades pragmáticas. Estudio de casos. Revista de Neurología, 38(1), 69-79.

Baltes, P. B. (1987). Theoretical propositions of life-span developmental psychology: On the dynamics between growth and decline. Developmental Psychology, 23, 611626.

Banco Mundial (2020). Primary school starting age (years). https://data.worldbank.org/indicator/SE.PRM.AGES

Barbero García, Maㅡ Isabel; Vila Abad Enrique y Holgado Tello, Francisco Pablo (2015). Psicometría. Madrid: Sanz y Torres.

Bernier, A., McMahon, C. A., \& Perrier, R. (2016). Maternal Mind-Mindedness and Children's School Readiness: A Longitudinal Study of Developmental Processes. Developmental Psychology. 53(2), 210-221. DOI: 10.1037/dev0000225

Blair, C. (2002). School readiness: Integrating cognition and emotion in a neurobiological conceptualization of children's functioning at school entry. American psychologist, 57(2), 111. 
Blair, C., \& Diamond, A. (2008). Biological processes in prevention and intervention: The promotion of self-regulation as a means of preventing school failure. Development and psychopathology, 20(3), 899-911.

Blair, C., \& Raver, C. C. (2015). School readiness and self-regulation: A developmental psychobiological approach. Annual review of psychology, 66(1), 711-731.

Bodrova, E. (2008). Make-believe play versus academic skills: a Vygotskian approach to today's dilemma of early childhood education. European early childhood education research journal, 16(3), 357-369.

Boivin \& Bierman (2008). School readiness: an introduction to a multifaceted and developmental construct. En Boivin \& Bierman (Eds.). Promoting School readiness and early learning.

Bravo-Valdivieso, L., Villalón, M., \& Orellana, E. (2006). Predictibilidad del rendimiento en la lectura: Una investigación de seguimiento entre primer y tercer año. Revista latinoamericana de psicología, 38(1), 9-20.

Buckner, R. L., \& Carroll, D. C. (2007). Self-projection and the brain. Trends in cognitive sciences, 11(2), 49-57.

Buysse, V., \& Peisner-Feinberg, E. (2010). Recognition \& response: Response to intervention for preK. Young Exceptional Children, 13(4), 2-13.

Buysse, V., \& Peisner-Feinberg, E. (2013). Handbook of response to intervention in early childhood (1ra ed.; Buysse, V., \& Peisner-Feinberg, E., Eds.). Baltimore: Paul H. Brookes Publishing Company.

Cairns RB, Cairns BD (2006). The making of developmental psychology. In W Damon, RM Lerner (Eds.) Handbook of Child Psychology. Vol 1: Theoretical Models of Human Development (pp. 89-165). Hoboken, NJ: Wiley. 6th ed.

Caron, C., \& Rutter, M. (1991). Comorbidity in child psychopathology: Concepts, issues and research strategies. Journal of child Psychology and Psychiatry, 32(7), 10631080.

Caspi, A., \& Shiner, R. L. (2006). Personality development. In W. Damon \& R. M. Lerner (Series Eds.) \& N. Eisenberg (Vol. Ed.), Handbook of child psychology: Vol. 3. Social, emotional, and personality development, 6th ed., pp. 300-365). Hoboken, NJ: Wiley.

Cavadel, E. W., \& Frye, D. A. (2017). Not just numeracy and literacy: Theory of mind development and school readiness among low-income children. Developmental Psychology, 53(12), 2290-2303. DOI: 10.1037/dev0000409

Clark, J. (2005). Locomotion. En Hopkins, B., Barr R, Michel, G. \& Rochat, P. (Eds.). The Cambridge encyclopedia of child development. Cambridge: Cambridge University Press.

Compte y Rique, E. (2010). El jardín de infantes de Montevideo en su relación con las escuelas libres, activas o nuevas. En M. Demarchi (comp.) Maestra militante de la vida: Enriqueta Compte y Rique. Montevideo: CODICEN. Trabajo original publicado en 1926.

Cuadro, A., \& Trías, D. (2008). Desarrollo de la conciencia fonémica: Evaluación de un programa de intervención. Revista Argentina de Neuropsicología, 11(8), 1-8. 
Cuetos, F., Rodríguez, B., \& Ruano, E. (1996). PROLEC: Evaluación de los procesos lectores. Madrid: TEA.

Davis, J. C., \& Ginsburg, H. P. (1993). Similarities and Differences in the Formal and Informal Mathematical Cognition of African, American, and Asian Children: The Roles of Schooling and Social Class. Cognition and Culture: A Cross-Cultural Approach to Cognitive Psychology, 343-360. DOI:10.1016/s0166-4115(08)61671-4

Dearing, E., McCartney, K., \& Taylor, B. A. (2009). Does Higher Quality Early Child Care Promote Low-Income Children's Math and Reading Achievement in Middle Childhood? Child Development, 80(5), 1329-1349.

Defior, S., \& Serrano, F. (2011a). Procesos fonológicos explícitos e implícitos, lectura y dislexia. Revista Neuropsicología, Neuropsiquiatría y Neurociencias, 11(1), 79-94.

Defior, S., \& Serrano, F. (2011b). La conciencia fonémica, aliada de la adquisición del lenguaje escrito. Revista de logopedia, foniatría y audiología, 31(1), 2-13.

Defior, S., Serrano, F., \& Marín-Cano, M. J. (2008). El poder predictivo de las habilidades de conciencia fonológica en la lectura y escritura en castellano. En E. Diez-Itza (Ed.), Estudios de desarrollo del lenguaje y educación (pp. 339-347). Oviedo: ICE Monografías Aulas Abierta.

Denham, S. A. (2006). Social-emotional competence as support for school readiness: What is it and how do we assess it? Early education and development, 17(1), 57-89.

Diamond, A. (2013). Executive functions. Annual review of psychology, 64(1), 135-168.

Diuk, B. G., \& Ferroni, M. V. (2014). Aprendizaje de letras en niños preescolares de nivel socioeconómico bajo. Interdisciplinaria, 31(1), 25-37.

Duncan, G. J., Dowsett, C. J., Claessens, A., Magnuson, K., Huston, A. C., Klebanov, P., . . . Japel, C. (2007). School readiness and later achievement. Developmental Psychology, 43(1), 1428-1446.

Eisenberg, N. (2015). Altruistic emotion, cognition, and behavior. Psychology Library Editions: Emotion. New York: Psychology Press.

Eisenberg, N. y Miller, P. (1990). The Development of Prosocial Behaviour versus Nonprosocial Behaviour in Children. En Lewis, M. y Miller, S. (Eds.). Handbook of Developmental Psychopathology (pp. 181-188). Boston, MA: Springer.

Eisenberg, N., \& Miller, P. (1987). The relation of empathy to prosocial and related behaviors. Psychological Bulletin, 101(1), 91-119.

Fanti, K. A., \& Henrich, C. C. (2010). Trajectories of pure and co-occurring internalizing and externalizing problems from age 2 to age 12: findings from the National Institute of Child Health and Human Development Study of Early Child Care. Developmental Psychology, 46(5), 1159-1175.

Feinstein, L., (2003). Inequality in the Early Cognitive Development of British Children in the 1970 Cohort. Economica, 70, 73-98. 
Fewell, R. R. \& Deutscher, B. (2004). Contributions to Early Language and Maternal Facilitation Variables to Later Language and Reading Abilites. Journal of Early Intervention, 26(2), 132-145.

Fiorentino, L., \& Howe, N. (2004). Language Competence, Narrative Ability, and School Readiness in Low-Income Preschool Children. Canadian Journal of Behavioural Science / Revue Canadienne des Sciences du Comportement, 36(4), 280-294. DOI: $10.1037 / \mathrm{h} 0087237$

Flanagan, D. P., Ortiz, S. O., Alfonso, V. C., \& Dynda, A. M. (2006). Integration of response to intervention and norm-referenced tests in learning disability identification: Learning from the Tower of Babel. Psychology in the Schools, 43(7), 807-825.

Fletcher, J. M., \& Vaughn, S. (2009). Response to intervention: Preventing and remediating academic difficulties. Child development perspectives, 3(1), 30-37.

Fuchs, D., \& Fuchs, L. S. (2006). Introduction to response to intervention: What, why, and how valid is it?. Reading research quarterly, 41(1), 93-99.

Furr, R. M., \& Bacharach, V. R. (2013). Psychometrics: An Introduction (1ra ed.). SAGE Publications.

Garaigordobil, M., \& Pérez, J. I. (2005). Escala de personalidad creadora: estudio psicométrico exploratorio. Estudios de Psicología, 26(3), 345-364.

Geary, D. C. (1994). Children's mathematical development: Research and practical applications (1ra ed.). Washington, DC: American Psychological Association.

Giedd, J. N., Lalonde, F. M., Celano, M. J., White, S. L., Wallace, G. L., Lee, N. R., \& Lenroot, R. K. (2009). Anatomical brain magnetic resonance imaging of typically developing children and adolescents. Journal of the American Academy of Child and Adolescent Psychiatry, 48(5), 465.

Ginsburg, H., Baroody, A. J., del Río, M. C. N., y Guerra, I. L. (2007). TEMA 3: Test de competencia matemática básica. Madrid: TEA.

Greenwood, C. R., Bradfield, T., Kaminski, R., Linas, M., Carta, J. J., \& Nylander, D. (2011). The response to intervention (RTI) approach in early childhood. Focus on Exceptional Children, 43(9), 1-22.

Grietens, H., Onghena, P., Prinzie, P., Gadeyne, E., Van Assche, V., Ghesquiere, P., \& Hellinckx, W. (2004). Comparison of mothers', fathers', and teachers' reports on problem behavior in 5-to 6-year-old children. Journal of psychopathology and behavioral assessment, 26(2), 137-146.

Grissmer, D., Grimm, K. J., Aiyer, S. M., Murrah, W. M., \& Steele, J. S. (2010). Fine motor skills and early comprehension of the world: two new school readiness indicators. Developmental Psychology, 46(5), 1008-1017.

Groth-Marnat, G. (2003). Handbook of Psychological Assessment (4ta ed.). Hoboken, NJ: Wiley. 
Hambleton, R. K., Merenda, P. F., \& Spielberger, C. D. (2005) (Eds.). Adapting educational and psychological tests for cross-cultural assessment (1ra ed). Psychology Press.

Hattie, J. (2008). Visible learning for teachers: Maximizing impact on learning. Routledge.

Housman, D. K., Denham, S. A., \& Cabral, H. (2018). Building Young Children's Emotional Competence and Self-Regulation from Birth: The" Begin to... ECSEL" Approach. International Journal of Emotional Education, 10(2), 5-25.

Howell, S., \& Kemp, C. (2005). Defining Early Number Sense: A participatory Australian study. Educational Psychology, 25(5), 555-571. DOI:10.1080/01443410500046838

Hughes, C., Daly, I., Foley, S., White, N., \& Devine, R. T. (2015). Measuring the foundations of school readiness: Introducing a new questionnaire for teachers-The Brief Early Skills and Support Index (BESSI). British Journal of Educational Psychology, 85(3), 332-356.

Ivaldi, E. (2014). La educación inicial: de la casa cuna a la escuela elemental. Montevideo: Ministerio de Relaciones Exteriores/UTU.

Janus, M., \& Duku, E. (2007). The school entry gap: Socioeconomic, family, and health factors associated with children's school readiness to learn. Early education and development, 18(3), 375-403.

Janus, M., \& Offord, D. R. (2007). Development and psychometric properties of the Early Development Instrument (EDI): A measure of children's school readiness. Canadian Journal of Behavioural Science/Revue canadienne des sciences du comportement, 39.

Jerrim, J. \& Vignoles, A. (2013) Social mobility, regression to the mean and the cognitive development of high ability children from disadvantaged homes. Journal of the Royal Statistical Society, 76(4), 887-906.

Kagan, S. L., Moore, E., \& Bredekamp, S. (1995). Reconsidering children's early learning and development: Toward shared beliefs and vocabulary. Washington, D.C.: National Education Goals Panel.

Kavale, K. A., \& Flanagan, D. P. (2007). Ability-achievement discrepancy, response to intervention, and assessment of cognitive abilities/processes in specific learning disability identification: Toward a contemporary operational definition. En Jimerson, S. R., Burns, M. K. \& VanDerHeyden, A. M. (Eds.) Handbook of response to intervention (pp. 130-147). Boston, MA: Springer.

Leong, D. J., \& Bodrova, E. (2012). Make-Believe Play. Young children, 29(1), 28-34.

Liz, M. \& Vásquez-Echeverría, A. (2018). "Proceso de construcción de los reportes automáticos del Inventario de Desarrollo Infantil (INDI): una experiencia de articulación investigación-extensión desde la colaboración UdelaR-CODICEN". Actas de las Jornadas Nacionales de Extensión. Montevideo: UdelaR. 
Liz, M. \& Vásquez-Echeverría, A. (en prensa). Respuesta a la intervención para la promoción de la preparación para la escolarización: hacia un modelo uruguayo. En Campos, N.; Habiga, V.; Méndez, E. y Presa, T. (Comps.), Miradas Sobre La Repetición Escolar. Montevideo.

Liz, M., Vásquez-Echeverría, A. \& Canet Juric, L. (en revisión) Autorregulación y Preparación para la escolarización. El funcionamiento ejecutivo en el preescolar predice el involucramiento escolar.

Malina, R. (2005). Milestones of motor development and indicators of biological maturity. En Hopkins, B., Barr R, Michel, G. \& Rochat, P. (Eds.). The Cambridge encyclopedia of child development. Cambridge: Cambridge University Press.

Martínez Arias, M. D. R., Chacón Gómez, J. C. \& Castellanos López, M. Á. (2014). Análisis de datos en psicología y ciencias de la salud. Vol. I. Exploración de datos y fundamentos probabilísticos. Madrid: EOS Universitaria.

Meneses, J., Barrios, M., Lozano, L. M., Bonillo, A., Turbany, J., Cosculluela, A., \& Valer, S. (2014). Psicometría.: Editorial UOC.

Ministerio de Salud Pública (2018). Guía nacional para la vigilancia del desarrollo del niño y la niña menores de 5 años.

Moreno Olivos, T. (2011). Consideraciones éticas en la evaluación educativa. REICE. Revista Electrónica Iberoamericana sobre Calidad, Eficacia y Cambio en Educación.

Morrison, F. J., Kim, M. H., Connor, C. M., \& Grammer, J. K. (2019). The Causal Impact of Schooling on Children's Development: Lessons for Developmental Science. Current Directions in Psychological Science, 28(5), 441-449.

Organización de Naciones Unidas (s/f). Objetivo 4: Garantizar una educación inclusiva, equitativa y de calidad y promover oportunidades de aprendizaje durante toda la vida para todos. www.un.org/sustainabledevelopment/es/education/

Pagani, L. S., Fitzpatrick, C., Archambault, I., \& Janosz, M. (2010). School readiness and later achievement: a French-Canadian replication and extension. Developmental psychology, 46(5), 984.

Perner, J., Kloo, D., \& Gornik, E. (2007). Episodic memory development: Theory of mind is part of re-experiencing experienced events. Infant and Child Development: An International Journal of Research and Practice, 16(5), 471-490.

Pesenti-Gritti, P., Spatola, C. A., Fagnani, C., Ogliari, A., Patriarca, V., Stazi, M. A., \& Battaglia, M. (2008). The co-occurrence between internalizing and externalizing behaviors. European child \& adolescent psychiatry, 17(2), 82-92.

Pintrich, P. R., Smith, D. A. F.; García, T., \& McKeachie, W. J. (1991). A manual for the use of the Motivated Strategies for Learning Questionnaire (MSLQ). Ann Arbor, MI: University of Michigan, National Center for Research to Improve Postsecondary Teaching and Learning.

Prior, M., Bavin, E., \& Ong, B. (2011). Predictors of school readiness in five-to six-yearold children from an Australian longitudinal community sample. Educational Psychology, 31(1), 3-16. 
Purpura, D. J., \& Lonigan, C. J. (2013). Informal numeracy skills: The structure and relations among numbering, relations, and arithmetic operations in preschool. American Educational Research Journal, 50(1), 178-209.

Rescorla, L. A. (2005). Assessment of young children using the Achenbach System of Empirically Based Assessment (ASEBA). Mental Retardation and Developmental Disabilities Research Reviews, 11(3), 226-237. DOI:10.1002/mrdd.20071

Romano, E., Babchishin, L., Pagani, L. S., \& Kohen, D. (2010). School readiness and later achievement: replication and extension using a nationwide Canadian survey. Developmental Psychology, 46(5), 995-1007.

Ryan, R. M., Fauth, R. C., \& Brooks-Gunn, J. (2006). Childhood Poverty: Implications for School Readiness and Early Childhood Education. In B. Spodek \& O. N. Saracho (Eds.), Handbook of research on the education of young children (p. 323-346). Lawrence Erlbaum Associates Publishers.

Sabol, T.J., Pianta, R.C. (2017). The state of young children in the United States: School Readiness. En: The Wiley Handbook of early childhood development programs, practices and policies. Wiley

Saeki, E., Jimerson, S. R., Earhart, J., Hart, S. R., Renshaw, T., Singh, R. D., \& Stewart, K. (2011). Response to intervention (Rtl) in the social, emotional, and behavioral domains: Current challenges and emerging possibilities. Contemporary School Psychology: Formerly "The California School Psychologist", 15(1), 43-52.

Sameroff, A. J., \& Haith, M. M. (1996). Interpreting developmental transitions. In A. Sameroff \& M. Haith (Eds.), The five to seven year shift: The age of reason and responsibility. Chicago, IL: The University of Chicago Press.

Shaul, S., \& Schwartz, M. (2014). The role of the executive functions in school readiness among preschool-age children. Reading and Writing, 27(4), 749-768.

Shiner, R. L., \& Masten, A. S. (2008). Personality in childhood: A bridge from early temperament to adult outcomes. International Journal of Developmental Science, 2, 158-175.

Sigel, I. (1968). The Distancing Hypothesis: A Hypothesis Crucial to the Development of Representational Competence. Detroit, MI: Merrill-Palmer Inst.

Suddendorf, T., \& Corballis, M. C. (2007). The evolution of foresight: What is mental time travel, and is it unique to humans? Behavioral and brain sciences, 30(3), 299-313.

Torrance, E. P. (1966). Torrance tests of creative thinking: Technical-norms manual. Lexington, MA: Personnel Press.

Tovar, J. (2007). Psicometría: tests psicométricos, confiabilidad y validez. Psicología: Tópicos de actualidad, 85-108.

Tulving, E. (1984). Précis of Elements of episodic memory. Behavioral and Brain Sciences, 7(02), 223. DOI:10.1017/s0140525x0004440x 
Unicef. (2012). School readiness: A conceptual framework. United Nations Children's Fund: New York.

Urbina, S. (2014). Essentials of psychological testing (2da ed.). Hoboken, NJ: Wiley.

Ursache, A., Blair, C., \& Raver, C. C. (2012). The Promotion of Self-Regulation as a Means of Enhancing School Readiness and Early Achievement in Children at Risk for School Failure. Child Development Perspectives, 6(2), 122-128. DOI: 10.1111/j.1750-8606.2011.00209.x

Uruguay Crece Contigo - CCEPI (2014). Marco Curricular para la atención y educación de niños y niñas uruguayos desde el nacimiento a los seis años. http://www.cep.edu.uy/documentos/2017/bibliotecaweb/marco curricular primera i nfancia digital opti.pdf

Van Lier, P. A., \& Koot, H. M. (2010). Developmental cascades of peer relations and symptoms of externalizing and internalizing problems from kindergarten to fourthgrade elementary school. Development and psychopathology, 22(3), 569-582.

Vásquez-Echeverría, A. \& Liz, M. (2019). El Inventario de Desarrollo Infantil (INDI): características y avances del periodo 2015-2019. En Vernucci, S. \& Zamora, E. (Comps.), La ciencia de enseñar: aportes desde la psicología cognitiva a la educación (1a ed.). Mar del Plata: Universidad Nacional de Mar del Plata.

Vásquez-Echeverria, A., \& Moreira, K. (2016). Preparación para la escolarización: Dimensiones y Medición. En E.I. Huaire, A.M. Eligier y G.D. Clerici (Eds.) Pensar la Niñez. Psicología del Desarrollo desde una perspectiva americana (pp. 155-174). Lima: Grijley.

Vereijken, B. (2005). Motor development. En Hopkins, B., Barr R, Michel, G. \& Rochat, P. (Eds.). The Cambridge encyclopedia of child development. Cambridge: Cambridge University Press.

Vila Abad, E. \& Holgado Tello, F. (2015). Psicometría (1ra ed.; Barbero García, M. I., Coord.). Madrid: Sanz y Torres.

Watts, T. W., Duncan, G. J., Siegler, R. S., \& Davis-Kean,P. E. (2014). What's past is prologue: Relations between early mathematics knowledge and high school achievement. Educational Researcher,43, 352-360.

Wellman, H. M., \& Liu, D. (2004). Scaling of theory-of-mind tasks. Child development, 75(2), 523-541.

Winsler, A., \& Wallace, G. L. (2002). Behavior problems and social skills in preschool children: Parent-teacher agreement and relations with classroom observations. Early education and development, 13(1), 41-58. 


\section{Anexos}

\section{Anexo 1. Referencias de instrumentos utilizados y número de participantes en los estudios de validez concurrente}

A continuación, se ofrece el nombre del instrumento utilizado, el año de estudio y el número de participantes. Las referencias de cada instrumento, siguiendo el mismo código alfabético, se describen más abajo.

[a] Peabody Test de Vocabulario en Imágenes (2015-2018, n=83-190)

[b] Inventario de Desarrollo Battelle -Áreas cognitiva y motora- (2015, $n=27-31 ; 2017, n=71-83$ )

[c] Bracken School Readiness Assessment (2017, $\mathrm{n}=72)$

[d] Test de Inteligencia Breve de Reynolds -Categorías- (2017, n=72)

[e] Test Breve de Inteligencia de Kaufman -Matrices, Vocabulario- (2015-2016, n=129-198)

[f] Escala de Inteligencia Wechsler para Preescolar y Primaria -Aritmética- (2017, n=54)

[g] Test de Competencia Matemática Básica III $(2015,2016$ n= 33-41)

[h] Woodcock-Johnson III Pruebas de habilidades cognitivas -Información general, Formación de conceptos y Planeamiento- $(2016, n=78-88)$

[i] Tareas experimentales -Deseos diversos, Falsas creencias y Contenido inesperado- (2016, $n=43-44 ; 2018, n=74$ )

[j] Tarea experimental -Tarea del viaje- $(2016 ; 2018, n=72-75)$

[k] Tarea experimental -Pantomima- $(2018, \mathrm{n}=44)$

[l] Tarea experimental -Cambio dimensional- $(2018, \mathrm{n}=82)$

[m] Batería Autorregulación en el Preescolar: Tareas de evaluación directa -Barra de equilibrio, Golpear el lápiz, Torre, Envolver la sorpresa, Retrasar la comida- $(2016, n=58)$

[n] Batería Autorregulación en el Preescolar: Reporte de evaluador -Atención y control de impulsos- $(2016, n=58 ; 2017, n=53 ; 2018, n=62)$

[o] Puntuaciones $Z$ de tareas experimentales de autorregulación -HTKS, Estatua, Barra de equilibrio, Torre- $(2017 ; n=53)$

[p] Formulario de Observación Directa y Escala de Observación de la Prosocialidad en aula $(2018, \mathrm{n}=81)$

Referencias de los instrumentos y tareas experimentales aplicadas

[a] Dunn, L. M., Dunn, L. M., \& Arribas, D. (2006). PPVT-III Peabody: Test de vocabulario en imágenes. Madrid: TEA.

[b] Newborg, J., Stock, J. R., \& Wnek, L. (1996). Inventario de desarrollo Battelle. Madrid: TEA. 
[c] Bracken, B. A. (2007). Bracken School Readiness Assessment (BSRA-3). Spanish edition. San Antonio, TX: Pearson.

[d] Reynolds, C. R., \& Kamphaus, R. (2009). RIAS Escalas de inteligencia de Reynolds y RIST test de inteligencia breve de Reynolds. Madrid: TEA.

[e] Kaufman, A. S., \& Kaufman, N. L. (2009). Test breve de inteligencia de Kaufman (KBIT). Adaptación española. Madrid: TEA.

[f] Wechsler, D. (1996). Escala de inteligencia de Wechsler para preescolar y primaria (WPPSI). Madrid: TEA.

[g] Ginsburg H. P., Baroody, A. J., Núñez del Río, M. C., \& Lozano Guerra, I. (2007). Tema 3 Test de Competencia Matemática Básica: Manual. Madrid: TEA.

[h] Muñoz-Sandoval, A. F., Woodcock, R. W., McGrew, K. S., \& Mather, N. (2005). Batería III Woodcock-Muñoz: Pruebas de habilidades cognitivas. Rolling Meadows, IL: Riverside.

[i] Wellman, H. M., \& Liu, D. (2004). Scaling of Theory of Mind Tasks. Child Development, 75(2), 523-541.

[j] Atance, C. M., \& Meltzoff, A. N. (2005). My future self: Young children's ability to anticipate and explain future states. Cognitive Development, 20(3), 341-361.

[k] Overton, W. F., \& Jackson, J. P. (1973). The representation of imagined objects in action sequences: A developmental study. Child Development, 44(2), 309-314.

[l] Zelazo, P. D. (2006). The Dimensional Change Card Sort (DCCS): A method of assessing executive function in children. Nature Protocols, 1(1), 297-301.

[m] [n] Smith-Donald, R., Raver, C. C., Hayes, T., \& Richardson, B. (2007). Preliminary construct and concurrent validity of the Preschool Self-regulation Assessment (PSRA) for fieldbased research. Early Childhood Research Quarterly, 22(2), 173-187.

[o] Kochanska, G., Murray, K., Jacques, T.Y., Koenig, A.L., Vandegeest, K. A. (1996). Inhibitory control in young children and its role in emerging internalization. Child Development, 67(2), 490507.

Korkman, M., Kirk, U., \& Kemp, S. (1998). Manual for the NEPSY. San Antonio, TX: Psychological Corporation.

Ponitz, C. C., McClelland, M. M., Jewkes, A. M., Connor, C. M., Farris, C. L., \& Morrison, F. J. (2008). Touch your toes! Developing a direct measure of behavioral regulation in early childhood. Early Childhood Research Quarterly, 23, 141-158.

Smith-Donald, R., Raver, C. C., Hayes, T., \& Richardson, B. (2007). Preliminary construct and concurrent validity of the Preschool Self-regulation Assessment (PSRA) for field-based research. Early Childhood Research Quarterly, 22(2), 173-187.

[p] McConaughy, S. \& Achenbach, T. (2009). Direct Observation Form (DOF). Recuperado de: www.aseba.org 